\title{
IntechOpen
}

\section{Current Topics in Children's Learning and Cognition}

Edited by Heidi Kloos, Bradley J. Morris and Joseph L. Amaral 



\section{CURRENT TOPICS IN CHILDREN'S LEARNING AND COGNITION}

Edited by Heidi Kloos, Bradley J. Morris and Joseph L. Amaral 


\section{Current Topics in Children's Learning and Cognition}

http://dx.doi.org/10.5772/1162

Edited by Heidi Kloos, Bradley J. Morris and Joseph L. Amaral

\section{Contributors}

Mieczyslaw Pokorski, Lukasz Borecki, Urszula Jernajczyk, Ana Flávia Lopes Magela Gerhardt, Kevin Downing, Heidi Kloos, Joseph Amaral, Bradley Morris, Steve Croker, Amy Masnick, Corinne Zimmerman, Steffie Van Der Steen (Ed.M.), Daisy Segovia, Angela Crossman

\section{(c) The Editor(s) and the Author(s) 2012}

The moral rights of the and the author(s) have been asserted.

All rights to the book as a whole are reserved by INTECH. The book as a whole (compilation) cannot be reproduced, distributed or used for commercial or non-commercial purposes without INTECH's written permission. Enquiries concerning the use of the book should be directed to INTECH rights and permissions department (permissions@intechopen.com).

Violations are liable to prosecution under the governing Copyright Law.

\section{(cc) BY}

Individual chapters of this publication are distributed under the terms of the Creative Commons Attribution 3.0 Unported License which permits commercial use, distribution and reproduction of the individual chapters, provided the original author(s) and source publication are appropriately acknowledged. If so indicated, certain images may not be included under the Creative Commons license. In such cases users will need to obtain permission from the license holder to reproduce the material. More details and guidelines concerning content reuse and adaptation can be foundat http://www.intechopen.com/copyright-policy.html.

\section{Notice}

Statements and opinions expressed in the chapters are these of the individual contributors and not necessarily those of the editors or publisher. No responsibility is accepted for the accuracy of information contained in the published chapters. The publisher assumes no responsibility for any damage or injury to persons or property arising out of the use of any materials, instructions, methods or ideas contained in the book.

First published in Croatia, 2012 by INTECH d.o.o.

eBook (PDF) Published by IN TECH d.o.o.

Place and year of publication of eBook (PDF): Rijeka, 2019.

IntechOpen is the global imprint of IN TECH d.o.o.

Printed in Croatia

Legal deposit, Croatia: National and University Library in Zagreb

Additional hard and PDF copies can be obtained from orders@intechopen.com

Current Topics in Children's Learning and Cognition

Edited by Heidi Kloos, Bradley J. Morris and Joseph L. Amaral

p. cm.

ISBN 978-953-51-0855-9

eBook (PDF) ISBN 978-953-51-5103-6 


\section{We are IntechOpen, \\ the world's leading publisher of Open Access books}

Built by scientists, for scientists

\section{$4,100+$}

Open access books available

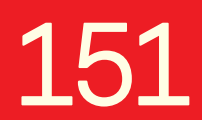

Countries delivered to
$116,000+$

International authors and editors
$120 \mathrm{M}+$

Downloads

Our authors are among the

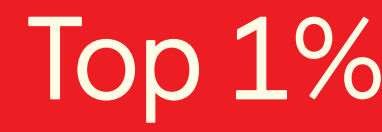

most cited scientists

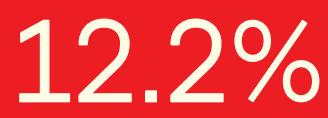

Contributors from top 500 universities

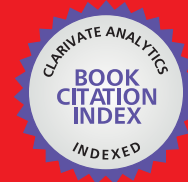

WEB OF SCIENCE ${ }^{\mathrm{TM}}$

Selection of our books indexed in the Book Citation Index in Web of Science ${ }^{\mathrm{TM}}$ Core Collection (BKCI)

Interested in publishing with us?

Contact book.department@intechopen.com

Numbers displayed above are based on latest data collected.

For more information visit www.intechopen.com

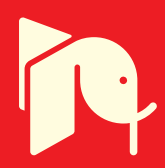





\section{Meet the editors}

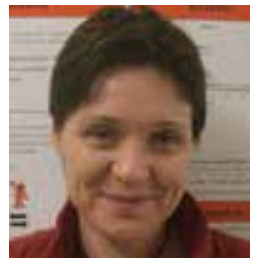

Dr. Heidi Kloos received her Ph.D. in psychology from the Arizona State University in 2001. Currently, she is associate professor in psychology at the University of Cincinnati and director of the Children's Cognitive Research lab in the department of psychology. Her research focuses on cognitive development and concept learning in early childhood, with an emphasis on young children's spontaneous learning about abstract concepts and the circumstances in which they can change a mistaken belief.

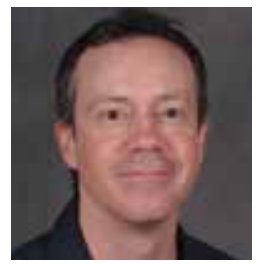

Bradley J. Morris is a Developmental Cognitive Scientist whose research program includes basic research in cognitive development and its application in designing effective K-12 STEM instruction. His research focuses on three domains: Scientific and Mathematical reasoning, Formal reasoning, and Motivation. The goal of his research program is to identify mechanisms underlying children's reasoning (e.g., strategy acquisition and selection) and motivation (e.g., praise type) using a variety of experimental methods (e.g., eye tracking) and computational modeling.

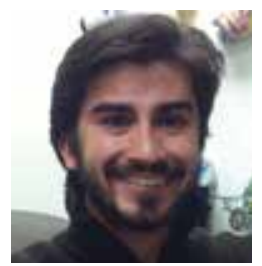

Joseph L. Amaral, M.S., M.A. received a M.S. in Counseling and Counselor Education from Indiana University in 2008 and a M.A. in psychology from the University of Cincinnati in 2011. His current research focuses on exploring cognitive and social development in children with Autism Spectrum Disorders with an emphasis on how contextual factors affect task performance. The overall goal of this work is to develop innovative assessment and intervention strategies. 



\section{Contents}

\section{Preface XI}

Chapter 1 Learning in Cognitive Niches 1

Ana Flávia Lopes Magela Gerhardt

Chapter 2 Using the Dynamics of a Person-Context System to Describe Children's Understanding of Air Pressure 21

Steffie Van der Steen, Henderien Steenbeek and Paul Van Geert

Chapter 3 Preschoolers Learning Science: Myth or Reality? 45

Heidi Kloos, Heather Baker, Eleanor Luken,

Rhonda Brown, David Pfeiffer and Victoria Carr

Chapter 4 The Emergence of Scientific Reasoning 61

Bradley J. Morris, Steve Croker,

Amy M. Masnick and Corinne Zimmerman

Chapter 5 Cognition and the Child Witness: Understanding the Impact of Cognitive Development in Forensic Contexts 83

Daisy A. Segovia and Angela M. Crossman

Chapter 6 Beyond the Black-and-White of Autism: How Cognitive Performance Varies with Context 105

Joseph L. Amaral, Susan Collins, Kevin T. Bohache and Heidi Kloos

Chapter 7 Psychological Fitness in Young

Adult Video Game Players 123

Mieczyslaw Pokorski, Lukasz Borecki and Urszula Jernajczyk

Chapter 8 The Impact of Moving Away from Home on Undergraduate Metacognitive Development 137

Kevin Downing 



\section{Preface}

How does a child make sense of her world? Every day, children are exposed to a plethora of stimulation, only little of which has apparent structure. Take visual stimulation, for example: With every motion of the eyes, the head, or the body, the retinal image changes - at least to some extent. Add to that the changes in apparent size and orientation due to object motion, changes in lightening, and changes that occur though the actions of others Yet, even babies learn to perceive stabilities in the environment, learn to make predictions about their surroundings, and learn to control situations through their own actions. At the center of this impressive feat is a child's ability to connect separate pieces of information into larger wholes. The resulting pattern of Gestalt makes it possible for children to distinguish relevant from irrelevant stimulation, and as a result, ignore stimulation that is potentially overwhelming. In short, it allows children to make sense of their surrounding (cf., Thagard, 2000).

The mental process of linking isolated events into overarching patterns of Gestalts, despite appearing trivial on some levels, is not well understood. How do children connect individual events spontaneously without any top-down guidance? How does the rate of linking events change over the course of development? And how is it possible to tune out some stimulation, while still being open to that which yields learning and development? These are only some of the many questions in the area of children's learning and cognition that have eluded a clear answer. This difficulty in generating a clear answer has its roots both in theory and empirical data.

On the theoretical level, the area of cognitive development has experienced something of a vacuum, ever since Piaget's stage theory was challenged. Challenges pertained not only to the specific time course of concept development (e.g., underestimating infant abilities), but also to having to explain substantial performance variability as a function of seemingly irrelevant task details. Other mainstream theories did not fare much better in terms of shedding light on how children make sense of their surrounding. This is because they traced the emergence of a knowledge organization to the presence of some already existing knowledge (cf., Spelke et al., 1992), leading to an infinite regress of explanations (cf., Juarrero, 1999). A more complete theory of learning and cognitive development would have to explain the emergence of a knowledge Gestalt without reducing it to yet another knowledge Gestalt. Such theories, geared towards explaining self-organization of coherent patterns (e.g., Jensen, 1998), provide promising tools for developmental scientists to investigate the dynamic processes underlying cognition and 
learning (cf., e.g., Stephen et al., 2009; Thelen \& Smith, 1994). However, they have not found their way into mainstream cognitive development (e.g., Siegler, 1998).

In addition to lacking a powerful theory on children's learning and cognition, progress in understanding children's sense-making has been slow due to issues with empirical data. Data collection with children is more time consuming and expensive than with adults. And methods are limited by children's interest, competence, attention span, and willingness to follow instructions. These factors are at least partially responsible for the fact that far more publications merely document the time course of a child's concept, not the nature of processes that give rise to these concepts. Given this state of affairs, the topic on children's learning and cognition is still in its beginnings, leading to the collection of essays published in this volume.

As a whole, the essays address theoretical and empirical issues related to children's learning and cognition. The first essay, titled Learning in Cognitive Niches, treats the process of sense making on a theoretical level, discussing the complexity of factors that give rise to children's learning. It is followed by an essay, titled Using the Dynamics of a Person-Context System to Describe Children's Understanding of Air Pressure, that applies ideas from complexity science and dynamics-systems theory to children's learning about science. The next four essays summarize and synthesize already published findings, in an effort to go beyond individual viewpoints and present a more nuanced picture of children's sense making. In particular, two of these summaries, Preschoolers Learning Science: Myth or Reality? and The Emergence of Scientific Reasoning, focus on children's ability to make sense of their physical environment. The essay Cognition and the Child Witness: Understanding the Impact of Cognitive Development in Forensic Contexts seeks to shed light on children's sense making relevant to forensic issues. And the essay Beyond the Black-and-White of Autism: How Cognitive Performance Varies with Context ventures in the area of autism, a disorder that demonstrates atypical processes of combining pieces of information. The final two essays provide original data to add to the discussion of what factors affect cognitive functioning. In particular, the essay Cognitive Fitness in Young Adult Video Game Players seeks to re-assess the often-assumed relation between video gaming and various aspects of thinking, memory, intelligence, and visual-spatial abilities. And the essay Impact of Moving Away from Home on Undergraduate Metacognitive Development explicitly connects life circumstances to the ability to monitor and control one's thinking. Together, the collection of essays are a further step towards understanding the process of sense making as children and young adults interact with their environment.

Heidi Kloos

Department of Psychology, University of Cincinnati, Cincinnati OH, USA

Bradley J. Morris

Kent State University, USA

Joseph L. Amaral

University of Cincinnati, Cincinnati, OH, USA 


\section{Cited References}

Jensen H.J. (1998). Self-Organized Criticality. Emergent Complex Behavior in Physical and Biological Systems. Cambridge University Press, Cambridge.

Juarrero A. (1999). Dnamics in Action: Intentional Behavior as a Complex System. MIT Press, Cambridge.

Siegler, R. S. (1998). Children's thinking (3rd ed.) Upper Saddle River, NJ: Prentice Hall.

Spelke, E. S., Breinlinger, K., Macomber, J. \& Jacobson, K. (1992). Origins of knowledge. Psychological Review, 99, 605-32.

Stephen, D. G., Dixon, J. A., \& Isenhower, R. W. (2009). Dynamics of representational change: Entropy, action, and cognition. Journal of Experimental Psychology: Human Perception \& Performance, 35, 1811-1822.

Thagard, P. (2000). Coherence in thought and action. Cambridge, MA: MIT Press.

Thelen E. and Smith L.B. (1994). A Dynamic Systems Approach to the Development of Cognition and Action. MIT Press, Cambridge, MA. 



\title{
Learning in Cognitive Niches
}

\author{
Ana Flávia Lopes Magela Gerhardt \\ Additional information is available at the end of the chapter
}

http://dx.doi.org/10.5772/33628

\begin{abstract}
"Once the hegemony of skin and skull is usurped, we may be able to see ourselves more truly as creatures of the world"

Andy Clark and David Chalmers
\end{abstract}

\section{Introduction}

In 2002, the first season's first episode of the Brazilian TV series City of Men, named "The Emperor's Crown", began with a scene of a History lesson in a public school of Rio de Janeiro. The teacher described the facts related to the journey of the Royal Portuguese Family from Portugal to Brazil in 1808, to escape from the threat of Napoleon's inbreak. She used a map of the Western World as a support to locate some countries involved in important historical events in the early nineteenth century: France, England, Germany, Italy, Russia, Portugal and Brazil. The children, characterized as students who lived in the slums built on the hills of Rio de Janeiro, asked questions about information not given by the teacher, but objects of interest to boys and girls familiar with the slum environment in Rio: modern weapons handling, war, violence and death. Some students expressed that the subject of the lesson was not clear for them (one of them thought that there was a participation of the Ancient Romans in the episode), and some had problems about the meaning of some words, such as the polysemous Portuguese word "coroa" (in English "crown"), but their doubts and questions were not solved by the teacher.

At the end of the episode, one of the students, called Acerola (actually a nickname), faced with the need to repeat the information given by the teacher, went towards the map and transposed the History of napoleonic invasions to the current reality of Rio: the countries became hills, each one of them managed by a head, who behaved as a brazilian druglord; the trade of manufactured goods and raw materials, which were pivotal do the emergent industrial capitalism, became drug trade; Brazil, which was a colony of Portugal at that time, became an immense and available space for occupation, conquer and mightiness. But 
in Acerola's narrative there was still a great lord who wanted to be the biggest leader of all the neighborhood, and for this aim he sent agents he trusted to govern the conquered territories and eliminate possible or real enemies.

Acerola's explanation reveals that he has clear in his mind that the Portuguese Royal Family had to scape to Brazil because of territorial dispute and power interests in $19^{\text {th }}$ century, but we cannot ensure if he knows that, as he "repeats" the teacher's story, he talks about Napoleon, and not about some druglord; and about Europe, not Rio de Janeiro. In other words, by now we cannot be sure that Acerola understood that the invasions and contentions of the $19^{\text {th }}$ century did not happen in the same terms, motivations and conditions which outline many events that we witness nowadays.

This chapter is about Acerola's speech, and the learning questions it arises: can we assert that Acerola really learned the teacher's lesson? What criteria should we employ to say that he learned it or not? If he only had repeated the teacher's words, this could mean learning? To what extent the interference of his previous knowledge about social problems in Rio over those historical facts ceases to be learning and starts to be free interpretation? And as to the map, which was a didactic artefact for both, the teacher and Acerola: is it the same object in both narratives, or could it be, respectively, a map of Western world and afterwards a map of Rio de Janeiro? Or could it be a third thing whose existence lasted only during the time that Acerola told his version of the story?

Whatever the answers we offer to these questions, they do not belie the fact that Acerola actively interacted not only with the contents expressed by the teacher in such a way to deeply alter them, but he also changed the object around which the lesson was taught - the map. Therefore, our answers must take into account his important agentic actions over the classroom setting, and the fact that these actions are closely related to his degree of learning.

To argue about these issues, this chapter aims to present the theoretical basis for observing learning as an agentic accomplishment based on a two-way affectment between the learner and the environment, and as an "adaptive reorganization of a complex system" (Hutchins, 1995, p. 289). As we define this theoretical basis, we need to raise three important criteria in order to not only discuss issues brought up on the observation of Acerola's actions in the classroom, but also establish how we can adjust this concept of learning to institutional terms: what is the view of cognition which allows us to recognize learning not only as internalization of concepts but also an action over the environment; what is the constitution of the learning environment which allows this twofold relationship; through which means it is possible to observe the didactic artifacts found in this environment, and how they contribute and are representative for learning as a cognitive action of constitutive interchange between person and environment.

This three criteria lead us to observe cognition in a distributed fashion, in order to postulate that the use of the environment in the cognitive elaboration does enhances cognitive action, through the access to more resources available than the neural apparatus. 
This idea, called the Distributed Cognition Hypothesis, enables us to establish for the learning environment the status of a cognitive niche: a dynamic setting where cognitive actions modify the cognizer's behavior and also the environment features and properties, including everything which can be perceived in there.

As to the learning niches, it is important to discuss the idea of affordances, features that emerge from the meaningful relationship between species and environment and are fundamental in the discussion about concept formation, learning, and the value of cognitive artifacts employed in didactic practices.

To speak about these issues we are guided by works on cognition which propose a specific mode of observing human actions and cognitive behaviours which establishes that the very act of thinking is not bounded to the brain and the visual system; rather, mind is constructed in a process that includes brain, body and the environment around them. Under this view, the person is someone able to, through reasoning, planning, learning and many other cognitive actions, change himself/herself and the place where he/she lives, interacts and develops.

These premises enable us to relate ideas on environmental perception to facts of conceptualization and meaning construction. Ultimately, it broadens our understanding of what is learning and favors the formulation of pedagogical projects based on the understanding of the learner's cognitive behavior in the classroom environment. In this sense, pedagogical projects which observe the artefacts of the environment as learning resources can accomplish a more productive and authentic relationship among the learner, the contents to be learned and the forms of learning.

The next sections briefly discuss the Distributed Cognition Hypothesis, which is the context of the studies on cognition which emerge from the possibility of observing the ecological dimension of the aspects related to cognitive actions, their motivations and effects. This perspective leads us to recognize the cognitive niches as a level of analysis for studies of learning within the school institution. Subsumed to the idea of cognitive niche, we stress the notion of affordance as a central component of the niche, and the forms of thinking about learning in cognitive niches through the perspective of the detection of affordances. We will focus specifically on didactic actions which can conduct to good or bad results in classroom activities.

\section{The distributed cognition hypothesis}

The Distributed Cognition Hypothesis (Clark and Chalmers, 1998; Hutchins, 1995, 2000; Sinha, 2005, 2010; Bardone, 2011, among others) brings the idea that the continuity among brain, body and the environment structures cognition. Following this premise, studies on distributed cognition are concerned about identifying and describing cognitive processes in terms of the relationship between person and environment.

The works affiliated to this hypothesis propose the rupture of the boundaries between internal and external representations and domains of experience, and generate new prospects for the view of what cognition is: no longer biased to the internal or the external 
factors which compose it, but requiring mutual and constitutive relationships between these domains (Zhang and Patel, 2006; Franks, 2011), which are evinced through cognitive processes.

The structural connections between species and environment are basically justified by the need to access extra material and symbolic resources that cannot be found in the brain, in order to accomplish the cognitive task posited to the person. The possibility of implementing these connections is recognized as an evolutionary feat of the Homo sapiens and some other species, and it exists for the fact that the complexity of our neural system sanctions the activity of incorporating features not foreseen by the genetics. This property demands the search for environmental artefacts in order to create, acquire, manipulate, and storage information and knowledge, to fulfil specific purposes of cognitive action and make correct and suitable decisions.

The ideas about the nature of cognition in an extended and distributed perspective bring, as a real challenge, the need to investigate the boundaries of the units of analysis in studies of cognition, and the set of mechanisms involved in cognitive processes (Hutchins, 2000). These two axes of investigation on cognition must take into account all domains of human existence, which are now seen not in an atomistic fashion, but as an integrated universe. They are respectively related to the concepts of cognitive niches and affordances, hence the importance to take into consideration these two constructs in the study of cognition and settings where cognitive processes and actions are at stake.

In order to do this we assume the non-previous ontological existence of information and features in the environment, because they cannot be found outside the cognizing field. Rather, the emergence of these features is associated to our comprehension that the identification of a given property of an object (which can be found in several other objects) is related to a particular use that we make of it (Bardone, 2011). According to this, it is possible to assert that the very perceptual detection of an object and its properties is constituted by the goals of physical and cognitive actions which justify its presence in that environment. In other words, we will not see anything in an object if it is not included in the universe of action possibilities in a given domain. We will not even see (in a perceptual sense) this object.

The constituents of the external domains can assume several and different tasks in cognitive construction. They were summarized in Zhang and Patel (2006, p. 335) and are transcripted below:

1. Provide short-term or long-term memory aids so that memory load can be reduced.

2. Provide information that can be directly perceived and used such that little effortful processing is needed to interpret and formulate the information explicitly.

3. Provide knowledge and skills that are unavailable from internal representations.

4. Support perceptual operators that can recognize features easily and make inferences directly

5. Change the nature of a task by generating more efficient action sequences.

6. Stop time and support perceptual rehearsal to make invisible and transient information visible and sustainable. 
7. Aid processibility by limiting abstraction.

8. Anchor and structure cognitive behaviour without conscious awareness.

9. Determine decision making strategies through accuracy maximization and effort minimization.

All the tasks stressed above are useful for studies on Education and learning. For example, the first one seems to be the main purpose of writing in a broad sense: they are "collective memory banks" (Donald, 1991, p. 311), which help us deal with the need for quick calculi, and retain and transmit information and knowledge. The map used in Acerola's (and the teacher's, we need to say) History lesson fits many of them, including 2: when Acerola employed the map of the $19^{\text {th }}$ century's Western World as if it could portray the reality of $21^{\text {st }}$ century's Rio de Janeiro (hills instead of countries and druglords instead of kings and emperors), he saved the students and himself from mentally launching themselves towards a space and time which they did not participate. So he liberated their minds for the important ideas of the lesson: the circumstances which led to the Portuguese Royal family getaway in 1808 .

The duty of recognizing how external representations can contribute for a satisfactory learning task can be better accomplished if every cognitive action is done with clear purposes. They define not only conceptual choices, but also the perception of the objects and their properties, the facts that occur in learning settings, the quality of the use of the features proposed by Zhang and Patel, and, since other people are part of the environment, the ways that the person will interpret the actions of his/her co-specifics. In this sense, goals, and also the problems that must be faced in order to fulfil them, are a kind of an external regulation which structures our actions, conceptualizations and joint commitments (Tummolini and Castelfranchi, 2006; Carassa, Colombetti and Morganti, 2008). Therefore, we can say that our cognition is essentially normatized by these features; normativity is present in the selection of the functions and boundaries of the environment, the perception of its features and the forms of relationship with our co-specifics.

Normativity, materialized in the goals for cognitive actions, is thus seen as a structuring factor of our way of thinking and social life as well (Tummolini and Castelfranchi, 2006). The assumption of normativity in these terms brings benefits not only to the study of the human being and his basic perceptual and conceptual experiences, but also to the social, cultural and institutional realms:

"In the continuist model of nature and culture [...], cultural norms do not have necessarily intentional or mentalist origins. They can arise from the phylogenetic and ontogenetic readiness of well-adapted beings to learn and use social forms and regularities as a basis for inference and action, which ends up loading them with a normative weight" (Kaufmann and Clément, 2007, p. 10).

Normativity can be found in high-level cognitive action (Schmidt, Rakoczy and Tomasello, 2011), and so as in Acerola's speech. He is doubly regulated from the relationships between him and the teacher, on the one hand, and between him and the students, on the other hand. 
They both at the same time compel him to built a kind of discourse which satisfies his didactic necessities: to minimally repeat what was said by the teacher, selecting the facts which defined the fugue of the Royal Family to Brazil, and accomplish this task in conditions to say things which can be meaningful to the students. To do this, he accesses the previous knowledge related to their own space and time, and leads them to understand what motivated facts occurred in another space and time. He could not be successful in his enterprise if he had not taken this twofold goal into account.

\section{Cognitive niches}

The History lesson depicted in this chapter is an event occurred in a highly institutionalized environment - the classroom, where we can find very specific social and cognitive practices. As to institutional contexts of learning, it is the most immediate level of analysis of these accomplishments, and is considered here as a cognitive niche.

A cognitive niche is a dynamic setting established and associated to the adaptative relationship between people (among other species) and environments. It comes from the idea of ecological niche in Evolutionary Biology (Cosmides and Tooby, 2000; Clark, 2006; Bardone and Magnani, 2007), and it is related to the dynamics of the adaptation mechanisms developed for living in different environments and habitats. A good definition for niches is given by Sinha (1988, p. 131), and fits perfectly the Distributed Cognition postulations: "a niche is a negotiated, ordered, spatial-temporally structured relationship between organism and habitat, in which behaviours are in part transformative of the environment to which they are adapted". Like any ecological-environmental structures constructed by many species, cognitive niches are made for protection and survival, a better perception of the environment, facilitated access to resources and resolution of immediate problems. As a result of the person's action, cognitive niches become meaningful settings wherein people can create tools and techniques, and develop abilities. This perspective brings possibilities to observe the ways in which the capacity of creating and maintaining niches give people the opportunity to develop themselves cognitively and learn, and favour the cultural and material enrichment of social groups.

Evidently, the idea that cognitive development and learning presuppose the person integrated to the environment is not new. It can be found for example in Vygotsky's work (Vygotsky, 1987), and substantiates influential theories such as the one presented in Tomasello (1999). But now the cognitive transformation proposed by these authors can be seen together with the fact that learning can also affect and re-structure the environment around the learner.

The idea of cognitive niches employed in studies of learning environment presupposes the articulation between concepts originally associated to perceptual mechanisms and theoretical constructs related to conceptualization and learning. This association is possible due to the fact that perception and conceptualization are strictly associated phenomena. Articulating this account to studies on cognition and learning can bring to light several phenomena and also expand our notion about learning, as this action allows us to define 
with more accuracy what components are desirable and what variables must be observed for a learning task to be accomplished.

The definition of the classroom as a cognitive niche, taking into account all the variables delineated above, can help to create for the students an atmosphere auspicious for their success in school, because it opens space for a reliable observation of issues, processes and artifacts associated to learning, and for a specific study of the school environment, which is a setting whose features and behaviors are already known by learners and school agents.

These actions take, as a core point, the student's cognition and knowledge as constitutive features of every learning accomplishment. Therefore, if we seek to understand the basis of the cognitive actions of the students, we will be able to perceive, from how they think, who they are, instead of establishing in advance who they will be, and from this prescribe how they learn - a criticism posed by many authors who problematize the institutionalized learning and meaning construction (Walkerdine, 1988; McDermott, 1993; Lave, 1993; Sinha, 1999, among many others).

In this chapter we are focusing on the cognitive niche as a setting constructed through a dynamics related to the understanding and engagement in interactions wherein intersubjectivity negotiations, normative crossings and possibilities of re-semiotization to solve problems of meaning (and recreate meanings as well) are at stake. It can help us assume cognition in a situated becoming, where things constitute an intersubjective flow of negotiation and (re)semiotization of the structuring features of our cognitive construals of the world.

In the History classroom niche that we are observing, two different events unfolded relatively to the goals of each one, to the learning conditions of each information, and from the establishment of who talks and who listens - since both exercised an agency over the cognitive processes that take place in that setting. In both cases, the niche remained the same as to its basic constraints, but each event made it work under different conditions, which were caused by the change of roles that the contingencies determined.

When the teacher was the keynote speaker, the intersubjectivity conditions were defined in advance and not negociated; rather, they were established in such a way that the students had to strive to transport themselves to the space-time depicted by her. Their previous knowledge was not accessed, because the teacher did not fulfill the task to bring information and contents of their everyday lives to the semiotic construcion in the classroom setting. The result was that there were free associations and a few actions of re-semiotization of material and symbolic objects to meet the needs of understanding. The possibilities of learning were not favored.

However, when Acerola was the keynote speaker, some diferences in the niche were observable: there was more intersubjective negotiation, promoted by the fact that Acerola and his colleagues dealed with the same everyday reality, thus he had the chance to bring and add common knowledge to the semiotic construction in the classroom, and helped them understand the contents of the lesson. This could have helped him fulfill his task. 
As to the intersubjectivity conditions which are specific to the classroom niche, we still need to stress that the possibility of the success of Acerola in interacting with his colleagues because they all bring together the same previous knowledge does not justify the failure of the teacher. On the other hand, having commom and shared everyday previous knowledge does not guarantee the teacher's success in promoting learning in the classroom. Rather, one of the fundamental actions for minimal conditions of referential intersubjectivity (Sinha and Rodriguez, 2008) is the recognition that the previous knowledge of the learners is a constitutive feature of the didactic practice. This condition allows them to build bridges between what they already know and the new information that the teacher is offering them. This is a basic didactic prescription and keeps its value in all perceptions about cognition and learning, whether or not distributed.

\section{The notion of affordance}

In the construction and maintenance of cognitive niches, the detection of affordances (Gibson, 1979; Norman, 1988; Zhang and Patel, 2000; Hutchby, 2001; Chemero, 2003; Gorniak and Roy 2007; Bardone, 2011) is a result of cognitive actions and emerges from the seek for artefacts available to fulfil specific action goals. They are not previously offered, but subespecified by the aims and/or norms for existing in a given environment.

Apart from the discussion about the source of affordances - whether they are detected via direct perception of objects, taking the line of study of Gibson (1979), or whether they encompass cognitive processing and previous knowledge, according to the alternative proposal of Norman (1988), if we observe them against the premise of the constitutive relationship between person and environment, we can establish that they are not in things, nor in us:

"Affordances are the primary entities that are perceived, and perceiving affordances is perceiving the meaningful world. Importantly for current purposes, affordances are not merely entities in the environment, and they are also not projections of meaning by animals onto a merely physical environment. Affordances are features of animalenvironment systems, and exist in such systems only in virtue of animals that have the appropriate abilities to perceive and take advantage of them" (Anderson and Chemero, 2009, p. 306).

Likewise, considering affordances as an important concept in Cognitive Psychology represents recognizing that cognition is a situated and, above all, qualitative dynamics, based on principles which define the values of things in environments, due to the fact that what is conceptualized as an affordance is something which can be useful to solve some problem and achieve some goal. Thus, in this sense, we can repeat Gibson's words (Gibson, 1979, p. 140), also quoted in Bardone (2011, p. 78): “The perceiving of an affordance is not a process of perceiving a value-free physical object (...) it is a process of perceiving a valuerich ecological object". But we can add that these objects are ecological as well as conceptual, and they are also a reliable source for us to understand, from our choices of what is 
important in a specific enterprise, what constitute our identities situatedly established in each context of action and thought.

This idea allows us to connect the concepts of affordance and cognitive niche in a Distributed Cognition perspective: the possibility of recognizing affordances in a specific setting is directly related to the recognition of this setting as a niche. The opposite can also be said: if the person is placed in a given environment and is not willing to recognize affordances (or something else) in that environment because he/she does not have any purposes to be there, it is quite possible that he/she does not recognize that setting as a real cognitive niche.

This fact reveals the extent to which what we see is tied by our goals of being there. It is in this sense that we construct cognitively the possibilities of affecting environment and being affected by it. In this perspective, the detection of affordances is an activity that, besides requiring and revealing intelligence, improves procedurally the intelligence of those who detect it (Dennett, 2000; Franks, 2011), because it is a procedure closely connected to the semiotization and re-semiotization of things, and is also an action that brings new things into existence.

If we take into account that affordances are built under the functionalities and contingencies of cognitive actions in a given niche, we can assert that material artefacts in the classroom can be affordances, to the extent that they are seen as something functionally useful in specific moments. In this sense, their functions can be re-created as this action becomes necessary to solve new problems.

So as the map used by the teacher and Acerola. The teacher has used the map in its prototipical function, but Acerola, as he delivered his lesson, he brought into existence a new kind of map, which came from the blending of conflicting dimensions: the Western World of the past, and the Rio de Janeiro of the present. It is not possible not necessary to design and manufacture a specific map which can bring these specific information. But it is possible to conceptually build it through the interaction of the determinant features of Acerola's and the teacher's speeches. He did that this way because the teacher's map did not fit his need to adapt the previous knowledge of the students to the information of the lesson.

\section{Affordances and conceptual integration}

The cognitive operation which describes the relationship between internal and external domains is called conceptual integration (Fauconnier and Turner, 2002; Sinha, 2005; Zhang and Patel, 2006), a general process which accounts for phenomena in low and high level cognition, as well as perceptual phenomena. Also known as blending, conceptual integration is the term which gives name to a net of sophisticated processes which subsumes relationships among domains of every kind and the creation of novel artefacts, ideas, techniques, etc. Conceptual integration is also used to describe online construction of meaning in every domain of experience. In the blend, features of these domains are coupled according to the aspects they bring which are relevant for the specific aim of the cognitive processing. There are no 
constraints for associating these domains and features, but these aspects are detected from the emergence of a generic space which opens the possibility that these features and domains be blended. The effect of the blend, located in the blend space, is the new "thing" - meaning, representation, concept, affordance and many other accomplishments, which carries features of the inputs but brings traces of its own (Fauconnier and Turner, 2002).

The detection of affordances is also in charge of conceptual integration. As elements found in the blend space, affordances can bring features which are unique entities in a unique event of mutual and transforming situated interchange between person and environment. This premise is important for us to detect the sources for the meanings and affordances produced in the niches, and what constitutes them.

The basic structural model for conceptual integration is summarized by Fauconnier and Turner (2002, p. 46) and adapted to the perspective proposed in this chapter.

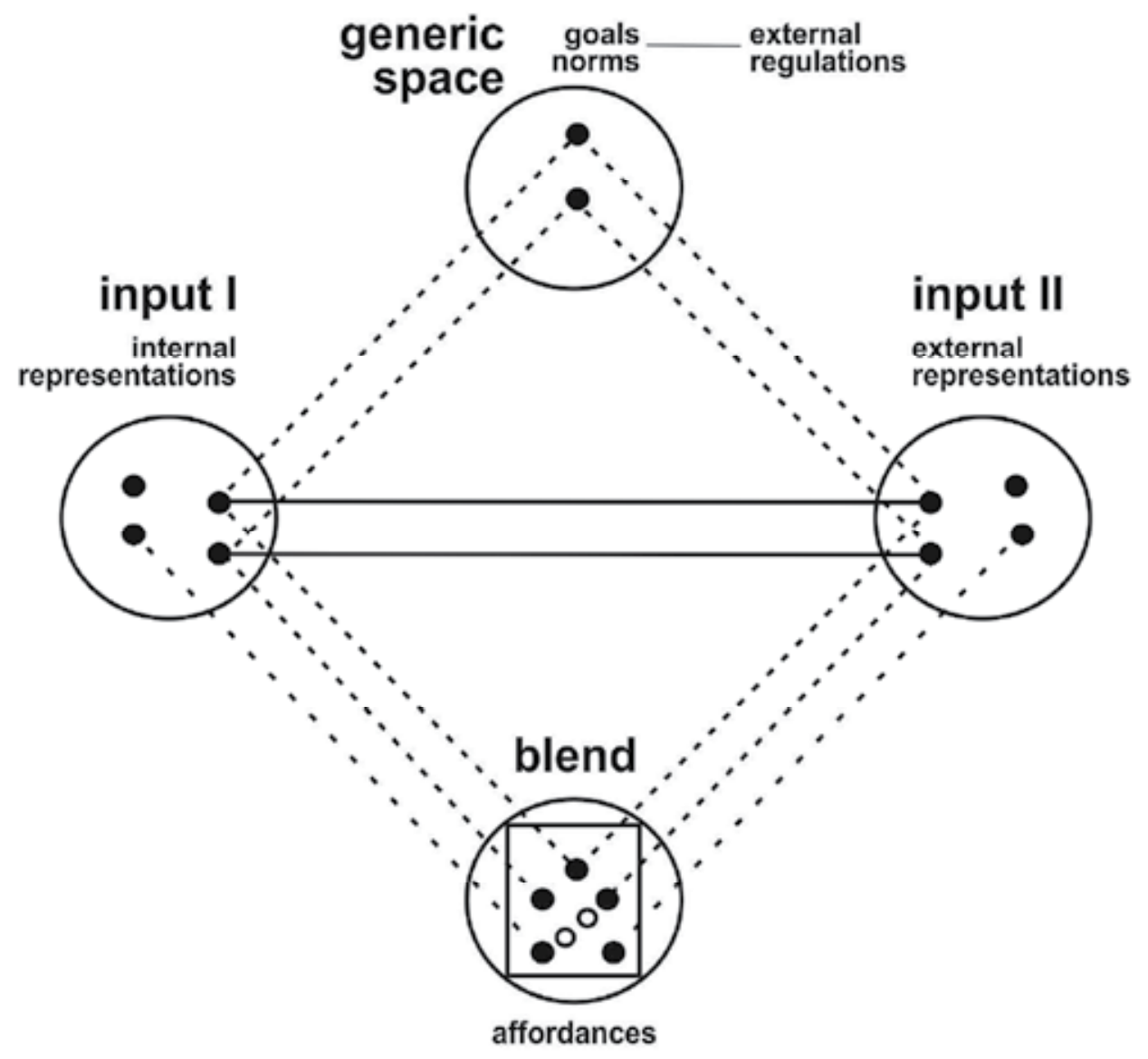

Figure 1. Structural schema of conceptual integration - detection of affordances

The conceptual integration model (blending) associated to affordances is of the doublescope kind (Turner, 2008). It occurs when the inputs are formed by different domains 
(Turner employs the term "frames") which do not share the same organizing structure - in the case of affordances, differently structured external and internal domains. The input spaces are filled by, on one side, the internal representations of the person, and, on the other side, the environmental representations. In this operation, the normative component includes the goals of cognitive activity; it embraces the generic space which allows the possibility of articulation between the inputs, and defines some terms and directions of the blending operation.

The blending scheme predicts that, although the input spaces can be filled by distinct domains, they can present matched counterparts (indicated by the full line). It also presumes that the formation of new concepts assumes an autonomous nature in relation to the inputs (signalled by the white circles), and admits that the effect of the process can function as input for other blending actuations. These properties turn the blending process into a cognitive processing model which can describe the detection of affordances not as the product of the construction and maintenance of niches, but as a part of the cognitive continuous flow from the bases recognized in this chapter. In sociogenetic terms, they are also a niche structuring component, providing the ratchet effect, which is the improvement of human inventions from generation to generation (Tomasello, 1999).

The possibility of describing the emergence of affordances as a blending process brings some advantages which motivate their use as a structural description for many cogntive phenomena, among them the creation of affordances in specific niches:

- It is a description which explains the relationship person-environment as a genuine cognitive process, since (among other reasons) it can be subsumed under some basic principles of non-autonomous and non-computational Cognitive Sciences, such as interdominial mapping (Fauconnier, 1997), and on-line and real-time nature of meaning construction (Coulson, 2001) - both of them clearly compatible with the Distributed Cognition Hypothesis; in this sense, it is associated to the Cognitive Psychology tradition, endorsing and refining classic studies about interactive information processing (McClelland and Rumelhart, 1981).

- It is a concept identified not only in the flow of the relationship person-environment, but also in the evolution and creation of artefacts, technologies, etc. (Fauconnier \& Turner, 2002; Sinha, 2005). For this reason, it is object of interest in studies in Evolutionary Anthropology (Mithen, 1999), and Developmental Psychology (KarmiloffSmith, 1992; Tomasello, 1999). It is used to explain and describe: in the phylogenesis, the evolutionary gains of Homo sapiens in his/her relationship with the environment; in the ontogenesis, the development of the person; and, in the sociogenesis, learning - in these contexts always keeping the idea that cognition can transform and (re)create environments.

- Last, but not least, it is a model which allows precise identification of the elements directly at issue in the detection of a specific affordance, without losing sight of the other features involved in the process. For this reason, it allows the managing of the context, favouring the work of those who need detailed descriptions of affordances to succeed in their cognitive actions. 
Mostly, the option for recognizing affordances through describing them via conceptual integration comes from the last item above, because it satisfies the need to systematize the cognitive behaviours which, allied to the socio-cultural experiences proper to the classroom, offer a scenario of the specific conditions of learning settings.

Indeed, when we describe the conceptual construction of the map used by Acerola as an affordance to help the students understand events if the past in a context of articulation with their previous knowledge, we can see clearly which features in this formulation were at stake. We can also see how was the image conceived by him from his own conceptualizations about the dimensions included in the process: space, time and territorial definition, to be articulated to the external information given by the teacher's map.

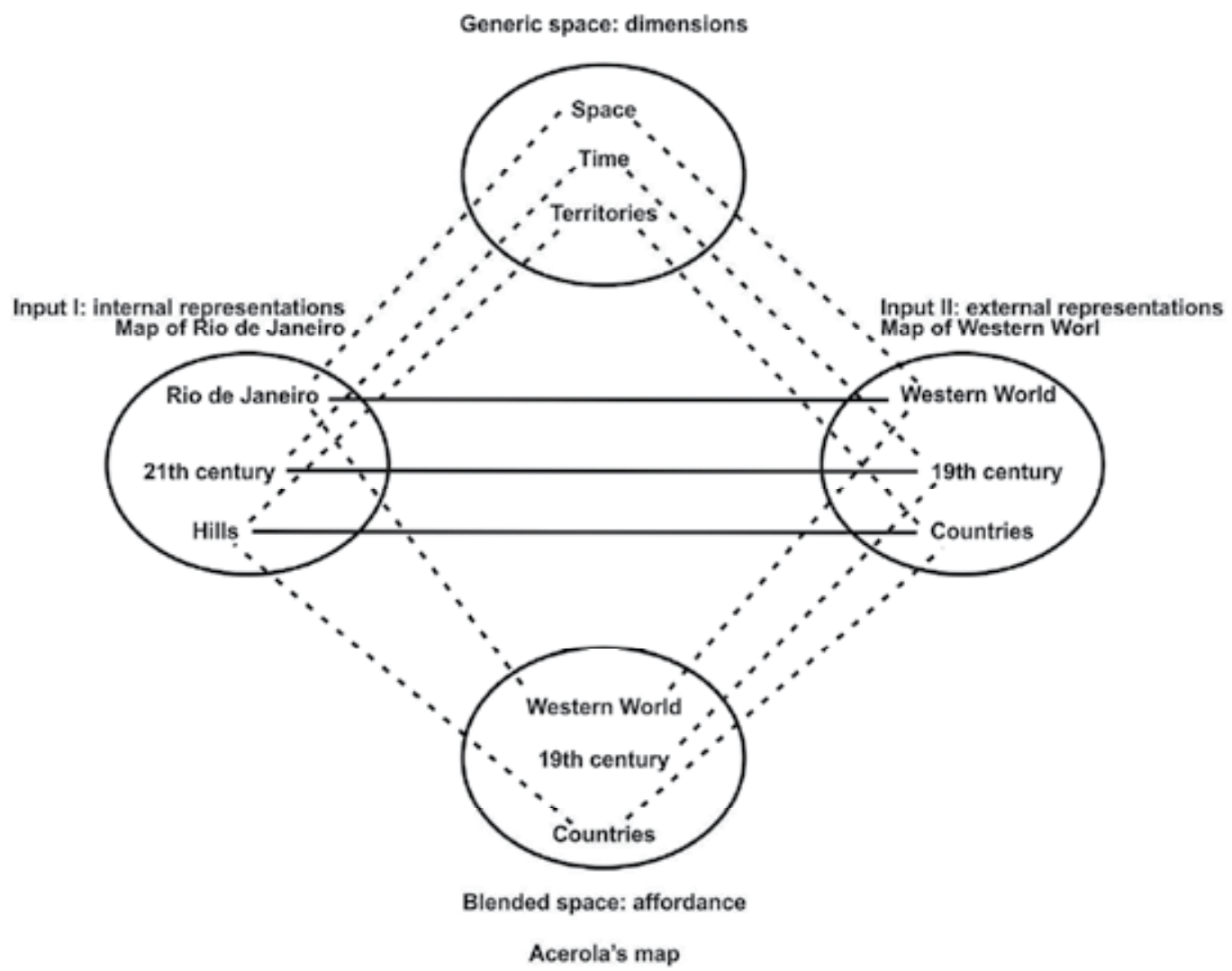

Figure 2. Structural schema of conceptual integration - Acerola's map

The map created by Acerola through conceptual integration, which presumes the existence of hills in the $19^{\text {th }}$ century's Western World, could never exist in a supposed exact reality, let alone exist previous to his lesson, because in the $19^{\text {th }}$ century there were not hills conceptualized as countries and occupied by slums. There was not even the concept of slum. As a matter of fact, the map cannot exist outside the events occurred in that niche, and outside the relationships, goals and norms that were regulating the meanings and affordances produced there. 
What enables the conceptualization of a map which depicts, at the same time, the Western Countries and the Rio de Janeiro's hills is a cognitive operation called compression (Fauconnier and Turner, 2002, p. 113). It is related to conceptual integration and refers to information, concepts and dimensions which are selected and adapted to create novel knowledge structures. What we can see now is that the effectiveness of this creation can be better acknowledged when it is observed in a situated fashion, and when the purposes of their existence are taken into concern. In the specific case of Acerola's map, it results from the compression of information associated to the dimension of space: the features of two different places are compressed, and this selective operation captured only information of these places which could not crash during his speech, in order for his colleagues to understand the facts he was portraying.

As an affordance, Acerola's map was an object created in a unique and specific niche construction, to suffice his specific task of appropriating the information given by the teacher and deliver them to his colleagues. He built it through the negotiation between the need to reproduce information about History and the will to express himself in order to be heard by the students. And it is quite presumable that he has been successful in this undertaking.

\section{Distributed cognition and school - Environments of learning}

The Distributed Cognition Hypothesis proposes the agency of the environment in meaning construction and the detection of what is meaningful and important for fulfilling action goals in a given setting. These ideas provoke methodological changes in cognitive investigation (Clark and Chalmers, 1998, p. 10), as elicits new and fresh comprehensions about facts and phenomena relating cognitive actions and behaviours - learning, and also memory, language acquisition, beliefs, intersubjectivity, cognitive development, psychomotor abilities. It means that the idea of learning in cognitive niches cannot be the same as the one put by traditional theories of cognition, which usually does not consider the situated identity of the learner in educational contexts. Learning in cognitive niches, as we see, is an agentic, dynamic and creative cognitive action which includes the appropriation of institutional practices, norms, instruments and behaviours (Wertsch, 1998; Sawyer \& Greeno, 2009).

Consequently, in the classroom cognitive niche, with its variety of material and symbolic artefacts, we can expect a set of cognitive behaviours and the emergence of a given kind of affordances which are specific of that niche, and are not found anywhere else - as we could testify in the observation of the History lesson depicted in this chapter.

Studies on Evolutionary Psychology corroborate the idea that the cognitive actions and behaviours identified in the classroom niche can be described as a phylogenetic achievement, due to the Developmental Psychology supposition for the phylogenetic basis for constructing and understanding cognitive behaviours related to specific settings for pedagogical actions (Premack and Premack, 1996; Csibra and Gergely, 2006). These studies favour the definition of the proper nature of pedagogy and teaching and learning actions as cognitive systems. So all people involved in teaching and learning activities are operating cognitively in a way which is specific for pedagogic purpose, and not for any other one. 
Assuming these postulations, we advocate that the classroom is a delimited universe where learners, at the same time, are affecting and being affected by its structural organization, which includes the contents to be taught and the material and symbolic artefacts chosen to instrumentalize learning. They construct (= act meaningfully) over the symbolic and material artefacts offered by the teacher and the courseware, and turn them into things that they can understand, utilize. In this structured setting, any semiotic object posited as a public use is an object of negotiation, so material and symbolic artefacts are part of the intersubjective negotiation and normative regulations in the classroom.

These regulations are institutional: the school as an institution structures the way people cognize in the niche: the process of institutionalization is a specific case of conceptualization of an entity in the world; it establishes a code which specifies how an action in a certain context should be interpreted, or, similarly, establishes the sufficient conditions for the application of institutional concepts (Tummolini and Castelfranchi, 2006). Even in classrooms of different Disciplines, their common normative regulations and intersubjectivity conditions lead people to assume functionally similar cognitive behaviours, recognizing themselves as situated subjects, and to tackle with material and symbolic objects in a functionally similar fashion as well.

These assumptions, together with the observation of the meaningful acts of Acerola in his role of teacher-learner, bring the importance of taking into account the importance of the students as cognoscent agents in the classroom semiotic construction, as well as the artefacts they interact with. Both need to be framed in the classroom as an institutional space. The quality of joint conceptualization from these artefacts, which includes the way they are seen by teachers and students, is an important variable for achieving the quality of interlocution, and learning, ultimately.

One of the consequences of this perspective is establishing the student as an agent of his own learning enterprise, although the asymmetric intersubjectivity condition is one of the classroom institutional patterns: teachers must assist students in the task of turning the classroom environment in a source of affordances. The duty of the one who searches for understanding and creating good learning environments and conditions is to define the bases from which this essential task can be accomplished, and how all important features of teaching and learning must be idealized and situated towards it.

About this concern, some initial points are already established: we know that learning occours with an improvement of our capacity of observing and detecting affordances in the niches where we are settled, relatively to our goals of cognizing. We also know that the previous knowledge of a person is pivotal for him/her to detect affordances. Therefore, the more previous knowledge he/she fits to the niche, the more useful affordances he/she will be able to capture. As a matter of fact, we could see, from the cognitive actions of Acerola, that his previous knowledge and the employment of the knowledge common to all the students in the classroom structured the creation of an affordance which could help him give more understandable information to his colleagues.

Therefore, teachers need to help students detect the affordances needed for the activity at issue, having in mind that the ability of perceiving affordances is directly related to the quality 
of the dynamics in the niche (Franks, 2011, p. 174). They do that by observing, before properly beginning the activity, what the students by themselves recognize as affordances in the classroom setting, and what artefacts and previous knowledge they bring to the classroom. In doing so, teachers will be identifying and eliciting the internal domains of the students which might be blended to the external ones in order for the students to detect all suitable affordances which will help them learning contents in a particular activity (Tomasello, 1999).

But teachers can only do this after having established to themselves and to the students the learning goals intended through that activity, and must be sensible to detect whether the students are keeping or not these goals in mind. This is necessary because the learners will only perceive what is important and useful for them to perform a specific activity in a given context if they know what they are performing that activity for. These actions can provide the students with more possibilities to act semiotically over the artefacts, and these behaviours are linked to their stronger singularization in the classroom, and to more possibilities of effective learning. During the years, the recurrence of this kind of action can help learners develop metacognitively (Perfect and Schwartz, 2002; Israel et al, 2005; Waters and Schneider, 2010), or, in other words, to construct their autonomy as learners, from the establishment of their own goals to accomplish a specific activity, and from the conscious employment of the resources for the established aims.

But obviously several factors can jeopardize the success in these actions, and they can be related to problems in the detection of affordances in a given environment. Bardone (2011) presents some of them, showing that these problems can be either in the person, or in the environment. Difficulties in the detection of affordances due to problems of the person are called "hidden affordances": they occur, according to Bardone, when the person cannot make use of the signals because either he/she is not enabled to detect affordances, or he/she does not see the clues for recognizing them. Difficulties in the detection of affordances for environmental problems are called "failed affordances", and occur when the affordances are badly offered or elaborated, and this impedes their identification.

Hidden and failed affordances can occur (at the same time, in some occasions) when the student does not bring to the classroom the previous knowledge enough to be articulated to the goals of action and cognitive behaviour specific of the learning task. They also occur when there is ambiguity in the configuration of the available signs, and this problem it not solved by the teacher. It also occurs when there is no clear definition of the goals to undertake a specific task in the classroom, or these goals are not offered as they should be.

Moreover, taken the asymmetrical nature of the relationship between students and teacher, the problems in the detection of affordances emerge when the teacher does not establishes himself/herself as the "triggerer" of the students' learning process, does not elicit the students' previous knowledge, and does not act upon the tasks in the classroom in order to adapt their structure to help the students detect by themselves the affordances as situated guides for learning.

That's what happened to Acerola's teacher: she was not sensitive to perceive that her students' were not aware of the time and space of the events that she was describing; that's 
why she heard questions about Ancient Romans and modern weapons, but didn't bother of them. The result was that the map that she was using as a possible affordance has failed in its aim to help students construct a conceptual view of past and elsewhere events.

\section{Final remarks}

At the end of this text it is time to answer the questions we put to ourselves at its beginning.

We do assert that Acerola really learned the teacher's lesson, since we established that learning and creating concepts are cognitive operations that blend the material and symbolic objects presented in the environment to the previous knowledge of the learner, and this operation brings new, unique and singular concepts. Notice that Acerola's learning can be attested because his speech selected information with great property: he omitted secondary data about countries and names, but kept the main ideas about the historical moment and motivations for the Royal Family's journey to Brazil.

From what is said above we can say that if he had only repeated the teacher's words, this could not mean learning, because in this situation he would not show precisely the conceptual integration which is the cognitive learning operation par excellence. But we have to stress that the interference of his previous knowledge about social problems in Rio over those historical facts ceases to be part of a learning process and starts to be free interpretation when we cannot identify in his speech the data which came from the objects and ideas found in the environment available as resources for creating new concepts.

The map was a didactic artefact for both the teacher and Acerola, but obviously the latter knew how to use it as a real affordance, because he showed that he could clearly understand the task to transport the students to another place and time, and saw the map as a way to go in this journey. This turned the map into something different from a map of Western World and a map of Rio de Janeiro: a map which cannot be taken as "real", but it was completely meaningful and did pertain to that special moment they constructed in the classroom.

In this chapter we intended to deliver some ideas about learning in institutional environments, from the perspective that human cognition operates and develops itself in a distributed fashion, and within the scope of cognitive niches. Taking this premise into account, discussing how learning occurs in the cognitive niches, and defining the classroom as an essential locus where this operation takes place, means taking into consideration not only the person who learns, but also the relationships between people themselves, and between people and context. The best advantage that this perspective can bring lies in the epigraph of this text: the more we search to understand what cognition is, in real contexts of cognitive action, and the more we incorporate to Cognitive Science the evidence that our relationship with the world is interchanged with our ways of thinking, the closer we find ourselves to understand who we are, ultimately. And, doing so, we will be able to effectively help the students who present learning problems - which in the past were considered as their problems, but now are seen as an outcome of how the school is being constituted as a niche and as an institution, relatively to the aims it is created for. 
This possibilities bring the task to improve didactic practices and pedagogic projects not only from a better understanding about learning as a cognitive accomplishment, but also from comprehending how it is possible to construct a better institutional structure for this aim. To face this challenge, the body of research in Cognitive Science, especially in distributed cognition, can bring resources for a wide and necessary institutional discussion about learning processes. And the assumption of the classroom as a cognitive niche can materialize the necessary interchange between cognitive and social sciences, because its complete comprehension demands the articulation of cognitive and cultural systems.

However, we must say that the non-autonomist and non-essentialist perspective of cognition, in which we are inscribed, is not turned to define a priori how people cognize in a given context. But the fact that the classroom is a normatized space, i.e., a space regulated by social and cultural constraints, elicits an attempt to establish some parameters of the way the students deal with symbolic and material artefacts, and deliver possible understandings about the intersubjective structures that can be found in the classroom. Keeping these purposes in mind, the studies on distributed cognition can ally to other achievements which have pointed to the need to problematize school as an institution - its alleged aims and the historical and ideological basis upon which it is funded, in order to provide the students with a better quality of work and learning, during the time that they are there.

\section{Author details}

Ana Flávia Lopes Magela Gerhardt

Federal University of Rio de Janeiro, Brazil

\section{Acknowledgement}

This text results from research performed during the Post-doctoral term on Cognitive Psychology at the University of Portsmouth, United Kingdom, granted by CAPES (Coordination For the Improvement of Senior Staff) - Brazil.

\section{References}

Anderson, M., and Chemero, A. (2009). Affordances and intentionality: reply to Roberts. Journal of Mind and Behavior, 30-4, p. 301-312.

Bardone, E. (2011). Seeking chances: from biased rationality to distributed cognition. Berlin: Springer-Verlag.

Bardone, E., Magnani, L. (2007). Sharing representations through cognitive niche construction. Data Science Journal, 6-9, p.87-91.

Carassa, A.; Colombetti, M.; Morganti, F. The role of joint commitment in intersubjectivity. In: F. Morganti, A. Carassa, G. Riva (Eds.). Enacting intersubjectivity: a cognitive and social perspective on the study of interactions. Amsterdam: IOS Press, 2008, p.187-201. 
Chemero, A. (2003). An outline of the theory of affordances. Ecological Psychology, 15-2, p. $181-195$.

Chemero. A. (2009). Radical embodied cognitive science. Cambridge: The MIT Press, 252 p.

Clark, A., and Chalmers, D. (1998). The extended mind. Analysis, 58-1, p. 7-19.

Clark, A. (2006). Language, embodiment, and the cognitive niche. Trends in cognitive sciences, 10-08, p. 370-374.

Csibra, G. and Gergely, G. (2006). Social learning and social cognition: the case for pedagogy. In Y. Munakata, M. H. Johnson (Eds.). Processes of change in brain and cognitive development: attention and performance, XXI. Oxford: University Press, p. 249-274.

Cosmides, L., and Tooby, J. (2000). Consider the source: The evolution of adaptations for decoupling and metarepresentation. In: D. Sperber (Ed.). Metarepresentations: A multidisciplinary perspective. Oxford: University Press.

Coulson, S. (2001). Semantic leaps: frame-shifting and conceptual blending in meaning construction. Cambridge: University Press.

Dennett, D. (2000). Making tools for thinking. On: D. Sperber (Ed.). Metarepresentation: $a$ multidisciplinary perspective. Oxford: University Press, pp.17-29.

Donald, M. (1991). Origins of the modern mind. Cambrigde, MA: Harvard University Press.

Fauconnier, G. (1997). Mappings in thought and language. Cambridge: University press. 205 p.

Fauconnier, G., and Turner, M. The way we think: conceptual blending and the mind's hidden complexities. New York: Basic Books, 440p.

Franks, B. (2011). Culture and cognition: evolutionary perspectives. London: Palgrave Macmillan, $358 \mathrm{p}$.

Gibson. J. (1979). The Ecological Approach to Visual Perception. Boston: Houghton Mifflin.

Gorniak, P., and Roy, D. (2007). Situated language understanding as perceiving filtered affordances. Cognitive Science, 31, p. 197-231.

Hutchby. I. (2001). Technologies, texts, and affordances. Sociology, 35-02, p. 441-456.

Hutchins, E. (1995). Cognition in the wild. Cambridge: The MIT Press.

Hutchins, E. (2000). Distributed cognition. In N. J. Smelser, P. B. Baltes. (Eds.). International Encyclopedia of the Social and Behavioral Sciences. Oxford: Elsevier Sciences Ltd. Available at $<$ htp:/ww.telelearning-pds.org/coa/distributed_cognition.pdf $>$ retrieved 10 December 2010.

Israel, S. E.; Block C. C; Bauserman K. L. and Kinnucan-Welsch, K. (Eds.) (2005). Metacognition in literacy learning. London: Lawrence Erlbaum.

Karmiloff-Smith, Annette (1992). Beyond modularity: a developmental perspective on cognitive science. Cambridge: The MIT Press.

Kaufmann, L., and Clément, F. (2007). How culture comes to mind: from social affordances to cultural analogies. Intellectica, 2(46), p. 1-30.

Lave, J. (1993). The practice of learning. In: Chaiklin, S. and Lave, J. (Eds.) Understanding Practice: perspectives on activity and context. Cambridge: University Press. p. 03-32. 
McClelland, J., and Rumelhart, D. (1981). An interactive activation model of context effects in letter perception: Part 1: an account of basic findings. Psychological Review, $\mathrm{n}^{\circ}$ 88, $\mathrm{p}$. 375-407.

McDermott, R. P. (1993). The acquisition of a child by a learning disability. In: Chaiklin, S. and Lave, J. (Eds.) Understanding Practice: perspectives on activity and context. Cambridge: University Press. p. 269-305.

Mithen, Steven (1999). The pre-history of mind: the cognitive origins of art, religion and science. London: Thames \& Hudson.

Norman, D. A. (1988). The Psychology of Everyday Things. New York: Basic Books.

Perfect, T. J., and Schawrtz, B. L. (orgs.) (2002). Applied metacognition. Cambridge: University Press.

Premack, D., and Premack, A., J. (1996). Why animals lack pedagogy and some cultures have more if than others. In: D. Olson, N. Torrance (Eds.). Education and human development. New York: Blackwell, p.302-323.

Sawyer, R. K. \& Greeno, J. G. (Eds.) (2009). Situativity and learning. In: P. Robbins, M. Aydede. The Cambridge Handbook of Situated Cognition. Cambridge: University Press.

Schmidt, M. Rakoczy, H. e Tomasello, M. (2011). Young children attribute normativity to novel actions without pedagogy or normative language. Developmental Science, 14:3. p. 530-539.

Sinha, C. (1988). Language and representation: a socio-naturalistic approach to human development. New York: University Press, 235 p.

SINHA, C. (1999). Situated Selves: learning to be a learner. Em: Bliss J.; Sãljõ, R.; Light, P. (Eds.). Learning Sites: Social and Technological Resources for Learning. Oxford: Pergamon. p. 32-48.

Sinha, C. (2005). Blending out of the background: play, props and staging in the material world. Journal of Pragmatics, 37, p. 1537-1554.

Sinha, C. (2010). Languages, culture and mind: ten lectures on development, evolution and cognitive linguistics. Beijing: Foreign Language Teaching and Research Press.

Sinha, C., and Rodriguez, C. (2008). Language and the Signifying object: from convention to imagination. In: J. Zlatev, T. Racine, C. Sinha \& E. Itkonen (Eds). The Shared Mind: Perspectives on intersubjectivity. Amsterdam: John Benjamins, p. 358-378.

Tomasello, M. (1999). The cultural origins of human cognition. Cambridge: The MIT Press. $248 \mathrm{p}$.

Tummolini, L. and Castelfranchi, C. (2006). The cognitive and behavioral mediation of institutions: towards an account of institutional actions. Cognitive Systems Research, 7, p. 307-323.

Turner, M. (2008). Frame Blending. In: Favretti, R. (Ed.). Frames, Corpora, and Knowledge Representation. Bologna: Bononia University Press. p. 13-32.

Vygotsky, L. S. (1978). Mind in Society: the development of higher mental processes. Cambridge: Harvard University Press, 163 p. 
Walkerdine, V. (1988). The mastery of reason: cognitive development and the production of rationality. London: Routledge. $230 \mathrm{p}$.

Waters, H. S. e Schneider, W. (Eds.) (2010). Metacognition, strategy use, and instruction. Nova York: Guildford Press

Wertsch, J. (1998). Mind as action. New York: Oxford University Press.

Zhang, J., and Patel, V. (2006). Distributed cognition, representation, and affordance. Pragmatics and Cognition, 14-2, p. 333-341. 


\section{Using the Dynamics of a Person-Context System to Describe Children's Understanding of Air Pressure}

Steffie Van der Steen, Henderien Steenbeek and Paul Van Geert

Additional information is available at the end of the chapter

http://dx.doi.org/10.5772/53935

\section{Introduction}

Understanding refers to "the ability to understand", which means "to comprehend, to apprehend the meaning or import of, or to grasp the idea of [something]" (Oxford English Dictionary, 1989). Understanding is a key concept within all fields of study concerning learning and development, such as cognitive psychology, pedagogy, educational sciences, and developmental psychology. Within these fields of study, understanding has been studied for different domains, such as scientific reasoning (e.g., Grotzer, 2004; Inhelder \& Piaget, 1958/2001; Rappolt-Schlichtmann, Tenenbaum, Koepke, \& Fischer, 2007), social development (e.g., Blijd-Hogeweys, 2008), mathematics (e.g., Dehaene, 1997; Gilmore \& Bryant, 2008), and many more. In the field of education, children's understanding is especially important, as understanding involves deep knowledge of concepts, and the active manipulation of this knowledge in the form of explaining, predicting, applying, and generalizing (Perkins \& Blythe, 1994). A model of understanding can give guidance to both researchers and educators dealing with children's understanding and the development of their understanding. In this chapter, we will present such a model, based on dynamic Systems and Skill Theory principles. The model is illustrated throughout this chapter with examples of children's understanding of scientific concepts, or more specifically, children's understanding of air flow and air pressure during a syringe task, which is described below. The syringes task is designed to let children explore how air flows through a system, and to introduce them to the relationship between pressure and volume, as well as the way in which pressure can exert forces on objects (see also De Berg, 1995). Although there are some basic questions the researcher asks every child during the administration of the task, most of the interaction between the boy and the researcher emerges in real-time, i.e. during the task itself. 
Between three and seven years of age, important changes in children's conceptual understanding of scientific concepts take place (Van Geert \& Steenbeek, 2008), in addition to changes in curiosity and exploration tendencies (Simonton, 1999), which are probably related to important changes in children's lives. That is, they go through a major transition when they enter first grade, and start learning to read, write, and to do arithmetic (Carrière, 2009). During this age period children's learning behavior gets shape, attitudes toward school are formed, and first interactions with peers and teachers in a school setting emerge, which are the building blocks of academic performance at a later age.

Moreover, this is also the age at which important cognitive developmental transitions take place. From the work of Piaget (1947/2001) we know that children between three and seven years old are in the pre-operational stage of development, which is characterized by the forming of concepts, and the use of symbols to think about the world, but also by centrism, i.e., focusing on a single aspect instead of more aspects while children reason or solve problems. More recently, research using Skill Theory, which is inspired by Piaget's theory, illustrated that the highest skill (understanding) level that children first reach between 3 and 7 years of age develops from single representations (understandings that go beyond specific actions on objects) to representational systems (linking several of these representations that define the object or concept at hand - see also section 3) (Fischer \& Bidell, 2006). However, this research also showed that children vary enormously in their skills across context, tasks, and within short periods of time. This variation is due to the fact that context dynamically contributes to the deployment of skills in the form of a real-time activity. That is, thinking or understanding takes place in the form of action. How does the process of understanding occur in action, taking into account the real-time interactions that constitute this process in a teaching environment, and taking into account the vast amount of intra-individual variability?

Based on our ongoing longitudinal research project, we will illustrate how short term "building blocks" of understanding give rise to various long-term patterns of understanding. In order to fully understand these short-term building blocks, we have selected one particular problem domain for this chapter, namely air flow and air pressure, because it provides a domain that is both limited and rich enough to study. Zooming in on these short-term interactive processes gives us important information to understand the development and transformations of understanding on the long term (Steenbeek, 2006; Thelen \& Smith, 1994).

During the ongoing longitudinal research project, a researcher repeatedly visits 32 young children (3 to 6-years old) as part of an ongoing longitudinal study on children's understanding of scientific concepts, such as the flow of air and air pressure. During one visit, the researcher presents each child with two empty medical syringes without a needle, which are joined together by a small transparent tube. One of the syringes' pistons is pulled out. "What do you think will happen if I push this [piston] in?" is one of the questions the researcher asks. This question triggers a variety of answers from the children. Some children think nothing happens, others say the tube will pop out, whereas others even think the 
material will explode. Some children say they don't know and others predict that the piston of the other syringe comes out, which is the right answer in this case. After the researcher demonstrates what happens, researcher and child discuss about possible explanations for this phenomenon. Again, multiple answers are given. Some children simply say they don't know. A few mention batteries or electricity as a causal explanation, whereas others say that water flows through the syringes and causes the piston to move upwards. Some children emphasize the tube that connects the syringes, and others understand that air flows through the tube and syringes.

What accounts for the differences in young children's understanding of scientific concepts, and what is the role of the environment, i.e., the teacher in supporting and promoting this understanding? To answer this question, a model of children's scientific understanding should take the complexity and dynamic nature of this into account, as well as the complex interactions with the environment on which the understanding of children is often based (Fischer \& Bidell, 2006). This chapter aims at explaining how children's understanding of scientific concepts can be studied using a model based on properties derived from dynamic systems Theory (e.g. Van Geert, 1994) and Skill Theory (Fischer, 1980; Fischer \& Bidell, 2006).

\section{Dynamic systems and understanding}

A dynamic systems approach describes how one condition changes into another, and how different time scales are interrelated (Van Geert, 1994; Van Geert, 1998; Van Geert \& Steenbeek, 2005, 2008; see also the theory of embedded-embodied cognition of Thelen \& Smith, 1994). Research in the dynamic systems paradigm investigates real-time processes and captures development as it unfolds through multiple interactions between a child and the environment (Van Geert \& Fischer, 2009). Such development can be viewed as a selforganizing process, since the state of the system organizes from the multiple interactions among the elements (e.g. the child and environment). Over time, the system's state may emerge toward certain stable states, or attractors (e.g., Thelen \& Smith, 1994). Dynamic systems theory has so far proven to be a valuable framework for studying human development, including reflexes (Smith \& Thelen, 2003), parent-child interactions (Fogel \& Garvey, 2007), language development (van Dijk \& Van Geert, 2007), scaffolding in teachinglearning situations (Van Geert \& Steenbeek, 2005), dyadic play interactions (Steenbeek, 2006), identity development (Lichtwarck-Aschoff, Van Geert, Bosma, \& Kunnen, 2008), and cognitive development (Fischer, 1980; Fischer \& Bidell, 2006). The approach makes use of methods to investigate time-serial processes, and test dynamical relations between these processes (Cheshire, Muldoon, Francis, Lewis, \& Ball, 2007; Lichtwarck-Aschoff, et al., 2008; Van Geert \& Steenbeek, 2005; 2007; Steenbeek \& Van Geert, 2005). For example, Van Geert and Steenbeek $(2005 ; 2007)$ present mathematical models to predict patterns and variations in combinations of variables over time. Other authors used time series to describe relationships between variables (van Dijk \& Van Geert, 2007) or state space grids (Hollenstein, 2007) to investigate interactions between dyads; as opposed to probabilistic approaches which rely on deviations from the mean and group differences. 
Applying a dynamic approach to the study of understanding scientific concepts means that several properties of this approach have to be taken into account. Below, four properties (intertwining person-context dynamics, iterativeness, interconnected time scales, and microgenetical variability) ${ }^{1}$ and examples of their application to the study of understanding (of e.g., scientific concepts) will be discussed. In section 5, the properties will be illustrated in light of an empirical example, in combination with Skill Theory's framework to measure the complexity level of understanding (Fischer \& Rose, 1999).

\subsection{Intertwining person-context dynamics}

Vygotsky (1934/1986) already pointed out that children develop understanding in close cooperation with their teachers and the material. His concept of the zone of proximal development is a dynamically changing concept, in which teacher and child co-construct the child's development. This means that the child's skills and understanding are constructed by a series of actions guided by the educator, instructions and tool-use, which are then internalized and personalized (cf., Van Geert, 1998; Van Geert \& Steenbeek, 2005).

From a dynamic systems perspective, understanding is seen as a process of intertwining person-context dynamics (Thelen \& Smith, 1994), meaning that the social (e.g., the science teacher) and material environment (e.g., materials used in science class) play an active part in the process and cannot be viewed separately, or merely as an outside-based influence. In fact, these elements are intertwined across time, in a continuous person-environment loop: at any moment in time, one component (e.g., the child) affects the other (e.g., the teacher) and the other affects the first, thus creating the conditions under which both components will operate during the next moment in time (Steenbeek, 2006). For example, interactions between a child, a researcher, and the syringes-task will organize toward certain distributed patterns of understanding at that moment (in real time), which eventually evolve toward stable attractors on a longer time scale (Thelen, 1989; Halley \& Winkler, 2008). Hence, understanding is an active process of what the child constructs in interaction with (not just within) a specific environment, in which each individual contribution is virtually meaningless if not viewed in light of the interaction (Van Geert \& Fischer, 2009). Merged together, person and context become what Fogel and Garvey (2007) call a "cooperative unit", in which both components not only contribute to the process of development, but are highly intertwined and form an unique process together.

Representationalists, such as Fodor (1981) hold the idea that understanding takes the form of internal structures (representations) within the child's mind. A child's scientific understanding thus consists of a collection of these internal structures which represent scientific facts and concepts, which are activated and used to coordinate our behavior toward the current environment (Haselager, de Groot, \& van Rappard, 2003). In this case, a

\footnotetext{
${ }^{1}$ Actually, the dynamic systems approach has many more properties or "tools" (Howe \& Lewis, 2005) to study development. However, we highlighted these four specific properties to illustrate how this approach sheds new light on the study of understanding scientific concepts.
} 
concept or representing model of the air pressure task would be represented in the child's mind, and this representation would guide the child's behavior as he or she is working on the actual air pressure task.

Terms such as "concept" or "representation" are actually more or less undefined, and derive their meaning from a particular theoretical framework. From a representationalist (or information-processing) view, these words refer to internal entities responsible for our thinking or actions toward the environment. From a dynamic view, however, these words refer to processes, perception and action structures, that emerge within a specific environment (Van Geert \& Fischer, 2009). Perceiving, acting and thinking are conscious processes that take a particular shape in the stream of consciousness of the participants, such as a child and the researcher (van Gelder, 1995; 1998). This shape is governed by the participants' actions on the objects, such as the syringes, or on physical representations of the syringes, such as prints or drawings, within their current context, and should not be identified with a retrieval of internally stored representations (Van Geert, 2011). We can construct much of this stream of consciousness by carefully watching the ongoing interaction between child and environment in terms of the intertwining of various forms of verbal and non-verbal behavior, such as eye and head movements, gestures, pointing, verbal descriptions, manipulations of the materials, etcetera. The child's current understanding of the concept at issue (for instance, the flow of air through two syringes connected by a tube), is the child's continuously changing state of mind, or stream of consciousness, as he picks up and reacts to whatever goes on in the current dynamic interaction. Thus, despite the fact that the process of constructing an understanding is a distributed process, involving the intertwining of person and context, understanding can still be specified as an individual and "internal" process corresponding with the individual child's ongoing state of mind, but only as a changing state that unfolds in this active process (Van Geert, 2011). Hence, representations are structures that emerge during a specific interaction in a specific environment, and are not internal symbolic structures which guide behavior.

\subsection{Iterativeness}

Within the process that results from an intertwining between person and context, understanding emerges through iteration, that is, every step in understanding is based on the previous one and embedded in the current context. More precisely, iterativeness (sometimes referred to as recursiveness) involves a series of computational operations, in which the input of the next operation is the output of the previous one. For instance, if a child determines that an empty syringe contains air, he can build on this knowledge by trying out what happens if he joins two of these syringes together by using a tube. Understanding changes through repeated interactions, instead of being the retrieval of a complete representation that is already there in memory. During a teaching interaction, each previous action of the child has an influence on the subsequent (re-)action. In other words, the existing understanding is the basis for the emergence of the next understanding as it develops in the interaction. 
In its simplest possible form, a dynamic systems model specifies the change in a variable (L) over time ( $\mathrm{t}$ ) as a function of the current level of the variable: $\mathrm{L} t+1=f(\mathrm{Lt})$. The function $f$ refers here to the change in 'understanding', but can specify any sort of influence or mechanism of change (Steenbeek, 2006). Understanding does not consist of particular moments within the interaction (e.g. when the child answers), but is in fact the whole iterative process itself, and every interaction unit is a component of this holistic understanding process during a particular problem solving event. Even though understanding consists of the whole iterative process, the child's answers are a reflection of the child's ongoing state of mind within that process and reveal his or her understanding at that very moment in time.

As Howe and Lewis (2005) point out, the iterative nature of the process of understanding can also explain some of the differences between children. When children's understanding depends on interactions, and each interaction is based on the previous one, small differences between children's initial states of understanding can grow bigger over several interactions. This is particularly so if the process takes the form of a positive feedback loop amplifying idiosyncratic properties of the answers, i.e. properties that are typical of a particular child. For example, if the child focuses on only one syringe and the researcher's follow-up questions center on that syringe as well, the difference between this child and another child who focuses on both syringes grows bigger. However, if the process takes the form of a negative feedback loop reducing the idiosyncrasies, small differences in initial states will most likely remain small over the course of the problem-solving process. This would be the case if the researcher switches the focus of her follow-up questions to the other syringe, thereby scaffolding the child towards a more complete picture of the task. The difference between this child and the child who initially focused on two syringes then becomes smaller.

\subsection{Time scales}

The property of interconnected time scales entails that the dynamics of long-term development of understanding are intrinsically related to the dynamics of short-term processes of understanding (Thelen \& Smith, 1994; Lewis, 2000). That is, in order to get a grip on long-term changes in understanding of children, it is worthwhile to focus on the short-term (micro-genetic) process, and examine properties of that process, such as variability (Granott, Fischer, \& Parziale, 2002; Steenbeek, 2006).

Iterativeness occurs on the short term as well as on the long term, meaning that on the short term (e.g. during one interaction between child and teacher in science class), each step in understanding is based on the previous step in understanding, while on the long term each interaction builds on the preceding interaction (e.g. the interaction during last week's science class). In this way, the same mechanisms are sculpting the development of understanding over a shorter and longer period. Thelen and Corbetta (2002) indicate that the general principles underlying behavioral change work at multiple time scales. The short- 
and long-term scales interact, in that repeated (iterative) processes on the short term time scale influence processes on the long-term time scale (Lewis, 2000). In addition, the emergence of large-scale patterns also influences what happens on the short-term time scale, by shaping the structure and function of the interaction on the short term (Lewis \& Granic, 2000; Smith \& Thelen, 2003; Van Geert \& Steenbeek, 2005; Steenbeek, 2006). The underlying idea is that all levels of the developing system interact with each other in a self-organizing way, and consist of nested processes that unfold over many time scales, from milliseconds to years (Thelen \& Smith, 1994; Lewis, 2000).

\subsection{Micro-genetical variability}

As a result of the iterative organization of the components and the intertwining between child and context that mark the process of children's understanding, we can observe microgenetical variability. This means that the complexity of children's understanding fluctuates within very short periods of time, e.g. during one task. While studying the processes of developmental change, it is crucial to take many observations (adopting a microgenetic research method) to detect the subtle changes that constitute understanding and its development (Siegler \& Crowly, 1991; Kuhn, 1995). Researchers note that, driven by bidirectional interactions with the environment, the complexity of children's understanding can increase during a task, but also temporally decrease, for example when the task difficulty increases, when the teacher's support decreases, or when children encounter something unexpected while working on a task. Understanding can change gradually or abruptly in a stage-like pattern in a short timeframe, even during a single task (Yan \& Fischer, 2007; Siegler \& Crowly, 1991).

Researchers have suggested that this variation is an important factor in development, since an increase in variability may be related to the ability to reach higher levels of skill (Howe \& Lewis, 2005; Thelen, 1989), or, more generally, to a transition to another pattern of behavior (i.e., attractor) (e.g., Thelen \& Smith, 1994; Van Geert, 1994). The variability on the shortterm (e.g. during the syringes-task or during a science lesson) can therefore yield important information about how the developmental pathways of understanding will be shaped on the long term.

In order to capture the complexity of understanding and variations in complexity over a short and longer time periods, we can use Skill Theory's framework of cognitive development (Fischer, 1980; Fischer \& Bidell, 2006). This framework can be used on both the long- and short-term time scale and is compatible with a dynamic systems approach. Even more so, Skill Theory could be considered as a specific dynamic system's theory applied to human skill development, since it assumes skills are built in an iterative and hierarchical way, i.e. each skill level builds on the previously obtained skill level. Moreover, skills are highly context-dependent and fluctuate over time, that is, they depend on the constraints and affordances of the context in which they are mastered (Fischer \& Bidell, 2006). 


\section{Skill theory and understanding}

Skill Theory focuses on the complexity and variability of children's skills, which consist of actions and thinking abilities, and the way these are constructed (Fischer, 1980; Fischer \& Bidell, 2006). Since skills are thinking structures mastered in a specific context, such as a science class, they hold both person-related as well as context-related characteristics (Parziale \& Fischer, 1998). An example of a skill is a child's ability to understand how air pressure works while manipulating the syringes-task. This understanding is reformulated when the student works on a similar task in another environment (e.g. with different materials or without the help of the researcher). Skills are thus highly influenced by the possibilities and constraints of the situation in which the skill is used.

Skill Theory explains both long- and short-term development of skills by measuring these on the same hierarchical complexity scale. This complexity scale consists of 10 levels, grouped into 3 tiers, which are sensorimotor, representational or abstract by nature. The scale can be applied to different cognitive (Fischer \& Granott, 1995; Schwartz \& Fischer, 2005), social (Fischer \& Bidell, 2006) and language domains (Fischer \& Corrigan, 1981), as it focuses on hierarchical complexity rather than content. This makes Skill Theory especially suitable to describe differences between children, as well as differences between skills in different domains for the same child (Parziale \& Fischer, 1998).

A child's understanding within a domain, as an emergent process in real-time, can be viewed along two dimensions: the first being the dimension of content (the subject), the second of complexity (the complicatedness). In order to evaluate children's understanding (of, for example, air pressure), we need a fair ruler to determine how elaborate their understanding is, and to evaluate whether they need extra help in some areas. One of the most powerful characteristics of Skill Theory (Fischer, 1980) is that it extracts complexity from content, resulting in a content-independent ruler of understanding. Because of the content-independent nature of the way Skill Theory approaches understanding (or other skills), it enables researchers to compare understanding across multiple time points, contexts, persons, and for different age ranges.

According to Fischer (1980) and Fischer and Bidell (2006), development in a particular domain goes through 10 levels of skills hierarchically grouped into three tiers that develop between 3 months and adulthood. The first tier consists of sensorimotor skills: simple connections of perceptions to actions or utterances. An example is a statement that two syringes are attached to a tube. Sensorimotor skills form the basis of the skills in the two subsequent tiers, i.e. they are the building blocks of the higher levels. The second tier constitutes of representational skills, these are understandings that go beyond current simple perception-action couplings, but are still based on them. Hence, the term representation refers to the coordination of several sensorimotor skills at the same time, not to an internal symbolic structure (Fischer, 1980). Within the context of the air pressure task for example, the child can predict what will happen if the piston is pushed in without literally touching or manipulating the syringe. Nonetheless, what he or she predicts depends on the material context, and on the sensorimotor skills that he or she mastered 
before. The third tier consists of abstractions, which are general nonconcrete rules that also apply in other situations (Schwartz \& Fischer, 2005). This would be an explanation about the relationship between pressure and volume inside a syringe.

Within each tier, three levels can be distinguished ${ }^{2}$, each one more complex than the previous one. The first one can be characterized as a single set, meaning a single action (or a single representation, or a single abstraction). The second level is a relation between two of these sets, which is referred to as a mapping. The third level is a system of sets, which is a relation between two mappings, in which each mapping consists of a relation between single sets. After this level, a new tier starts, which is divided in single sets, mappings and systems as well (Fischer \& Bidell, 2006). For the emergence of each level, evidence of discontinuities and differences between levels has been demonstrated using analysis methods based on Rasch scaling (Schwartz \& Fischer, 2005).

Fischer and colleagues (Fischer, 1980; Fischer \& Bidell, 2006; Yan \& Fischer, 2002; Schwartz \& Fischer, 2005; Granott \& Parziale, 2002) showed that Skill Theory can not only describe and explain the development of skills on the long term, but also describe the micro-genesis of problem solving. When facing a new task or problem within a domain, even high-skilled adults go through the same cycles of development. That is, at the beginning they show skill levels that are mostly sensorimotor, which build up to more elaborate levels during the course of the task. During a task (and also during the long-term development of skills), people do not go through the skill cycles in a linear fashion. Instead, they repeatedly build up skill levels and show collapse before they obtain their highest possible level, something Yan and Fischer (2002) call "scalloping". During a task, people vary constantly within a bandwidth between their highest and lowest possible complexity levels, which is also known as the developmental range. The highest levels within the bandwidth are only reachable when the environment provides sufficient support (Fischer \& Bidell, 2006; see also Yan \& Fischer, 2002).

Skill theory also accounts for inter-individual differences in understanding and is therefore especially suitable for describing individual developmental pathways (Fischer, Rose \& Rose, 2007). Yan and Fischer (2002) showed that adults' performance on a computer task can move through a variety of pathways, each one showing nonlinear fluctuations. Of all participants, novices showed the most frequent and rapid fluctuations in performance. Experts however fluctuated less frequent in their performance, meaning that variations followed on each other in a slower fashion.

In sum, a model of understanding needs some kind of ruler to determine the complexity of understanding levels children show. Skill Theory (Fischer, 1980; Fischer \& Bidell, 2006) provides a content-independent ruler for understanding, which can be applied to different

2 After the 3 levels of the abstraction tier, a higher complexity level emerges, also known as 'single principles', which is the $10^{\text {th }}$ level of the scale. Additionally, people function on the few highest levels usually in early adulthood, but only for their domains of expertise. For most other domains, people function on a lower complexity level. 
time scales of development, and takes both the role of context, as well as inter- and intraindividual variability into account.

\section{A model of understanding}

Using the four properties from the dynamic systems paradigm and Skill Theory's ruler, we can construct a model of understanding to guide research and practice in education, but also in other areas that require the evaluation of cognitive growth. The general model of understanding here is that it is an active process, distributed across people involved, and that it is dynamic, i.e., it continuously changes, and self-organizes through iteration. It is important to keep in mind that, even though the four properties describe distinct mechanisms, they all work at the same time while the process of understanding unfolds. Below, we will present the model and briefly highlight its components, after which we discuss these in more detail by using an empirical example.

As Figure 1 shows, children construct levels of understanding during short-term interactions with the environment, such as during a task they are working on together with an adult. Both child and adult are characterized by specific distal factors (e.g. years of schooling) that influence their behaviour. However, those distal factors are not what we focus on, since the figure can be characterized as an action model, that is, it focuses on understandings which are constructed during an interaction by means of a process that is distributed across the child, the adult, and the material context with which they interact or which they manipulate. This means that during an interaction, there is a bidirectional influence between the child's answers and the adult's questions within the material context. This is illustrated in the big square (part A) of figure 1.

Moreover, the process is iterative, meaning that it changes through repeated interactions, instead of being the retrieval of a complete representation that is already there in memory. During a teaching interaction, each previous action of the child has an influence on the subsequent (re-)action. This is illustrated by the big arrows between adult and child (part B of figure 1) and the small arrows on the side of the boxes indicating the child and adult.

Each task-related utterance has two dimensions: a specific content and a complexity level. During interactions, we can observe the complexity level of understanding, as it comes forward in the child's distinct utterances, which are often reactions to what the adult is saying, or are part of the ongoing discussion between an adult and a child. This complexity level, measured by Skill Theory (Fischer, 1980), will vary between different children, and will fluctuate over time within the same child. This is illustrated by part C in figure 1.

Lastly, the long-term development of children's understanding unfolds through several of these short-term interactions. As an example, figure 1 displays the sessions with 3-month intervals we used in our study of young children's understanding of scientific concepts. The link between short- and long-term development is indicated in part D of figure 1 . 


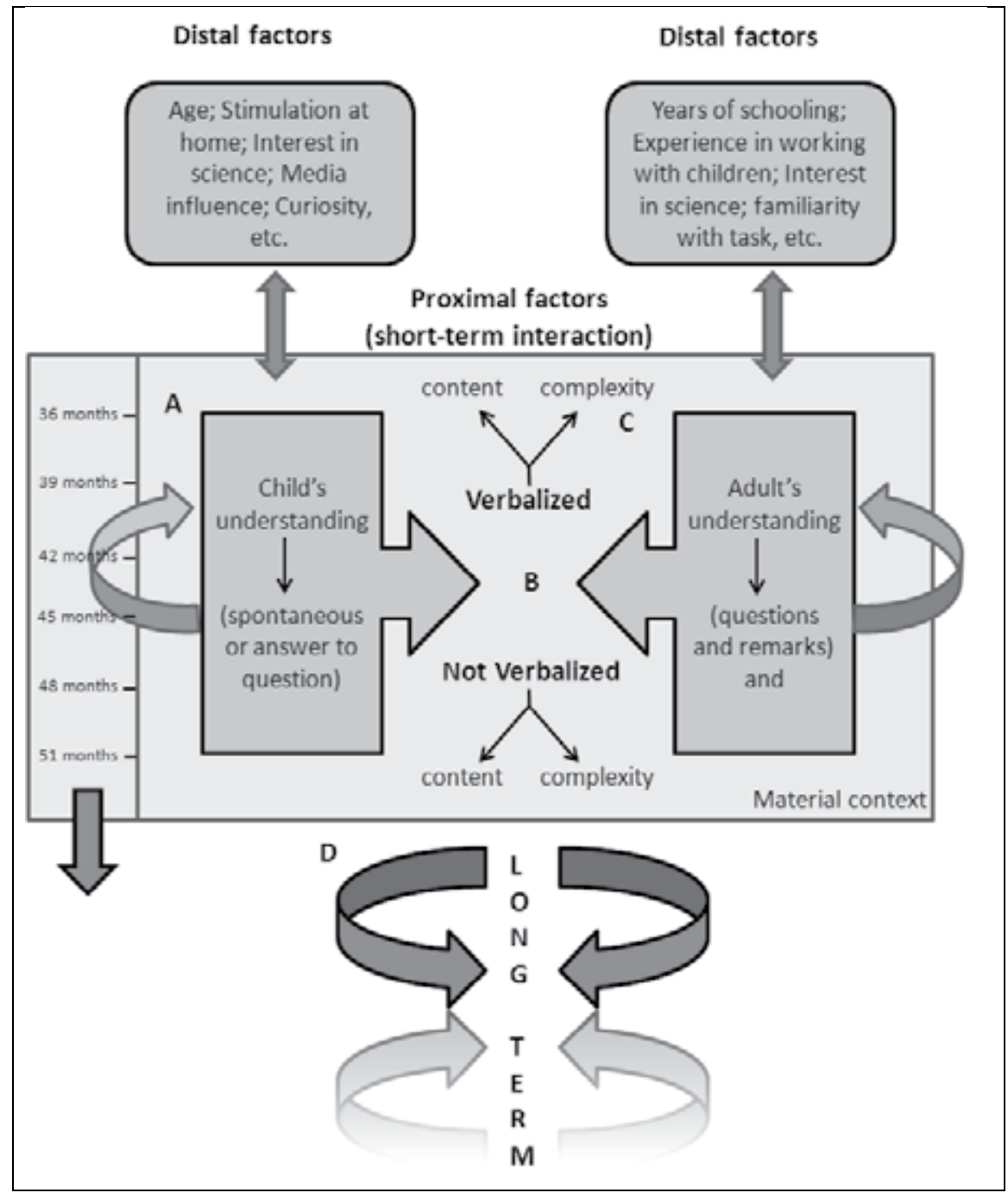

Figure 1. A conceptual (action) model of understanding based on principles derived from dynamic systems theory and Skill Theory

\section{An empirical example and illustration of the model}

In the next sections, we illustrate the model and the four properties by using an example (see table 1) derived from our empirical study focusing on the long-term development of understanding air pressure (and other scientific concepts, such as gravity) in three to seven year old children. Table 1 is an excerpt of a transcribed session in which a boy (4 years, 6 months) and a researcher explore the syringes task mentioned in the introduction. The transcript starts right after the point in which the researcher and the boy explored the exterior of the syringes. That is, they compared them in size and examined the numbers written on the outside. 


\begin{tabular}{|c|c|c|c|}
\hline Person & Content: verbal (gestures, manipulations, gaze directions) & Complexity & $\mathrm{Nr}$ \\
\hline Researcher & $\begin{array}{l}\text { (Attaches the two syringes by a small transparent tube, gives } \\
\text { one syringe to the boy) "I attached the tube to these. What } \\
\text { do you think will happen if I push mine in?" }\end{array}$ & & 1 \\
\hline Boy & (Looks at his own syringe) "I don't know" & No level & 2 \\
\hline Researcher & "But what do you think?" & & 3 \\
\hline Boy & (Looks from the researcher to his syringe) "Uhm..." & No level & 4 \\
\hline Researcher & $\begin{array}{l}\text { (Pauses) "You said they are the same. I pulled this } \\
\text { piston out (Touches the piston), and pushed the other } \\
\text { piston in (Points down to the other piston). Then I } \\
\text { attached the tube. What do you think will happen if I } \\
\text { push this one in?" (Gestures as if she is pushing down) }\end{array}$ & & 5 \\
\hline Boy & $\begin{array}{l}\text { "Then this one will go up like this." (Holds his syringe in } \\
\text { one hand, while his other hand pushes the end of the piston } \\
\text { on the table, then he moves his hands up) }\end{array}$ & $\begin{array}{l}\text { Single } \\
\text { representation } \\
\text { (prediction) }\end{array}$ & 6 \\
\hline Researcher & $\begin{array}{l}\text { (Points to this syringe the boy holds) "Is that one going } \\
\text { up?" }\end{array}$ & & 7 \\
\hline Boy & $\begin{array}{l}\text { "Yes, and then that one is going down" (Points at the } \\
\text { piston of the syringe the researcher is holding) }\end{array}$ & $\begin{array}{c}\text { Single } \\
\text { representation }\end{array}$ & 8 \\
\hline Researcher & "Really? Why does that happen?" & & 9 \\
\hline Boy & $\begin{array}{l}\text { "Because we attached the tube." (Follows the tube with his } \\
\text { finger to the tip of his syringe) }\end{array}$ & $\begin{array}{c}\text { Sensorimotor } \\
\text { system }\end{array}$ & 10 \\
\hline Researcher & $\begin{array}{l}\text { "I see... If we would take away the tube, it wouldn't } \\
\text { work?" }\end{array}$ & & 11 \\
\hline Boy & (Shakes his head) "No". & & 12 \\
\hline Researcher & (Pushes her piston in, pauses) "Were you right?" & & 13 \\
\hline Boy & (Watches his own syringe as the piston pulls out) "Yes" & & 14 \\
\hline Researcher & "Can you do it as well?" (Holds her syringe up) & & 15 \\
\hline Boy & (Looks at both syringes, pushes the piston of his syringe in) & & 16 \\
\hline Researcher & $\begin{array}{l}\text { "How is this possible? You're pushing it over there } \\
\text { (Points at the piston of the boy's syringe) and then this one } \\
\text { goes backwards!" }\end{array}$ & & 17 \\
\hline Boy & (Pushes piston in and pulls it out) "I don't know" & $\begin{array}{l}\text { No level, } \\
\text { zero }\end{array}$ & 18 \\
\hline Researcher & $\begin{array}{l}\text { "OK, but it has something to do with the tube, you said. } \\
\text { What do you think is inside the syringes and tube?" }\end{array}$ & & 19 \\
\hline Boy & (Pauses for a long time, looks around) "I don't know" & $\begin{array}{l}\text { No level, } \\
\text { zero }\end{array}$ & 20 \\
\hline Researcher & "I think there's no water in it" (Shakes her syringe) & & 21 \\
\hline Boy & "No" (Starts shaking the syringe) & & 22 \\
\hline
\end{tabular}




\begin{tabular}{|c|c|c|c|}
\hline Person & Content: verbal (gestures, manipulations, gaze directions) & Complexity & $\mathrm{Nr}$ \\
\hline Researcher & $\begin{array}{l}\text { "But then, what is in it? And how is it possible that we } \\
\text { can move one by pushing the other?" }\end{array}$ & & 23 \\
\hline Boy & $\begin{array}{l}\text { "Because this is attached (Touches the end of the tube) and } \\
\text { then it can move out" (Pulls the piston out) }\end{array}$ & $\begin{array}{c}\text { Sensorimotor } \\
\text { system }\end{array}$ & 24 \\
\hline Researcher & $\begin{array}{l}\text { "You know what; we can also attach a longer tube! (Gets } \\
\text { a longer tube) "What do you think will happen then?" }\end{array}$ & & 25 \\
\hline Boy & $\begin{array}{l}\text { (Gets the end of the tube and attaches it to his syringe) "I } \\
\text { think still the same." }\end{array}$ & $\begin{array}{l}\text { Single } \\
\text { representation } \\
\text { (prediction) }\end{array}$ & 26 \\
\hline Researcher & "Even with a longer tube?" & & 27 \\
\hline Boy & "Yes" (Looks at his syringe) & & 28 \\
\hline Researcher & (Pushes her piston in, it works) "So now it works as well" & & 29 \\
\hline Boy & (Pauses, pushes the piston of his syringe in, then pulls it out) & & 30 \\
\hline Researcher & "So it has to do with the tube or something like that..." & & 31 \\
\hline Boy & $\begin{array}{l}\text { "Yes, because the tube is attached to this one (Looks at } \\
\text { syringe while he pushes the piston back in), and it is } \\
\text { attached to here (Points at the point where syringe and tube } \\
\text { are connected), and then goes (Makes a gesture for pushing } \\
\text { the piston in) this (Points at the tip of the syringe), it goes } \\
\text { like this" (Follows the tube from the tip until he is halfway) }\end{array}$ & $\begin{array}{c}\text { Single } \\
\text { representation }\end{array}$ & 32 \\
\hline Researcher & "I see... what do you mean when you say 'this'?" & & 33 \\
\hline Boy & $\begin{array}{l}\text { (Keeps on following the tube with his finger, can't reach for } \\
\text { the last bit, so follows it in the air) "The tube, it goes like } \\
\text { this" }\end{array}$ & $\begin{array}{c}\text { Single } \\
\text { representation }\end{array}$ & 34 \\
\hline Researcher & $\begin{array}{l}\text { (Follows the last bit of the tube with her finger) "Yes, but } \\
\text { what is going through the tube?" }\end{array}$ & & 35 \\
\hline Boy & $\begin{array}{l}\text { "That... (Pauses and looks at the tip of his syringe) "The sigh } \\
\text { is going through the tube (Gestures for pushing the piston } \\
\text { in) "And then it goes, like this, and this, and this" } \\
\text { (Follows the tube until halfway) }\end{array}$ & $\begin{array}{l}\text { Single } \\
\text { representation } \\
\text { /representa- } \\
\text { tional } \\
\text { mapping } \\
\end{array}$ & 36 \\
\hline Researcher & "The sigh is going through the tube and flows to mine?" & & 37 \\
\hline Boy & "Yes" (Pulls the piston of his syringe out) & & 38 \\
\hline
\end{tabular}

Table 1. Excerpt of a session from our longitudinal project in which a boy (4 years, 6 months) explores the syringes task together with a researcher.

\subsubsection{Person-context dynamics - social construction}

An important part of these context dynamics is the social part of the context, meaning the people around the child. Thus, the development of the child's understanding occurs in 
interaction with the social environment (e.g. the teacher), and it is this interaction that drives the process of understanding, enabling the student to receive adaptive assistance and make progress step by step (Hirsch-Pasek, Golinkoff, Berk, \& Singer, 2009; Van Geert \& Steenbeek, 2005). In our example (see table 1), the child constructs his answers together with the researcher. The researcher's questions are guided by, and on their turn guide, the child's answers. An illustration of this can be seen in fragments 2 to 6 of table 1 . After the boy answers he does not know what happens with the syringe he is holding if the researcher pushes the piston of the other one in, the researcher asks him "What do you think?" In this way, she is trying to get the boy to make predictions, encouraging him to hypothesize. In response, the boy looks around and does not answer the question. The researcher, in turn, helps him getting started by summarizing what he said before and by a verbal repetition of her actions with the task material. After having heard the adult's repetition of her actions, the boy starts to construct an answer on a higher complexity level than before. In terms of Skill Theory, this answer can be classified as a single representation, as he makes a prediction that goes beyond simpler perception-action couplings (skill levels, when applicable, are indicated the right column of table 1).

Two things are important here. First, the researcher is responding to the boy in this way, because he did not know the answer. Had the boy given the answer, she may had pushed the piston in, or asked him to elaborate on his answer. Because the boy does not know the answer, she needs an approach to determine whether he really has no idea, and if so, how she can help him to make a prediction based on what he knows about the syringes. In order to do this, she tries out two different approaches. First, she asks him what he thinks, which can be a starting point for further elaboration on his side. When the boy does not reply, she decides to help him to get started by giving some information about what they have done and seen before. The boy now hypothesizes what happens if the piston of one of the syringes is pushed in. The answer to the question "What do you think will happen?" (see fragment 1 of table 1) is therefore the product of the interaction between the boy and researcher. In her reactions to the boy's "I don't know" the researcher is trying to guide his understanding. In turn, after hearing the researcher's summary, the boy constructs his understanding. What happens with regard to the boy's understanding during the interaction with the researcher is not mere retrieval of earlier gathered knowledge, or a reaction to a trigger (whether it be the syringe itself or the questions), but a (re)construction of knowledge through a constellation of interactions with researcher and material. If we look at understanding while it occurs in real time, we can only study the person-context aggregation that results from this interactive process and cannot distinguish the unique contribution of the individual components (Van Geert \& Fischer, 2009). Even though one can describe what the child does in answer to a specific action or expression of the adult; it is not possible to distinguish the adult's or child's contribution to the (variance in) understanding during the task.

Parallels can be drawn with other teacher-student interactions, such as in scaffolding during instructions in arithmetic lessons. In their model of scaffolding, Van Geert and Steenbeek (2005) model the process of scaffolding during an arithmetic class taking a dynamic systems 
approach. Scaffolding is an interactive process in which the student makes progress using the help of a teacher, which scaffold-level should be adapted to the student's level in order to have the right effect. One of the most interesting properties of this dynamic model is that it accounts for transactions between teacher and student, and that it portrays a dynamic, real-time combination of both the student's performance level and the scaffold-level of the teacher. One of the parameters in the model is the optimal scaffolding distance, a bandwidth which differs among individuals and contexts, within which help stimulates learning. Within that bandwidth, the optimal scaffolding distance is the distance between the pupil's level and the level of help or scaffolding for which the learning effect is maximal. Just like in our model of understanding, the actions of student and teacher form a unique process built of bi-directional relationships (Fogel \& Garvey, 2007).

\subsubsection{Person-context dynamics - the material context}

In addition to the social context, the material context (such as the syringes) also plays an important role in the process of understanding. The syringes should not be conceived of as fixed or monolithic things, but are instead part of the emerging dynamics. Even an unmovable material object is dynamic in terms of its effect on the child, in the sense that the child continuously changes his angle of vision towards the object and thus sees different parts of the object. The dynamic and intertwining nature of the material context is even more strongly illustrated by the syringes task, in which the child or the adult manipulate the syringe, and are thus changing the nature of the object in line with their activities.

In the example (table 1), the syringes and tube are frequently touched by the boy and the researcher to emphasize or guide their verbal expressions (see fragments 5, 6, and 10). The best illustration of this, however, can be found in fragments 32 to 36. In this fragment, the boy uses the material extensively, after which a higher level of complexity emerges: he transitions from a sensorimotor systems level to a single representation/representational mappings level. Note how the boy substitutes words for gestures and pointing in fragments 32 and 34, following the process of what happens with his hands. Parallels can be drawn with fragment 5 , in which the researcher is talking the boy through what happened before. In fragments 32 and 34, however, the boy uses the material instead of the researcher's words to construct his understanding. Before fragment 32, he predicted that one piston comes out when you push the piston of the other syringe in. However, so far, he was not able to explain why. Now, using his hands to examine the syringe, he is able to represent the process, and concludes that "it" is going through the tube. Eventually, guided by the researcher's question "But what is going through the tube?" which seems to suggest that he is on the right track, he is able to replace the word "this" in his explanation for "sigh".

\subsection{Second property: Understanding is an iterative process}

In figure 1, the iterative character of the understanding dynamics between student and researcher is shown in that each previous action of the student has an influence on the subsequent (re-)action of the researcher, and vice versa. Over time, each session has an influence on the subsequent session of this student-researcher pair, which implies that the 
influences between the child and environment are bidirectional, meaning that not only the action of the researcher influences the next (re)action of the student, but also that the previous interaction influences the next interaction. Iterativeness is thus the form in which the cyclical or reciprocal character of causality occurs.

In our example (table 1), the iterative nature of the process is not only illustrated by how the researcher and child react to what has been said previously throughout the whole transcript, but also by how the child's understanding develops during the interaction. With regard to the prediction he makes in the first half of the interaction, the child goes from "I don't know" (fragments 2 and 4; no skill level) to "This one goes up like this" (fragment 6; single representation). This change in understanding is constructed in reaction to what the researcher said right before in fragment 5 . With regard to the explanation of the boy why this happens, his understanding goes from "Because this [the tube] is attached" (fragment 24; sensorimotor system), to "Something goes like this [through the tube]" (fragment 32; sensorimotor system/single representation), to "The sigh is going through the tube" (fragment 36; single representation/representational mapping)." The statement that the tube is attached, which the researcher repeats and emphasizes in fragments 19 and 31, leads to the conclusion that there must be something flowing inside the tube. Since there is no water in the tube fragments 21 and 22), or anything else visible for that matter, it must be "sigh" (fragment 36).

This step-wise refining of the boy's understanding, in which each previous step is the beginning of the next step, illustrates the iterative nature of the process nicely. Not only does iterativeness occur on the conversation level (what the child says depends on what the researcher said previously and vice versa), it also occurs on the complexity level of understanding (each understanding of the child depends on the previous understanding). Finally, the iterative nature of the process can also be seen over sessions, meaning that previous sessions influence subsequent sessions.

\subsection{Understanding is micro-genetically variable}

In our example (see table 1), micro-genetical variability is seen in the child's understanding of how the material works. First, in fragment 10 the boy names a single cause for what happens: "Because we attached the tube". This is an answer on a sensorimotor system level; he gives a single, observable causal explanation for the phenomenon, not taking the volume of the syringes or the air into account (see also the third column of table 1). Over the course of the interaction, he briefly regresses to "I don't know" (fragments 18 and 20; no skill level), and restores his previously gained skill level again in fragment 24: "Because this [the tube] is attached". From there, he further constructs his understanding, and eventually reaches a higher level in fragment 36: "The sigh is going through the tube", for which he needs a representation of the role of air in the system.

In Figure 2 a time-serial illustration of the fluctuations in the boy's answer levels during the air pressure task is depicted. The graph shows how the understanding of the boy fluctuates over time. While Skill Theory's level 4 (single representation) is mostly observed during the interaction, the boy also regularly shows understandings at level 3 (sensorimotor system). 
Even though his understanding seems to increase in complexity over time (on average the boy reaches level 4 more often in the second half of the interaction), his understanding often regresses to level 3 and to incorrect/irrelevant understandings. Hence, understanding is not a fixed entity, but varies over time, even within a single task.

The short-term intra-individual variability influences the variations in development we can see on the long term (Fischer \& Bidell, 2006; Van Geert \& Fischer, 2009). If micro-genetical variability is associated with reaching higher-level skills (Howe \& Lewis, 2005; Thelen, 1989), long-term trajectories of understanding may differ between children showing more periods of variability versus children showing little periods of variability within short-term interactions. This also makes sense in combination with the property Iterativeness, as a shortterm interaction showing a broad range of skill levels makes it more likely that skill levels subsequently move toward a higher level (cf., a phase transition), compared to a previous interaction showing a narrow range of skill levels. After all, the interaction with a broad range of skill levels yields more possibilities for the next interaction than an interaction with a narrow range. In conclusion, as Howe and Lewis (2005) mention, understanding gets form over various instances and in turn, drives long-term developmental change. This connection between the short- and long-term scale of development brings us to the next property, that of interconnected timescales.

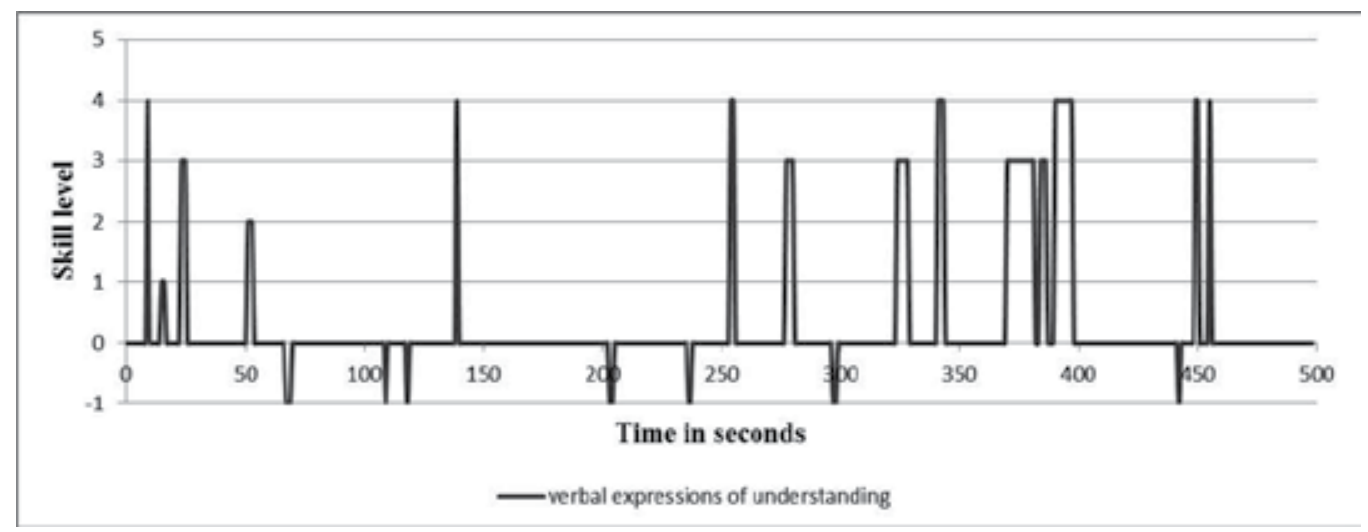

Figure 2. Time-serial illustration of the variability in the boy's understanding during the air pressure task, measured by using Skill Theory (Fischer, 1980). For this boy, levels on the y-axis range from 1 (single sensorimotor set) to 4 (single representation). A -1 score represents an incorrect or irrelevant answer.

\subsection{Fourth property: Interconnected timescales}

Three months later, the researcher returns with the syringes and the tube. The researcher starts by asking "Do you remember what we had to do with this?" In response, the boy immediately grasps the material and attaches the tube to the syringes. Then he replies: "Yes, when you push this one in, the air will go over here". He doesn't need more time to think about the process in a stepwise fashion: That it works like this because the tube is attached, 
that there must be something going through that tube, etcetera. Based on the previous interaction, he now knows that air is going through the tube and makes the pistons move. Note, however, that this is not a mere retrieval from memory. The boy first attaches the syringes to the tube, and answers afterwards. Moreover, the question of the researcher is phrased in a way that encourages him to think about what they did before. Even though the researcher's role is not as prominent as it was in the previous interaction, the social context still plays a role in the construction of understanding. However, three months earlier, the understanding was clearly a co-construction between child and researcher. Now the child can directly introduce this understanding to the interaction, triggered by the researcher's question and the material, but without further interference.

\section{Discussion}

From a theoretical point of view, we discussed a number of dynamic properties in combination with Skill Theory's ruler of cognitive development. We argued that using these properties and ruler give both educators and researchers important means to get a grip on how children's understanding of scientific concepts builds up over time. More specifically, it helps to understand how children organize their knowledge in concordance with the context, i.e. the teacher, and highlights the importance of being aware of teachers' accounts in conversations with children, for example during a science lesson.

There are many different types of knowledge generation processes, one of which is the socially situated process between adult, child and task that we are discussing here. When a child is assessed or diagnosed, a different process of knowledge generation occurs. In these instances, the child is asked to construct knowledge without the help of an adult, but usually in interaction with a particular symbolic substrate, such as a piece of paper to draw on, or the structure of language that the child is using to describe knowledge. It is however wrong to think that only the latter process (in which the child works without help) is a reflection of the child's "real" knowledge. In fact, both the co-constructed as well as the individually constructed knowledge reflect the child's "real" understanding. Variations in complexity levels within one type of knowledge generation, but also between different types of knowledge generation, illustrate the intrinsic variation of understanding as such.

The model we proposed helps in re-conceptualizing the process of understanding in individual children, and the underlying mechanisms of change in their understanding. The latter is especially important, since "Developmental psychologists are not simply interested in the stable states achieved by individuals along their lifespan, but also about the mechanisms of change that lead from one state to the next." (Howe \& Lewis, 2005, p.248). The advantage of a dynamic systems approach to the study of understanding is that it makes the development of understanding more transparent and no longer limited to an invisible process inside the individual learner (Van Geert \& Fischer, 2009). Instead, it enables us to closely monitor interactions between child and environment to determine how the outcome (a form of understanding at some point) is constructed in real time. 
In an applied sense, it is of great importance for parents, (science) teachers, and other practitioners to have knowledge about how children grasp varied concepts and how their understanding develops over time. By having this knowledge, they will be able to challenge children in their current level of understanding in order to promote children's optimal developmental trajectories with regard to cognitive understanding, and by doing so, promote children's optimal development in a broader sense. Departing from the idea of understanding as a process of change in which the child and the (social and material) context intertwine, the ways and complexity levels at which educators interact with their pupils have an important influence on the development of understanding. With regard to iterativeness, it is important for educators to acknowledge that how understanding changes at one moment in time depends on the understanding at a previous time point. That is, from a dynamic systems perspective, there are no internal operations on representations of knowledge that cause intellectual growth. Understanding organizes on the spot, and gets internalized over time through multiple interactions with the environment. Regarding micro-genetical variability, it is important for educators to understand that the highest complexity level on which children operate (e.g. when they learn about scientific concepts) can change rapidly during short-term interactions, not only when the environment or the amount of support visibly changes. Finally, a better understanding of the temporal stream of understanding will help educators to become aware of their own role in the long-term learning process, and may help them to change their actions when necessary or wanted. Students who are engaged in (scientific discovery) learning need adequate support to construct their knowledge (Alfieri, Brooks, Aldrich, \& Tenenbaum, 2010).We claim that teachers' awareness of their own role is an important indicator for the quality of their support, which is a crucial factor in improving children's learning (McKinsey, 2007).

We need to work further on completing the empirical picture of possible trajectories of understanding that can emerge in individual children and investigate how these are related to processes on the short-term time scale. This will help us to differentiate components that build up to children's successful and unsuccessful learning trajectories with regard to scientific understanding. This knowledge will also help science educators to teach children to successfully master scientific concepts, as children's understanding of scientific concepts is not always accurate (Grotzer, 2004). When children have more expertise in science, feel confident about this, and enjoy science lessons, this may eventually boost the current number of young people pursuing a scientific academic career. In order to maintain economic growth, people with a scientific education who can ensure continuous technical capability of the highest standards in all fields of expertise are very much needed.

An important next step in the study of the development of children's understanding of scientific concepts as a dynamic system is to try to map individual learning trajectories and build a dynamic simulation model, based on a general theory of action or agent behavior on interacting time scales, and a general theory of mechanisms of change (see van Geert, 1994; Van Geert \& Steenbeek, 2008; Steenbeek, 2006). With the help of such a simulation model, the important role of the (science) educator in the emergence of understanding can be unravelled. As a result, such a simulation model will have an important educational value, 
by making the dynamic principles that play a crucial role in the development of understanding accessible for a broader public of educators. Based on the short-term interaction patterns we see emerge, and the implications this has for the long term, we can eventually construct adaptive teaching programs, lessons and materials for science education, which are better adapted to children's current levels of understanding and how this understanding develops in interaction.

An example of an adaptive educational and assessment (computer) program is Mathgarden (van der Maas, Klinkenberg, \& Straatemeier, 2010), an educational computer game with a wide range of sums children that can play at school or at home. Children's responses (the short-term child-computer interactions) are frequently analyzed and reported to their teachers by means of error analyses, individual growth curves, and comparisons between the particular child and his classmates (or the broader population of peers). The program itself uses the child's data by varying the complexity of the sums adaptively, depending on the percentage of right answers, but also on the child's reaction time. Moreover, using the responses and reaction times of all individual children, the items of Mathgarden are arranged (and get frequently re-arranged) in terms of complexity. This program shows how multiple short-term interactions provide information about the individual's long-term development and how this information can inform educational practice. These kinds of adaptive teaching and assessment programs translate dynamic principles into concrete materials that help children to develop their understanding in an optimal way.

In conclusion, as Vygotksy (1934/1986) already noted: “To devise successful methods of instructing the schoolchild in systematic knowledge, it is necessary to understand the development of scientific concepts in the child's mind. No less important than this practical aspect of the problem is its theoretical significance for psychological science." (p. 146). We think that by studying the development of children's understanding of scientific concepts using a model based on properties derived from dynamic systems theory and Skill Theory an important contribution to both this applied and scientific goal is made.

\section{Author details}

Steffie Van der Steen, Henderien Steenbeek and Paul Van Geert University of Groningen, The Netherlands

\section{References}

Alfieri, L, Brooks, P. Aldrich, N., \& Tenenbaum, H. (2010). Does discovery-based instruction enhance learning? Journal of Educational Psychology, 103, 1-18.

Blijd-Hogewys, E. M. A. (2008). The development of theory-of-mind and the theory-of-mind storybooks. Unpublished doctoral dissertation, University of Groningen, The Netherlands.

Carrière, R. M. (2009). The transition to early education: A dynamic theoretical framework. Unpublished doctoral dissertation, University of Groningen, The Netherlands. 
Cheshire, A., Muldoon, K. P., Francis, B., Lewis, C. N. \& Ball, L. J. (2007). Modelling change: New opportunities in the analysis of microgenetic data. Infant and Child Development, 134, 119-134. doi: 10.1002/icd.498

De Berg, K.C. (1995). Student understanding of the volume, mass, and pressure of air within a sealed syringe in different states of compression. Journal of Research in Science Teaching, 32, 871-884.

Dehaene, S. (1997). The number sense: How the mind creates mathematics. New York: Oxford University Press.

Fischer, K. W. \& Corrigan, R. (1981). A skill approach to language development. In R. Stark (Ed.), Language behavior in infancy and early childhood, (pp. 245-273). Amsterdam: Elsevier.

Fischer, K. W. (1980). A theory of cognitive development: The control and construction of hierarchies of skills. Psychological Review 87(6), 477-531.

Fischer, K. W., \& Bidell, T. R. (2006). Dynamic development of psychological structures in action and thought. In R. M. Lerner (Ed.), Handbook of child psychology: Vol. 1. Theoretical models of human development (5th ed., pp. 313-399). New York: John Wiley \& Sons.

Fischer, K. W., \& Granott, N. (1995). Beyond one-dimensional change: Parallel, concurrent, socially distributed processes in learning and development. Human Development, 38, 302-314.

Fischer, K. W., \& Rose, S. P. (1999). Rulers, models, and nonlinear dynamics: Measurement and method in developmental research. In G. Savelsbergh, H. van der Maas, and P. Van Geert (Eds.), Nonlinear developmental processes (pp. 197-212). Amsterdam: Edita-KNAW.

Fischer, K. W., Rose, L. T., \& Rose, S. P. (2007). Growth cycles of mind and brain: Analyzing developmental pathways of learning disorders. In K. W. Fischer, J. H. Bernstein, \& M. H. Immordino-Yang (Eds.), Mind, brain and education in reading disorders (pp. 101 - 129). Cambridge, MA: Cambridge University Press.

Fodor, J. A. (1981). Representations: Philosophical essays on the foundations of cognitive science. Brighton, Sussex, U.K.: The Harvester Press.

Fogel, A. \& Garvey, A. (2007). Alive communication. Infant Behavior and Development, 30, 251-257. doi: 10.1016/j.infbeh.2007.02.007

Gilmore, C. K. \& Bryant, P. (2008). Can children construct inverse relations in arithmetic? Evidence for individual differences in the development of conceptual understanding and computational skill. British Journal of Developmental Psychology, 26, 301-316. doi: $10.1348 / 026151007 X 236007$

Granott, N., \& Parziale, J. (2002). Microdevelopment: A process-oriented perspective for studying development and learning. In N. Granott, \& J. Parziale (Eds.) Microdevelopment: Transition processes in development and learning (pp. 1-28). Cambridge, MA: Cambridge University Press.

Granott, N., Fischer, K. W., \& Parziale, J. (2002). Bridging to the unknown; A transition mechanism in learning and development. In N. Granott \& J. Parziale (Eds.), Microdevelopment: Transition processes in development and learning (pp. 183-212). New York: Cambridge University Press.

Grotzer, T. A. (2004). Putting everyday science within reach. Principal Leadership, 5, 16-21. 
Halley, J. D. \& Winkler, D. A. (2008). Classification of emergence and its relation to selforganization. Complexity, 13, 10-15. doi: 10.1002/cplx.20216

Haselager, P., de Groot, A., \& van Rappard, H. (2003). Representationalism vs. antirepresentationalism: A debate for the sake of appearance. Philosophical psychology, 16, 524. doi: 10.1080/0951508032000067761

Hirsch-Pasek, K., Golinkoff, R. M., Berk, L. E., \& Singer, D. G. (2009). A mandate for playful learning in preschool: Presenting the evidence. New York: Oxford University Press.

Hollenstein, T. (2007). State space grids: Analyzing dynamics across development. International Journal of Behavioral Development, 31, 384-396. Doi: 10.1177/0165025407077765

Inhelder, B., \& Piaget, J. (2001). The growth of logical thinking from childhood to adolescence. (A. Parsons \& S. Milgram, Trans.) (Rev. ed.) New York: Basic Books. (Original work published in 1958).

Kuhn, D. (1995). Microgenetic study of change: What has it told us? Psychological Science, 6 (3), 133-139.

Lewis, M. D. (2000). Emotional self-organization at three time scales. In M.D. Lewis and I. Granic (Eds.) Emotion, Development, and Self-Organization (pp. 37-69). Cambridge, MA: Cambridge University Press

Lewis, M. D. \& Granic, I. (2000). Emotion, Development, and Self-Organization. Cambridge, MA: Cambrige University Press.

Lichtwarck-Aschoff, A., Van Geert, P., Bosma, H., Kunnen, S. (2008). Time and identity: A framework for research and theory formation. Developmental Review, 28, 370-400. doi: 10.1016/j.dr.2008.04.001

McKinsey \& Company (2007). How the world's best-performing schoolsystems come out on top. etrieved on June 2011 from:

http://www.mckinsey.com/clientservice/Social_Sector/our_practices/Education/Knowle dge_Highlights/How\%20School\%20Systems\%20Get\%20Better.aspx

Parziale, J. \& Fischer, K.W. (1998). The practical use of skill theory in classrooms. In R.J. Sternberg and W.M. Williams (Eds.), Intelligence, instruction and assessment (pp. 96-100). Hillsdale, NJ: Lawrence Erlbaum Associates.

Perkins, D., \& Blythe, T. (1994). Putting understanding up front. Educational Leadership, 51, 47.

Piaget, J. (2001). The Psychology of Intelligence (M. Piercy \& D. E. Berlyne, Trans.) (Rev. ed.) London: Routhledge Classics (Original work published in 1947).

Rappolt-Schlichtmann, G., Tenenbaum, H. R., Koepke, M. F., \& Fischer, K. W. (2007). Transient and robust knowledge: Contextual support and the dynamics of children's reasoning about density. Mind, Brain, and Education, 1, 98-108. doi: 10.1111/j.1751228X.2007.00010.x

Schwartz, M. \& Fischer, K. W. (2005). Building general knowledge and skill: Cognition and microdevelopment in science learning. In A. Demetriou \& A. Raftopoulos (Eds.), Cognitive developmental change: Theories, models, and measurement (pp. 157-185). Cambridge, U.K.: Cambridge University Press. 
Simonton, D. K. (1999). Talent and its development: An emergenic and epigenetic model. Psychological Review, 106, 435-357.

Siegler, R. S., \& Crowly, K. (1991). The microgenetic method: A direct means for studying cognitive development. American Psychologist, 46, 606-620.

Smith, L. B. \& Thelen, E. (2003). Development as a dynamic system. Trends in Cognitive Sciences, 7, 343-348. doi: 10.1016/S1364-6613(03)00156-6

Steenbeek, H. W. (2006). Modeling dyadic child-peer interactions: sociometric status, emotional expressions, and instrumental actions during play. Unpublished doctoral dissertation, University of Groningen, The Netherlands.

Steenbeek, H. W., \& Van Geert, P. (2005). A dynamic systems model of dyadic interaction during play of two children. European Journal of Developmental Psychology, 2, 105-145. doi: 10.1080/17405620544000020

Steenbeek, H. W., \& Van Geert, P. (2007). 'Do you still like to play with him?' Netherlands Journal of Psychology, 63(3), 79-92. doi: 10.1007/BF03061069

Thelen, E. \& Smith, L. B. (1994). A dynamic systems approach to the development of cognition and action. Cambridge, MA: The MIT Press.

Thelen, E. (1989). Self-organization in developmental processes: Can systems approaches work? In M. Gunnar and E. Thelen (Eds.) Systems and development: Vol. 22. The Minnesota symposium in child psychology (pp. 77-117). Hillsdale, NJ: Lawrence Erlbaum Associates.

Thelen, E. (1992). Development as a dynamic system. Current directions in psychological science, 1, 189-193.

Thelen, E., \& Corbetta, D. (2002). Microdevelopment and dynamic systems: Applications to infant motor development. In N. Granott \& J. Parziale (Eds.), Microdevelopment: Transition processes in development and learning (pp. 59-79). Cambridge, U.K.: Cambridge University Press.

Understanding. (1989). Oxford English dictionary. Oxford University Press. Retrieved June 24, 2011, from http://www.oed.com/view/Entry/212090.

Van Dijk, M. \& Van Geert, P. (2007). Wobbles, humps and sudden jumps: A case study of continuity, discontinuity and variability in early language development. Infant and Child Development, 33, 7-33. doi: 10.1002/icd.506

Van Geert, P. \& Fischer, K. W. (2009). Dynamic systems and the quest for individual-based models of change and development. In J.P. Spencer, M. S. C. Thomas, \& J. McClelland (Eds.), Toward a new grand theory of development? Connectionism and dynamic systems theory reconsidered (pp. 313-337). Oxford, U.K.: Oxford University Press.

Van Geert, P. \& Steenbeek, H. (2005). The dynamics of scaffolding. New Ideas in Psychology, 25, 115-218. doi: 10.1016/j.newideapsych.2006.05.003

Van Geert, P. (1994). Dynamic systems of development: Change between complexity and chaos. New York: Harvester Wheatsheaf.

Van Geert, P. (1998). A dynamic systems model of basic developmental mechanisms: Piaget, Vygotsky, and beyond. Psychological Review, 105, 634-677. doi: 10.1037/0033295X.105.4.634-677

Van Geert, P. (2004). Dynamic Modelling of cognitive development: Time, situatedness and variability. In A. Demetriou, \& A. Raftopoulos (Eds.) Cognitive developmental change: 
Theories, models and measurement (pp. 354-379). Cambridge, MA: Cambridge University Press.

Van Geert, P., \& Steenbeek, H. W. (2008). Brains and the dynamics of 'wants' and 'cans': A commentary on Immordino-Yang's tale of two cases. Mind, Brain, and Education, 2, 6266.

Van Geert, P. (2011). Talent and Excellence for Science and Technology in Young Children: A Review of the Literature. Unpublished manuscript, Department of Developmental Psychology, University of Groningen and Platform BetaTechniek, The Hague, The Netherlands.

Van Gelder, T. J. (1995) What might cognition be, if not computation? Journal of Philosophy, 91, 345-381.

Van Gelder, T. J. (1998). The dynamical hypothesis in cognitive science. Behavioral and Brain Sciences, 21, 615-628.

Van der Maas, H., Klinkenberg, S., \& Straatemeier (2010). Rekentuin.nl: combinatie van oefenen en toetsen. [Mathgarden.com: a combination of practice and assessment]. Examens, 2010.

Vygotksy, L. S. (1986). Thought and Language (A. Kozulin, Trans.). Cambridge, MA: The MIT Press (Original work published in 1934).

Yan, Z., \& Fischer, K. W. (2002). Always under construction: Dynamic variations in adult cognitive development. Human Development, 45, 141-160.

Yan, Z., \& Fischer, K. W. (2007). Pattern emergence and pattern transition in microdevelopmental variation: Evidence of complex dynamics of developmental processes. Journal of Developmental Processes, 2, 39-62. 


\title{
Preschoolers Learning Science: Myth or Reality?
}

\author{
Heidi Kloos, Heather Baker, Eleanor Luken, \\ Rhonda Brown, David Pfeiffer and Victoria Carr
}

Additional information is available at the end of the chapter

http://dx.doi.org/10.5772/54119

\section{Introduction}

Teacher: "Now, kids, this is a book about dinosaurs. Are dinosaurs alive today?"

Preschooler 1: "Yeah, at the zoo."

Preschooler 2: "I saw one on TV."

Teacher: "The ones at the zoo are just pretend dinosaurs, aren't they? (Children nod). Does anyone know what the word 'extinct' means?"

Preschooler 3: "I farted ..."

Teacher: "Say 'Excuse me."'

Preschooler 3 continues: "... in my house."

Teacher: "Let's keep thinking about dinosaurs...."

30 minutes later, Teacher: "Okay, listen up. I want you to think about what you've learned today. Can anyone tell me something they learned about dinosaurs?"

Several Preschoolers: "They're mean."

Teacher: "They're mean? Okay. Does anyone remember what the word 'extinct' means?"

Preschooler 4: "Farted."

(Pfeiffer, 2012)

After Piaget's seminal claims on children's slow emergence of adult-like thought, research in cognitive development has skyrocketed to reveal ever-so-amazing competencies in younger and younger children. These competencies pertain to understanding cause-effect relations, physical truisms, or mathematical operations, to name just a few (e.g., see Bremner \& Fogel, 
2004, for a summary). Many of these findings have had the effect of changing how children are taught, for example by pushing more complex curricula early on, building upon children's already existing understanding, and supporting children's abstract reasoning skills (e.g., Brenneman, Stevenson-Boyd \& Frede, 2009; Eshach \& Fried, 2005). In the current chapter we review the research findings of these efforts, focusing explicitly on early science learning.

The area of science learning, while only a small part within the field of children's learning, has several features that warrant interest for the cognitive-development community. First science concepts are abstract, transcending a concrete context that commonly embeds everyday concepts. As such, science learning relates to the emergence of abstract thought, knowledge transfer and symbol manipulation. Second, scientific concept formation is a specific case of everyday concept formation, thus shedding light on the dynamics of collapsing large amounts of information into systematic beliefs (cf., Havu-Nuutinen, 2005). Third, a focus on early learning is likely to uncover the spontaneous working of the mind, processes yet unaffected by formal instruction or by standardized assessment. An understanding of preschoolers' science learning therefore transcends the field of early childhood education and sheds light on the spontaneous development of abstract thought in young children.

Note first that early science learning is a rather unorganized terrain. Unlike the areas of reading or math, this area still grapples with questions of what constitutes success in science learning, how learning should progress, and how to assess its milestones. There are no generally agreed-upon 'letters' that form the alphabet of science, and there are no central 'operations' in science that constitute the base upon which to build. Indeed, research studies differ greatly in how 'science' is defined in the first place, for example whether science concepts need to be abstract, relevant to every-day experience, or interconnected with other concepts. Similarly, assessment tools differ greatly in whether they measure the presence of a particular concept, the way it is applied, or its semantic network. As a result, there are no generally accepted instructional tools (cf., Kirchner, Sweller \& Clark, 2006), and there are no generally accepted assessments that could capture milestones of science learning across curricula (for reviews see Brenneman, 2011; Scott-Little, Lesko, Martella, \& Milburn, 2007). The current chapter is a first step towards filling this gap.

For our purposes, science is defined to incorporate two aspects: scientific facts and concepts, and the processes by which science knowledge is generated. These two aspects - knowledge of science concepts and knowledge of how the science concepts were derived - are of course closely linked (cf. Schauble, 1990). We nevertheless treat them as separate for the purpose of organizing the research findings on early science learning. Note also that this review is by no means exhaustive. The literature on young children's science learning has exploded in the last decade, being published in numerous educational and cognitive-development journals, as well as in journals devoted to this topic entirely (e.g., Science and Children; Research in Science Education). Here we present a cross-section of pertinent research, as a means of finding a common thread and setting the stage for a more integrated discussion 
about young children's learning. For example, we describe research on how to support young children's reasoning about abstract concepts, how to replace their mistaken beliefs with more appropriate ones, how to engage them in scientific discourse and explorations, and how to scaffold their attempt to organize isolated pieces of knowledge into coherent networks of interrelated facts.

\section{Can preschoolers learn about scientific facts?}

A central part of science is a shared understanding of concepts and facts, for example from the domain of physical sciences, life sciences, or earth and space sciences. Research in cognitive development has documented that even young children know something about these science domains. For example, young children know that the behavior of objects is affected by their physical properties (cf., Kotovsky \& Baillargeon, 1998; Schilling \& Clifton, 1998); they know that the identity of living things is determined internally (Simons \& Keil, 1995; Springer, 1995); and they understand the effect of gravity (e.g., Vosniadou, 1994). Of course, sometimes their beliefs are mistaken; they hold misconceptions. For example, children believe that heavy stuff sinks fast (e.g., Kloos \& Somerville, 2001; Penner \& Klahr, 1996), that the sun is alive, but not plants (Venville, 2004), or that the earth is disc-shaped (e.g., Vosniadou \& Brewer, 1992). To what extent can early science instruction build upon children's existing knowledge to convey new facts and change mistaken beliefs?

Conveying Something New. Science facts differ in the degree to which they rely on concrete versus abstract pieces of information. That is to say, science facts vary in whether relevant pieces of information are readily perceivable - or whether they need to be extracted from irrelevant information. That a spider has eight legs requires a relatively low level of abstraction, because the fact's relevant pieces of information are readily accessible in a single event. By contrast, the idea that caterpillars turn into butterflies is more abstract: caterpillars and butterflies need to be conceptually connected, while differences between the two need to be ignored (e.g., shape, behavior). Similarly, the idea that water can turn into ice is less abstract than the idea that materials consist of particles that are invisible to the naked eye. The latter requires the learner to ignore salient features of an object (e.g., the shape or size of a material), and instead note underlying patterns of how materials interact and change.

Can young children learn low-abstraction science facts? This question is relatively trivial, as one might guess from every-day experiences with children (e.g., Cumming, 2003). For example, preschoolers can learn with little effort the names of new species, the names of the planets, and even the terms associated with material properties and chemical change (e.g., Fleer \& Hardy, 1993). However, educators sometimes worry that children's learning of facts is no more than passive rote memorization, far from reflecting 'truly understanding' the facts. At the crux of this concern is that young children might not be able to go beyond mere facts to interconnect them under a common concept. Even though there is evidence of spontaneous abstractions in young children (e.g., Hickling \& Gelman 1995; Hickling \& 
Wellman, 2001), higher-order concepts pertinent to science knowledge might be too abstract for them. The more central question, therefore, is whether young children can learn abstract concepts.

There is an interesting drawback when it comes to learning abstract concepts. Unlike what one would expect, findings show that overly detailed and richly embedded learning materials have a negative impact on children's ability to abstract underlying concepts (e.g., Goldstone \& Sakamoto, 2003; Goldstone, \& Son; 2005; Kaminski, Sloutsky, \& Heckler, 2008; Ratterman, Gentner, \& DeLoache, 1990; Son, Smith, \& Goldstone, 2008). For example, when the learning materials were colored shaped intricately, children had more difficulty discovering an abstract mathematical rule than when the materials were black-and-white simple shapes (Kaminski et al., 2008). When the shapes were such that they helped children intuit the rules, learning improved, but transfer to a new task nevertheless suffered, compared to using none-specific and generic shapes (see also DeLoache, 1995; Bassok \& Holyoak, 1989; Mix, 1999; Ratterman \& Gentner, 1998; Sloutsky, Kaminski, \& Heckler, 2005; Uttal, Liu, \& DeLoache, 1999; Uttal, Scudder, \& DeLoache, 1997). Taken together, there seems to be a pronounced advantage of sparse contexts when learning abstract concepts. The advantage lies in minimizing distraction, undermining the possibility of forming mistaken ideas, and highlighting relevant pieces of information.

Of course, when it comes to young children, a motivational factor needs to be taken into account (cf., Mantzicopoulos, Patrick, \& Samarapungavan 2008; Zembylas, 2008). A setting without rich details might fail to engage the child sufficiently to prompt learning. For example, a young child might not be inclined to explore objects unless they vary in color, shape, and texture in interesting ways. Therefore, to make abstract ideas accessible to young children, it might not be possible to strip the context of any unnecessary complexity. A different approach to instruction is needed, one that helps make abstract ideas visible to children, while, at the same time, retaining a richly detailed context. Such approach might require a pedagogy that bootstraps the understanding of abstract ideas, rather than waiting for young children to detect them by themselves. Findings show that such approach is indeed possible.

Take for example the abstract idea of object conservation, the idea that matter exists, even when it is not visible with the naked eye. To understand this concept, children have to ignore their phenomenological experience of an object's presence and therefore engage in abstract reasoning. Immersing children into a richly detailed environment might not make this abstract idea salient. On the other hand, providing children with the opportunity to reflect on guided explorations of material transformation improved their understanding of object conservation (Acher, Arca \& Sanmarti, 2007). In particular, 7- to 8-year-olds were asked to observe possible changes in materials (e.g., stones, wood, water, metal) when they were trying to break them down, mix them in water, or burn them. After each manipulation, children were encouraged to draw the changes they observed in the materials. They also participated in group discussions designed to help them conceptualize their experiences. Findings show not only that children were able to express opinions and counter arguments, 
but also that they could understand object conservation. Even 5-year-old preschoolers can appreciate the idea that water, when invisible to the naked eye, is nevertheless still present in some form (Tytler \& Peterson, 2000).

Replacing Existing Beliefs. Learning about a new science concept can be problematic, beyond the required abstract-reasoning skills. This is because in some cases, children's naïve ideas about the domain conflict with the pertinent science concept. The detrimental power of mistaken ideas has been recognized for decades, leading to extensive research into understanding both the nature of the misconceptions across ages and how they can be changed (e.g., see Ohlsson, 2011; Vosniadou, 2008, for an extensive discussion). Indeed, existing misconceptions appear to be very difficult to change (e.g., Anderson \& Smith, 1987; Gunstone, Champagne, \& Klopfer, 1981; Hannust, \& Kikas, 2007; Kloos \& Somerville, 2001; Linn \& Burbules, 1988; Schneps, 1987). In many instances, children prefer mistaken ideas over correct ideas, even after extensive training and even after shortcomings of mistaken ideas have been pointed out explicitly. Take for example findings with 5- to 7-year-olds who participated in an astronomy curriculum on the spherical properties of the earth (Hannust, \& Kikas, 2007). The four-week curriculum involved hands-on mini-lessons designed to target several apparent contractions, for example why the earth is perceived to be flat, or why people living on the "down-side" of the earth do not fall off. Yet, despite this relatively extensive intervention, children's understanding did not change significantly over the course of the instruction. While their performance on a pretest was below chance $(11 \%$ correct), it stayed low even after the lessons (15\% correct). In fact, results show that children relied more heavily on their phenomenological experience after instruction than before (see also Kloos \& Van Orden, 2005 for similar counter effects of teaching interventions).

Given such resistance to change, one might speculate that a child's mistaken ideas are innate. But upon closer look into the nature of beliefs, it turns out that misconceptions arise when misleading pieces of information are more salient than pieces of information that are relevant to the particular science concept (cf., Kloos, Fisher, \& Van Orden, 2010). Therefore, to change a child's mistaken ideas in a science domain, a pedagogical approach is needed that can change the salience of relevant compared to irrelevant pieces of information (i.e., increase the salience of science-relevant pieces of information). With such change in making relevant information salient, misconceptions might be avoided altogether. Indeed, children who have benefitted from focused instruction seem to harbor fewer misconceptions in later years at school (cf., Novak \& Gowin, 1984.)

A promising approach in this regard is the use of conceptual models, also known as conceptual schemas, mental models, or scientific models (e.g., Glynn \& Duit, 1995; Kenyon, Schwarz, \& Hug, 2008; Mayer, 1989, Penner, Giles, Lehrer, \& Schauble, 1997; Smith, Snir, \& Grosslight, 1992; Smith \& Unger, 1997, for a review see Vosniadou, 2008). Conceptual models are abstract representations of a science phenomenon - external diagrams of some sort that children can internalize. Models do not represent the real world in its full degree of complexity. Instead, they are schematics of the real world, designed to highlight only a selected number of relations (the ones that are relevant to the science concept of interest), 
while downplaying other relations (ones that are less relevant or misleading). Importantly, models represent predictive and explanatory rules, thus making visible the components of science phenomenon that are difficult to be perceived on the basis of phenomenological experience alone. As such, they make relevant science facts salient, in effect decreasing the salience of irrelevant pieces of information.

There are several studies that show the effectiveness of conceptual models in young children (e.g., Gobert \& Buckley, 2000; Kenyon et al. 2008; Wiser \& Smith, 2008; Baker, Haussmann, Kloos, \& Fisher, 2011). An illustrative example uses the science domain of material density, a concept that is defined by the ratio of the two highly salient dimensions of mass and volume. Predictably, children often ignore density and use instead perceived heaviness of an object as the sole predictor of the object's buoyancy (e.g., Piaget \& Inhelder, 1974; Kloos et al., 2010). To help children overcome this mistaken focus on an object's heaviness, a conceptual model of density was developed, also known as dot-per-box (e.g., Smith \& Unger, 1997; Wiser \& Smith, 2008). It involves a display in which the volume of an object is represented as a certain number of boxes, and mass is represented as number of dots inside the boxes. Thus, density is represented as the spacing between dots (the more crowded the dots, the more dense the material); and irrelevant variation of color, shape, and texture are omitted. Thus, density of the material is now similar in salience to that of mass or volume. Children indeed benefited from these abstract representations of density (for a discussion of these findings, see Wiser \& Smith, 2008). Similar learning success was reported with 4- to 5year-olds, whether children were recruited from Head Start preschools or from preschools serving upper middle class families (Baker et al., 2011).

Introducing conceptual models early on might have a positive effect on learning as children get older. Support for this claim comes from research in the domain of evaporation and condensation, another domain that is a notoriously difficult area of instruction in science (Kenyon et al., 2008). Children between 6 and 8 years of age underwent a multi-week training on evaporation and condensation, which included observing the evaporation and condensation in a soda bottle, drawing diagrams to capture the system through various moments in time, testing their models through experiments, using tools to measure the amount of water in the air, and revising their models as needed. Findings show that the instructed students significantly outperformed the uninstructed students in their understanding of relevant concepts. Importantly, when students began the formal study of science in Grade 7, instructed students improve in their understanding of concepts much faster than uninstructed students. Clearly, the students who were helped to form basic science concepts in early grades had developed an understanding of the domain that continued to facilitate their meaningful learning, further developing their understandings and reducing their misconceptions (for related discussions, see Muthukrishna, Carnine, Grossen, \& Miller, 1993).

In sum, research-based evidence points in a clear direction when it comes to promoting an understanding of science concepts. Unlike what a Piagetian stage model of abstract reasoning might imply, young children are indeed able to learn abstract concepts early on, even when the concepts run counter to what children already believe. Their learning 
strongly depends on an instructional environment that makes abstract relations salient, allowing them to visualize the relations without getting distracted by irrelevant information in the immediate context. To put it more pointedly, the limits on a child's ability to learn abstract science concepts might be the limits of the instruction that is provided. Open questions pertain to the exact interplay between decontextualized and carefully simplified environments to maximize children's learning about science concepts and events directly related to their lives (e.g., food, weather, seasons, animals, vehicles, light, magnets, etc.).

\section{Can preschoolers learn to generate science knowledge?}

The second aspect of science learning pertains to understanding the process by which science knowledge is generated. Rather than learning about established and accepted science facts and concepts, this aspect includes an understanding of how science facts are generated in the first place. This includes the ability to create settings that are sufficiently informative for science knowledge to be generated. And it includes the meta-cognitive understanding of how new information can change existing knowledge. It is important to note that the process of generating science concepts is in part affected by cultural norms. Norms pertain to constraints about what to count as an explanation of events (cf., Pearl, 2009), under what circumstances to abandon an existing theory (cf. Kuhn, 1996), or how to treat expected versus unexpected observations (cf., Popper, 1959). So far, these constraints have not been studied explicitly in the realm of early science learning. Instead, the emphasis is on understanding how children's everyday interactions with their environment can help children generate science knowledge (e.g., Zimmerman, 2000).

The question of children's ability to generate science knowledge through observations is debated heavily, both in cognitive development and in educational research. In cognitive development, the ongoing debate centers on the question of whether young children are at all capable of engaging in appropriate knowledge-generating activities. Such activities, referred to as scientific reasoning, require the child to detect gaps in their existing knowledge base, ask questions in response to the identified gaps, carry out the experiments that could lead to an answer, and critically evaluate the evidence (cf., Klahr, 2005). Each one of these steps can be difficult for children (and even for adults), for several reasons: First, the mind is biased towards perceiving order, making it difficult to perceive disorder, missing information, or gaps (cf., e.g., Quinn, Eimas, \& Rosenkrantz, 1993). Second, the mind is biased towards confirming already existing beliefs, rather than questioning their shortcomings, making it difficult to spontaneously challenge existing beliefs (e.g., Schauble, 1990). Under this view, scientific reasoning has to be trained explicitly.

In contrast to the cognitive-development debate, educational research already presupposes the child's ability to generate science knowledge, following the theoretical bent of constructivism (cf., Olson, 1996). For example, it is generally accepted that children can engage in inquiry, the processes of wondering, questioning, exploring, investigating, discussing, reflecting, and formulating ideas and theories (e.g., Kuhn, 2010). Indeed, 
preschool education places strong emphasis on exploration, the idea being that exploration is at the center of what allows children to generate knowledge about the world (e.g., Luken, Carr, \& Brown, 2011). The debate then centers on the question of how children's spontaneous inquiry can be supported by teacher interventions, explicit instruction, and/or feedback. In what follows, we review findings that speak to this question. In particular, we focus on the efficacy of three strategies that help children generate science knowledge. They include (1) engaging children in scientific discourse, (2) teaching them to keep track of their observations, and (3) helping them organize their knowledge.

Can young children engage in scientific discourse? What is also referred to as 'science talk' (Lemke, 1990) or exploratory language (Peterson \& French, 2008), scientific discourse differs from a standard question-answer format for which the person asking the question already knows, expects to hear, and rewards the right answer. Scientific discourse instead promotes sense-making of events: accepted science terms, concepts, and methods are transmitted in the context of children asking scientifically valid questions (cf., Crowder, 1996). It is therefore a large part of inquiry and scientific reasoning. While scientific discourse is heavily studied in school-aged children (e.g., Kafai \& Carter Ching, 2001), preschool teachers and parents of young children are likely to engage in such discourse naturally, as they guide children's explorations of topics relevant to their everyday life. The ideal context is likely to require an active and knowledgeable listeners and a shared science vocabulary that children are sufficiently comfortable with (cf., Crowley, Callanan, Jipson, et al., 2001; Fleer, 1996; Pramling \& Pramling-Samuelson, 2001).

The effectiveness of science talk with preschoolers was demonstrated empirically with the domains of metamorphosis and plant growth (e.g., Witt \& Kimple, 2008). Children were first given a pretest on these two science domains, asking questions such as What is a cocoon?, What kind of food helps caterpillars and butterflies grow?, How does a plant soak up water?, and Do seeds grow faster in direct sunlight, darkness, or a mixture of both?. Preschoolers then participated in two several-weeks-long activities, one pertaining to creating an environment for caterpillars and observing the metamorphosis, and one pertaining to planting seeds and observing the growth in different climates and environments (e.g., hot and sunny vs. cold and dark). Preschoolers were frequently engaged in conversations, allowing them to reflect on their observations and experience. Post-test performance showed remarkable improvement in science knowledge: Every child improved in their answers, and every question showed gains. For example, while none of the preschoolers knew the meaning of 'cocoon' or the conditions under which seeds grow best, all of them did so during the posttest.

Promising results for the effectiveness of science talk were also reported with the domain of electrical currents (Fleer, 1991; Fleer \& Beasley, 1991). The task was to explore flashlights, find out what they are made out of and how they work, and construct their own flashlights using batteries, bulbs, and wires. With the use of guided interaction with the teachers, preschoolers and $1^{\text {st }}$-graders learned to formulate questions about the working of the flashlights, and they learned to report the findings of their own explorations. Even better results were obtained when children were given direct instruction on how the electricity 
flowed around the circuit, both through the reading of factual books, and through one-onone interactions with the teachers as children explored the materials. In particular, after direct instruction, all children could talk about how the electricity continuously flowed around a simple electric circuit, an understanding they still held 2 months later. Without such direct instruction, and despite being able to connect the circuit, children's beliefs about electricity, measured through their entries in a 'notebook' did not change over the course of three months: All children with comparison data expressed exactly the same view of 'electricity' in both interviews.

As this previous study implies, a scientific discourse is aided when children can keep track of their explorations across time, for example in science journals. This is not only because children are exposed to richer information over time (e.g., to detect a contrast in an abstract dimension that is not available in snapshot events). Science journals also provide teachers with an opportunity to engage children in a targeted and individualized way (cf., Doris, 1991; Light \& Simmons 1983). Recent findings show that even preschoolers can be taught to keep a science journal (e.g., Brenneman \& Louro 2008). This is might involve over-simplified drawings and an explanation written by a teacher. Nevertheless, they provide an authentic medium for teachers to encourage scientific reasoning. For example, children's drawings make it possible for teachers to convey the difference between true observations and a child's imagination, the importance of dating the entries, and the focus on hidden features (e.g., the inside of a pumpkin). The outcome was a rich interaction between teachers and preschoolers, promoting children's ability to observe objectively, to record observations with some precision, and to become aware of patterns of change..

So far, we have discussed the benefits of engaging children in science talk and encouraging them to make note of their observations. An even more targeted way of helping children generate science knowledge involves helping them organize their observations and beliefs in a systematic way. It involves the use of so-called concept maps (cf., Novak, 2010). Concept maps consist of nodes (to represent objects) and arrows between nodes (to represent events). The resulting flow charts (e.g., 'plants $\rightarrow$ go in $\rightarrow$ gardens') can be organized hierarchically to capture the relations between what children think and experience. For example, when presented with a targeted question about the cycle of growth, concepts maps make it possible for children to organize information about animals and plants in a way that yields both relevant science knowledge and an understanding of how such knowledge could be generated.

The Young Florida Naturalist Program used such a concept-map strategy with 3- to 4-yearolds from urban early childhood center children (e.g., Hunter, Monroe-Ossi, \& Fountain, 2008). The goal was to increase children's knowledge about the butterfly life cycle and plant growth over the course of an eight-week instructional period. A concept map was constructed first, using a set of pertinent pictures (e.g., tree roots, leaves, caterpillars, butterflies, cocoons), to capture children's initial understandings. The concept map was then posted in the classroom as a point of reference, and to allow for modifications as children learned new information. To stimulate children's thinking, a butterfly garden was planted on the center's grounds, and children engaged in various experiments with water, sunlight, 
soil, etc. to explore plant growth. At the end of the period, children's understanding was assessed in semi-structured interviews to infer a child's individual concept map. For example, children were asked to sort and organize a set of pictures, they were encouraged to talk about what they know about plants and butterflies, and they were asked about their understandings of the final class concept map (e.g., 'what do the pictures tell you about plants?"). Results document that a large majority of both 3- and 4-year-olds could make higher-order propositions, and they could recall terms and concepts relevant to parts of plants and aspects of butterfly transformation.

Taken together, these results show that young children can benefit from quite sophisticated adult support in order to generate science-relevant knowledge. That is to say, children's natural curiosity can be harnessed to help them explore their surroundings in scientifically appropriate ways. Adult support can range from merely providing children with a context for explorations to engaging them in guided discussions about their explorations, to helping them document their findings and organize their thoughts. As part of this process, young children are likely to learn the cultural norms of what is considered science, what counts as a worthwhile phenomenon, how it should be explored and evaluated, and what kind of knowledge construal would be acceptable (i.e., what can be ignored and what must be included). Open questions pertain to the relative benefit of allowing children to develop their own representations of what they observe versus working with representations provided to them in a top-down fashion.

\section{Coda}

Science is a rather difficult subject to teach, for several reasons. First, relevant science concepts are often far less salient than superficial aspects of an observation. In fact superficial features lead to mistaken beliefs that resist change. Second, science explorations require a level of systematicity that is difficult for young children to attain. Young children get easily distracted, failing to isolate relevant variables or to note their effect. Third, agreed upon scientific knowledge is incomplete - at least to some extent: it includes necessary simplifications to capture general rules and usable models. As such, there are choices to be made in terms of what to consider a valid science understanding. And finally, given that science understanding depends on the acquisition of a novel nomenclature and seemingly isolated facts, science learning can be dull and unmotivating.

Nevertheless, young children are equipped to learn about scientific concepts early on, as cognitive-development research shows. Most importantly, they can organize individual experiences into over-arching patterns early on (cf., Thagard, 2000) - a process that forms the basic building block of the abstract reasoning necessary in science learning. Building upon these abilities, a variety of methods and pedagogical tools have shown to support early science learning (e.g., Worth and Grollman, 2003; Chalufour and Worth, 2003, 2004, 2005). Summarizing across the available findings, the following aspects appear to play a crucial role. First, science learning is aided when children engage with scientifically literate adults who understand how to use scientifically valid representations and who anticipate 
children's already existing ideas about science (cf., Davis \& Krajcik, 2005). Second, science learning is aided when intentional teaching is incorporated with play, such that teaching practices not only become purposeful and thoughtful, but also engage young children with topic-specific phenomena and inquiry (cf., Bodrova \& Leong, 2007; Crowley \& Jacobs, 2002; Copple \& Bredekamp, 2009; NAEYC, 2009). The promise is to make accessible relevant science concepts to young children - even abstract concepts and those that run counter to already existing beliefs - forming the foundation upon which young learners will construct their ideas later in life (cf., Lucas, 1993).

Research on early science learning also highlights the gaps that still remain in our understanding of children's learning (cf., Davis, 2009). In fact, existing efforts to measure early science learning might be merely a first step. A more complete understanding calls for findings on how to best organize a child's science education throughout the curriculum, how to measure their progress across science domains, how to harness individual differences among children, and what kind of early exposure leads to long-term gains in science learning. Related, empirical questions still remain about how inquiry and explorations interface with direct instructions of science concepts, and how a child's attitude towards science learning both affects and is affected by learning of science. Without research-based findings to speak to these issues, our intuitions about early science learning, while fueling arguments among various viewpoints, might nevertheless jeopardize progression the area of early science learning.

\section{Author details}

Heidi Kloos, Heather Baker and David Pfeiffer

Department of Psychology, University of Cincinnati, Cincinnati OH, USA

Eleanor Luken and Victoria Carr

Early Childhood Education, University of Cincinnati, Cincinnati OH, USA

Rhonda Brown

Educational Studies, University of Cincinnati, Cincinnati OH, USA

\section{Acknowledgement}

Working on this paper was partly funded though awards from the National Science foundation to HK (DRL 0723638) and to VC, RB, and HK (DRL 1114674). Please address correspondence to Heidi Kloos (heidi.kloos@uc.edu).

\section{References}

Acher, A., Arca, M., Sanmarti, N., (2007) Modeling as a teaching learning process for understanding materials: a case study in primary education. Wiley InterScience. 9, 1398418. 
Anderson, C.W., \& Smith, E. (1987). Teaching Science. in V. Richardson-Koehler (Ed.), Educator's handbook: A research perspective (pp. 84-111). New York: Longman

Baker, H., Haussmann, A., Kloos, H., \& Fisher, A. (2011). Preschoolers' Learning about Buoyancy: Does it help to give away the answer? Proceedings of the First Joint International Conference on Learning and Development and Epigenetic Robotics. Frankfurt, Germany: IEEE.

Bassok, M., \& Holyoak, K . J . (1989) . Interdomain transfer between isomorphic topics in algebra and physics. Journal of Experimental Psychology: Learning, Memory, and Cognition, 15, 153-166.

Bodrova, E., \& Leong, D. J. (2007). Tools of the mind: The Vygotskian approach to early childhood education (2nd Ed). Upper Saddle River, NJ: Prentice-Hall.

Bremner, G. \& Fogel, A. (2004). Blackwell Handbook of Infant Development. Oxford, UK: Backwell Publishing.

Brenneman, K. (2011). Assessment for Preschool Science Learning and Learning Environments. Assessment, 13(1).

Brenneman, K., Stevenson-Boyd, J., \& Frede, E. C. (2009). Mathematics and Science in Preschool: Policy and Practice ( No. 19). Preschool Policy Brief. New Brunswick, NJ: National Institute for Early Education Research.

Brenneman, K., \& Louro, I. F. (2008). Science Journals in the Preschool Classroom. Early Childhood Education Journal, 36(2), 113-119.

Chalufour, I., \& Worth, K. (2003). Discovering nature with young children. St Paul, MN: Redleaf Press.

Chalufour, I., \& Worth, K. (2004). Building structures with young children. St Paul, MN: Redleaf Press.

Chalufour, I., \& Worth, K. (2005). Exploring water with young children. St Paul, MN: Redleaf Press.

Copple, C. \& Bredekamp, S. (Eds.). (2009). Developmentally Appropriate Practice in Early Childhood Programs Serving Children from Birth through Age 8 (3rd ed.). Washington, D.C.: National Association for the Education of Young Children.

Cumming, J. (2003). Do runner beans really make you run fast? Young children learning about science-related food concepts in informal settings. Research in Science Education, 33, 483-501.

Crowder, E. M. (1996). Gestures at work in sense-making science talk. The Journal of the Learning Sciences, 5(3), 173-208

Crowley, K., Callanan, M. A., Jipson, J. L., Galco, J., Topping, K., \& Shrager, J. (2001). Shared scientific thinking in everyday parent-child activity. Science Education, 85(6), 712-732.

Crowley, K., \& Jacobs, M. (2002). Islands of expertise and the development of family scientific literacy. Learning conversations in museums, 333-356.

Davis, J. (2009). Revealing the research "hole" of early childhood education for sustainability: a preliminary survey of the literature. Environmental Education Research, 15(2), 227-241.

Davis, E.A., \& Krajcik, J. (2005). Designing educative curriculum materials to promote teacher learning. Educational Researcher, 34(3), 3-14. 
DeLoache, J.S. (1995). Early symbol understanding and use. In Douglas L. Medin (Ed.), The psychology of learning and motivation: Advances in research and theory. Vol. 33, pp. 65-114. New York: Academic Press.

Doris, E. (1991). Doing what scientists do: Children learn to investigate their world. Portsmouth, $\mathrm{NH}$ : Heinemann.

Eshach, H., \& Fried, M. N. (2005). Should Science be Taught in Early Childhood? Journal of Science Education and Technology, 14(3), 315-336.

Fleer, M. (1991). Socially constructed learning in early childhood science education. Research in Science Education, 21, 96-103.

Fleer, M., \& Beasley, W. (1991). A study of conceptual development in early childhood. Research in Science Education, 21, 104-112.

Fleer, M., \& Hardy, T. (1993). How can we find out what 3 and 4 year olds think?: New approaches to eliciting very young children's understandings in science. Research In Science Education, 23, 68-76.

Fleer, M. (1996). Fusing the boundaries between home and preschool to support children's scientific learning. Research in Science Education, 26(2), 143-154.

Glynn, S. M., \& Duit, R. (1995). Learning science meaningfully: Constructing conceptual models. Learning science in the schools: Research reforming practice, 3-33.

Gobert, J. D., \& Buckley, B. C. (2000). Introduction to model-based in teaching and learning in science education. International Journal of Science Education, 22 (9), 891 - 894.

Goldstone, R. L., \& Sakamoto, Y. (2003). The Transfer of Abstract Principles Governing Complex Adaptive Systems. Cognitive Psychology, 46, 414-466.

Goldstone, R. L., \& Son, J. Y. (2005). The transfer of scientific principles using concrete and idealized simulations. The Journal of the Learning Sciences, 14, 69-110.

Gunstone, R. F., Champagne, A. B., \& Klopfer, L. E. (1981). Instruction for Understanding: A case study. Australian Science Teachers Journal, 27 (3), 27-32.

Hannust, T., \& Kikas, E. (2007). Children's knowledge of astronomy and its change in the course of learning. Early Childhood Research Quarterly, 22(1), 89-104.

Havu-Nuutinen, S. (2005). Examining young children's conceptual change process in floating and sinking from a social constructivist perspective. International Journal of Science Education, 27(3), 259.

Hickling, A. K., \& Gelman, S. A. (1995). How Does Your Garden Grow? Early Conceptualization of Seeds and Their Place in the Plant Growth Cycle. Child Development, 66(3), 856-876.

Hickling, A. K., \& Wellman, H. M. (2001). The emergence of children's causal explanations and theories: Evidence from everyday conversation. Developmental Psychology, 37(5), 668-683.

Hunter, J., Monroe-Ossi, H., \& Fountain, C. (2008). Young Florida naturalists: Concept mapping and science learning of preschool children. In A. J. Cañas, P. Reiske, M. Åhlberg. D. Novak (Eds.) Concept Maps: Connecting Educators. Proceedings of the Third International Conference on Concept Mapping. Tallinn, Estonia \& Helsinki, Finland: University of Finland.

Kafai, Y. B., Carter Ching, C. (2001). Affordances of collaborative software design planning for elementary students' science talk. The Journal of the Learning Sciences, 10(3), 323-363. 
Kaminski, J. A., Sloutsky, V. M., \& Heckler, A. F. (2008). The advantage of abstract examples in learning math. Science, 230, 454-455.

Kenyon, L., Schwarz, C., and Hug, B. (2008). The benefits of scientific modeling: Constructing, using, evaluating, and revising scientific models helps students advance their scientific ideas, learn to think critically, and understand the nature of science. Science and Children, 46(2), 40-44.

Kirschner, P. A., Sweller, J., \& Clark, R. E. (2006). Why minimal guidance during instruction does not work: An analysis of the failure of constructivist, discovery, problem-based, experiential, and inquiry-based teaching. Educational Psychologist, 41(2), 75-86.

Klahr, D. (2005). Early Science Instruction. Psychological Science, 16(11), 871 -873.

Kotovsky, L. \& Baillargeon, R. (1998). The development of calibration-based reasoning about collision events in young children. Cognition, 67, 311-351.

Kuhn, D. (1997). Constraints or guideposts? Developmental psychology and science education. Review of educational research, 67(1), 141.

Kuhn, D. (2010). What is scientific thinking and how does it develop? In U. Goswami (Ed.), Handbook of childhood cognitive development. Oxford: Blackwell. (2nd ed.)

Kloos, H., Fisher, A. \& Van Orden, G. C. (2010). Situated Naïve Physics; Task Constraints Decide what Children Know about Density. Journal of Experimental Psychology: General, 139(4), 625-637.

Kloos, H., \& Somerville, S. C. (2001). Providing impetus for Conceptual change: The effect of organizing the input. Cognitive Development, 16, 737-759.

Kloos, H., \& Van Orden, G. C. (2005). Can a preschooler's mistaken beliefs benefit learning? Swiss Journal of Psychology, 64, 195-205.

Kuhn, T. (1996) The Structure of Scientific Revolutions. University of Chicago Press; 3rd edition

Lemke, J. L. (1990). Talking science: Language, learning, and values. Norwood, NJ: Ablex.

Light, P., \& Simmons, B. (1983). The effects of a communication task upon the representation of depth relationships in young children's drawings. Journal of Experimental Child Psychology, 35, 81-92.

Linn, M. C.. \& Burbules, N. C. (1988). RESPONSE to contradictions: Scientific reasoning during adolescence. Journal of Educational Research, 80 (1), 67-75.

Lucas, A. M. (1993). Constructing knowledge from fragments of learning?. In P. Black \& A. Lucas (Eds.), Children's informal ideas in science. London and New York: Routledge.

Luken, E., Carr, V., \& Brown, R. D. (2011). Playscapes: Designs for Play, exploration and science inquiry. Children, Youth and Environments, 21, 325-337.

Mantzicopoulos, P., Patrick, H., \& Samarapungavan, A. (2008). Young children's motivational beliefs about learning science. Early Childhood Research Quarterly, 23(3), 378-394.

Muthukrishna, N., Carnine, D., Grossen, B., \& Miller, S. (1993). Children's alternative frameworks: Should they be directly addressed by science instruction? Journal of Research in Science Teaching, 30, 233-248.

Mayer, R. E. (1989). Models for understanding. Review of educational research, 59(1), 43.

Mix, K. S. (1999). Similarity and numerical equivalence: appearances count. Cognitive Development, 14, 269-297. 
Novak, J. D. (2010). Learning, creating, and using knowledge: Concept maps as facilitative tools in schools and corporations ( $2^{\text {nd }}$. Ed). Mahwah, NJ: Lawrence Erlbaum Associates.

Novak, J. D., Gowin, D. B. (1984). Learning How to Learn. Cambridge: Cambridge University Press.

Ohlsson, S. (2011). Deep Learning: How the Mind Overrides Experience. NY: Cambridge University Press.

Pearl, J. (2009). Causality: Models, Reasoning, and Inference. $2^{\text {nd }}$ ed. New York: Cambridge University Press.

Penner, D. E., Giles, N. D., Lehrer, R., \& Schauble, L. (1997). Building functional models: Designing an elbow. Journal of Research in Science Teaching, 34(2), 125-143.

Penner, D., \& Klahr, D. (1996). The Interaction of Domain-Specific Knowledge and DomainGeneral Discovery Strategies: A Study with Sinking Objects. Child Development, 67, 27092727.

Peterson, S. M., \& French, L. (2008). Supporting young children's explanations through inquiry science in preschool. Early Childhood Research Quarterly, 23(3), 395-408.

Piaget, J., \& Inhelder, B. (1974). The child's construction of physical quantities. London: Routledge and Kegan Paul.

Pfeiffer, D. (2012) Personal Communication.

Pramling, N., \& Pramling-Samuelson, I. (2001). “It is floating 'cause there is a hole:" A young child's experience of natural science. Early Years, 21(2), 139-149.

Popper, K. R. (1959). The Logic of Scientific Discovery. New York: Basic Books.

Quinn, P.C., Eimas, S.L., \& Rosenkrantz, S.L. (1993) Evidence for representations of perceptually similar natural categories by 3-month old and 4- month old infants. Perception, 22, 463-475.

Ratterman, M.J., Gentner, D., \& DeLoache, J. (1990). The effects of familiar labels on young children's performance in an analogical mapping task. Proceedings of the Twelfth Annual Conference of the Cognitive Science Society, 22-29. Hillsdale, NJ: LEA.

Ratterman, M.J., \& Gentner, D. (1998). The effect of language on similarity: The use of relational symbols improves young children's performance on a mapping task. In K.D. Holyoak, D. Gentner, \& B. Kokinov (Eds.), Advances in analogy research: Integration of theory and data from the cognitive, computational and neural sciences (pp. 274-282). Sofia, Bulgaria: New Bulgarian University.

Schauble, L. (1990). Belief revision in children: The role of prior knowledge and strategies for generating evidence. Journal of Experimental Child Psychology, 49(1), 31-57.

Schilling, T.H. \& Clifton, R.K. (1998). Nine-month-old infants learn about a physical event in a single session: Implications for infants' understanding of physical phenomena. Cognitive Development, 13, 165-184.

Schneps, M. H: (Producer, Director). (1987). A private universe (Film). Boston, MA: Harvard University and Smithsonian Institute.

Scott-Little, C., Lesko, J., Martella, J., \& Milburn, P. (2007). Early learning standards: Results from national survey to document trends in state-level policies and practices. Early Childhood Research \& Practice, 9(1).

Simons, D. J., \& Keil, F. C. (1995). An abstract to concrete shift in the development of biological thought: the insides story. Cognition 56, 129-163. 
Sloutsky, V. M., Kaminski, J. A., \& Heckler, A. F. (2005).The advantage of simple symbols for learning and transfer. Psychonomic Bulletin \& Review, 12, 508-513.

Smith, C., Snir, J., \& Grosslight, L. (1992). Using conceptual models to facilitate conceptual change: The case of weight-density differentiation. Cognition and Instruction, 9(3), 221-283.

Smith, C., \& Unger, C. (1997). What's in dots-per-box? Conceptual bootstrapping with stripped-down visual analogs. The Journal of the Learning Sciences, 6(2), 143-181.

Son, J. Y., Smith, L. B., \& Goldstone, R. L. (2008). Simplicity and generalization: Short-cutting abstraction in children's object categorization. Cognition, 108, 626-638.

Thagard, P. (2000). Congruence in Thought and Action. Cambridge, MA: MIT Press.

Tytler, R., \& Peterson, S. (2000). Deconstructing learning in science - young children's responses to a classroom sequence on evaporation. Research in Science Education, 30(4), 339-355.

Uttal, D. H., Liu, L. L., \& DeLoache, J. S. (1999). Taking a hard look at concreteness: do concrete objects help young children learn symbolic relations? In L. Balter \& C. TamisLeMonda (Eds.), Child psychology: A handbook of contemporary issues (pp. 177-192). Philadelphia: Psychology Press.

Uttal, D. H., Scudder, K. V., \& DeLoache, J. S. (1997). Manipulatives as symbols: A new perspective on the use of concrete objects to teach mathematics. Journal of Applied Developmental Psychology, 18, 37-54.

Venville, G. (2004). Young children learning about living things: a case study of conceptual change from ontological and social perspectives. Journal of Research in Science Teaching,41(5), 449-480.

Vosniadou S. (Ed.), 2008. Handbook of research on conceptual change. Hillsdale, NJ: Erlbaum.

Vosniadou, S. \& Brewer, W. (1992). Mental models of the earth: A study of conceptual change in childhood. Cognitive Psychology, 24, 535-585.

Vosniadou, S. (1994). Capturing and modeling the process of conceptual change. Learning and Instruction, 4, 45-69.

Wiser, M., \& Smith, C. L. (2008). Learning and teaching about matter in grades K-8: When should the atomic-molecular theory be introduced. International handbook of research on conceptual change, 205-239.

Witt, S. D., \& Kimple, K.P. (2008). 'How does your garden grow?' Teaching preschool children about the environment. Early Child Development and Care, 178, 41-48.

Worth, K., \& Grollman, S. (2003). Worms, shadows and whirlpools: Science in the early childhood classroom. Portsmouth, NH: Heinemann.

Zembylas, M. (2008) Affect and early childhood science education. Contemporary Perspectives on Science and Technology in Early Childhood Education, 65-85. Information Age Publishing.

Zimmerman, C. (2000). The development of scientific reasoning skills. Developmental Review, 20(1), 99-149. 


\title{
The Emergence of Scientific Reasoning
}

\author{
Bradley J. Morris, Steve Croker, Amy M. Masnick and Corinne Zimmerman
}

Additional information is available at the end of the chapter

http://dx.doi.org/10.5772/53885

\section{Introduction}

Scientific reasoning encompasses the reasoning and problem-solving skills involved in generating, testing and revising hypotheses or theories, and in the case of fully developed skills, reflecting on the process of knowledge acquisition and knowledge change that results from such inquiry activities. Science, as a cultural institution, represents a "hallmark intellectual achievement of the human species" and these achievements are driven by both individual reasoning and collaborative cognition (Feist, 2006, p. ix).

Our goal in this chapter is to describe how young children build from their natural curiosity about their world to having the skills for systematically observing, predicting, and understanding that world. We suggest that scientific reasoning is a specific type of intentional information seeking, one that shares basic reasoning mechanisms and motivation with other types of information seeking (Kuhn, 2011a). For example, curiosity is a critical motivational component that underlies information seeking (Jirout \& Klahr, 2012), yet only in scientific reasoning is curiosity sated by deliberate data collection and formal analysis of evidence. In this way, scientific reasoning differs from other types of information seeking in that it requires additional cognitive resources as well as an integration of cultural tools. To that end, we provide an overview of how scientific reasoning emerges from the interaction between internal factors (e.g., cognitive and metacognitive development) and cultural and contextual factors.

The current state of empirical research on scientific reasoning presents seemingly contradictory conclusions. Young children are sometimes deemed "little scientists" because they appear to have abilities that are used in formal scientific reasoning (e.g., causal reasoning; Gopnik et al., 2004). At the same time, many studies show that older children (and sometimes adults) have difficulties with scientific reasoning. For example, children have difficulty in systematically designing controlled experiments, in drawing appropriate conclusions based on evidence, and in interpreting evidence (e.g., Croker, 2012; Chen \& Klahr, 1999; Kuhn, 1989; Zimmerman, 2007). 
In the following account, we suggest that despite the early emergence of many of the precursors of skilled scientific reasoning, its developmental trajectory is slow and requires instruction, support, and practice. In Section 2 of the chapter, we discuss cognitive and metacognitive factors. We focus on two mechanisms that play a critical role in all cognitive processes (i.e., encoding and strategy acquisition/selection). Encoding involves attention to relevant information; it is foundational in all reasoning. Strategy use involves intentional approaches to seeking new knowledge and synthesizing existing knowledge. These two mechanisms are key components for any type of intentional information seeking yet follow a slightly different development trajectory in the development of scientific reasoning skills. We then discuss the analogous development of metacognitive awareness of what is being encoded, and metastrategic skills for choosing and deploying hypothesis testing and inference strategies. In Section 3, we describe the role of contextual factors such as direct and scaffolded instruction, and the cultural tools that support the development of the cognitive and metacognitive skills required for the emergence of scientific thinking.

\section{The development of scientific reasoning}

Effective scientific reasoning requires both deductive and inductive skills. Individuals must understand how to assess what is currently known or believed, develop testable questions, test hypotheses, and draw appropriate conclusions by coordinating empirical evidence and theory. Such reasoning also requires the ability to attend to information systematically and draw reasonable inferences from patterns that are observed. Further, it requires the ability to assess one's reasoning at each stage in the process. Here, we describe some of the key issues in developing these cognitive and metacognitive scientific reasoning skills.

\subsection{Cognitive processes and mechanisms}

The main task for developmental researchers is to explain how children build on their intuitive curiosity about the world to become skilled scientific reasoners. Curiosity, defined as "the threshold of desired uncertainty in the environment that leads to exploratory behavior" (Jirout \& Klahr, 2012, p. 150), will lead to information seeking. Information seeking activates a number of basic cognitive mechanisms that are used to extract (encode) information from the environment and then children (and adults) can act on this information in order to achieve a goal (i.e., use a strategy; Klahr, 2001; Kuhn, 2010). We turn our discussion to two such mechanisms and discuss how these mechanisms underlie the development of a specific type of information seeking: scientific reasoning.

A mechanistic account of the development of scientific reasoning includes information about the processes by which this change occurs, and how these processes lead to change over time (Klahr, 2001). Mechanisms can be described at varying levels (e.g., neurological, cognitive, interpersonal) and over different time scales. For example, neurological mechanisms (e.g., inhibition) operate at millisecond time scales (Burlea, Vidala, Tandonneta, \& Hasbroucq, 2004) while learning mechanisms may operate over the course of minutes (e.g., inhibiting irrelevant information during problem solving; Becker, 2010). Many of the 
cognitive processes and mechanisms that account for learning and for problem solving across a variety of domains are important to the development of scientific reasoning skills and science knowledge acquisition. Many cognitive mechanisms have been identified as underlying scientific reasoning and other high-level cognition (e.g., analogy, statistical learning, categorization, imitation, inhibition; Goswami, 2008). However, due to space limitations we focus on what we argue are the two most critical mechanisms - encoding and strategy development - to illustrate the importance of individual level cognitive abilities.

\subsubsection{Encoding}

Encoding is the process of representing information and its context in memory as a result of attention to stimuli (Chen, 2007; Siegler, 1989). As such, it is a central mechanism in scientific reasoning because we must represent information before we can reason about it, and the quality and process of representation can affect reasoning. Importantly, there are significant developmental changes in the ability to encode the relevant features that will lead to sound reasoning and problem solving (Siegler, 1983; 1985). Encoding abilities improve with the acquisition of encoding strategies and with increases in children's domain knowledge (Siegler, 1989). Young children often encode irrelevant features due to limited domain knowledge (Gentner, Loewenstein, \& Thompson, 2003). For example, when solving problems to make predictions about the state of a two-arm balance beam (i.e., tip left, tip right, or balance), children often erroneously encode distance to the fulcrum and amount of weight as a single factor, decreasing the likelihood of producing a correct solution (which requires weight and distance to be encoded and considered separately as causal factors, while recognizing noncausal factors such as color; Amsel, Goodman, Savoie, \& Clark, 1996; Siegler, 1983). Increased domain knowledge helps children assess more effectively what information is and is not necessary to encode. Further, children's encoding often improves with the acquisition of encoding strategies. For example, if a child is attempting to recall the location of an item in a complex environment, she may err in encoding only the features of the object itself without encoding its relative position. With experience, she may encode the relations between the target item and other objects (e.g., the star is in front of the box), a strategy known as cue learning. Encoding object position and relative position increases the likelihood of later recall and is an example of how encoding better information is more important than simply encoding more information (Chen, 2007; Newcombe \& Huttenlocher, 2000).

Effective encoding is dependent on directing attention to relevant information, which in turn leads to accurate representations that can guide reasoning. Across a variety of tasks, experts are more likely to attend to critical elements in problem solving, and less likely to attend to irrelevant information, compared to novices (Gobet, 2005). Domain knowledge plays an important role in helping to guide attention to important features. Parents often direct a child's attention to critical problem features during problem solving. For example, a parent may keep track of which items have been counted in order to help a child organize counting (Saxe, Guberman, \& Gearhart, 1987). Instructional interventions in which children were directed towards critical elements in problem solving improved their attention to these 
features (Kloos \& Van Orden, 2005). Although domain knowledge is helpful in directing attention to critical features, it may sometimes limit novel reasoning in a domain and limit the extent to which attention is paid to disconfirming evidence (Li \& Klahr, 2006). Finally, self-generated activity improves encoding. Self-generation of information from memory, rather than passive attention, is associated with more effective encoding because it recruits greater attentional resources than passive encoding (Chi, 2009).

\subsubsection{Strategy development}

Strategies are sequences of procedural actions used to achieve a goal (Siegler, 1996). In the context of scientific reasoning, strategies are the steps that guide children from their initial state (e.g., a question about the effects of weight and distance in balancing a scale) to a goal state (e.g., understanding the nature of the relationship between variables). We will briefly examine two components of strategy development: strategy acquisition and strategy selection. Strategies are particularly important in the development of scientific reasoning. Children often actively explore objects in a manner that is like hypothesis testing; however, these exploration strategies are not systematic investigations in which variables are manipulated and controlled as in formal hypothesis-testing strategies (Klahr, 2000). The acquisition of increasingly optimal strategies for hypothesis testing, inference, and evidence evaluation leads to more effective scientific reasoning that allows children to construct more veridical knowledge.

New strategies are added to the repertoire of possible strategies through discovery, instruction, or other social interactions (Chen, 2007; Gauvain, 2001; Siegler, 1996). There is evidence that children can discover strategies on their own (Chen, 2007). Children often discover new strategies when they experience an insight into a new way of solving a familiar problem. For example, 10- and 11-year-olds discovered new strategies for evaluating causal relations between variables in a computerized task only after creating different cars (e.g., comparing the effects of engine size) and testing them (Schauble, 1990). Similarly, when asked to determine the cause of a chemical reaction, children discovered new experimentation strategies only after several weeks (Kuhn \& Phelps, 1982). Over time, existing strategies may be modified to reduce time and complexity of implementation (e.g., eliminating redundant steps in a problem solving sequence; Klahr, 1984). For example, determining causal relations among variables requires more time when experimentation is unsystematic. In order to identify which variables resulted in the fastest car, children often constructed up to 25 cars, whereas an adult scientist identified the fastest car after constructing only seven cars (Schauble, 1990).

Children also gain new strategies through social interaction, by being explicitly taught a strategy, imitating a strategy, or by collaborating in problem solving (Gauvain, 2001). For example, when a parent asks a child questions about events in a photograph, the parent evokes memories of the event and helps to structure the child's understanding of the depicted event, a process called conversational remembering (Middleton, 1997). Conversational remembering improves children's recall of events and often leads to children spontaneously using this strategy. Parent conversations about event structures 
improved children's memory for these structures; for example, questions about a child's day at school help to structure this event and improved recall (Nelson, 1996). Children also learn new strategies by solving problems cooperatively with adults. In a sorting task, preschool children were more likely to improve their classification strategies after working with their mothers (Freund, 1990). Further, children who worked with their parents on a hypothesistesting task were more likely to identify causal variables than children who worked alone because parents helped children construct valid experiments, keep data records, and repeat experiments (Gleason \& Schauble, 2000).

Children also acquire strategies by interacting with an adult modeling a novel strategy. Middle-school children acquired a reading comprehension strategy (e.g., anticipating the ending of a story) after seeing it modeled by their teacher (Palinscar, Brown, \& Campione, 1993). Additionally, children can acquire new strategies from interactions with other children. Monitoring other children during problem solving improves a child's understanding of the task and appears to improve how they evaluate their own performance (Brownell \& Carriger, 1991). Elementary school children who collaborated with other students to solve the balance-scale task outperformed students who worked alone (Pine \& Messer, 1998). Ten-year-olds working in dyads were more likely to discuss their strategies than children working alone and these discussions were associated with generating better hypotheses than children working alone (Teasley, 1995).

More than one strategy may be useful for solving a problem, which requires a means to select among candidate strategies. One suggestion is that this process occurs by adaptive selection. In adaptive selection, strategies that match features of the problem are candidates for selection. One component of selection is that newer strategies tend to have a slightly higher priority for use when compared to older strategies (Siegler, 1996). Successful selection is made on the basis of the effectiveness of the strategy and its cost (e.g., speed), and children tend to choose the fastest, most accurate strategy available (i.e., the most adaptive strategy).

Cognitive mechanisms provide the basic investigation and inferential tools used in scientific reasoning. The ability to reason about knowledge and the means for obtaining and evaluating knowledge provide powerful tools that augment children's reasoning. Metacognitive abilities such as these may help explain some of the discrepancies between early scientific reasoning abilities and limitations in older children, as well as some of the developmental changes in encoding and strategy use.

\subsection{Metacognitive and metastrategic processes}

Sodian, Zaitchik, and Carey (1991) argue that two basic skills related to early metacognitive acquisitions are needed for scientific reasoning. First, children need to understand that inferences can be drawn from evidence. The theory of mind literature (e.g., Wellman, Cross, \& Watson, 2001) suggests that it is not until the age of 4 that children understand that beliefs and knowledge are based on perceptual experience (i.e., evidence). As noted earlier, experimental work demonstrates that preschoolers can use evidence to make judgments 
about simple causal relationships (Gopnik, Sobel, Schulz, \& Glymour, 2001; Schulz \& Bonawitz, 2007; Schulz \& Gopnik, 2004; Schulz, Gopnik,\& Glymour, 2007). Similarly, several classic studies show that children as young as 6 can succeed in simple scientific reasoning tasks. Children between 6 and 9 can discriminate between a conclusive and an inclusive test of a simple hypothesis (Sodian et al., 1991). Children as young as 5 can form a causal hypothesis based on a pattern of evidence, and even 4-year-olds seem to understand some of the principles of causal reasoning (Ruffman, Perner, Olson, \& Doherty, 1993).

Second, according to Sodian et al. (1991), children need to understand that inference is itself a mechanism with which further knowledge can be acquired. Four-year-olds base their knowledge on perceptual experiences, whereas 6-year-olds understand that the testimony of others can also be used in making inferences (Sodian \& Wimmer, 1987). Other research suggests that children younger than 6 can make inferences based on testimony, but in very limited circumstances (Koenig, Clément, \& Harris, 2004). These findings may explain why, by the age of 6 , children are able to succeed on simple causal reasoning, hypothesis testing, and evidence evaluation tasks.

Research with older children, however, has revealed that 8- to 12-year-olds have limitations in their abilities to (a) generate unconfounded experiments, (b) disconfirm hypotheses, (c) keep accurate and systematic records, and (d) evaluate evidence (Klahr, Fay, \& Dunbar, 1993; Kuhn, Garcia-Mila, Zohar, \& Andersen, 1995; Schauble, 1990, 1996; Zimmerman, Raghavan, \& Sartoris, 2003). For example, Schauble (1990) presented children aged 9-11 with a computerized task in which they had to determine which of five factors affect the speed of racing cars. Children often varied several factors at once (only $22 \%$ of the experiments were classified as valid) and they often drew conclusions consistent with belief rather than the evidence generated. They used a positive test strategy, testing variables believed to influence speed (e.g., engine size) and not testing those believed to be non-causal (e.g., color). Some children recorded features without outcomes, or outcomes without features, but most wrote down nothing at all, relying on memory for details of experiments carried out over an eight-week period.

Although the performance differences between younger and older children may be interpreted as potentially contradictory, the differing cognitive and metacognitive demands of tasks used to study scientific reasoning at different ages may account for some of the disconnect in conclusions. Even though the simple tasks given to preschoolers and young children require them to understand evidence as a source of knowledge, such tasks require the cognitive abilities of induction and pattern recognition, but only limited metacognitive abilities. In contrast, the tasks used to study the development of scientific reasoning in older children (and adults) are more demanding and focused on hypothetico-deductive reasoning; they include more variables, involve more complex causal structures, require varying levels of domain knowledge, and are negotiated across much longer time scales. Moreover, the tasks given to older children and adults involve the acquisition, selection, and coordination of investigation strategies, combining background knowledge with empirical evidence. The results of investigation activities are then used in the acquisition, selection, and coordination 
of evidence evaluation and inference strategies. With respect to encoding, increases in task complexity require attending to more information and making judgments about which features are relevant. This encoding happens in the context of prior knowledge and, in many cases, it is also necessary to inhibit prior knowledge (Zimmerman \& Croker, in press).

Sodian and Bullock (2008) also argue that mature scientific reasoning involves the metastrategic process of being able to think explicitly about hypotheses and evidence, and that this skill is not fully mastered until adolescence at the very earliest. According to Amsel et al. (2008), metacognitive competence is important for hypothetical reasoning. These conclusions are consistent with Kuhn's $(1989,2005,2011 a)$ argument that the defining feature of scientific thinking is the set of cognitive and metacognitive skills involved in differentiating and coordinating theory and evidence. Kuhn argues that the effective coordination of theory and evidence depends on three metacognitive abilities: (a) The ability to encode and represent evidence and theory separately, so that relations between them can be recognized; (b) the ability to treat theories as independent objects of thought (i.e., rather than a representation of "the way things are"); and (c) the ability to recognize that theories can be false, setting aside the acceptance of a theory so evidence can be assessed to determine the veridicality of a theory. When we consider these cognitive and metacognitive abilities in the larger social context, it is clear that skills that are highly valued by the scientific community may be at odds with the cultural and intuitive views of the individual reasoner (Lemke, 2001). Thus, it often takes time for conceptual change to occur; evidence is not just evaluated in the context of the science investigation and science classroom, but within personal and community values. Conceptual change also takes place in the context of an individual's personal epistemology, which can undergo developmental transitions (e.g., Sandoval, 2005).

\subsubsection{Encoding and strategy use}

Returning to the encoding and retrieval of information relevant to scientific reasoning tasks, many studies demonstrate that both children and adults are not always aware of their memory limitations while engaged in investigation tasks (e.g., Carey, Evans, Honda, Jay, \& Unger, 1989; Dunbar \& Klahr, 1989; Garcia-Mila \& Andersen, 2007; Gleason \& Schauble, 2000; Siegler \& Liebert, 1975; Trafton \& Trickett, 2001). Kanari and Millar (2004) found that children differentially recorded the results of experiments, depending on familiarity or strength of prior beliefs. For example, 10- to 14-year-olds recorded more data points when experimenting with unfamiliar items (e.g., using a force-meter to determine the factors affecting the force produced by the weight and surface area of boxes) than with familiar items (e.g., using a stopwatch to experiment with pendulums). Overall, children are less likely than adults to record experimental designs and outcomes, or to review notes they do keep, despite task demands that clearly necessitate a reliance on external memory aids.

Children are often asked to judge their memory abilities, and memory plays an important role in scientific reasoning. Children's understanding of memory as a fallible process 
develops over middle childhood (Jaswal \& Dodson, 2009; Kreuzer, Leonard, \& Flavell, 1975). Young children view all strategies on memory tasks as equally effective, whereas 8- to 10-year-olds start to discriminate between strategies, and 12-year-olds know which strategies work best (Justice, 1986; Schneider, 1986). The development of metamemory continues through adolescence (Schneider, 2008), so there may not be a particular age that memory and metamemory limitations are no longer a consideration for children and adolescents engaged in complex scientific reasoning tasks. However, it seems likely that metamemory limitations are more profound for children under 10-12 years.

Likewise, the acquisition of other metacognitive and metastrategic skills is a gradual process. Early strategies for coordinating theory and evidence are replaced with better ones, but there is not a stage-like change from using an older strategy to a newer one. Multiple strategies are concurrently available so the process of change is very much like Siegler's (1996) overlapping waves model (Kuhn et al., 1995). However, metastrategic competence does not appear to routinely develop in the absence of instruction. Kuhn and her colleagues have incorporated the use of specific practice opportunities and prompts to help children develop these types of competencies. For example, Kuhn, Black, Keselman, and Kaplan (2000) incorporated performance-level practice and metastrategic-level practice for sixth- to eighthgrade students. Performance-level exercise consisted of standard exploration of the task environment, whereas metalevel practice consisted of scenarios in which two individuals disagreed about the effect of a particular feature in a multivariable situation. Students then evaluated different strategies that could be used to resolve the disagreement. Such scenarios were provided twice a week during the course of ten weeks. Although no performance differences were found between the two types of practice with respect to the number of valid inferences, there were more sizeable differences in measures of understanding of task objectives and strategies (i.e., metastrategic understanding).

Similarly, Zohar and Peled (2008) focused instruction in the control-of-variables strategy (CVS) on metastrategic competence. Fifth-graders were given a computerized task in which they had to determine the effects of five variables on seed germination. Students in the control group were taught about seed germination, and students in the experimental group were given a metastrategic knowledge intervention over several sessions. The intervention consisted of describing CVS, discussing when it should be used, and discussing what features of a task indicate that CVS should be used. A second computerized task on potato growth was used to assess near transfer. A physical task in which participants had to determine which factors affect the distance a ball will roll was used to assess far transfer. The experimental group showed gains on both the strategic and the metastrategic level. The latter was measured by asking participants to explain what they had done. These gains were still apparent on the near and far transfer tasks when they were administered three months later. Moreover, low-academic achievers showed the largest gains. It is clear from these studies that although meta-level competencies may not develop routinely, they can certainly be learned via explicit instruction. 
Metacognitive abilities are necessary precursors to sophisticated scientific thinking, and represent one of the ways in which children, adults, and professional scientists differ. In order for children's behavior to go beyond demonstrating the correctness of one's existing beliefs (e.g., Dunbar \& Klahr, 1989) it is necessary for meta-level competencies to be developed and practiced (Kuhn, 2005). With metacognitive control over the processes involved, children (and adults) can change what they believe based on evidence and, in doing so, are aware not only that they are changing a belief, but also know why they are changing a belief. Thus, sophisticated reasoning involves both the use of various strategies involved in hypothesis testing, induction, inference, and evidence evaluation, and a metalevel awareness of when, how, and why one should engage in these strategies.

\section{Scientific reasoning in context}

Much of the existing laboratory work on the development of scientific thinking has not overtly acknowledged the role of contextual factors. Although internal cognitive and metacognitive processes have been a primary focus of past work, and have helped us learn tremendously about the processes of scientific thinking, we argue that many of these studies focused on individual cognition have, in fact, included both social factors (in the form of, for example, collaborations with other students, or scaffolds by parents or teachers) and cultural tools that support scientific reasoning.

\subsection{Instructional and peer support: The role of others in supporting cognitive development}

Our goal in this section is to re-examine our two focal mechanisms (i.e., encoding and strategy) and show how the development of these cognitive acquisitions and metastrategic control of them are facilitated by both the social and physical environment.

\subsubsection{Encoding}

Children must learn to encode effectively, by knowing what information is critical to pay attention to. They do so in part with the aid of their teachers, parents, and peers. Once school begins, teachers play a clear role in children's cognitive development. An ongoing debate in the field of science education concerns the relative value of having children learn and discover how the world works on their own (often called "discovery learning") and having an instructor guide the learning more directly (often called "direct instruction"). Different researchers interpret these labels in divergent ways, which adds fuel to the debate (see e.g., Bonawitz et al., 2011; Hmelo-Silver, Duncan, \& Chinn, 2007; Kirshner, Sweller, \& Clark, 2006; Klahr, 2010; Mayer, 2004; Schmidt, Loyens, van Gog, \& Paas, 2007). Regardless of definitions, though, this issue illustrates the core idea that learning takes place in a social context, with guidance that varies from minimal to didactic. 
Specifically, this debate is about the ideal role for adults in helping children to encode information. In direct instruction, there is a clear role for a teacher, often actively pointing out effective examples as compared to ineffective ones, or directly teaching a strategy to apply to new examples. And, indeed, there is evidence that more direct guidance to test variables systematically can help students in learning, particularly in the ability to apply their knowledge to new contexts (e.g., Klahr \& Nigam, 2004; Lorch et al., 2010; Strand-Cary \& Klahr, 2008). There is also evidence that scaffolded discovery learning can be effective (e.g., Alfieri, Brooks, Adrich, \& Tenenbaum, 2011). Those who argue for discovery learning often do so because they note that pedagogical approaches commonly labeled as "discovery learning," such as problem-based learning and inquiry learning, are in fact highly scaffolded, providing students with a structure in which to explore (Alfieri et al., 2011; Hmelo-Silver et al., 2007; Schmidt et al., 2007). Even in microgenetic studies in which children are described as engaged in "self-directed learning," researchers ask participants questions along that way that serve as prompts, hints, dialogue, and scaffolds that facilitate learning (Klahr \& Carver, 1995). What there appears to be little evidence for is "pure discovery learning" in which students are given little or no guidance and expected to discover rules of problem solving or other skills on their own (Alfieri et al., 2011; Mayer, 2004). Thus, it is clear that formal education includes a critical role for a teacher to scaffold children's scientific reasoning.

A common goal in science education is to correct the many misconceptions students bring to the classroom. Chinn and Malhotra (2002) examined the role of encoding evidence, interpreting evidence, generalization, and retention as possible impediments to correcting misconceptions. Over four experiments, they concluded that the key difficulty faced by children is in making accurate observations or properly encoding evidence that does not match prior beliefs. However, interventions involving an explanation of what scientists expected to happen (and why) were very effective in mediating conceptual change when encountering counterintuitive evidence. That is, with scaffolds, children made observations independent of theory, and changed their beliefs based on observed evidence. For example, the initial belief that a thermometer placed inside a sweater would display a higher temperature than a thermometer outside a sweater was revised after seeing evidence that disconfirmed this belief and hearing a scientist's explanation that the temperature would be the same unless there was something warm inside the sweater. Instructional supports can play a crucial role in improving the encoding and observational skills required for reasoning about science.

In laboratory studies of reasoning, there is direct evidence of the role of adult scaffolding. Butler and Markman (2012a) demonstrate that in complex tasks in which children need to find and use evidence, causal verbal framing (i.e., asking whether one event caused another) led young children to more effectively extract patterns from scenes they observed, which in turn led to more effective reasoning. In further work demonstrating the value of adult scaffolding in children's encoding, Butler and Markman (2012b) found that by age 4, children are much more likely to explore and make inductive inferences when adults intentionally try to teach something than when they are shown an "accidental" effect. 


\subsubsection{Strategy development and use}

As discussed earlier in this chapter, learning which strategies are available and useful is a fundamental part of developing scientific thinking skills. Much research has looked at the role of adults in teaching strategies to children in both formal (i.e., school) and informal settings (e.g., museums, home; Fender \& Crowley, 2007; Tenenbaum, Rappolt-Schlichtmann, \& Zanger, 2004).

A central task in scientific reasoning involves the ability to design controlled experiments. Chen and Klahr (1999) found that directly instructing 7- to 10-year-old children in the strategies for designing unconfounded experiments led to learning in a short time frame. More impressively, the effectiveness of the training was shown seven months later, when older students given the strategy training were much better at correctly distinguishing confounded and unconfounded designs than those not explicitly trained in the strategy. In another study exploring the role of scaffolded strategy instruction, Kuhn and Dean (2005) worked with sixth graders on a task to evaluate the contribution of different factors to earthquake risk. All students given the suggestion to focus attention on just one variable were able to design unconfounded experiments, compared to only $11 \%$ in the control group given their typical science instruction. This ability to design unconfounded experiments increased the number of valid inferences in the intervention group, both immediately and three months later. Extended engagement alone resulted in minimal progress, confirming that even minor prompts and suggestions represent potentially powerful scaffolds. In yet another example, when taught to control variables either with or without metacognitive supports, 11-year-old children learned more when guided in thinking about how to approach each problem and evaluate the outcome (Dejonckheere, Van de Keere, \& Tallir, 2011). Slightly younger children did not benefit from the same manipulation, but 4- to 6year-olds given an adapted version of the metacognitive instruction were able to reason more effectively about simpler physical science tasks than those who had no metacognitive supports (Dejonckheere, Van de Keere, \& Mestdagh, 2010).

\subsection{Cultural tools that support scientific reasoning}

Clearly, even with the number of studies that have focused on individual cognition, a picture is beginning to emerge to illustrate the importance of social and cultural factors in the development of scientific reasoning. Many of the studies we describe highlight that even "controlled laboratory studies" are actually scientific reasoning in context. To illustrate, early work by Siegler and Liebert (1975) includes both an instructional context (a control condition plus two types of instruction: conceptual framework, and conceptual framework plus analogs) and the role of cultural supports. In addition to traditional instruction about variables (factors, levels, tree diagrams), one type of instruction included practice with analogous problems. Moreover, 10- and 13-year-olds were provided with paper and pencil to keep track of their results. A key finding was that record keeping was an important mediating factor in success. Children who had the metacognitive awareness of memory limitations and therefore used the provided paper for record keeping were more successful 
at producing all possible combinations necessary to manipulate and isolate variables to test hypotheses.

\subsubsection{Cultural resources to facilitate encoding and strategy use}

The sociocultural perspective highlights the role that language, speech, symbols, signs, number systems, objects, and tools play in individual cognitive development (Lemke, 2001). As highlighted in previous examples, adult and peer collaboration, dialogue, and other elements of the social environment are important mediators. In this section, we highlight some of the verbal, visual, and numerical elements of the physical context that support the emergence of scientific reasoning.

Most studies of scientific reasoning include some type of verbal and pictorial representation as an aid to reasoning. As encoding is the first step in solving problems and reasoning, the use of such supports reduces cognitive load. In studies of hypothesis testing strategies with children (e.g., Croker \& Buchanan, 2011; Tschirgi, 1980), for example, multivariable situations are described both verbally and with the help of pictures that represent variables (e.g., type of beverage), levels of the variable (e.g., cola vs. milk), and hypothesis-testing strategies (see Figure 1, panel A). In classic work by Kuhn, Amsel, and O'Loughlin (1988), a picture is provided that includes the outcomes (children depicted as healthy or sick) along with the levels of four dichotomous variables (e.g., orange/apple, baked potato/French fries, see Kuhn et al., 1988, pp. 40-41). In fact, most studies that include children as participants provide pictorial supports (e.g., Ruffman et al., 1993; Koerber, Sodian, Thoermer, \& Nett, 2005). Even at levels of increasing cognitive development and expertise, diagrams and visual aids are regularly used to support reasoning (e.g., Schunn \& Dunbar, 1996; Trafton \& Trickett, 2001; Veermans, van Joolingen, \& de Jong, 2006).

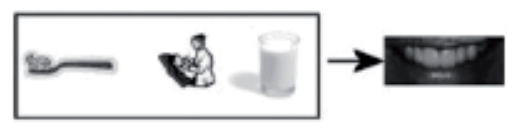

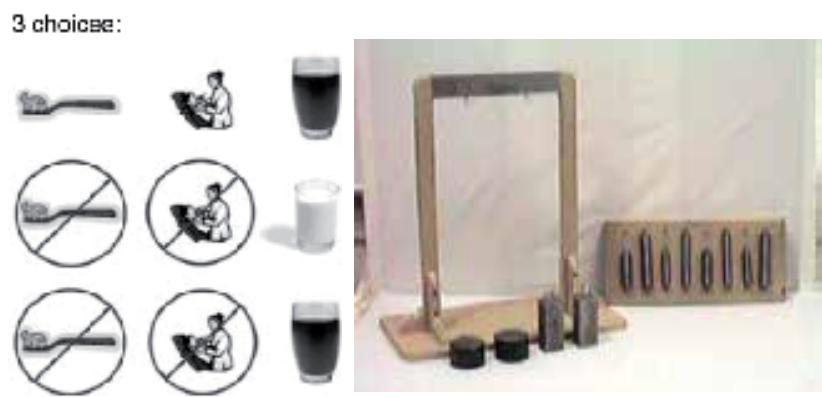

(A)
(B)

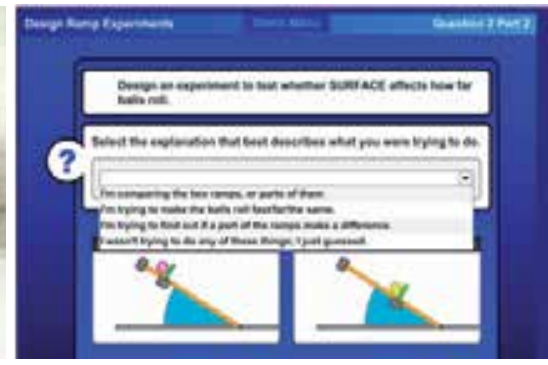

(C)

Figure 1. Panel A illustrates the type of pictorial support that accompanies the verbal description of a hypothesis-testing task (from Croker \& Buchanan, 2011). Panel B shows an example of a physical apparatus (from Triona \& Klahr, 2007). Panel C shows a screenshot from an intelligent tutor designed to teach how to control variables in experimental design (Siler \& Klahr, 2012; see

http://tedserver.psy.cmu.edu/demo/ted4.html, for a demonstration of the tutor). 
Various elements of number and number systems are extremely important in science. Sophisticated scientific reasoning requires an understanding of data and the evaluation of numerical data. Early work on evidence evaluation (e.g., Shaklee, Holt, Elek, \& Hall, 1988) included $2 \times 2$ contingency tables to examine the types of strategies children and adults used (e.g., comparing numbers in particular cells, the "sums of diagonals" strategy). Masnick and Morris (2008) used data tables to present evidence to be evaluated, and varied features of the presentation (e.g., sample size, variability of data). When asked to make decisions without the use of statistical tools, even third- and sixth-graders had rudimentary skills in detecting trends, overlapping data points, and the magnitude of differences. By sixth grade, participants had developing ideas about the importance of variability and the presence of outliers for drawing conclusions from numerical data.

Although language, symbols, and number systems are used as canonical examples of cultural tools and resources within the socio-cultural tradition (Lemke, 2001), recent advances in computing and computer simulation are having a huge impact on the development and teaching of scientific reasoning. Although many studies have incorporated the use of physical systems (Figure 1, panel B) such as the canal task (Gleason \& Schauble, 2000), the ramps task (e.g., Masnick \& Klahr, 2003), mixing chemicals (Kuhn \& Ho, 1980), and globes (Vosniadou, Skopeliti, \& Ikospentaki, 2005), there is an increase in the use of interactive computer simulations (see Figure 1, panel C). Simulations have been developed for electric circuits (Schauble, Glaser, Raghavan, \& Reiner, 1992), genetics (Echevarria, 2003), earthquakes (Azmitia \& Crowley, 2001), flooding risk (Keselman, 2003), human memory (Schunn \& Anderson, 1999), and visual search (Métrailler, Reijnen, Kneser, \& Opwis, 2008). Non-traditional science domains have also been used to develop inquiry skills. Examples include factors that affect TV enjoyment (Kuhn et al., 1995), CD catalog sales (Dean \& Kuhn, 2007), athletic performance (Lazonder, Wilhelm, \& Van Lieburg, 2009), and shoe store sales (Lazonder, Hagemans, \& de Jong, 2010).

Computer simulations allow visualization of phenomena that are not directly observable in the classroom (e.g., atomic structure, planetary motion). Other advantages include that they are less prone to measurement error in apparatus set up, and that they can be programmed to record all actions taken (and their latencies). Moreover, many systems include a scaffolded method for participants to keep and consult records and notes. Importantly, there is evidence that simulated environments provide the same advantages as isomorphic "hands on" apparatus (Klahr, Triona, \& Williams, 2007; Triona \& Klahr, 2007).

New lines of research are taking advantage of advances in computing and intelligent computer systems. Kuhn (2011b) recently examined how to facilitate reasoning about multivariable causality, and the problems associated with the visualization of outcomes resulting from multiple causes (e.g., the causes for different cancer rates by geographical area). Participants had access to software that produces a visual display of data points that represent main effects and their interactions. Similarly, Klahr and colleagues (Siler, Mowery, Magaro, Willows, \& Klahr, 2010) have developed an intelligent tutor to teach experimentation 
strategies (see Figure 1, panel C). The use of intelligent tutors provides the unique opportunity of personally tailored learning and feedback experiences, dependent on each student's pattern of errors. This immediate feedback can be particularly useful in helping develop metacognitive skills (e.g., Roll, Alaven, McLaren, \& Koedinger, 2011) and facilitate effective student collaboration (Diziol, Walker, Rummel, \& Koedinger, 2010).

Tweney, Doherty, and Mynatt (1981) noted some time ago that most tasks used to study scientific thinking were artificial because real investigations require aided cognition. However, as can be seen by several exemplars, even lab studies include support and assistance for many of the known cognitive limitations faced by both children and adults.

\section{Summary and conclusions}

Determining the developmental trajectory of scientific reasoning has been challenging, in part because scientific reasoning is not a unitary construct. Our goal was to outline how the investigation, evidence evaluation, and inference skills that constitute scientific reasoning emerge from intuitive information seeking via the interaction of individual and contextual factors. We describe the importance of (a) cognitive processes and mechanisms, (b) metacognitive and metastrategic skills, (c) the role of direct and scaffolded instruction, and (d) a context in which scientific activity is supported and which includes cultural tools (literacy, numeracy, technology) that facilitate the emergence of scientific reasoning. At the outset, we intended to keep section boundaries clean and neat. What was apparent to us, and may now be apparent to the reader, is that these elements are highly intertwined. It was difficult to discuss pure encoding in early childhood without noting the role that parents play. Likewise, it was difficult to discuss individual discovery of strategies, without noting such discovery takes place in the presence of peers, parents, and teachers. Similarly, discussing the teaching and learning of strategies is difficult without noting the role of cultural tools such as language, number, and symbol systems.

There is far more to a complete account of scientific reasoning than has been discussed here, including other cognitive mechanisms such as formal hypothesis testing, retrieval, and other reasoning processes. There are also relevant non-cognitive factors such as motivation, disposition, personality, argumentation skills, and personal epistemology, to name a few (see Feist, 2006). These additional considerations do not detract from our assertion that encoding and strategy use are critical to the development of scientific reasoning, and that we must consider cognitive and metacognitive skills within a social and physical context when seeking to understand the development of scientific reasoning. Scientific knowledge acquisition and, importantly, scientific knowledge change is the result of individual and social cognition that is mediated by education and cultural tools. The cultural institution of science has taken hundreds of years to develop. As individuals, we may start out with the curiosity and disposition to be little scientists, but it is a long journey from information seeking to skilled scientific reasoning, with the help of many scaffolds along the way. 


\section{Author details}

Bradley J. Morris

Kent State University, USA

Steve Croker and Corinne Zimmerman

Illinois State University, USA

Amy M. Masnick

Hofstra University, USA

\section{Acknowledgements}

All authors contributed equally to the manuscript. The authors thank Eric Amsel, Deanna Kuhn, and Jamie Jirout for comments on a previous version of this chapter.

\section{References}

Alfieri, L., Brooks, P. J., Aldrich, N. J., \& Tenenbaum, H. R. (2011). Does discovery-based instruction enhance learning?. Journal Of Educational Psychology, 103, 1-18.

Amsel, E., Goodman, G., Savoie, D., \& Clark, M. (1996). The development of reasoning about causal and noncausal influences on levers. Child Development, 67, 1624-1646.

Amsel, E., Klaczynski, P. A., Johnston, A., Bench, S., Close, J., Sadler, E., \& Walker, R. (2008). A dual-process account of the development of scientific reasoning: The nature and development of metacognitive intercession skills. Cognitive Development, 23, 452-471.

Azmitia, M. \& Crowley, K. (2001). The rhythms of scientific thinking: A study of collaboration in an earthquake microworld. In K. Crowley, C.D., Schunn, \& T. Okada (Eds). Designing for science: Implications from everyday, classroom, and professional settings (pp. 51-81). Mahwah, NJ: Lawrence Erlbaum.

Becker, S. I. (2010). The role of target-distractor relationships in guiding attention and the eyes in visual search. Journal of Experimental Psychology: General, 139, 247-265.

Bonawitz, E., Shafto, P., Gweon, H., Goodman, N. D., Spelke, E., \& Schulz, L. (2011). The double-edged sword of pedagogy: Instruction limits spontaneous exploration and discovery. Cognition, 120, 322-330.

Brownell, C. A., \& Carriger, M. S. (1991). Collaborations among toddler peers: Individual contributions in social contexts. In L. B. Resnick, J. M. Levine, \& S. D. Teasley (Eds.), Perspectives on socially shared cognition (pp. 365-383). Washington, D. C.: American Psychological Association.

Burlea, C., Vidala, F., Tandonneta, C., \& Hasbroucq, T. (2004). Physiological evidence for response inhibition in choice reaction time tasks. Brain and Cognition, 56, 153-64.

Butler, L., \& Markman, E. (2012a). Finding the cause: Verbal framing helps children extract causal evidence embedded in a complex scene. Journal of Cognition and Development, 13, 38-66. 
Butler, L., \& Markman, E. (2012b). Preschoolers use intentional and pedagogical cues to guide inductive inferences and exploration. Child Development, 83, 1416-1428.

Carey, S., Evans, R., Honda, M., Jay, E., \& Unger, C. (1989). “An experiment is when you try it and see if it works": A study of grade 7 students' understanding of the construction of scientific knowledge. International Journal of Science Education, 11, 514-529.

Chen, Z. (2007). Learning to map: Strategy discovery and strategy change in young children. Developmental Psychology, 43, 386-403.

Chen, Z., \& Klahr, D. (1999). All other things being equal: Acquisition and transfer of the Control of Variables Strategy. Child Development, 70, 1098-1120.

Chi, M. (2009). Active-Constructive-Interactive: A conceptual framework for differentiating learning activities. Topics in Cognitive Science, 1, 73-105.

Chinn, C. A., \& Malhotra, B. A. (2002). Children's responses to anomalous scientific data: How is conceptual change impeded? Journal of Educational Psychology, 94, 327-343.

Croker, S. (2012). The development of cognition. Andover, UK: Cengage.

Croker, S., \& Buchanan, H. (2011). Scientific reasoning in a real world context: The effect of prior belief and outcome on children's hypothesis testing strategies. British Journal of Developmental Psychology, 29, 409-424.

Dean, D., \& Kuhn, D. (2007). Direct instruction vs. discovery: The long view. Science Education, 91, 384-397.

Dejonckheere, P. N., Van De Keere, K., \& Mestdagh, N. (2009). Training the scientific thinking circle in pre- and primary school children. The Journal of Educational Research, 103, 1-16.

Dejonckheere, P., Van de Keere, K., \& Tallir, I. (2011). Are fourth and fifth grade children better scientists through metacognitive learning?. Electronic Journal of Research in Educational Psychology, 9, 133-156.

Diziol, D., Walker, E., Rummel, N., \& Koedinger, K. R. (2010). Using intelligent tutor technology to implement adaptive support for student collaboration. Educational Psychology Review, 22, 89-102.

Dunbar, K., \& Klahr, D. (1989). Developmental differences in scientific discovery processes. In D. Klahr \& K. Kotovsky (Eds.), Complex information processing: The impact of Herbert A. Simon (pp. 109-143). Hillsdale, NJ: Lawrence Erlbaum Associates.

Echevarria, M. (2003). Anomalies as a catalyst for middle school students' knowledge construction and scientific reasoning during science inquiry. Journal of Educational Psychology, 95, 357-374.

Feist, G. J. (2006). The psychology of science and the origins of the scientific mind. New Haven, CT: Yale University Press.

Fender, J. G., \& Crowley, K. (2007). How parent explanation changes what children learn from everyday scientific thinking. Journal Of Applied Developmental Psychology, 28, 189210.

Freund, L. S. (1990). Maternal Regulation of Children's Problem-solving Behavior and Its Impact on Children's Performance. Child Development, 61, 113-126. 
Garcia-Mila, M., \& Andersen, C. (2007). Developmental change in notetaking during scientific inquiry. International Journal of Science Education, 29, 1035-58.

Gauvain, M. (2001). The social context of cognitive development. New York: Guilford.

Genter, D., Loewenstein, J., \& Thompson, L. (2003). Learning and transfer: A general role for analogical encoding. Journal of Educational Psychology, 95, 393-408.

Gleason, M. E., \& Schauble, L. (2000). Parents' assistance of their children's scientific reasoning. Cognition and Instruction, 17, 343-378.

Gobet, F. (2005). Chunking models of expertise: Implications for education. Applied Cognitive Psychology, 19, 183-204.

Gopnik, A., Glymour, C., Sobel, D. M., Schulz, L. E., Kushnir, T., \& Danks, D. (2004). A theory of causal learning in children: Causal maps and Bayes nets. Psychological Review, 111, 3-32.

Gopnik, A., Sobel, D. M., Schulz, L. E., \& Glymour, C. (2001). Causal learning mechanisms in very young children: Two-, three-, and four-year-olds infer causal relations from patterns of variation and covariation. Developmental Psychology, 37, 620-629.

Goswami, U. (2008). Cognitive development: The learning brain. Hove, UK: Psychology Press.

Hmelo-Silver, C. E., Duncan, R., \& Chinn, C. A. (2007). Scaffolding and achievement in problem-based and inquiry learning: A response to Kirschner, Sweller, and Clark (2006). Educational Psychologist, 42, 99-107.

Jaswal, V. K., \& Dodson, C. S. (2009). Metamemory development: Understanding the role of similarity in false memories. Child Development, 80, 629-635.

Jirout, J., \& Klahr, D. (2012). Children's scientific curiosity: In search of an operational definition of an elusive concept. Developmental Review, 32, 125-160.

Justice, E.M. (1986). Developmental changes in judgments of relative strategy effectiveness. British Journal of Developmental Psychology, 4, 75-81.

Kanari, Z., \& Millar, R. (2004). Reasoning from data: How students collect and interpret data in science investigations. Journal of Research in Science Teaching, 41, 748-769.

Keselman, A. (2003). Supporting inquiry learning by promoting normative understanding of multivariable causality. Journal of Research in Science Teaching, 40, 898-921.

Kirschner, P. A., Sweller, J., \& Clark, R. E. (2006). Why minimal guidance during instruction does not work: An analysis of the failure of constructivist, discovery, problem-based, experiential, and inquiry-based teaching. Educational Psychologist, 41(2), 75-86.

Klahr, D. (1984). Transition processes in quantitative development. In R. Sternberg (Ed.), Mechanisms of cognitive development. San Francisco, CA: W. H. Freeman.

Klahr, D. (2000). Exploring science: The cognition and development of discovery processes. Cambridge, MA: MIT Press.

Klahr, D. (2010) Coming up for air: But is it oxygen or phlogiston? A response to Taber's review of Constructivist Instruction: Success or Failure? Education Review, 13(13), 1-6.. http://www.edrev.info/essays/v13n13.pdf

Klahr, D., \& Carver, S. M. (1995). Scientific thinking about scientific thinking. Monographs of the Society for Research in Child Development, 60(4), 137-151. 
Klahr, D., Fay, A., \& Dunbar, K. (1993). Heuristics for scientific experimentation: A developmental study. Cognitive Psychology, 25, 111-146.

Klahr, D., \& Nigam, M. (2004). The equivalence of learning paths in early science instruction. Psychological Science, 15, 661 - 667.

Klahr, D., Triona, L.M., \& Williams, C. (2007). Hands on what? The relative effectiveness of physical versus virtual materials in an engineering design project by middle school children. Journal of Research in Science Teaching, 44, 183-203.

Kloos, H., \& Van Orden, G. C. (2005). Can a preschooler's mistaken belief benefit learning? Swiss Journal of Psychology, 64, 195-205.

Koenig, M. A., Clément, F., \& Harris, P. L. (2004). Trust in testimony: Children's use of true and false statements. Psychological Science, 10, 694-698.

Koerber, S., Sodian, B., Thoermer, C., \& Nett, U. (2005). Scientific reasoning in young children: Preschoolers' ability to evaluate covariation evidence. Swiss Journal of Psychology, 64, 141-152.

Kreutzer, M., Leonard, C., \& Flavell, J. H. (1975). An interview study of children's knowledge about memory. Monographs of the Society for Research in Child Development, 40 (1, Serial No. 159).

Kuhn, D. (1989). Children and adults as intuitive scientists. Psychological Review, 96, 674-689.

Kuhn, D. (2005). Education for thinking. Cambridge, MA: Harvard University Press.

Kuhn, D. (2011a). What is scientific thinking and how does it develop? In U. Goswami (Ed.), Handbook of childhood cognitive development (2 ${ }^{\text {nd }}$ ed., pp. 497-523). Oxford, UK: WileyBlackwell.

Kuhn, D. (2011b, June). The universal and the particular in scientific reasoning. Plenary talk presented at the $41^{\text {st }}$ Annual Meeting of the Jean Piaget Society. Berkeley, CA.

Kuhn, D., Amsel, E., \& O'Loughlin, M. (1988). The development of scientific thinking skills. Orlando, FL: Academic Press.

Kuhn, D., Black, J., Keselman, A., \& Kaplan, D. (2000). The development of cognitive skills to support inquiry learning. Cognition and Instruction, 18, 495-523.

Kuhn, D., \& Dean, D. R. (2005). Is developing scientific thinking all about learning to control variables?. Psychological Science, 16, 866-870.

Kuhn, D., Garcia-Mila, M., Zohar, A., \& Andersen, C. (1995). Strategies of knowledge acquisition. Monographs of the Society for Research in Child Development, 60(4), 1-128.

Kuhn, D., \& Ho, V. (1980). Self-directed activity and cognitive development. Journal of Applied Developmental Psychology, 1, 119-130.

Kuhn, D., \& Phelps, E. (1982). The development of problem-solving strategies. In H. Reese (Ed.), Advances in child development and behavior (pp. 2-44). New York: Academic.

Lazonder, A. W., Hagemans, M. G., \& de Jong, T. (2010). Offering and discovering domain information in simulation-based inquiry learning. Learning and Instruction, 20, 511-520.

Lazonder, A. W., Wilhelm, P., \& Van Lieburg, E. (2009). Unraveling the influence of domain knowledge during simulation-based inquiry learning. Instructional Science, 37, 437-451. 
Lemke, J. L. (2001). Articulating Communities: Sociocultural perspectives on science education. Journal of Research in Science Teaching, 38, 296-316.

Li, J. \& Klahr, D. (2006). The psychology of scientific thinking: Implications for science teaching and learning. In J. Rhoton, \& P. Shane (Eds.), Teaching science in the $21_{\text {st }}$ century. National Science Teachers Association and National Science Education Leadership Association: NSTA Press.

Lorch, R. Jr., Lorch, E. P., Calderhead, W. J., Dunlap, E. E., Hodell, E. C., \& Freer, B. (2010). Learning the control of variables strategy in higher and lower achieving classrooms: Contributions of explicit instruction and experimentation. Journal of Educational Psychology, 102, 90-101. doi:10.1037/a0017972

Masnick, A. M., \& Klahr, D. (2003). Error matters: An initial exploration of elementary school children's understanding of experimental error. Journal of Cognition and Development, 4, 67-98.

Masnick, A. M., \& Morris, B. J. (2008). Investigating the development of data evaluation: The role of data characteristics. Child Development, 79, 1032-1048.

Mayer, R. E. (2004). Should there be a three-strikes rule against pure discovery learning?. American Psychologist, 59, 14-19.

Metrailler, Y. A., Reijnen, E., Kneser, C., \& Opwis, K. (2008). Scientific problem solving in a virtual laboratory: A comparison between individuals and pairs. Swiss Journal of Psychology, 67, 71-83.

Middleton, D. (1997). The social organization of conversational remembering: Experience as individual and collective concerns. Mind, Culture, and Activity, 4, 71-85.

Nelson, K. (1996). Language in cognitive development. Cambridge, UK: Cambridge University Press.

Newcombe, N. S., \& Huttenlocher, J. (2000). Making space: The development of spatial representation and reasoning. Cambridge, MA: MIT Press.

Palinscar, A. S., Brown, A., \& Campione, J. C. (1993). First-grade dialogs for knowledge acquisition and use. In E. A. Foreman, N. Minick, \& C. A. Stone (Eds.), Contexts for learning: Sociocultural dynamics in children's development (pp. 43-57). New York: Oxford University Press.

Pine, K. J., \& Messer, D. J. (1998). Group collaboration effects and the explicitness of children's knowledge. Cognitive Development, 13, 109-126.

Roll, I., Aleven, V., McLaren, B. M., \& Koedinger, K. R. (2011). Improving students' helpseeking skills using metacognitive feedback in an intelligent tutoring system. Learning and Instruction, 21, 267-280.

Ruffman, T., Perner, J., Olson, D. R., \& Doherty, M. (1993). Reflecting on scientific thinking: Children's understanding of the hypothesis-evidence relation. Child Development, 64, 1617-1636.

Sandoval, W. A. (2005). Understanding students' practical epistemologies and their influence on learning through inquiry. Science Education, 89, 634-656. doi:10.1002/sce.20065 
Saxe, G. B., Guberman, S. R., \& Gearhart, M. (1987). Social processes in early number development. Monographs of the Society for Research in Child Development, 52(2).

Schauble, L. (1990). Belief revision in children: The role of prior knowledge and strategies for generating evidence. Journal of Experimental Child Psychology, 49, 31-57.

Schauble, L. (1996). The development of scientific reasoning in knowledge-rich contexts. Developmental Psychology, 32, 102-119.

Schauble, L., Glaser, R., Raghavan, K., \& Reiner, M. (1991). Causal models and experimentation strategies in scientific reasoning. The Journal of the Learning Sciences, 1 , 201-238.

Schmidt, H. G., Loyens, S. M., van Gog, T., \& Paas, F. (2007). Problem-based learning is compatible with human cognitive architecture: Commentary on Kirschner, Sweller, and Clark (2006). Educational Psychologist, 42, 91-97.

Schneider, W. (1986). The role of conceptual knowledge and metamemory in the development of organizational processes in memory. Journal of Experimental Child Psychology, 42, 218-236.

Schneider, W. (2008), The development of metacognitive knowledge in children and adolescents: Major trends and implications for education. Mind, Brain, and Education, 2, 114-121.

Schneider, W., Visé, M., Lockl, K., \& Nelson, T. O. (2000). Developmental trends in children's memory monitoring: Evidence from a judgment-of-learning task. Cognitive Development, 15, 115-134.

Schulz, L., \& Bonawitz, E. B. (2007) Serious fun: Preschoolers play more when evidence is confounded. Developmental Psychology, 43, 1045-1050.

Schulz, L. E., \& Gopnik, A. (2004). Causal learning across domains. Developmental Psychology, 40, 162-176.

Schulz, L. E., Gopnik, A., \& Glymour, C. (2007). Preschool children learn about causal structure from conditional interventions. Developmental Science, 10, 322-332.

Schunn, C. D., \& Anderson, J. R. (1999). The generality/specificity of expertise in scientific reasoning. Cognitive Science, 23, 337-370.

Schunn, C. D., \& Dunbar, K. (1996). Priming, analogy, and awareness in complex reasoning. Memory \& Cognition, 24, 271-284.

Shaklee, H., Holt, P., Elek, S., \& Hall, L. (1988). Covariation judgment: Improving rule use among children, adolescents, and adults. Child Development, 59, 755-768.

Siegler, R. S. (1983). How knowledge influences learning: What children already know about scientific and mathematical concepts influences how they acquire additional information. American Scientist, 71, 631-638.

Siegler, R. S. (1985). Encoding and the development of problem solving. In S. F. Chipman, J. W. Segal, and R. Glaser (Eds.), Thinking and learning skills (pp. 161-185). Hillsdale, NJ: Lawrence Erlbaum Associates.

Siegler, R. S. (1989). Mechanisms of cognitive development. Annual Review of Psychology, 40, 353-379. 
Siegler, R. S. (1996). Emerging minds: The process of change in children's thinking. New York: Oxford University Press.

Siegler, R. S., \& Liebert, R. M. (1975). Acquisition of formal scientific reasoning by 10- and 13-year-olds: Designing a factorial experiment. Developmental Psychology, 11, 401-402.

Siler, S. \& Klahr, D. (2012). Detecting, classifying and remediating children's explicit and implicit misconceptions about experimental design. In Proctor, R. W., \& Capaldi, E. J. (Eds.), Psychology of Science: Implicit and Explicit Processes (pp. 137-180). New York: Oxford University Press.

Siler, S. A., Mowery, D., Magaro, C., Willows, K., \& Klahr, D. (2010, June). Comparison of a computer-based to a hands-on lesson in experimental design. Poster presented at the Tenth International Conference on Intelligent Tutoring Systems, Pittsburgh, PA.

Sodian, B. \& Bullock, M. (2008). Scientific reasoning - where are we now? [Special issue]. Cognitive Development, 23(4).

Sodian, B., \& Wimmer, H. (1987). Children's understanding of inference as a source of knowledge. Child Development, 58, 424-433.

Sodian, B., Zaitchik, D., \& Carey, S. (1991). Young children's differentiation of hypothetical beliefs from evidence. Child Development, 62, 753-766.

Strand-Cary, M., \& Klahr, D. (2008). Developing elementary science skills: Instructional effectiveness and path independence. Cognitive Development, 23, 488-511. doi:10.1016/j.cogdev.2008.09.005

Teasley, S. D. (1995). The role of talk in children's peer collaboration. Developmental Psychology, 31, 207-220.

Tenenbaum, H. R., Rappolt-Schlichtmann, G., \& Zanger, V. (2004). Children's learning about water in a museum and in the classroom. Early Childhood Research Quarterly, 19, 40-58.

Tschirgi, J. E. (1980). Sensible reasoning: A hypothesis about hypotheses. Child Development, 51, 1-10.

Trafton J. G., \& Trickett, S. B. (2001). Note-taking for self-explanation and problem solving. Human-Computer Interaction, 16, 1-38.

Triona, L. M. \& Klahr, D. (2003). Point and click or grab and heft: Comparing the influence of physical and virtual instructional materials on elementary school students' ability to design experiments. Cognition and Instruction, 21, 149-173.

Triona, L.M., \& Klahr, D. (2007). Hands-on science: Does it matter what students' hands are on? The Science Education Review, 6, 126-130.

Tweney, R. D., Doherty, M. E., \& Mynatt, C. R. (Eds.). (1981). On scientific thinking. New York: Columbia Univ. Press.

Veermans, K., van Joolingen, W., \& de Jong, T. (2006). Use of heuristics to facilitate scientific discovery learning in a simulation learning environment in a physics domain. International Journal of Science Eduction, 28, 341-361.

Vosniadou, S., Skopeliti, I., \& Ikospentaki, K. (2005) Reconsidering the role of artifacts in reasoning: Children's understanding of the globe as a model of the earth. Learning and Instruction, 15, 333-351. 
Wellman, H. M., Cross, D., \& Watson, J. (2001). Meta-analysis of theory-of-mind development: The truth about false belief. Child Development, 72, 655-684.

Zimmerman, C. (2007). The development of scientific thinking skills in elementary and middle school. Developmental Review, 27, 172-223.

Zimmerman, C., \& Croker, S. (in press). Learning science through inquiry. To appear in G. Feist \& M. Gorman (Eds.), Handbook of the Psychology of Science. Springer Publishing.

Zimmerman, C., Raghavan, K., \& Sartoris, M. L. (2003). The impact of the MARS curriculum on students' ability to coordinate theory and evidence. International Journal of Science Education, 25, 1247-1271.

Zohar, A., \& Peled, B. (2008). The effects of explicit teaching of metastrategic knowledge on low- and high-achieving students. Learning and Instruction, 18, 337-353. 


\title{
Cognition and the Child Witness: Understanding the Impact of Cognitive Development in Forensic Contexts
}

\author{
Daisy A. Segovia and Angela M. Crossman \\ Additional information is available at the end of the chapter
}

http://dx.doi.org/10.5772/53938

\section{Introduction}

Children's normal cognitive development allows them to thrive and succeed in a wide variety of contexts, particularly those well suited to their emerging abilities. However, there are domains in which children are forced to participate that are not necessarily well adapted to their developing cognitive skills and abilities. One of these is the legal system. Designed to operate with adults in mind, children are often poorly equipped to cope with its demands and rigors (Malloy, Mitchell, Block, Quas, \& Goodman, 2007), and their performance in these contexts is often evaluated in ways that might under- or overestimate their contributions (Bottoms, Golding, Stevenson, Wiley, \& Yozwiak, 2007). Hence, examining children's cognitive abilities in forensic contexts can be an important means of helping calibrate the usefulness of their contributions.

While the nature of children's participation in the legal system varies, child witnesses must have certain basic cognitive abilities, such as the capacity to perceive, recall and communicate appropriate, relevant information clearly and accurately to provide evidence in legal contexts (Federal Rules of Evidence 601, 602). They must be able to understand and respond to questions effectively, without succumbing to suggestion or interviewer influence, and they must be able to do so credibly, or their evidence might be disregarded, dismissed or otherwise disbelieved (Leippe \& Romanczyk, 1989; Ruva \& Bryant, 2004). Thus, beyond the cognitive capacity to perceive, recall and report on past events, child witness credibility is an important factor in the extent and type of impact a child witness might have in a given case.

While there are numerous influences on perceptions of child witness credibility, it is likely that their cognitive development impacts both their actual accuracy and perceptions of their 
accuracy and credibility. Yet, this impact likely varies as a function of case content. That is, cognitive maturity might be an important consideration in weighing a child's custody preferences, but be considered less relevant for an alleged sexual abuse victim, for whom perceived trustworthiness is more critical (Crossman, Powell, Principe, \& Ceci, 2002; Duggan, Aubrey, Doherty, Isquith, Levine \& Scheiner, 1989). To understand the role and impact of child witnesses in the legal system, it is thus important to consider what aspects of cognitive development, if any, are related to child witness accuracy and credibility.

In the current chapter, cognitive development is explored as it pertains to children in different forensic contexts. First, aspects of memory development are considered in terms of how they likely impact child witness perception and reporting of events, in addition to factors that might influence witness memory, such as trauma. Then, additional factors related to child witness strengths and vulnerabilities are considered, including intelligence, source monitoring abilities, and suggestibility. Finally, the interplay between case content and cognitive development is explored for its impact on child witness effectiveness. While the central focus of this chapter is on children as victims/witnesses, children also interact in the justice system as suspects and perpetrators. One of the central concerns in those cases is with lie-telling, which is addressed elsewhere in this volume, but here we consider issues such as juvenile confessions in relation to their cognitive development.

\section{The developing cognitive abilities of the child witness}

There is no one "child witness" and the variety of forensic contexts in which children participate makes it difficult to define uniform aspects of cognitive development that are relevant to all child witnesses. Nevertheless, various aspects of cognitive development have been heavily examined for their importance to child witness accuracy and credibility, as detailed below.

\subsection{Memory development - Witnessing an event}

Most critical for child witnesses is memory development. Although the ability to create memories seems to be present at least from birth, lasting autobiographical memories that a child can report of an experienced event are rare until approximately 3 years of age (Fivush, 1994, 1997; Jack, Simcock, \& Hayne, 2012), likely facilitated and organized by language development (Simcock \& Hayne, 2002). Nevertheless, once developed, children's memories can be highly accurate. In terms of eyewitness identifications, child witnesses can be as accurate in identifying a culprit as adult witnesses (Humphries, Holliday, \& Flowe, 2012; Pozzulo \& Lindsay, 1998).

Generally speaking, to be effective witnesses, children must be able to communicate facts of a forensic nature about which they are knowledgeable because they directly perceived and remember them. Thus, a child's ability to properly encode an event in memory is paramount. Effective encoding can be influenced by attention and prior knowledge, while memory retention might be affected by memory strength, script knowledge, and memory storage capacity. 
Attention. One does not necessarily encode into one's memory information that did not receive attention. This is relevant to child witnesses, as children often do not attend to the same aspects of an event as adults (Johnson \& Foley, 1984; Mandler, 1990; Yarmey, 1979). This could be protective for children, as recent findings using the Deese-RoedigerMcDermott paradigm (DRM) suggest. The DRM paradigm asks participants to recall lists of semantically related words (e.g., slumber, dream, tired, snooze) from which a critical lure word is missing (e.g., sleep). The procedure tests for false memory of the lure words. Otgaar, Peters and Howe (2012) found that children presented with a divided attention task were less likely to have false memories in the DRM paradigm, while adults with divided attention were more likely to have false memories. In both groups, however, true memories were not impacted by the attention manipulation. Also, while adults and children might focus on different aspects of a perpetrator's appearance, they nevertheless both seem to be vulnerable to weapon focus effects (Davies, Smith, \& Blincoe, 2008). That is, adults and children may focus on a weapon (or other object inconsistent with their expectations) to the detriment of their recall of other aspects of an event that captured less attention (Davies et al., 2008; Pickel, Narter, Jameson, \& Lenhardt, 2008).

Prior knowledge. Children's knowledge, which grows with age, impacts the accuracy of their event memory as well. It influences what they attend to, how they understand and interpret events and what they encode into memory (Principe, Ornstein, Baker-Ward, \& Gordon, 2000). For example, a child expert in a domain (e.g., chess) can outperform an adult in recalling locations of chess pieces on a chess board (Chi, 1978), and prior expert knowledge can overwhelm the effect of general intellectual aptitude on story recall (Schneider, Bjorklund, \& Maier-Brückner, 1996).

On the other hand, children begin to develop awareness of culturally-based stereotypes during the preschool years (e.g., obesity, mental illness, sex, race; Corrigan \& Watson, 2007), and these stereotypes can lead children to selectively encode or inaccurately reconstruct their memories to be in line with their stereotypes (Bigler \& Liben, 1993; Klaczynski, 2008; Martin \& Halverson, 1983). This suggests that child witness memory accuracy could be undermined by children's stereotypes (Leichtman \& Ceci, 1995a, b). Overall, then, knowledge can enrich and deepen a child's event recall and understanding, but also undermine their accuracy.

Memory strength and scripts. Once encoded, strength of a memory likely influences a child's ability to recall that memory. That is, events that are highly salient or meaningful to a child, or events that are repeated, might be associated with a stronger memory trace. This can protect the memory over time from degradation or other influences, such as suggestion (Christianson, 1992; Hamann, 2001; Holliday, Douglas, \& Hayes, 1999; Howe, 1997; Pezdek \& Roe, 1995). With sufficient replication, children can develop scripts, or generalized event representations abstracted from repeated instances of an event. For example, a child might develop a script for 'going out to eat' that involves multiple actors (e.g., host/hostess; waiter/waitress) and a particular set of ordered events (e.g., order beverages; read menu; order; eat; pay bill). The same abstraction can occur for abuse events (Roberts \& Powell, 2001). 
Children become more efficient in their ability to abstract event scripts with age. Farrar and Goodman (1992) showed that 4-year-olds did not seem to develop an event script following three repetitions of an event, while 7-year-olds did. More generally, children increasingly connect meaning across different exemplars of a target with age (e.g., apple juice, lemonade, and orange juice are all sweet drinks; Brainerd, Reyna, \& Ceci, 2008). Thus, in some cases, younger children might not yet have the elaborate scripts that older children have developed. This can insulate them from making erroneous assumptions or interpretations about events (Brainerd et al., 2008; Lindberg, 1991; Pickel et al., 2008).

However, despite their efficiency, event scripts can interfere with recall of specific, individual instances of an event, such as abuse (Powell \& Thomson, 1996). This could be problematic for a testifying child witness asked to describe and differentiate between multiple abuse incidents - perhaps because the defense is seeking to present alibi evidence. If the incidents were so similar that they became script-like for the child, it could be extremely difficult for the child to differentiate the events or to identify a unique incident at a specific date and time (Roberts \& Powell, 2001), potentially undermining their credibility.

Memory storage. Children's memory capacity grows with age (Gathercole, Pickering, Ambridge, \& Wearing 2004), such that they become increasingly able to recall larger amounts of information over time. For child witnesses, this can become visible when they are asked to provide free recall reports in response to open-ended questions, such as "What happened?". Younger children tend to provide very little event detail when asked such questions. Nevertheless, even young children are capable of accurately recalling and reporting their experiences from memory (Goodman, 2006).

An important moderator of children's ability to store memories is the amount of time between encoding and retrieval. With longer delays, child witnesses have greater difficulty providing complete and accurate memory reports, particularly younger children, as their memory traces seem to decay more rapidly than older children or adults (Brainerd \& Rayna, 1995). However, offering children an opportunity to recall an event after a short delay might help to inoculate their reports and maintain them over time (Peterson, Pardy, TizzardDrover, \& Warren, 2005), particularly when the event context is reinstated during the interview (La Rooy, Pipe, \& Murray, 2007). This suggests that the development of children's memory storage facilitates better witness reports with age. It also suggests that there are means of helping even young children to overcome some of their memory shortcomings.

\subsection{Memory development - Reporting an event}

Having witnessed an event (e.g., a crime), the child witness's next responsibility is to report the relevant facts, as observed. A child's memory report accuracy is therefore dependent on his or her memory retrieval ability and communication/linguistic skills.

Memory retrieval. When asked to retrieve a memory (i.e., reconstruct the event from memory storage), children become increasingly able to structure that information into narrative form with age (Lamb et al., 2003). Younger children must often rely on adult 
assistance, in the form of questions, to provide a narrative account of an event. Older children, on the other hand, are increasingly able to provide a structured, coherent narrative description of their experiences in response to simpler prompts, such as "What happened?". Thus, interviewers (and parents) frequently ask questions that are more supportive, or "leading", with younger children, in part to provide the narrative structure children need to produce a coherent event account (e.g., Dent \& Stephenson, 1979; Hudson, 2006; Poole \& Lindsay, 1998).

However, researchers consistently find that the least directive questions (e.g., free recall) tend to elicit the most accurate information and have the lowest risk of eliciting false information from children. They also elicit less information overall from children (Bjorklund et al., 2000; Poole \& Lindsay, 1995). Interview strategies have thus been designed that attempt to provide additional structure and cues to children to maximize the amount of accurate event recall, while minimizing false recall. Techniques include contextreinstatement (La Rooy et al., 2007) and full interviewing protocols such as the Cognitive Interview (Fisher \& Schreiber, 2007) and the NICHD Protocol (Lamb, Orbach, Hershkowitz, Esplin, \& Horowitz, 2007). These practices seem to facilitate child witnesses' attempts to reconstruct events from memory.

Communication and linguistic ability. A child who cannot communicate effectively in the justice system may lack credibility, leading perhaps to future victimization or to conviction, in the case of a juvenile defendant. Most child victims, for instance, must be able to disclose abuse in order for the abuser to be stopped or prosecuted. However, it seems clear from the number of adults who never reported childhood abuse that this remains a problem for many children (Bottoms, Rudnicki, \& Epstein, 2007; London, Bruck, Wright, \& Ceci, 2008). Yet, when abuse is suspected, the interview strategies noted above can help children to disclose (Pipe et al., 2007).

Some child witnesses must testify in court, subsequent to a disclosure. This can be traumatic, particularly if it must be repeated (Quas et al., 2005). In many cases, children must first undergo a competency evaluation. These typically attempt to assess their understanding of truths and lies, which emerges in the preschool years and becomes more nuanced with age (Talwar \& Crossman, 2012). However, it is likely that competency evaluations underestimate children's understanding of truth/lie concepts and are not likely to be related to a child witness' actual truth-telling (Talwar \& Crossman, 2012), raising questions about their usefulness.

When they testify, children are immersed in the linguistically foreign legal system, for which they are often not developmentally prepared (Walker, 1993). They may face the challenge of deciphering legal jargon, as well as linguistically complex questions that they are ill equipped to answer (as are many adults; Carter, Bottoms, \& Levine, 1996; Perry et al., 1995). However, this might not undermine children's credibility, as one study of trial transcripts found that complex questions asked by defense attorneys predicted convictions, rather than acquittals in those cases (Evans, Lee, \& Lyon, 2009). Nevertheless, children also may be required to offer testimony on concepts that are developmentally beyond their 
reach. For instance, caution is warranted when asking young children to locate in time or enumerate past events (e.g., age, month, or season; which occurrence, $1^{\text {st }}, 2^{\text {nd }}$, etc.; Friedman, Reese, \& Dai, 2011), particularly maltreated children (Wandrey, Lyon, Quas, \& Friedman, 2012), as they may struggle to do so accurately until adolescence.

Another challenge for all witnesses is cross-examination. Unfortunately, research examining children's performance under cross-examination suggests that they risk losing credibility, despite their cognitive ability to provide accurate information. This is because they often change answers in response to cross-examination - both their correct and their incorrect direct examination answers (Zajac \& Hayne, 2003; Zajac, Jury, \& O'Neill, 2009). In fact, preschoolers, older children and adults are vulnerable to the deleterious impact of crossexamination (Zajac \& Hayne, 2006; Zajac \& Cannan, 2009) - highlighting the fact that social pressures can undermine accurate memory reporting. Providing support persons for child witnesses and preparation for legal participation are procedures meant to alleviate some of the stresses of testifying for children and seem to offer some benefits (Malloy et al., 2007). Nevertheless, it is clear that the justice system demands a significant degree of communicative and linguistic competency from child witnesses, some of which is beyond their capacities.

\subsection{Memory and trauma}

Memory and stress. The nature of memory for traumatic events has been debated for decades. Early research supported the notion that memory for traumatic events was different than memory for neutral or positive events. The high emotionality and salience of traumatic events were thought to create "flashbulb memories"-memories that were embedded in one's mind like a "photographic imprint" (Conway, Anderson, Steer, \& Donnely, 1994; Winograd \& Killinger, 1983). These memories were thought to be highly accurate and fixed due to the overstimulation of the event, which led to over consolidation of memory (McGaugh, 1990; Pitman, 1989). However, more recent research supports the view that memory for traumatic events, like other events, is subject to alteration, is malleable, and is not necessarily completely accurate (Engelhard, van der Hout, \& McNally, 2008; Southwick, Morgan, Nicolau, \& Charney, 1997). The effect of traumatic experiences on memory is of great importance in the legal system because it could alter the accuracy and effectiveness of a child's eyewitness testimony.

Many crimes are highly stressful in nature and witnessing or being involved in a crime can be psychologically traumatic, particularly for a child. Findings from studies investigating the impact of stressful events on memory have been largely mixed. On the one hand, research has shown that highly stressful situations can adversely affect one's memory. For example, Quesada and others (2012) examined the effect of stress on 8- to 11-year-olds' memory performance. Children were randomly assigned to a stressful or non-stressful condition and then asked to play a memory game. Children who were exposed to stress performed worse, making more errors in retrieval. These decrements in memory performance may result because cognitive resources otherwise used to encode and store 
details of the events are focused on coping or self-regulation (Vandermass, Hess, \& BakerWard, 1993) or because cortisol levels produced by stress can affect the hippocampus, which affects memory retrieval (Quesada et al., 2012).

On the other hand, stress from emotionally salient experiences could lead eyewitnesses to have a stronger memory for a target event (Goodman, Hirschman, Hepps, \& Rudy, 1991; Pezdek \& Taylor, 2002; Shrimpton, Oates, \& Hayes, 1998). Some researchers argue that the stressful nature of traumatic events renders them more personally meaningful and distinctive, which may lead to higher levels of cognitive activation directed toward encoding significant details of the event (Christianson, 1992; Hamann, 2001; Howe, 1997). Indeed, Ochsner, Zaragoza, and Mitchell (1999) found that children who witnessed a staged theft were more accurate on recall and recognition measures compared to children who viewed a similar but neutral event.

Finally, it is possible that stress is related to memory in a curvilinear fashion, with low levels of stress not eliciting enough attention to encode details of an event, but too much stress causing decrements in memory performance. Bahrick, Parker, Fivush and Levitt (1998) found that children exposed to moderate amounts of hurricane damage to their homes recalled more than those with minimal or extensive damage (i.e., low or high stress). However, follow-up interviews showed that the effect did not seem to persist over time (Fivush, Sales, Goldberg, Bahrick, \& Parker, 2004).

Overall, studies investigating children's memory for stressful events have shown that younger children tend to recall less information and make more mistakes (e.g., Goodman, Quas, Batterman-Faunce, \& Riddlesberger, 1994; Goodman, Quas, Batterman-Faunce, Riddlesberger, \& Kuhn, 1997), but individual cognitive factors that affect memory have rarely been examined. However, there may be some cognitive factors that can predict children's memory performance for stressful experiences. For example, Alexander and her colleagues (2002) interviewed 51 children between the ages of 3 and 7 years, two weeks after they received inoculation shots at the doctor's office-an experience that can be very stressful for children. They found that children with better cognitive inhibition ability were less likely to provide incorrect details in free-recall and were less likely to make omission errors when asked misleading questions (e.g., "The nurse didn't give you a shot, did she?") than children with lower cognitive inhibition, controlling for age. Cognitive inhibition, briefly, is the ability to process information while impeding other irrelevant or distracting information or stimuli (Harnishfeger \& Bjorklund, 1994; Lorsbach \& Reimer, 1997). Alexander and her colleagues reasoned that children with better inhibitory skills were better able to prevent distractions from impeding encoding during the inoculation, thus allowing for better memory of the event. Further, they also argued that their superior inhibitory skills allowed them to suppress suggestive thoughts, allowing them to better resist suggestive questions. More research needs to be conducted to further probe these results and to explore what other cognitive processes affect memory for stressful events.

Memory and maltreatment. Examining the effect of stress on memory is important to the legal arena, but it is particularly important to investigate if these findings generalize to 
children who face recurrent stressful experiences, such as children who are victims of abuse. Maltreated children may come into contact with the legal system frequently, especially if the abuse has been substantiated and if they are required to testify. Maltreated children may differ from children who only experience traumatic or stressful events once, in that the constant exposure to stress may affect how maltreated children encode and retrieve information. Some research has yielded evidence for developmental delays in maltreated children, especially those who have been physically abused or neglected (see Veltman \& Browne, 2001 for a review). Maltreated children have been shown to perform at levels one or two years behind nonabused peers in areas such as intelligence, language, short-term memory, and executive function (Alessandri 1991; Carrick, Quas, \& Lyon, 2010; Cicchetti, Rogosch, Maughan, Toth, \& Bruce, 2003; Trickett \& McBride-Chang, 1995). These delays can be problematic when obtaining a memory report from a maltreated child because they can affect a child's ability to adequately understand and respond to questions (e.g., Eigsti \& Cicchetti, 2004; Zajac \& Hayne; 2003).

On the other hand, a child's constant exposure to traumatic events might help his or her memory. The constant stress may lead a child to adopt processing strategies that make him or her hyper-vigilant to stressful stimuli, thereby encoding that information better than nonstressful stimuli (McNally, Metzger, Lasko, Clancy, \& Pitman, 1998). A maltreated child may also have extensive knowledge of trauma-related information, which could support better memory (Goodman, Quas, \& Ogle, 2010). However, there is evidence to suggest that this hyper-vigilance is generally associated with emotion-regulating strategies (McNally, Kaspi, Riemann, \& Zeitlin, 1990; Williams \& Broadbent, 1986), rather than cognitive factors.

Overall, despite the findings of developmental delays among maltreated children, research has shown that maltreated children can be as accurate in their memory reports as their nonabused counterparts (Goodman et al., 2010; Howe, 1997; Howe, Toth, \& Cicchetti, 2011). For example, Eisen and others (2002) examined 189 3- to 17-year-olds who were allegedly maltreated. These children were questioned about an anogenital examination they received as part of their child maltreatment investigations. Results mimicked those found by studies examining nonabused children: younger children made more errors and reported fewer details than older children. Importantly, the children with prior histories of abuse performed on par with children with no prior history of abuse. Thus, child maltreatment does not necessarily deprive children of their ability to provide accurate event reports, nor does it seem to alter the predictors of memory accuracy (Eisen et al., 2002, 2007).

\section{Vulnerability to error and influence}

Beyond memory issues, additional factors can influence the accuracy of children's memory reports - and their vulnerability to influence. These include children's intelligence, mental health, source monitoring ability, suggestibility and the use of suggestive interview aids.

Intelligence and mental health. For child witnesses, intelligence is most relevant to memory accuracy and resistance to suggestion. That is, individuals with higher IQ scores tend to 
have better memory skills and to provide more detailed recall when reporting an event (Gudjonsson \& Henry, 2003; Zhu et al., 2010). Although a legal professional might not need to take into account the intelligence of typically developing (TD) children, it is important to be aware that children who suffer from learning and other intellectual disabilities (ID) may be more vulnerable in forensic contexts (Henry \& Gudjonsson, 2007). Indeed, the rate at which children's memory performance improves across age may be slower for ID children than for TD children, with mental age a better predictor of eyewitness memory performance than IQ measures (Henry \& Gudjonsson, 2007). Thus, children with ID are at risk of being less accurate and more suggestible in their event reporting than are TD children.

These effects may be exacerbated among children who are in the justice system as defendants. ID is overrepresented among juvenile delinquents (Najdowski, Bottoms, \& Vargas, 2009), as is mental illness (Redlich, 2007), both of which increase adolescent vulnerability to interrogative pressure, which is already heightened among youths (Redlich, 2007; Richardson, Gudjonsson, \& Kelly, 1995). Indeed, research demonstrates that children and adolescents (particularly ID and mentally ill juveniles) are at greater risk for falsely confessing transgressions that they did not commit (Najdowski et al., 2009; Redlich, 2007). Given these findings, it is vital that intellectual ability and mental health be taken into account when considering child and adolescent witness and defendant statements.

Source monitoring. Children's memory reports can also become inaccurate due to faulty source monitoring, which is the process of determining the origin (or source) of their knowledge, memories and/or beliefs (Johnson, Hashtroudi, \& Lindsay, 1993). Child witnesses, like any other witnesses, might be asked to provide specific details about criminal events, such as when a crime happened, who committed it, where it happened, and distinguish whether it was a perpetrator's actions or someone else's that they are recalling. Unfortunately, pre- and post-event information from outside sources can influence one's memory, thus making it difficult to distinguish between real event details and suggested details (Poole \& Lindsay, 2002; Roberts \& Blades, 1999; Thierry, Spence, \& Memon, 2001). The source of one's misinformation can vary from television, to word-of-mouth, to intentional suggestion, to name a few. But regardless of the source, the concern is the same that a child exposed to incorrect information following an event will fail to identify the true source of the novel information and provide inaccurate testimony as a result. Indeed, there is clear developmental growth in the ability to recall source information, identified at the neural level (Sprondel, Kipp, \& Mecklinger, 2011). Hence, researchers have begun to explore what factors might influence source monitoring.

There are several factors that can influence the likelihood of committing source monitoring errors for children. These include the similarity of events, delays in recall, suggestive interviewing, and agent identity (i.e., whether the event was about oneself, a friend, or an unfamiliar person; Roberts, 2002). When pre- or post-event information is similar to the target information, it is more likely that children will make source monitoring errors (Johnson et al., 1993; Lindsay, Johnson, \& Kwon, 1991). Indeed, although children with stronger source monitoring abilities seem better able to resist post-event suggestions, 
particularly when encouraged to identify the source of the suggestions, they are less able to do so when those suggestions are consistent with their event schema (Roberts \& Powell, 2006). When information that is similar in nature is encoded, there are few cognitive cues to help to distinguish the sources (Day, Howie, \& Markham, 1998; Roberts \& Blades, 1999). This can be important in instances where children experience multiple similar incidents, such as in the case of prolonged child abuse. Unfortunately, in forensic contexts such as court, children may be asked to distinguish between these multiple incidents or identify multiple perpetrators.

On the other hand, children tend to make fewer source monitoring errors when the target information regards the self rather than others (Baker-Ward, Hess, \& Flannagan, 1990; Roberts \& Blades, 1998). In other words, they are better able to accurately report on events that happened to themselves than on events they witnessed other people experiencing. For example, Roberts and Blades (1998) found that 6- and 9-year-olds were more accurate and made fewer source monitoring errors answering questions about activities they had performed versus those they observed, while 4-year-olds showed the reverse relation. Further, children remember better actions performed by a familiar person compared to an unfamiliar person (Baker-Ward et al., 1990). Some have posited that this is due to the cognitive processes that are elicited when encoding familiar (self and peer) information (Baker-Ward et al., 1990; Foley et al., 1989). Specifically, children in these situations are using cognitive processing that requires them to use more cognitive effort-they are anticipating what must be done, anticipating the action's consequence, and reflecting on the cognitive processes that were required to perform that action (Ratner, Foley, \& Gimpert, 2000). Children can then use records of these cognitive processes as cues to discriminate between sources (Roberts, 2002).

All of these factors are relevant when considering child witnesses and techniques for interviewing them. For example, misleading or suggestive interview questions that are script-consistent and plausible are more readily accepted by child witnesses and are more likely to elicit source monitoring errors (Pezdek, Fingers, \& Hodge, 1997). Additionally, the nature of the inquiry can impact the accuracy of the report. For instance, Roberts and Blades (1995) found that younger children were more accurate in their source identifications when asked to report information nonverbally compared to verbally. Moreover, children committed fewer source monitoring errors during free recall than when answering specific questions (Roberts \& Blades, 1998, 1999), reinforcing the importance of free recall when interviewing child witnesses. To date, however, explicit training in source monitoring appears to be beneficial for older (i.e., 7- to 8-year-old), but not for younger (3- to 6-year-old) child witnesses (Poole \& Lindsay, 2002).

Suggestibility. Another potential source of children's errors in forensic contexts is via suggestibility. Suggestibility has been defined as the ease with which a person is persuaded and influenced, and the degree to which one accepts and changes one's own judgments, opinions, or patterns of behavior without critical response (Drukteinis, 2001). In a forensic context, this is usually exhibited by changes in memory reports due to suggestive 
questioning by an interviewer. For example, a question such as, "Was the man's jacket red or blue?" is suggestive because it implies that the man was wearing a jacket (he may or may not have been). Children may have difficulty accurately answering suggestive questions because they may not have the cognitive or social skills to identify that they do not know the answer and do not have to choose an answer.

Studies to date indicate that individual difference variables may be more likely to influence the degree to which people are suggestible than situational factors (Gudjonsson, 1994). Indeed there are several traits that might make an individual more susceptible to suggestive questioning (Bain, Baxter, \& Ballantyne, 2007; Singh \& Gudjonsson, 1992), such as age. Both adults and children are susceptible to suggestive questioning, but younger children tend to be especially vulnerable to suggestive interview techniques (Ceci \& Bruck, 1993, 1995; Chae, Goodman, Eisen, \& Qin, 2011; Eisen et al., 2002). These age differences can usually be explained by differences in cognitive development between older and younger children. In fact, when age is controlled, children with better cognitive functioning are overall less suggestible and produce fewer memory errors due to suggestive questioning (Chae et al., 2011; Karpinski \& Scullin, 2009). Moreover, as noted above, children with intellectual disabilities are highly susceptible to suggestive questioning (Henry \& Gudjonsson, 1999, 2003, 2004, 2007).

Findings for other potential cognitive predictors of suggestibility have been mixed (see Bruck \& Melnyk, 2004 for a review). However, research has shown that children with advanced language skills, better memory test performance, (Clark-Stewart et al., 2004; Danielsdottir, Sigurgeirsdottir, Einarsdottir, \& Haraldsson, 1993; Henry \& Gudjonsson, 2003), better event accuracy (Marche, 1999; Marche \& Howe, 1995; Pezdek \& Roe, 1995), and/or more creativity (Brown, 1999; Clarke-Stewart et al., 2004) are often less suggestible than other children.

Concerns about children's suggestibility are common in legal cases, especially in instances where the child's memory report is key evidence. In fact, in child sexual abuse cases, the child's accusation may be the only evidence available to the court. It is thus important to consider interviewing techniques and the potential for suggestion when evaluating child witnesses' memory reports.

Interview aids. A special case of suggestibility might be said to arise through the use of some interview aids, such as anatomically detailed dolls. First used clinically as a means of communicating nonverbally about children's emotional issues, forensic interviewers began to use anatomically detailed dolls to assist children in reporting difficult or embarrassing events (i.e., sexual abuse; Poole, Bruck, \& Pipe, 2011). Unfortunately, the dolls seemed to be inherently suggestive, leading some children to demonstrate genital or anal cavity insertions on the dolls that did not occur (Bruck, Ceci, \& Francoeur, 2000). Thus, researchers and policy groups have concluded that children's interactions with such dolls are not diagnostic of abuse, they should not be used to elicit abuse reports, their use is particularly problematic for children under age 5, and they do not appear to facilitate or enhance children's reporting even when used after verbal reports have been provided (Poole et al., 2011). 
Part of the reason for the dolls' ineffectiveness with very young children could be children's immature representational abilities (DeLoache, 2000). That is, young children may have difficulty perceiving the doll as a representation or symbol of themselves and acting on it as such. They might also have difficulty ignoring the dolls' salient, play-like qualities and unique features to use it as a symbol instead (DeLoache, 2000; Poole et al., 2011).

More recent efforts have focused on the use of body diagrams - pictures - to assist children in reporting abuse allegations. Although pictures seem less challenging for children to use as symbols, concern remains about their suggestiveness (Poole et al., 2011). Specifically, as with dolls, use of the diagrams seems to increase false reports of bodily touch, even among school-aged children (Poole \& Dickinson, 2011). Further, their use seems to lead interviewers away from recommended, open-ended questioning styles toward more leading, specific questions (Aldridge et al., 2004; Poole et al., 2011). Finally, their use does not seem to enhance children's disclosures or lead to greater elaboration of their reports (Bruck, 2009). Thus, these symbolic interview aids seem to be suggestive, particularly for young children who might not be capable of using them symbolically, and their forensic use is discouraged (Poole et al., 2011).

\section{Conclusions}

In this chapter, we reviewed aspects of cognitive development that are most relevant to child witnesses and, to some extent, child suspects in the criminal and juvenile justice systems. The findings above highlight the areas of concern with any witness - but particularly child witnesses. Yet, their implications are not uniform. In fact, the implications of children's cognitive development in forensic situations are likely to vary as a function of a variety of factors, including the type of witness and case involved, as a child's credibility may be dependent on assessments of their trustworthiness and competence. Children who are perceived as lacking competence for a variety of reasons are likely to be considered lacking in credibility. However, this effect is likely more pronounced in some types of cases than in others. Cases requiring strong memory for detailed information that was experienced only once might demand a higher expectation for cognitive ability than a case of child neglect by a well-known caregiver. Similarly, a child's trustworthiness is likely impacted by the type of case, with some arguing that in child sexual abuse cases, honesty is more salient than cognitive abilities - and that perceived suggestibility likely impacts perceptions of the child's honesty in such cases (Connolly et al., 2010). The type of child witness is important as well. Children with intellectual disabilities might be more vulnerable to suggestion as witnesses. Children who are defendants in the juvenile justice system are at higher risk of suffering from both cognitive deficits and mental illness, making them particularly susceptible to suggestion and false confession. At the same time, one's identity as a defendant likely raises more questions about trustworthiness than when one is a child witness.

Despite many of the risks for child witnesses, however, and the poor fit between children's cognitive development and the justice system, it is clear that children are capable of 
participating accurately and effectively as witnesses. They often partake in family court decision-making, provide evidence in eyewitness identification cases, and testify against their assailants in child abuse cases. There is a great deal still to be learned about important cognitive factors, such as whether there are means of improving younger children's source monitoring skills, how to improve children's eyewitness identification accuracy when the perpetrator is not present in a lineup, and how to help children resist misleading questions and suggestions. More needs to be learned about the impact of emotion on children's eyewitness memory and recall as well. Perhaps the growing research on the neural correlates of children's memory will further our understanding and allow for greater forensic sensitivity to child witness strengths and vulnerabilities. These and other results, it is hoped, will contribute to more effective interviewing, testimony and treatment of child witnesses.

\section{Author details}

Daisy A. Segovia and Angela M. Crossman

John Jay College and the Graduate Center, Cuny, USA

\section{References}

Aldridge, J., Lamb, M. E., Sternberg, K. J., Orbach, Y., Esplin, P. W., \& Bowler, L. (2004). Using a human figure drawing to elicit information from alleged victims of child sexual abuse. Consulting and Clinical Psychology, 72, 304-316.

Alessandri, S. M. (1991). Play and social behavior in maltreated preschoolers. Development and Psychopathology, 3, 191-205.

Alexander, K., Goodman, G. S., Schaaf, J. M., Edelstein, R. S., Quas, J. A., \& Shaver, P. R. (2002). The role of attachment and cognitive inhibition in children's memory and suggestibility for a stressful event. Journal of Experimental Child Psychology, 83(4), 262290. doi:10.1016/S0022-0965(02)00149-2

Bahrick, L. E., Parker, J., Fivush, R., \& Levitt, M. (1998). The effects of stress on young children's memory for a natural disaster. Journal of Experimental Psychology: Applied, 4(4), 308-331.

Bain, S. A., Baxter, J. S., \& Ballantyne, K. (2007). Self-monitoring style and levels of interrogative suggestibility. Personality and Individual Differences, 42, 623-630.

Baker-Ward, L., Hess, T. M., \& Flannagan, D. A. (1990). The effects of involvement on children's memory for events. Cognitive Development, 5(1), 55-69. doi:10.1016/08852014(90)90012-I

Bigler, R. S., \& Liben, L. S. (1993). A cognitive-developmental approach to racial stereotyping and reconstructive memory in Euro-American children. Child Development, 64, 1507-1518. doi: 10.2307/1131549

Bjorklund, D. F., Cassel, W. S., Bjorklund, B. R., Brown, R. D., Park, C. L., Ernst, K., et al. (2000). Social demand characteristics in children's and adults' eyewitness memory and suggestibility: The effect of different interviewers on free recall and recognition. Applied 
Cognitive Psychology, 14, 421-433. doi: 10.1002/1099-0720(200009)14:5<421::AIDACP659>3.0.CO;2-4

Bottoms, B. L., Golding, J. M., Stevenson, M. C., Wiley, T. R. A., \& Yozwiak, J. A. (2007). A review of factors affecting jurors' decisions in child sexual abuse cases. In J. D. Read, D. Ross, M.Toglia, \& R. Lindsay (Eds.), The psychology of eyewitness memory (pp. 509-543). Mahwah, NJ: Erlbaum.

Bottoms, B. L., Rudnicki, A. G., \& Epstein, M. A. (2007). A retrospective study of factors affecting the disclosure of childhood sexual and physical abuse. In M.-E. Pipe, M. E. Lamb, Y. Orbach, \& A.-C. Cederborg (Eds.), Child sexual abuse: Disclosure, delay, and denial (pp. 175-194). Mahwah, NJ: Erlbaum.

Brainerd, C. J., \& Reyna, V. F. (1995). Learning rate, learning opportunities, and the development of forgetting. Developmental Psychology, 31, 251-262. doi: 10.1037/00121649.31.2.251

Brainerd, C. J., Reyna, V. F., \& Ceci, S. J. (2008). Developmental reversals in false memory: A review of data and theory. Psychological Bulletin, 134, 343-382. doi: 10.1037/00332909.134.3.343

Brown, R. D. (1999). Event type and individual differences in children's false-memory creation. Unpublished doctoral dissertation, Florida Atlantic University, Boca Raton, Florida.

Bruck, M. (2009). Human figure drawings and children's recall of touching. Journal of Experimental Psychology: Applied, 15, 361-374.

Bruck, M., Ceci, S. J., \& Francoeur, E. (2000). Children's use of anatomically detailed dolls to report genital touching in a medical examination: Developmental and gender comparisons. Journal of Experimental Psychology: Applied, 6, 74-83.

Bruck, M., \& Melnyk, L. (2004). Individual differences in children's suggestibility: A review and synthesis. Applied Cognitive Psychology, 18(8), 947-996. doi:10.1002/acp.1070

Carter, C. A., Bottoms, B. L., \& Levine, M. (1996). Linguistic and socioemotional influences on the accuracy of children's reports. Law and Human Behavior, 20, 335-358.

Carrick, N., Quas, J. A., \& Lyon, T. (2010). Maltreated and nonmaltreated children's evaluations of emotional fantasy. Child Abuse $\mathcal{E}$ Neglect, 34(2), 129-134. doi:10.1016/j. chiabu.2009.02.009

Ceci, S. J., \& Bruck, M. (1993). Suggestibility of the child witness: A historical review and synthesis. Psychological Bulletin, 113, 403-439.)

Ceci, S. J., \& Bruck, M. (1995). Jeopardy in the courtroom: A scientific analysis of children's testimony. Washington, DC: American Psychological Association.

Chae, Y., Goodman, G. S., Eisen, M. L., \& Qin, J. (2011). Event memory and suggestibility in abused and neglected children: Trauma-related psychopathology and cognitive functioning. Journal of Experimental Child Psychology, 110(4), 520-538. doi:10.1016/j.jecp.2011.05.006

Chi, M. T. H. (1978). Knowledge structures and memory development. In R. S. Siegler (Ed.), Children's thinking: What develops? Hillsdale, NJ: Erlbaum.

Christianson, S. (1992). Emotional stress and eyewitness memory: A critical review. Psychological Bulletin, 112(2), 284-309. doi:10.1037/0033-2909.112.2.284 
Cicchetti, D., Rogosch, F. A., Maughan, A., Toth, S. L., \& Bruce, J. (2003). False belief understanding in maltreated children. Development and Psychopathology, 15(4), 10671091. doi:10.1017/S0954579403000440

Conway, M. A., Anderson, S. J., Larsen, S. F., \& Donnelly, C. M. (1994). The formation of flashbulb memories. Memory \& Cognition, 22(3), 326-343.

Clarke-Stewart, K. A., Malloy, L. C., \& Allhusen, V. D. (2004). Verbal ability, self-control, and close relationships with parents protect children against misleading suggestions. Applied Cognitive Psychology, 18, 1037-1058.

Connolly, D. A., Price, H. L., \& Gordon, H. M. (2010). Judicial decision making in timely and delayed prosecutions of child sexual abuse in Canada: A study of honesty and cognitive ability in assessments of credibility. Psychology, Public Policy, and Law, 16, 177-199.

Corrigan, P. W., \& Watson, A. C. (2007). How children stigmatize people with mental illness. International Journal of Social Psychiatry, 53(6), 526-546.

Crossman, A. M., Powell, M. B., Principe, G. F., \& Ceci, S. J. (2002). Child testimony in custody cases: A review. Journal of Forensic Psychology Practice, 2(1), 1-31.

Danielsdottir, G., Sigurgeirsdottir, S., Einarsdottir, H. R., \& Haraldsson, E. (1993). Interrogative suggestibility in children and its relationship with memory and vocabulary. Personality and Individual Differences, 14, 499-502.

Davies, G. M., Smith, S., \& Blincoe, C. (2008). A 'weapon focus' effect in children. Psychology, Crime \& Law, 14(1), 19-28. doi:10.1080/10683160701340593

Day, K., Howie, P., \& Markham, R. (1998). The role of similarity in developmental differences in source monitoring. British Journal of Developmental Psychology, 16(2), 219232. doi:10.1111/j.2044-835X.1998.tb00920.x

DeLoache, J. S. (2000). Dual representation and young children's use of scale models. Child Development, 71, 329-338. doi: 10.1111/1467-8624.00148

Dent, H. R., \& Stephenson, G. M. (1979). An experimental study of the effectiveness of different techniques of questioning child witnesses. British Journal of Social and Clinical Psychology, 18, 41-51.

Drukteinis, A. M. (2001). The role of suggestibility in mental damage claims. American Journal of Clinical Psychiatry \& Law, 26, 15-35.

Duggan, L. M., Aubrey, M., Doherty, E., Isquith, P., Levine, M., \& Scheiner, J. (1989). The credibility of children as witnesses in a simulated sexual abuse trial. In S. J. Ceci, D. F. Ross, \& M. P. Toglia (Eds.)., Perspectives on children's testimony (pp. 71-99). New York: Springer-Verlag).

Eigsti, I., \& Cicchetti, D. (2004). The impact of child maltreatment on expressive syntax at 60 months. Developmental Science, 7(1), 88-102. doi:10.1111/j.1467-7687.2004.00325.x

Eisen, M. L., Goodman, G. S., Qin, J., Davis, S., \& Crayton, J. (2007). Maltreated children's memory: accuracy, suggestibility, and psychopathology. Developmental Psychology, 43, 1275-94.

Eisen, M. L., Qin, J., Goodman, G. S., \& Davis, S. L. (2002). Memory and suggestibility in maltreated children: Age, stress arousal, dissociation, and psychopathology. Journal of Experimental Child Psychology, 83(3), 167-212. doi:10.1016/S0022-0965(02)00126-1 
Engelhard, I. M., van den Hout, M. A., \& McNally, R. J. (2008). Memory consistency for traumatic events in Dutch soldiers deployed to Iraq. Memory, 16, 3-9.

Evans, A. D., Lee, K., \& Lyon, T. D. (2009). Complex questions asked by defense lawyers but not prosecutors predicts convictions in child abuse trials. Law and Human Behavior, 33, 258-264.

Farrar, M. J., \& Goodman, G. S. (1992). Developmental changes in event memory. Child Development, 63, 173-187. doi: 10.2307/1130911

Fed. R. Evid. 601.

Fed. R. Evid. 602.

Fisher, R. P., \& Schreiber, N. (2007). Interview protocols for improving eyewitness memory. In M. P. Toglia, J. D. Read, D. F. Ross, \& R. C. L. Lindsay (Eds.), The handbook of eyewitness psychology, Vol. 1: Memory for events (pp. 53-80). Mahwah, NJ: Erlbaum.

Fivush, R. (1994). Young childrens event recall: Are memories constructed through discourse. Consciousness and Cognition, 3, 356-373.

Fivush, R. (1997). Event memory in early childhood. In N. Cowan (Ed.), The development of memory in childhood (pp. 139-161). Hove, England: Psychology Press.

Fivush, R., Sales, J. M., Goldberg, A., Bahrick, L., \& Parker, J. (2004). Weathering the storm: Children's long-term recall of Hurricane Andrew. Memory, 12(1), 104-118.

Foley, M. A., Santini, C., \& Sopasakis, M. (1989). Discriminating between memories: Evidence for children's spontaneous elaborations. Journal of Experimental Child Psychology, 48(1), 146-169. doi:10.1016/0022-0965(89)90045-3

Friedman, W. J., Reese, E., \& Dai, J. (2011). Children's memory for the times of events from the past years. Applied Cognitive Psychology, 25, 156-165. doi: 10.1002/acp.1656

Gathercole, S. E., Pickering, S. J., Ambridge, B., \& Wearing, H. (2004). The structure of working memory from 4 to 15 years of age. Developmental Psychology, 40(2), 177-190. doi:10.1037/0012-1649.40.2.177

Goodman, G. S. (2006). Children's eyewitness memory: A modern history and contemporary commentary. Journal of Social Issues, 62, 811-832. doi:10.1111/j.1540-4560.2006.00488.x

Goodman, G. S., Hirschman, J. E., Hepps, D., \& Rudy, L. (1991). Children's memory for stressful events. Merrill-Palmer Quarterly: Journal of Developmental Psychology, 37(1), 109157.

Goodman, G. S., Quas, J. A., Batterman-Faunce, J. M., \& Riddlesberger, M. M. (1994). Predictors of accurate and inaccurate memories of traumatic events experienced in childhood. Consciousness and Cognition: An International Journal,3(3-4), 269-294. doi:10.1006/ccog.1994.1016

Goodman, G. S., Quas, J. A., Batterman-Faunce, J. M., Riddlesberger, M. M., \& Kuhn, J. (1997). Children's reactions to and memory for a stressful event: Influences of age, anatomical dolls, knowledge, and parental attachment. Applied Developmental Science, 1(2), 54-75. doi:10.1207/s1532480xads0102_1

Goodman, G. S., Quas, J. A., \& Ogle, C. M. (2010). Child maltreatment and memory. Annual Review of Psychology, 61, 325-351. doi:10.1146/annurev.psych.093008.100403 
Gudjonsson, G. H. (1994). Interrogative suggestibility: Does the setting where the subjects are tested make a difference to the scores on the GSS 1 and GSS 2? Personality $\mathcal{E}$ Individual Differences, 18, 789-790.

Gudjonsson, G. H., \& Henry L. (2003). Child and adult witnesses with intellectual disability: The importance of suggestibility. Legal and Criminological Psychology, 8(2), 241-252.

Hamann, S. (2001). Cognitive and neural mechanisms of emotional memory. Trends in Cognitive Sciences, 5(9), 394-400. doi:10.1016/S1364-6613(00)01707-1

Harnishfeger, K., \& Bjorklund, D. F. (1994). A developmental perspective on individual differences in inhibition. Learning and Individual Differences, 6(3), 331-355. doi:10.1016/1041-6080(94)90021-3

Henry, L. A., \& Gudjonsson, G. H. (1999). Eyewitness memory and suggestibility in children with mental retardation. American Journal on Mental Retardation, 104(6), 491-508. doi:10.1352/0895-8017(1999)104<0491:EMASIC>2.0.CO;2

Henry, L. A., \& Gudjonsson, G. H. (2003). Eyewitness memory, suggestibility, and repeated recall sessions in children with mild and moderate intellectual disabilities. Law and Human Behavior, 27(5), 481-505. doi:10.1023/A:1025434022699

Henry, L. A., \& Gudjonsson, G. H. (2004). The effects of memory trace strength on eyewitness recall in children with and without intellectual disabilities. Journal of Experimental Child Psychology, 89(1), 53-71. doi:10.1016/j.jecp.2004.05.002

Henry, L. A., \& Gudjonsson, G. H. (2007). Individual and developmental differences in eyewitness recall and suggestibility in children with intellectual disabilities. Applied Cognitive Psychology, 21, 361-381.

Holliday, R. E., Douglas, K., \& Hayes, B. K. (1999). Children's eyewitness suggestibility: Memory trace strength revisited. Cognitive Development, 14(3), 443-462. doi: 10.1016/S0885-2014(99)00014-3

Howe, M. L. (1997). Children's memory for traumatic experiences. Learning and Individual Differences, 9(2), 153-174. doi:10.1016/S1041-6080(97)90004-2

Howe, M. L., Toth, S. L., \& Cicchetti, D. (2011). Can maltreated children inhibit true and false memories for emotional information? Child Development, 82(3), 967-981. doi:10.1111/j.1467-8624.2011.01585.x

Hudson, J. A. (2006). The development of future time concepts through mother-child conversation. Merrill-Palmer Quarterly: Journal of Developmental Psychology, 52(1), 70-95. doi: 10.1353/mpq.2006.0005

Humphries, J. E., Holliday, R. E., \& Flowe, H. D. (2012). Faces in motion: Age-related changes in eyewitness identification performance in simultaneous, sequential, and elimination video lineups. Applied Cognitive Psychology, 26(1), 149-158. doi:10.1002/acp.1808

Jack, F., Simcock, G., \& Hayne, H. (2012). Magic memories: Young children's verbal recall after a 6-year delay. Child Development, 83, 159-172. doi: 10.1111/j.1467-8624.2011.01699.x

Johnson, M. K., \& Foley, M. A. (1984). Differentiating fact from fantasy: The reliability of children's memory. Journal of Social Issues, 40(2), 33-50.

Johnson, M. K., Hashtroudi, S., \& Lindsay, S. D. (1993). Source monitoring. Psychological Bulletin, 114, 3-28. 
Karpinski, A. C., \& Scullin, M. H. (2009). Suggestibility under pressure: Theory of mind, executive function, and suggestibility in preschoolers. Journal of Applied Developmental Psychology, 30(6), 749-763. doi:10.1016/j.appdev.2009.05.004

Klaczynski, P. A. (2008). There's something about obesity: Culture, contagion, rationality, and children's responses to drinks 'created' by obese children. Journal of Experimental Child Psychology, 99, 58-74. doi: 10.1016/j.jecp.2007.08.005

Lamb, M. E., Orbach, Y., Hershkowitz, I., Esplin, P. W., \& Horowitz, D. (2007). A structured forensic interview protocol improves the quality and informativeness of investigative interviews with children: A review of research using the NICHD Investigative Interview Protocol. Child Abuse \& Neglect, 31(11-12), 1201-1231.

Lamb, M. E., Sternberg, K. J., Orbach, Y., Esplin, P. W., Stewart, H., \& Mitchell, S. (2003). Age differences in young children's responses to open-ended invitations in the course of forensic interviews. Journal of Consulting and Clinical Psychology, 71(5), 926-934. doi:10.1037/0022-006X.71.5.926

La Rooy, D., Pipe, M.-E., \& Murray, J. E. (2007). Enhancing children's event recall after long delays. Applied Cognitive Psychology, 21, 1-17. doi: 10.1002/acp.1272

Leichtman, M. D., \& Ceci, S. J. (1995a). The effects of stereotypes and suggestions on preschoolers' reports. Developmental Psychology, 31, 568-578. doi:10.1037/00121649.31.4.568

Leichtman, M. D., \& Ceci, S. J. (1995b). The effects of stereotypes and suggestions on preschoolers' reports: Correction. Developmental Psychology, 31, 758. doi:10.1037/00121649.31.5.758

Leippe, M. R., \& Romanczyk, A. (1989). Reactions to child (versus adult) eyewitnesses: The influence of jurors' preconceptions and witness behavior. Law and Human Behavior, 13, 103-132.

Lindberg, M. (1991). An interactive approach to assessing the suggestibility and testimony of eyewitnesses. In J. Doris (Ed.), The suggestibility of children's recollections (pp. 47-55). Washington, DC US: American Psychological Association. doi:10.1037/10097-004

Lindsay, D., Johnson, M. K., \& Kwon, P. (1991). Developmental changes in memory source monitoring. Journal of Experimental Child Psychology, 52(3), 297-318. doi:10.1016/00220965(91)90065-Z

London, K., Bruck, M., Wright, D., \& Ceci, S. J. (2008). Review of the contemporary literature on how children report sexual abuse to others: Findings, methodological issues, and implications for forensic interviewers. Memory, 16, 29-47. doi:10.1080/09658210701725732.

Lorsbach, T. C., \& Reimer, J. F. (1997). Developmental changes in the inhibition of previously relevant information. Journal of Experimental Child Psychology, 64(3), 317-342. doi:10.1006/jecp.1996.2350

Malloy, L. C., Mitchell, E., Block, S., Quas, J. A., \& Goodman, G. S. (2007). Children's eyewitness memory: Balancing children's needs and defendants' rights when seeking the truth. In M. P. Toglia, J. D. Read, D. F. Ross, \& R. C. L. Lindsay (Eds.), The handbook of eyewitness psychology, Vol 1: Memory for events (pp. 545-574). Mahwah, NJ: Erlbaum. 
Mandler, J. M. (1990). Recall and its verbal expression. In R. Fivush \& J. A. Hudson (Eds.), Knowing and remembering in young children (pp. 317-330). New York: Cambridge University Press.

Marche, T. A. (1999). Memory strength affects reporting of misinformation. Journal of Experimental Child Psychology, 73, 45-71.

Marche, T. A., \& Howe, M. L. (1995). Preschoolers report misinformation despite accurate memory. Developmental Psychology, 31, 554-567.

Martin, C. L., \& Halverson, C. F. (1983). The effects of sex-typing schemas on young children's memory. Child Development, 54, 563-574. doi: 10.2307/1130043

McGaugh, J. L. (1990). Significance and remembrance: The role of neuromodulatory systems. Psychological Science, 1(1), 15-25. doi:10.1111/j.1467-9280.1990.tb00060.x

McNally, R. J., Kaspi, S. P., Riemann, B. C., \& Zeitlin, S. B. (1990). Selective processing of threat cues in posttraumatic stress disorder. Journal of Abnormal Psychology, 99(4), 398402. doi:10.1037/0021-843X.99.4.398

McNally, R. J., Metzger, L. J., Lasko, N. B., Clancy, S. A., \& Pitman, R. K. (1998). Directed forgetting of trauma cues in adult survivors of childhood sexual abuse with and without posttraumatic stress disorder. Journal of Abnormal Psychology, 107(4), 596-601. doi:10.1037/0021-843X.107.4.596

Najdowski, C. J., Bottoms, B. L., \& Vargas, M. C. (2009). Jurors' perceptions of juvenile defendants: The influence of intellectual disability, abuse history, and confession evidence. Behavioral Sciences \& the Law, 27, 401-430.

Ochsner, J. E., Zaragoza, M. S., \& Mitchell, K. J. (1999). The accuracy and suggestibility of children's memory for neutral and criminal eyewitness events. Legal and Criminological Psychology, 4(Part 1), 79-92. doi:10.1348/135532599167806

Otgaar, H., Peters, M., \& Howe, M. L. (2012). Dividing attention lowers children's but increases adults' false memories. Journal of Experimental Psychology: Learning, Memory, and Cognition, 38, 204-210. doi: 10.1037/a0025160

Perry, N. W., McAuliff, B. D., Tam, P., Claycomb, L., Dostal, C., \& Flanagan, C. (1995). When lawyers question children: Is justice served? Law and Human Behavior, 19, 609-629.

Peterson, C., Pardy, L., Tizzard-Drover, T., \& Warren, K. L. (2005). When initial interviews are delayed a year: Effect on children's 2-year recall. Law and Human Behavior, 29, 527541. doi: 10.1007/s10979-005-6833-6

Pezdek, K., Finger, K., \& Hodge, D. (1997). Planting false childhood memories: The role of event plausibility. Psychological Science, 8(6), 437-441. doi:10.1111/j.14679280.1997.tb00457.x

Pezdek, K., \& Roe, C. (1995). The effect of memory trace strength on suggestibility. Journal of Experimental Child Psychology, 60, 116-128.

Pezdek, K., \& Taylor, J. (2002). Memory for traumatic events in children and adults. In M. L. Eisen, J. A. Quas, \& G. S. Goodman (Eds.), Memory and suggestibility in the forensic interview (pp. 165-183). Mahwah, NJ: Erlbaum.

Pickel, K. L., Narter, D. B., Jameson, M. M., \& Lenhardt, T. T. (2008). The weapon focus effect in child eyewitnesses. Psychology, Crime $\mathcal{E}$ Law, 14, 61-72. doi: 10.1080/10683160701391307 
Pipe, M.-E., Lamb, M. E., Orbach, Y., Sternberg, K. J., Stewart, H. L.. \& Esplin, P. W. (2007). Factors associated with nondisclosure of suspected abuse during forensic interviews. In M.-E. Pipe, M. E. Lamb, Y. Orbach, \& A.-C. Cederborg (Eds.), Child sexual abuse: Disclosure, delay, and denial (pp. 77-96). Mahwah, NJ: Erlbaum.

Pitman, R. K. (1989). Post-traumatic stress disorder, hormones, and memory. Biological Psychiatry, 26(3), 221-223. doi:10.1016/0006-3223(89)90033-4

Poole, D. A., Bruck, M., \& Pipe, M.-E. (2011). Forensic interviewing aids: Do props help children answer questions about touching? Current Directions in Psychological Science, 20, 11-15. doi: 10.1177/0963721410388804

Poole, D. A., \& Dickinson, J. J. (2011). Evidence supporting restrictions on uses of body diagrams in forensic interviews. Child Abuse $\mathcal{E}$ Neglect, 35, 659-669. doi: 10.1016/j.chiabu.2011.05.004

Poole, D. A., \& Lindsay, D. S. (1995). Interviewing preschoolers: Effects of nonsuggestive techniques, parental coaching, and leading questions on reports of nonexperienced events. Journal of Experimental Child Psychology, 60, 129-154. doi: 10.1006/jecp.1995.1035

Poole, D. A., \& Lindsay, D. S. (1998). Assessing the accuracy of young children's reports: Lessons from the investigation of child sexual abuse. Applied and Preventive Psychology, 7, 1-26.

Poole, D. A., \& Lindsay, D. S. (2002). Reducing child witnesses' false reports of misinformation from parents. Journal of Experimental Child Psychology, 81, 117-140.

Powell, M. B., \& Thomson, D. M. (1996). Children's memory of an occurrence of a repeated event: Effects of age, repetition, and retention interval across three question types. Child Development, 67, 1988-2004. doi: 10.2307/1131605

Pozzulo, J. D., \& Lindsay, R. L. (1998). Identification accuracy of children versus adults: A meta-analysis. Law and Human Behavior, 22(5), 549-570. doi:10.1023/A:1025739514042

Principe, G. F., Ornstein, P. A., Baker-Ward, L., \& Gordon, B. N. (2000). The effects of intervening experiences on children's memory for a physical examination. Applied Cognitive Psychology, 14, 59-80.

Quas, J. A., Goodman, G. S., Ghetti, S., Alexander, K. W., Edelstein, R., Redlich, A. D., Cordon, I. M., \& Jones, D. P. H. (2005). Childhood sexual assault victims: Long-term outcomes after testifying in criminal court. Monographs of the Society for Research in Child Development, 70(2), 1-128.

Quesada, A. A., Wiemers, U. S., Schoofs, D. D., \& Wolf, O. T. (2012). Psychosocial stress exposure impairs memory retrieval in children. Psychoneuroendocrinology, 37(1), 125-136.

Ratner, H., Foley, M., \& Gimpert, N. (2000). Person perspectives on children's memory and learning: What do source-monitoring failures reveal? In K. P. Roberts, \& M. Blades (Eds.), Children's source monitoring (pp. 85-114). Mahwah, NJ: Erlbaum.

Redlich, A. D. (2007). Double jeopardy in the interrogation room for youths with mental illness. American Psychologist, 62, 609-611.

Richardson, G., Gudjonsson, G. H., \& Kelly, T. P. (1995). Interrogative suggestibility in an adolescent forensic population. Journal of Adolescence, 18, 211-216. 
Roberts, K. P. (2002). Children's ability to distinguish between memories from multiple sources: Implications for the quality and accuracy of eyewitness statements. Developmental Review, 22(3), 403-435. doi:10.1016/S0273-2297(02)00005-9

Roberts, K. P., \& Blades, M. (1995). Children's discrimination of memories for actual and pretend actions in a hiding task. British Journal of Developmental Psychology, 13(4), 321333. doi:10.1111/j.2044-835X.1995.tb00683.x

Roberts, K. P., \& Blades, M. (1998). The effects of interacting in repeated events on children's eyewitness memory and source monitoring. Applied Cognitive Psychology, 12(5), 489-503. doi:10.1002/(SICI)1099-0720(199810)12:5<489::AID-ACP535>3.0.CO;2-\#

Roberts, K. P., \& Blades, M. (1999). Children's memory and source monitoring of real-life and televised events. Journal of Applied Developmental Psychology, 20(4), 575-596. doi:10.1016/S0193-3973(99)00030-1

Roberts, K. P., \& Powell, M. B. (2001). Describing individual incidents of sexual abuse: A review of research on the effects of multiple sources of information on children's reports. Child Abuse \& Neglect, 25, 1643-1659. doi: 10.1016/S0145-2134(01)00290-3

Roberts, K. P., \& Powell, M. B. (2006). The consistency of false suggestions moderates children's reports of a single instance of a repeated event: Predicting increases and decreases in suggestibility. Journal of Experimental Child Psychology, 94, 68-89. doi: 10.1016/j.jecp.2005.12.003

Ruva, C. L., \& Bryant, J. B. (2004). The impact of age, speech style, and question form on perceptions of witness credibility and trial outcome. Journal of Applied Social Psychology, 34, 1919-1944.

Schneider, W., Bjorklund, D. F., \& Maier-Brückner, W. (1996). The effects of expertise and IQ on children's memory: When knowledge is, and when it is not enough. International Journal of Behavioral Development, 19, 773-796. doi: 10.1080/016502596385578

Shrimpton, S., Oates, K., \& Hayes, S. (1998). Children's memory of events: Effects of stress, age, time delay and location of interview. Applied Cognitive Psychology, 12(2), 133-143.

Simcock, G., \& Hayne, H. (2002). Breaking the barrier? Children fail to translate their preverbal memories into language. Psychological Science, 13, 225-231. doi: 10.1111/14679280.00442

Singh, K. K., \& Gudjonsson, G. J. (1992). Interrogative suggestibility among adolescent boys and its relationship with intelligence, memory and cognitive set. Journal of Adolescence, 15, 155-161.

Sprondel, V., Kipp, K. H., \& Mecklinger, A. (2011). Developmental changes in item and source memory: Evidence from an ERP recognition memory study with children, adolescents, and adults. Child Development, 82, 1938-1953.

Southwick, S. M., Morgan, C. A., III, Nicolaou, A. L., \& Charney, D. S. (1997). Consistency in memory for combat-related traumatic events in veterans of Operation Desert Storm. American Journal of Psychiatry, 154, 173-177.

Talwar, V., \& Crossman, A. M. (2012). Children's lies and their detection: Implications for child witness testimony. Developmental Review.http://dx.doi.org/10.1016/j.dr.2012.06.004 
Thierry, K. L., Spence, M. J., \& Memon, A. (2001). Before misinformation is encountered: Source monitoring decreases child witness suggestibility. Journal of Cognition $\mathcal{E}$ Development, 2(1), 1-26. doi:10.1207/S15327647JCD0201_1

Trickett, P. K., \& McBride-Chang, C. (1995). The developmental impact of different forms of child abuse and neglect. Developmental Review,15(3), 311-337. doi:10.1006/drev.1995.1012

Vandermass, M. O., Hess, T. M. \& Baker-Ward, L. (1993). Does anxiety affect children's reports of memory for a stressful event? Applied Cognitive Psychology, 7, 109-128.

Veltman, M.W. M., \& Browne, K. D. (2001). Three decades of child maltreatment research: implications for the school years, Trauma Violence Abuse, 2, 215-39.

Walker, A. G. (1993). Questioning young children in court: A linguistic case study. Law and Human Behavior, 17, 59-81.

Wandrey, L., Lyon, T. D., Quas, J. A., \& Friedman, W. J. (2012). Maltreated children's ability to estimate temporal location and numerosity of placement changes and court visits. Psychology, Public Policy, and Law, 18, 79-104.

Williams, J., \& Broadbent, K. (1986). Autobiographical memory in suicide attempters. Journal of Abnormal Psychology, 95(2), 144-149. doi:10.1037/0021-843X.95.2.144

Winograd, E., \& Killinger, W. A. (1983). Relating age at encoding in early childhood to adult recall: Development of flashbulb memories. Journal of Experimental Psychology: General, 112(3), 413-422. doi:10.1037/0096-3445.112.3.413

Yarmey, A. (1979). Through the looking glass: Sex differences in memory for self-facial poses. Journal of Research in Personality, 13(4), 450-459. doi:10.1016/0092-6566(79)90007-2

Zajac, R., \& Cannan, P. (2009). Cross-examination of sexual assault complainants: A developmental comparison. Psychiatry, Psychology and Law, 16(Suppl 1), S36-S54.

Zajac, R., \& Hayne, H. (2003). I don't think that's what really happened: The effect of crossexamination on the accuracy of children's reports. Journal of Experimental Psychology, 9, 187-195.

Zajac, R., \& Hayne, H. (2006). The negative effect of cross-examination style questioning on children's accuracy: Older children are not immune. Applied Cognitive Psychology, 20, 316.

Zajac, R., Jury, E., \& O'Neill, S. (2009). The role of psychosocial factors in young children's responses to cross-examination style questioning. Applied Cognitive Psychology, 23, 918935.

Zhu, B., Chen, C., Loftus, E. F., Lin, C., He, Q., Chen, C., et al. (2010). Individual differences in false memory for misinformation: Cognitive factors. Memory, 18, 543-555. 


\title{
Beyond the Black-and-White of Autism: How Cognitive Performance Varies with Context
}

\author{
Joseph L. Amaral, Susan Collins, Kevin T. Bohache and Heidi Kloos
}

Additional information is available at the end of the chapter

http://dx.doi.org/10.5772/53937

\section{Introduction}

A child's cognitive performance can vary considerably from one task context to the next, even when only small details of the task are changed. Such context dependence has given rise to a new way of looking at the underlying processes of children's thinking (e.g. Smith, Thelen, Titzer, \& McLin, 1999; Spencer, Thomas, \& McClelland, 2009). Rather than attributing performance to a particular competence (or a lack thereof), performance is attributed to a synergy between the actor and environment, highly sensitive to even seemingly irrelevant details of the task context. Though not complete, this view makes it possible to map out how changes in the context could be harnessed to bring about changes in a child's behavior. The current chapter looks at whether the same view can be applied to autism spectrum disorder (ASD). A first step in this direction is to explore the extent to which cognitive performance in ASD is affected by apparently irrelevant variations of the task context.

Autism spectrum disorder comprises of a cluster of disorders that include Autistic Disorder (also known as "classic" autism), Asperger's Syndrome, and Pervasive Developmental Disorder-Not Otherwise Specified (DSM-IV-TR; American Psychiatric Association, 2000). Though there are important differences between these sub-groups, they share a common set of general symptoms that arise early in a child's life: ASD is characterized by pronounced social difficulties and communication impairment, along with restricted, repetitive behaviors or interests (APA, 2000). In particular, children often demonstrate atypical eye contact, a lack of verbal speech or atypical language use, odd mannerisms such as arm flapping, and narrow, obsessive interests (e.g.: an encyclopedic knowledge of former U.S. Secretaries of the Interior; Klinger, Dawson, \& Renner, 2003).

Importantly, despite extensive research into ASD, no causal factors have been isolated so far. For example, even though the patters of neurological activity show numerous 
differences between typical development and ASD, no single difference appears to capture the disorder (for a review see Fein, 2011). And even though ASD appears to have a strong genetic component, genome variations appear diffuse (e.g., Devlin \& Scherer, 2012). This raises the possibility that the disorder is not reducible to a static causal factor that can differentiate between typical development and ASD. Instead, the disorder might be the result of complex interdependence among multiple factors that change each other's effect as they interact over time. Take for example, the language impairments documented in ASD. Rather than being attributed to a stable factor (language-specific, neurological, genetic, or otherwise), these behaviors might have their origin in virtually undetectably minimal discrepancies in how the perceptual system combines information into higher-order patterns. The discrepancy from typical development might be minimal at first, but then get amplified by a variety of child-internal, environmental, and social factors (e.g., a difficulty detecting higher-order patterns, a low tolerance for over-stimulation, the hierarchical order inherent in a language, a disrupted communication synchrony between child and caregiver, etc). The coming-together of environmental factors further intensify the initially minimal difference in perceptual processes - which then in turn amplify environmental and social factors. In other words, what may start out as a barely noticeable difference in how information is integrated might enter a cycle of forces that amplify each other's effect over time, an interdependence that heralds a major departure from typical development.

The view that ASD behavior is the result of interdependent factors that amplify each other's effects over time is a stark departure from the view that overt behavior is reducible to a stable factor that marks autism. And while there is no conclusive evidence to support the former view, there is nevertheless strong support in the developmental literature of ASD. First, it is difficult to predict the developmental trajectories of individual children (for a review, see Seltzer, Shattuck, Abbeduto \& Greenberg, 2004). For example, while overall language abilities can improve over time (Sigman \& McGovern, 2005), various atypicalities sometimes remain, including echolalia or fixations on various topics of interest (Lord, Rici, \& Pickles, 2004). Some children may even exhibit an increase in general symptom severity over time (e.g., Nordin \& Gillberg, 1998).

Second, developmental patterns tracked over time sometimes show a non-linear trajectory. For example, differences in social behavior (e.g. eye contact, visual tracking, visual disengagement, imitation, social interest, and sensory-motor behaviors), apparent at 12 months of age, are missing in younger children (Zwaigenbaum et al., 2005; Bryson , Brian, Roberts, Szatmari, Rombough, \& McDermott 2007). And while 6-month-old infants with a high risk of autism show less frontal Gamma power than low-risk children, this difference is negligible when infants are 24 months old (Keehn, Luyster, Vogel-Farley, Tager-Flusberg \& Nelson, 2012). Explaining such non-linear trajectories under the reductionist viewpoint would require an additional assumption, namely that the isolated causal factor comes online at a certain point in time. These trajectories imply instead that the disorder has to be attributed to complex interactions among factors that change in nature over time.

The interdependence view on ASD has strong implications for how to go about studying the source of this disorder and its treatment. Rather than looking for black-and-white 
differences between ASD and typical development, and interdependence view advocates the study of trajectories, the stability of trajectories, and how stable cycles can be perturbed. Furthermore, an interdependence view implies that even small changes in the context can potentially have a large effect on behavioral outcomes. In the remainder of the chapter, we review performance variability of already published research to describe such context dependence in cognitive tasks. As such, this review differs from already existing reviews (e.g., Klinger, Dawson, \& Renner, 2003; Rajendran \& Mitchell, 2007) in one crucial way. Rather than emphasizing consistencies in findings to promote the idea of a stable difference in ASD (and discussing conflicting findings to undermine one over another reductionist ASD theory), our goal is to highlight context effects detected in ASD research.

The chapter is organized as follows: we will first highlight some findings in pattern perception, a large research field centered on the idea of the so-called weak central coherence (cf., Frith, 1989). We will then turn to findings related to learning, focusing specifically on learning of higher-order patterns and statistical information in sequences. Next, we will discuss ASD research on executive functioning, the child's ability to control their actions to achieve a certain outcome. Finally, we will turn to research on social reasoning, discussing findings in joint attention and theory of mind.

\section{Perception}

Perceiving meaningful configurations in the array of ever-changing information (visual or otherwise) requires the mind to combine separate bursts of sensation into an organized unit of perception. The mind has to detect or impose coherence (cf., Thagard, 1989) For example, in order to perceive a painting, the mind has to ignore the individual pixels of color and detect the higher-order organization of objects and scenes. The possible patterns of organization are nested hierarchically, ranging from a very local organization (e.g., an individual object in the painting) to a more global organization (e.g., the theme of the painting). The ability to detect patterns of organization at various levels of abstraction is commonly studied under the framework of local versus global perception, with the central question pertaining to the degree to which local and global perception interfere with one another (cf. e.g., Baylis \& Driver, 1993; Herrmann \& Bosch, 2001; Humphreys, Olson, Romani, \& Riddoch, 1996; Kahneman \& Henik, 1981; Kahneman \& Treisman, 1984; Kimchi, 1992; Kramer \& Jacobson, 1991; Maurer, Le Grand, \& Mondloch, 2002; Moore \& Egeth, 1997; Pellicano \& Rhodes, 2003).

An essential difference between ASD and typical development is the degree to which the perception of global order interferes with the perception of local order. Rather than exhibiting a bias towards coherence, perception of individuals with ASD is typically characterized by what is known as weak central coherence. Best example of this difference was established with the classical Navon task, a task in which stimuli consist of many small letters configured in the arrangement of a large letter (cf., Navon, 1977). In typical development, results show a distinct interference of large letters on the perception of small letters, both in children (Ozonoff Strayer, McMahon \& Filloux 1994; Plaisted, Swettenham, 
and Rees, 1999) and in adults (Fagot \& Deruelle, 1997; Navon, 1977). In particular, when participants are asked to focus on small letters, reaction time is longer for trials in which large and small letters differ than on trials in which large and small letters match. This global interference is non-detectable in participants with ASD: They perform equally fast in both letter-mismatch trials and letter-match trials - and that with high accuracy (e.g. Mottron, Burack, Stauder, \& Robaey, 1999; Plaisted et al., 1999).

Another example of weak central coherences in ASD comes from face-perception tasks. The identity of a face is defined not only by its individual parts (e.g., nose, eyes, mouth), but also by the holistic configuration of these parts, something that appears to be disrupted when faces are presented upside down. For typically developing children, recognition accuracy decreases when faces are presented upside down, compared to trials in which faces are presented upright (Mondloch, Le Grand, \& Maurer, 2002). In contrast, children with ASD do not perform differently as a function of face orientation (Langdell, 1978; Tantam, Monaghan, Nicholson, \& Stirling, 1989). Along the same lines, participants with ASD could classify faces better when local rather than global features were exaggerated (through the use of a high-pass vs. low-pass filter; Deruelle, Rondan, Salle-Collemiche, Bastard-Rosset, \& Da Fonséca, 2008). The inverse pattern of results was obtained for typically developing children.

A final example of preferential local focus comes from research involving auditory perception (Foxton Stewart, Barnard, Rodgers, Young, O’Brien, \& Griffiths 2003). Stimuli were 5-tone sequences that varied in specific tones, pattern of switch in pitch direction (e.g., a down sequence was followed by up sequence), and timing of the switch. In the crucial task (a global-interference condition), participants had to focus on only one of these features, ignoring changes in the other features. In particular, they had to decide on whether two sequences match in the patterns of switch, ignoring differences in specific tones or differences in timing. Result show superior performance for participants with ASD than matched controls. Vice versa, when sequences differed only in specific tones (the patterns and timing of the sequences being identical), ASD performance matched that of control participants (see also Mottron, Peretz \& Menard, 2000). Further evidence for enhanced local processing of auditory information comes from the finding that individuals with ASD can label isolated tones better than TD controls and are more likely to have perfect pitch, meaning that they can replicate or identify individual musical tones without assistance (Bonnel, Mottron, Peretz, Trudel, Gallun, \& Bonnel 2003; Heaton, Hermelin, \& Pring, 1998).

In broad strokes, while typical development is characterized by a bias towards perceiving higher-order Gestalts over perceiving an isolated detail, this bias is thought to be missing or at least less prevalent in ASD (for reviews, see Happé, 2000; Happé \& Booth, 2008; Happé \& Frith, 2006). However, even though research generally supports the idea of a weak bias towards higher-order Gestalt in ASD, there are some interesting exceptions. For example, when individuals with ASD are told to look at relevant information in face processing tasks, they perform in a similar way to typically developing children (Lopez, Donnelly, Hadwin, \& Leekam, 2004). The task was to determine which of two test items matched with a target face. In configuration trials, the test items were faces, one of which always matched the 
target, while the other one differed in a single feature. And on feature trials, the test items were individual features (e.g., eyes), one of which match the respective feature of the target. Critically, participants were sometimes provided with a cue indicating on which feature to focus. For example, they were told "look at the eyes." In cued configuration trials, the cue focused attention to the mismatched feature. On feature trials, it focused attention to the matching feature. The typically developing group demonstrated superior performance on configuration trials, compared to feature trials, regardless of cueing. The ASD group, in contrast, demonstrated a configural advantage only on cued trials, but not in un-cued trials.

A similar effect of instruction was found when the task was to read sentences that contained homographs (words that have the same spelling are a pronounced differently, depending on the context of a sentence). As one would predict from a weak-central-coherence assumption, individuals with ASD are less likely than typically developing individuals to use the context of a sentence to disambiguate homographs (Frith \& Snowling, 1983; Happé, 1997; Jolliffe \& Baron-Cohen, 1999; Lopez \& Leekam, 2003). For example, when asked to read aloud a sentence containing the homograph "tear", participants with ASD are less likely to take the sentence context into account when deciding on how to pronounce the word. However, this pattern of performance changes dramatically when attention is explicitly directed to the homographs (Snowling \& Frith, 1986). That is, when explicitly told to look for homographs, their use of proper pronunciation approaches that of typically developing individuals.

Variations in instruction also affect ASD performance on tasks involving optical illusions, another area that attests to Gestalt interference in typical development. Typically, the task is to focus on a local piece of information and ignore the embedding context. For example, in the Muller-Lyer illusion, the task is to compare the length of the two lines, ignoring the arrows on each end of the lines. Findings show that typically developing participants are strongly affected by the embedded context, succumbing to the illusion to the expense of focusing on the local elements (for a review, see Changizi, Hsieh, Nijhawan, Kanai, \& Shimojo, 2008). While individuals with ASD are far less affected by such visual configurations (e.g., Brosnan Scott, Fox, \& Pye, 2004), important context effects are apparent. For example, participants with ASD were found to be more susceptible to Muller-Lyer illusions when asked, "which line looks longer," versus "which line is longer" (Scott, Brosnan, \& Wheelwright, in preparation, as cited in Happé \& Frith, 2006). It appears that individuals with ASD can see both that the lines are equally long, and that the lines look like they differ in length.

In sum, while individuals with ASD differ from typical development in the degree to which they focus on the higher-Gestalt of a pattern (vs. the local elements), this difference is susceptible to variations in task context. Findings reviewed here pertain to the domains of shifting attention from local elements to global patterns (and vice versa), face perception (which depends on detecting relations between facial parts), reading homographs (which require the entire sentence to be taken into account), and optical illusions (which depends on children failing to ignore the embedding aspects of the target). Such context effects on perception have led to some revisions in the ASD theory of weak central coherence (e.g. Happé \& Booth, 2008). Rather than positing an all-or-none competence of Gestalt 
processing, weak central coherence is now seen as a tendency, a preference of some sort that could be changed under ideal task contexts.

\section{Learning of patterns}

As mentioned above, ASD is characterized by delays in language learning, including the learning of new words, their use, the pragmatics of language, or the fluidity of use (see e.g., Lord, Risi, \& Pickles, 2004, for a review). These delays, as well as other symptoms of autism, have been attributed to differences in how patterns of information are learned (e.g., L. G. Klinger, Klinger, \& Pohlig, 2007). More specifically, individuals with autism might have difficulty learning underlying patterns of events when hypothesis-testing strategies cannot be applied. This kind of learning is commonly studied under the umbrella of implicit learning (see Perruchet, 2008; Shanks, 2005, for reviews), artificial-grammars learning (e.g., Reber, 1967), or pattern detection in category formation (e.g., Ashby \& Maddox, 2005; Keri, 2003). Here, we use the term "implicit learning", consistent with the term used in ASD research.

Studies of pattern learning have led to interesting findings in ASD. On the one hand, there are several findings that suggest impaired implicit learning in ASD (e.g., Romero-Munguía, 2008). Consider, for example, findings obtained with the so-called serial reaction time (SRT) task: Participants are asked to press a key to indicate a particular stimulus in a sequence. Learning is reflected in a decrease in reaction time for sequences that contain subtle repeated patterns, compared to random sequences (cf., Nissen \& Bullemer, 1987). While typically developing children demonstrated such learning, participants with ASD did not (Mostofsky, Goldberg, Landa, \& Denckla, 2000). Further support for compromised implicit learning comes from findings on prototype learning (Klinger \& Dawson, 2001). The task was to categorize fictitious animals that differed in features like ear length, leg length, and neck length (cf., Younger, 1993). Children with ASD performed more poorly than control participants match in verbal age (see also Klinger et al., 2007). In fact, performance on implicit learning tasks was highly correlated with ASD symptomatology, including communication skills, social skills, and the occurrence of repetitive behaviors.

However, the difference in implicit-learning abilities between ASD and control participants is not stable across task context, even when tested in the same lab (cf., Klinger \& Dawson 2001; Klinger et al., 2001). Consider the SRT task again: when the inter-stimulus interval was reduced to 120ms (Barnes, Howard, Howard, Gilotty, Kenworthy, Gaillard 2008) or omitted altogether (Travers, Klinger, Mussey, \& Klinger 2010), there was no difference between ASD and control participants. Both groups of children could learn to anticipate the rule-based sequence, compared to a random sequence (see also Muller, Cauich, Rubio, Mizuno, \& Couchesne, 2004). Similarly, there was evidence for sequence learning when the rule was greatly simplified and the training extended to multiple sessions (Gordon \& Stark, 2007). Furthermore, children with ASD demonstrate repetition priming effects comparable to those of controls (i.e., they could identify studies items better than non-studied items; Renner, Klinger, \& Renner, 2000). And they were found to have intact semantic priming for simple common words (Toichi \& Kamio, 2002) - further evidence for implicit-learning abilities in 
ASD. Overall, these findings have undermined a claim that ASD is characterized by a general difficulty with implicit learning, in turn undermining an effort to explain social deficits, motor abnormalities, and language deficits associated with the disorder.

There are many ways in which context effects on implicit learning could be explained. For example, one could address the differences in findings by looking for differences in the groups of participants, whether in age, symtomatology, or co-morbidity. It is possible that the findings fail to univocally address the question of implicit-learning competence in ASD because participants differ across different tasks. Or one could look for differences in other internal processes that could explain the pattern of performance. Tasks might differ in the degree to which they tap a participant's working memory. Or they differ in the extent to which they require the integration of gross-motor movements. Or they differ in whether they afford or undermine the use of explicit (i.e., hypothesis-testing) strategies. Indeed, ASD performance is comparable to that of typically developing children when the prototype learning task required a rule-based approach (Klinger \& Dawson, 2001). And an exceedingly short inter-stimulus interval might have forced the minds of participants with ASD to abandon their bias to use a hypothesis-testing strategy and therefore make room for an implicit-learning process. There are multiple problems with this kind of reasoning, a major one being that it fails to address the entire list of context effects - beyond a comparison of a few studies.

\section{Executive functioning}

Executive functioning (EF) is an umbrella term to describe various cognitive abilities assumed to be involved in conscious problem-solving. They pertain, for example, to inhibiting incorrect but dominant actions, planning a future action, and flexibly switching attention when instructed to do so (e.g., Zelazo \& Müeller, 2002). EF plays an important role in cognitive development, as it leads to an improved ability to override automatic responses (Garon, Bryson, \& Smith, 2008). A classical EF task - but by far not the only one - is the Stroop task, a task in which participants are asked to name the color of the ink used for a printed word, the word spelling a particular color (Stroop, 1935). The central finding is a slowing in reaction time when the ink color differs from the spelled-out color (compared to trials in which the ink color matches the spelled-out color), demonstrating the difficulty of inhibiting the automatic tendency to read the word.

EF is thought to be associated with typical ASD attributes, including the need for sameness, difficulty with switching attention, a tendency to perseverate, and a lack of impulse control. Indeed, there are tasks in which participants with ASD show difficulty with inhibition (for a review see Rajendran \& Mitchell, 2007). Consider, for example, an inhibition task in which participants have to point to an empty window in order to receive the reward shown in a non-empty window (Hala, \& Russel 2001). Unlike control participants, a majority of participants with ASD have difficulty inhibiting their natural response of pointing to the reward they desire, compared to controls matched on mental age. Other examples of EF difficulties consist of difficulties with planning (e.g., (Ozonoff \& Jensen, 1999, Ozonoff, Pennington, \& Rogers, 1991), mental flexibility (e.g., Hughes, Russell, \& Robbins, 1994; 
Ozonoff, 1997), the generation of novel ideas (Turner, 1999), and self-monitoring (e.g., Hughes, 1996; Phillips, Baron-Cohen, \& Rutter 1998; Russell \& Jarrold, 1998, 1999).

However, there are findings that undermine a straightforward ASD theory surrounding EF differences. For example, participants with ASD do not have more difficulty with the Stroop task than control participants (e.g., Ozonoff \& Jensen, 1999; Eskes, Bryson, \& McCormick, 1990): participants with ASD were found to show a typical slowing in reaction time when naming the ink of a word that spells a different color. Similarly, context effects were found with planning task that involves keeping in mind a certain set of rules to produce an outcome (e.g., Tower of Hanoi task, Stockings of Cambridge task). ASD performance was equivalent to typically developing performance on trials with only a small number of required steps for completion. Performance only differentiated between groups on longer, more complex trials. Further, performance appeared modulated by each individual child's nonverbal IQ, rather than symptomology (Hughes, Russell, \& Robbins, 1994).

It appears that a claim about EF differences between typical development and ASD is not supported in all instances (for further review, see Hill, 2004). Performance seems instead dependent on specifics of the tasks and individual differences among children. Of course, it is always possible to interpret discrepant results consistent with a reductionist viewpoint. For example, one could argue that EF differences between typical and atypical development are most pronounced in so-called "hot" EF task, those that involve an emotional component (cf., Hongwanishkul, Happaney, Lee, \& Zelazo, 2005). The differences might disappear in "cool" EF tasks, those that lack immediate rewards. These claims, though plausibly incorporating currently existing data, might not be able to capture context effects likely to accumulate as more data is being collected.

\section{Social reasoning}

Adaptive functioning includes social reasoning, or a child's ability to engage in social interactions. ASD is characterized by major difficulties in this domain, ranging from attending to irrelevant features of social situations (e.g., Dawson, Meltzoff, Osterling, Rinaldi, \& Brown, 1998; Klin, Jones, Schultz, Volkmar \& Cohen 2002), giving atypical responses to social cues (e.g., Kjelgaard \& Tager-Flusberg, 2001; Mottron, 2004; Mundy, Sigman \& Kasari, 1990; Parish-Morris et al., 2007; Sigman \& Ruskin, 1999; Stone, Ousley, Yoder, Hogan, \& Hepburn 1997), having difficulty understanding the intentions of others (e.g., Baron-Cohen, 1995; Preissler \& Carey, 2005; Warreyn, Roeyers, Oelbrandt, \& De Groote 2005), and poor imitation skills (e.g., Hobson \& Lee, 1999; Loveland, Tunali-Kotoski, Pearson, Brelsford, Ortegon, \& Chen 1994). Here we describe findings for two of these areas, namely joint attention (i.e., the act of sharing another's attentional focus) and of theory of mind (i.e., the understanding of others' intentions).

\subsection{Joint attention}

The ability to share somebody else's focus of attention, known as joint attention, is critical for successful social interactions, setting up a context in which a child can learn from others. 
For example, a child needs to know what a person is looking at to understand what a new label might refer to. Indeed, joint attention has been studied extensively in relation to children's word learning (e.g., Baldwin, 1995; Mundy \& Newell, 2007; Carpenter, Nagell, \& Tomasello, 1998; Tomasello, 1995; see also Flom, Lee, \& Muir, 2007). A common task involves presenting children with a set of objects, and an adult visibly looking at the one that is being named. Both the amount of time the participant follows the eye-gaze of the adult and the degree of labelling are thought to reflect the amount of joint attention that occurs between them.

Children with ASD have demonstrated difficulty following the gaze of an adult in joint attention tasks (for a review, see Meindl \& Cannella-Malone, 2011). And this deficit is observed alongside difficulties with learning new object names (Baron-Cohen, Baldwin, \& Crowson, 1997; McDuffie, Yoder, \& Stone, 2006; Parish-Morris, Hennon, Hirsh-Pasek, Golinkoff, \& Tager-Flusberg, 2007; Preissler \& Carey, 2005). For example, there is a pronounced learning difference between children with ASD and typically developing children when the labeled object was held by the experimenter, versus by the child (Preissler \& Carey, 2005). This difference cannot be attributed to general word-learning deficits because word learning did not differ between diagnostic groups when the labeled object was in the child's hand. Similarly, learning did not differ between diagnostic groups when the labeled object was the only novel object.

Yet, despite strong evidence in favor of ASD impairments in joint attention, findings from other research complicate the picture: participants with ASD appear perfectly capable of joint attention in some contexts, if not even more skilled than their typically developing counterparts (Chawarska, Klin, Volkmar 2003; Kylliainen \& Hietanen, 2004; Vlamings, Strauder, van Son, Mottron 2005). Consider, for example, a task in which participants have to press a corresponding button as soon as they see a target appear either at the top left or the bottom right of a monitor. A face was also shown in the center of the monitor. The gaze of the face was straight ahead, averted to the top left, or averted to the bottom right, $200 \mathrm{~ms}$ before the target appeared. Findings show faster reaction time on trials in which the target appeared on the same side of the screen as the face's gaze, with no difference between diagnostic groups (Kylliainen \& Hietanen, 2004).

An argument could be made that different joint-attention tasks are not equally suited to capture the construct of joint attention. Maybe the reaction time task is a better reflection of joint-attention processes than a word-learning task. Such argument about what task might best reflect a stable factor is a common argument in the larger literature of cognition and cognitive development. However, it gets quickly overwhelmed as more context effects accumulate.

\subsection{Theory of mind}

Another aspect of social reasoning is the ability to understand someone else's mental state, including their desires, motivation or beliefs. This kind of understanding is coined as theory of mind, with numerous studies investigating it and its development (Perner, 1991; Wellman, 1990). In a traditional theory of mind task, children are presented with two hiding 
locations, a basket and a box and two dolls, Sally and Anne. The story involves Sally placing a marble in a basket, which is then moved into the box by Anne - without Sally being present. The critical task is to determine the location where Sally would search for her marble upon her return. If children understand Sally's mental state, they should pick the basket, because that is the marble's location known to Sally. If, on the other hand, children go by their own beliefs, they should pick the box, because they know that Anne has moved the marble into the box.

Many studies have sought to identify general deficits in theory of mind reasoning in individuals with ASD, as a means of better understanding their social deficits (for reviews see Rajendran \& Mitchell, 2007). For example, Baron-Cohen et al. (1985) found that $80 \%$ of children with ASD failed the Sally-and-Anne test, compared to only $20 \%$ of matched controls. This difference cannot be attributed to general difficulties understanding the task instructions, given that children with ASD were able to answer control questions about the various locations of the marbles. Taken alone, these data appear to highlight a pathology specific impairment to theory of mind reasoning in individuals with ASD.

However, highly variable performance between similar theory of mind tasks has been observed (Grant, Grayson and Boucher, 2001; Baron-Cohen, Leslie, \& Frith 1985; Yirmiya, Solomonica-Levi, Shulman \& Pilowsky, 1996; Zelazo, Burack, Benedetto, \& Frye 1996). Consider, for example, findings with the so-called deceptive-box task, a task in which the content of a box does not match with the label on the box (Grant, Grayson \& Boucher, 2001). After being shown the content of the box, participants are asked about what another participant would predict about the contents of the box (without having seen inside the box). To answer accurately, the participant must understand that their knowledge of the contents of the box is not accessible to the other participant. Comparison of performance on the deceptive-box and Sally-and-Anne tasks revealed important differences in ASD: Performance was better on the deceptive-box task than the Sally-and-Anne task, despite the conceptual similarity.

In defense of a reductionist framework for ASD, one could go about dissecting the tasks in order to find the stable factor that could explain ASD. For example, one could argue that the two tasks differ in whether they involve real people (the deceptive box task) or puppets (the Salley-and-Anne task). Variable performance between these tasks may therefore reflect a difference in the perception of behavior associated with living versus inanimate actors. However, this explanation falls apart when the larger body of theory of mind research is considered: The inconsistent findings in theory of mind tasks (for a review, see Rajendran \& Mitchell, 2007) to do separate on the fault line of inanimate vs. animate stimuli.

\section{Summary and conclusions}

ASD is diagnosed in about 1 in every 88 children (CDC, 2012), many of whom will have poor outcomes as adults, requiring some level of assistance throughout their lives (Seltzer, 
Shattuck, \& Greenberg, 2004). In addition to this high prevalence of the disorder, there is a high heterogeneity, high co-morbidity, and the possibility of several subgroups of ASD. Together, these factors make it imperative to better understand the disorder and develop effective interventions. However, as more research accumulates, so do inconsistent findings and unexpected differences in patterns of performance on tasks that were designed to measure the same cognitive process or factor.

In the current chapter, we have reviewed some context effects taken from the domains of perception, learning, executive functioning, and social reasoning. On the one hand, while there are robust differences in performance in all of these domains, these differences can disappear under certain task contexts - rendering them less robust than initially thought. Specifically, while ASD is characterized by a focus on local details (vs. on an overall Gestalt), by difficulty with implicit learning, executive functioning, and social reasoning, these differences disappear as the variability in tasks increases. It is plausible that more context effects accumulate as ASD research expands in cognitive development, further exasperated by a focus on individual children.

Context effects are nothing new in the literature of cognitive development (e.g., Kloos \& Van Orden, 2009). A plausible reaction is to dismiss them as isolated instances, leaving an existing hypothesis intact, or refining it to incorporate the context effects. The problem, however, is that both these solutions can only address context effects locally. Yet, context effects are not a local phenomenon. And they are not likely to disappear with more participants, more precise methods, or simply more data. In fact, if research with typically developing participants is any guide for predicting the patterns of findings, context effects are a necessary feature of the enterprise. And with more research we are likely to find more context effects (e.g., see Shanks, Rowland \& Ranger, 2005, for a discussion on implicit learning in neuro-typical adults). An expanding of a reductionist theory of ASD to incorporate them all is unlikely to retain its usefulness. Instead, context effects undermine a reductionist theory altogether.

Rather than focusing on a binary interpretation of patterns of performance, context effects hint at the possibility of a complex interplay between factors that make a black-and-white approach to understanding performance insufficient. By shifting attention away from searching for a "smoking gun" of ASD, it may be possible to better understand the emergence of how the components are coordinated. It is possible that the coordination among components is compromised in individuals with ASD, reverberating through all areas of functioning, and amplifying itself with development. It gives rise to atypical perception patterns, implicit learning, planning, and social interactions - at least when the immediate task context does not support an adaptive coordination of interdependent components. This approach, while failing to reduce ASD to a single deficit, has important implications for training and teaching strategies. In particular, this approach makes it possible to map out how changes in support of coordination exist in the environment to bring about improved task performance. 


\section{Author details}

Joseph L. Amaral*, Susan Collins, Kevin T. Bohache and Heidi Kloos

University of Cincinnati, Cincinnati, OH, USA

\section{Acknowledgement}

Writing of this chapter was partially supported by a University of Cincinnati Research Council Summer Fellowship awarded to Joseph Amaral. We thank Samantha Linsky and Alexandra Matthews for editorial help.

\section{References}

American Psychiatric Association. (2000). Diagnostic and statistical manual of mental disorders (4th ed., text rev). Washington, DC: Author.

Ashby, F. G. \& Maddox, W. T. (2005). Human category learning. Annual Review of Psychology, 56, 149-178.

Baldwin, D. A. (1995). Understanding the link between joint attention and language. In C. Moore, \& P. J. Dunham (Eds.) Joint attention: Its origin and role in development (pp. 131158). Hillsdale, NJ: Lawrence Erlbaum Associates.

Barnes, K. A., Howard, J. H., Jr., Howard, D. V., Gilotty, L., Kenworthy, L., Gaillard, W. D., et al. (2008). Intact implicit learning of spatial context and temporal sequences in childhood autism spectrum disorder. Neuropsychology, 22(5), 563-570.

Baron-Cohen, S. (1995). Mindblindness. Cambridge, MA: MIT Press.

Baron-Cohen, S., Baldwin, D. A., \& Crowson, M. (1997). Do children with autism use the speaker's direction of gaze strategy to crack the code of language? Child Development, 68 , 48-57.

Baron-Cohen, S., Leslie, A. M., \& Frith, U. (1985). Does the autistic-child have a theory of mind. Cognition, 21, 37-46.

Baylis, G.C., \& Driver, J.S. (1993). Visual attention and objects: Evidence for heirarchical coding of locations. Journal of Experimental Psychology: Human Perception and Performance, $19,451-470$.

Bonnel, A., Mottron, L., Peretz, I., Trudel, M., Gallun, E., \& Bonnel, A. M. (2003). Enhanced pitch sensitivity in individuals with autism: A signal detection analysis. Journal of Cognitive Neuroscience, 15, 226-235.

Brosnan, M. J., Scott, F. J., Fox, S., \& Pye, J. (2004). Gestalt processing in autism: failure to process perceptual relationships and the implications for contextual understanding. Journal of Child Psychology And Psychiatry, 45(3), 459-469.

Bryson, S.E., Zwaigenbaum, L., Brian, J., Roberts, W., Szatmari, P., Rombough, V., \& McDermott, C. (2007). A prospective case series of high-risk infants who developed autism. Journal of Autism and Developmental Disorders, 37, 12-24.

\footnotetext{
" Corresponding Author
} 
Carpenter, M., Nagell, K., \& Tomasello, M. (1998). Social cognition, joint attention, and communicative competence from 9 to 15 months of age. Monographs of the Society for Research in Child Development, 63 (4), serial no. 255.

Centers for Disease Control \& Prevention (2012). Prevalence of autism spectrum disorders: Autism and developmental disabilities monitoring network, 14 sites, united states, 2008. Morbidity and Mortality Weekly Report: Surveillance Summaries, 61(3), 1-18.

Changizi, M. A., Hsieh, A., Nijhawan, R., Kanai, R., \& Shimojo, S. (2008) Perceiving the present and a systematization of illusions. Cognitive Science 32, 459-503.

Chawarska, K., Klin, A., Volkmar, F. (2003). Automatic attention cueing through eye movement in 2-year-old children with autism. Child Development, 74(4), 1108-1122.

Dawson, G., Meltzoff, A., Osterling, J., Rinaldi, J., \& Brown, E. (1998). Children with autism fail to orient to naturally occurring social stimuli. Journal of Autism and Developmental Disorders, 28(6), 479-485.

Deruelle, C., Rondan, C., Salle-Collemiche, X., Bastard-Rosset, D., \& Da Fonséca, D. (2008). Attention to low- and high- spatial frequencies in categorizing facial identities, emotions and gender in children with autism. Brain and Cognition, 66, 115-123.

Devlin, B., \& S.W. Scherer (2012). Genetic architecture in autism spectrum disorder. Current Opinion in Genetics \& Development, 22(3), 229-237.

Eskes, G. A., Bryson, S. E., \& McCormick, T. A. (1990). Comprehension of concrete and abstract words in autistic children. Journal of Autism and Developmental Disorders, 20, 6173.

Fagot, J., \& Deruelle, C. (1997). Processing of global and local visual information and hemispheric specialization in humans (Homo sapiens) and baboons (Papio papio). Journal of Experimental Psychology: Human Perception and Performance, 23(2), 429-442.

Fein, D. A. (2011). The neuropsychology of autism. New York: Oxford University Press.

Flom, R., Lee, K., \& Muir, D. (Eds.). (2007). Gaze-following: Its development and significance. Mahwah, NJ: Erlbaum.

Foxton, J. M., Stewart, M. E., Barnard, L., Rodgers, J., Young, A. H., O’Brien, G., \& Griffiths, T. D. (2003). Absence of auditory global interference in autism. Brain, 126, 2703-2709.

Frith, U. (1989). Autism: Explaining the enigma. Oxford, UK: Blackwell Publishing.

Frith, U., \& Snowling, M. (1983). Reading for meaning and reading for sound in autistic and dyslexic children. British Journal of Developmental Psychology, 1, 329-342.

Garon, N., Bryson, S. E., \& Smith, I. M. (2008). Executive function in preschoolers: A review Using an integrative framework. Psychological Bulletin, 134, 31-60.

Gordon, B., \& Stark, S. (2007). Procedural learning of a visual sequence in individuals with autism. Focus on Autism \& Other Developmental Disabilities, 22, 14-22.

Grant, C., Grayson, A., \& Boucher, J. (2001). Using tests of false belief with children with autism: How valid and reliable are they? Autism, 5, 135-145.

Hala, S., \& Russel, J. (2001). Executive control within strategic deception: A window on early cognitive development. Journal of Experimental Child Psychology, 80(2), 112-141.

Happé, F. G. E. (1997). Central coherence and theory of mind in autism: Reading homographs in context. British Journal of Developmental Psychology, 15, 1-12. 
Happé, F. G. E. (2000). Parts and wholes, meaning and minds: Central coherence and its relation to theory of mind. In S. Baron-Cohen, H. Tager-Flusberg, \& D. Cohen (Eds.), Understanding other minds: Perspectives from autism and developmental cognitive neuroscience (2nd Ed.) (pp. 203-221). Oxford, UK: Oxford University Press.

Happé, F. G. E., \& Frith, U. (2006). The weak coherence account: Detail-focused cognitive style in autism spectrum disorders. Journal of Autism and Developmental Disorders, 36, 525.

Happé, F. G. E. \& Booth, R. D. L. (2008). The power of the positive: Revisiting weak coherence in autism spectrum disorders. The Quarterly Journal of Experimental Psychology, 61, 50-63.

Heaton, P., Hermelin, B., \& Pring, L. (1998). Autism and pitch processing: A precursor for savant musical ability. Music Perception, 15, 291-305.

Herrmann, C. S.Ca, \& Bosch, V. (2001). Gestalt perception modulates early visual processing. Cognitive Neuroscience and Neuropsychology, 12(5), 901-904.

Hill, E. L. (2004). Evaluating the theory of executive dysfunction in autism. Developmental Review, 24, 189-233.

Hobson, R. P., \& Lee, A. (1999). Imitation and identification in autism. Journal of Child Psychology and Psychiatry, and Allied Disciplines, 40(4), 649-659.

Hongwanishkul, D., Happaney, K. R., Lee, W. S. C., \& Zelazo, P. D. (2005) assessment of hot and cool executive function in young children: Age-related changes and individual differences. Developmental Neuropsychology, 28(2), 617-64.

Hughes, C. (1996). Brief report: Planning problems in autism at the level of motor control. Journal of Autism and Developmental Disorders, 26, 99-107.

Hughes, C., Russell, J., \& Robbins, T. (1994).Evidence for executive dysfunction in autism. Neruopsychologia, 32(4), 477-492.

Humphreys, G. W., Olson, A., Romani, C. \& Riddoch, M. J. (1996). Competitive mechanisms of selection by objects and space. In A. Kramer \& N. Coles (Eds.), Converging operations in the study of visual selective attention. Hillsdale, N. J.: Erlbaum.

Jolliffe, T., \& Baron-Cohen, S. (1999). The strange stories test: a replication with highfunctioning adults with autism or asperger syndrome. Journal of Autism and Developmental Disorders, 29(5), 395-406.

Kahneman, D., \& Henik, A. (1981). Perceptual organization and attention. In M. Kubovy \& J.R. Pomerantz (Eds.), Perceptual organization (pp. 181-211). Hillsdale, NJ: Erlbaum.

Kahneman, D., \& Treisman, A. (1984). Changing views of attention and automaticity. In R. Parasuraman, D.R. Davies \& J. Beatty (Eds.), Variants of attention (pp. 29-61). New York: Academic Press.

Keehn, B., Luyster, R., Vogel-Farley, V., Tager-Flusberg, H., \& Nelson, C. (2012). GammaBand Activity and Coherence in Response to Familiar and Unfamiliar Faces in Infants at Risk for Autism Spectrum Disorder. Paper presented at the International Meeting for Autism Research, May 19, Toronto.

Keri, S. (2003). The cognitive neuroscience of category learning. Brain Research Reviews, 43, 85-109. 
Kimchi, R. (1992). Primacy of wholistic processing and global/local paradigm: A critical review. Psychological Bulletin, 112, 24-38.

Kjelgaard, M. M., \& Tager-Flusberg, H. (2001). An investigation of language impairment in autism: Implications for genetic subgroups. Language and Cognitive Processes, 16(2/3), 287-308.

Klin, A., Jones, W., Schultz, R., Volkmar, F. \& Cohen, D. (2002). Defining and quantifying the social phenotype in autism. American Journal of Psychiatry, 159, 895-908.

Klinger, L.G., Dawson, G., \& P. Renner (2003). Autistic disorder. In E.J. Mash \& R.A. Barkley (Eds.), Child Psychopathology (409-454). New York: Guilford.

Klinger, L. G., Klinger, M. R., \& Pohlig, R. (2007). Implicit learning impairments in autism spectrum disorders: Implications for treatment. In J. M. Perez, P. M. González, M. L. Comí, \& C. Nieto (Eds.), New developments in autism: The future is today (pp. 76-103). London: Jessica Kingsley.

Kloos, H., \& Van Orden, G. C. (2009). Soft-assembled mechanisms for the unified theory. In J.P. Spencer, M. Thomas, \& J. McClelland (Eds.) Toward a Unified Theory of Development: Connectionism and Dynamic Systems Theory Re-Considered,pp 253-267. Oxford University Press.

Kramer, A. F., \& Jacobson, A. (1991). Perceptual organization and focused attention: the role of objects and proximity in visual processing. Perception \& Psychophysics, 50, 267284.

Kylliainen, A., \& Hietanen, J. (2004). Attention orienting by another's gaze direction in children with autism. Journal of Child Psychology and Psychiatry, 45(3), 435-444.

Langdell, T. (1978). Recognition of faces : an approach to the study of autism. Journal of Child Psychology and Psychiatry, and Allied Disciplines, 19(3) 255-268.

Lopez, B., Donnelly, N., Hadwin, J. A., \& Leekam, S. R. (2004). Face processing in highfunctioning adolescents with autism: Evidence for weak central coherence. Visual Cognition, 11(6), 673-688.

Lopez, B. \& Leekam, S. R. (2003). Do children with autism fail to process information in context? Journal of Child Psychology and Psychiatry, 44(2), 285-300.

Lord, C., Risi, S., \& Pickles, A. (2004). Trajectory of language development in autistic spectrum disorders. In M. L. Rice \& S. F. Warren (Eds.) Developmental Language Disorders: From Phenotypes to Etiologies (7-29). Mahwah, NJ: Lawrence Erlbaum Associates.

Loveland, K. A., Tunali-Kotoski, B., Pearson, D. A., Brelsford, K. A., Ortegon, J., \& Chen, R. (1994). Imitation and expression of facial affect in autism. Development and Psychopathology, 6, 433-444.

Maurer, D., Le Grand, R., \& Mondloch, C. (2002). The many faces of configural processing. Trends in Cognitive Science, 6, 255-260.

McDuffie, A., Yoder, P., \& Stone, W. (2006). Fast-mapping in young children with autism spectrum disorders. First Language, 26, 421-436.

Meindl, J. N., \& Cannella-Malone, H. I. (2011). Initiating and responding to joint attention bids in children with autism: A review of the literature. Research in Developmental Disabilities, 1441-1454. 
Mondloch, C.J., Le Grand, R., \& Maurer, D. (2002). Configural face processing develops more slowly than featural face processing. Perception, 31, 553-566.

Moore, C. M., \& Egeth, H. (1997). Perception without attention: Evidence of grouping under conditions of inattention. Journal of Experimental Psychology: Human Perception and Performance, 23, 339-352.

Mostofsky, S. H., Goldberg, M. C., Landa, R. J., \& Denckla, M. B. (2000). Evidence for a deficit in procedural learning in children and adolescents with autism: Implications for cerebellar contribution. Journal of the International Neuropsychological Society, 6 (7), 752759.

Mottron, L. (2004). Matching strategies in cognitive research with individuals with highfunctioning autism: Current practices, instrument biases, and recommendations. Journal of Autism and Developmental Disorders 34, 19-27.

Mottron, L., Burack, J. A., Stauder, J. E. A., \& Robaey, P. (1999). Perceptual processing among high-functioning persons with autism. Journal of Child Psychology \& Psychiatry, 40, 203-211.

Mottron, L., Peretz, I., \& Menard, E. (2000). Local and global processing of music in highfunctioning persons with autism: beyond central coherence? Journal of Child Psychology and Psychiatry, 41, 1057-1065.

Müller, R., Cauich, C., Rubio, M.A., Mizuno, A., \& Courchesne, E. (2004). Abnormal activity patterns in premotor cortex during sequence learning in autistic patients. Biological Psychiatry, 56, 323-332.

Mundy, P., \& Newell, L. (2007). Attention, joint attention, and social cognition. Current Directions in Psychological Science, 16(5), 269-274.

Mundy, P., Sigman, M., \& Kasari, C. (1990). A longitudinal study of joint attention and language development in autistic children. Journal of Autism and Developmental Disorders, 20, 115-128.

Navon, D. (1977). Forest before trees: The precedence of global features in visual perception. Cognitive Psychology, 9, 353-383.

Nissen, M. J., \& Bullemer, P. (1987). Attentional requirements of learning: Evidence from performance measures. Cognitive Psychology, 19, 1-32.

Nordin, V., \& Gillberg, C. (1998). The long-term course of autistic disorders: Update on follow-up studies. Acta Psychiatrica Scandinavica, 97(2), 99-108.

Ozonoff, S. (1997). Components of executive function in autism and other disorders. In J. Russell (Ed.) Autism as an Executive Disorder (pp. 179-211). Oxford, UK: Oxford University Press.

Ozonoff, S., \& Jensen, J. (1999). Brief report: Specific executive function profiles in three neurodevelopmental disorders. Journal of Autism and Developmental Disorders, 29(2), 171177.

Ozonoff, S., Pennington, B., \& Rogers, S. (1991). Executive function deficits in highfunctioning autistic individuals: relationship to theory of mind. Journal of Child Psychology and Psychiatry, and Allied Disciplines, 32(7), 1081-1105. 
Ozonoff, S., Strayer, D.L., McMahon, W.M., \& Filloux, F. (1994). Executive function abilities in autism and Tourette syndrome: An information processing approach. Journal of Child Psychology and Psychiatry, 35, 1015-1032.

Parish-Morris, J., Hennon, E., Hirsh-Pasek, K., Golinkoff, R., \& Tager-Flusberg, H. (2007). Children with autism illuminate the role of social intention in word learning. Child Development, 78(4), 1265-1287.

Pellicano, E., \& Rhodes, G. (2003) Holistic processing of faces in preschool children and adults, Psychological Science, 14, 618-622.

Perner, J. (1991). Understanding the representational mind. Cambridge, MA: MIT Press.

Perruchet, P. (2008). Implicit learning. In H. Roediger III (Ed.), Cognitive psychology of memory. Oxford, UK: Elsevier.

Phillips, W., Baron-Cohen, S., \& Rutter, M. (1998). Understanding intention in normal development and autism. British Journal of Developmental Psychology, 16, 337-348.

Plaisted, K., Swettenham, J., \& Rees, L. (1999). Children with autism show local precedence in a divided attention task and global precedence in a selective attention task. Journal of Child Psychology and Psychiatry and Allied Disciplines, 40(5), 733-742.

Preissler, M., \& Carey, S. (2005). The role of inferences about referential intent in word learning: evidence from autism. Cognition, 97, B13-B23.

Rajendran, G., \& Mitchell, P. (2007). Cognitive theories of autism. Developmental Review, $27(2), 224-260$.

Reber, A. S. (1967). Implicit learning of artificial grammars. Journal of Verbal Learning and Verbal Behavior, 77, 317-327.

Romero-Munguía, M. A. (2008). Amnesic imbalance: A cognitive theory about autism spectrum disorders. Annals of General Psychiatry, 7, 20.

Russell, J., \& Jarrold, C. (1998). Error-correction problems in autism: Evidence for a monitoring impairment. Journal of Autism and Developmental Disorders, 28, 177-188.

Russell, J., \& Jarrold, C. (1999). Memory for actions in children with autism: Self versus other. Cognitive Neuropsychiatry, 4, 303-331.

Seltzer, M., Shattuck, P., Abbeduto, L., \& Greenberg, J. (2004). Trajectory of development in adolescents and adults with autism. Mental Retardation and Developmental Disabilities Review, 10(4), 234-247.

Scott, F.J., Brosnan, M., \& Wheelwright, S. (in preparation) Perception of Illusions by People with Autism: is there a low-level central coherence deficit? University of Cambridge, UK.

Shanks, D. R., Rowland, L. A., \& Ranger, M. S. (2005). Attentional load and implicit sequence learning. Psychological Research, 69(5-6). 369-382.

Shanks, D. R. (2005). Implicit learning. In K. Lamberts \& R. L. Goldstone (Eds.), Handbook of Cognition (pp. 202-220). London, UK: Sage.

Sigman, M., \& McGovern, C. (2005). Improvement in cognitive and language skills from preschool to adolescence in autism. Journal of Autism and Developmental Disorders, 35, 15-23.

Snowling, M., \& Frith, U. (1986). Comprehension in hyperlexic readers. Journal of Experimental Child Psychology, 42, 392-415.

Smith, L. B., Thelen, E., Titzer, R., \& McLin, D. (1999). Knowing in the context of acting: The task dynamics of the A-not-B-error. Psychological Review, 106(2), 235-260. 
Sigman, M., \& Ruskin, E. (1999). Continuity and change in the social competence of children with autism, Down syndrome, and developmental delays. Monographs of the Society for Research in Child Development, 64, v-114.

Spencer, J.P., Thomas, M.S., \& McClelland, J.L. (Eds.) (2009). Toward a Unified Theory of Development: Connectionism and Dynamic Systems Theory Re-Considered. New York: Oxford University Press.

Stone, W., Ousley, O., Yoder, P., Hogan, K., \& Hepburn, S. (1997). Nonverbal communication in two- and three-year-old children with autism. Journal of Autism and Developmental Disorders, 27, 677-696.

Stroop, J. R. (1935). The basis of Ligon's theory. The American Journal of Psychology, 47(3), 499504.

Tantam, D., Monaghan, L., Nicholson, H., \& Stirling, J. (1989). Autistic children's ability to interpret faces: A research note. Journal of Child Psychology and Psychiatry, and Allied Disciplines, 30(4), 623-630.

Thagard, P. (1989). Explanatory coherence. Behavioral and Brain Sciences, 12, 435-502.

Travers, B. G. , Klinger, M. R., Mussey, J. L., \& Klinger, L. G. (2010). Motor-linked implicit learning in persons with autism spectrum disorders. Autism Research, 3, 68-77.

Toichi, M. \& Kamio, Y. (2002). Long-term memory and levels-of-processing in autism. Journal of Autism and Developmental Disorders, 31, 483-90.

Tomasello, M. (1995). Joint attention as social cognition. In C. Moore, \& P. J. Dunham (Eds.) Joint attention: Its origins and role in development (pp. 103-129). New Jersey: Erlbaum, Hillsdale.

Vlamings, P., Strauder, J., van Son, I., Mottron, L. (2005). Atypical visual orienting to gazeand arrow-cues in adults with high functioning autism. Journal of Autism and Developmental Disorders, 35(3), 267-277.

Warreyn, P., Roeyers, H., Oelbrandt, T. \& De Groote, I. (2005). What are you looking at? Joint attention and visual perspective taking in young children with autism spectrum disorder. Journal of Developmental and Physical Disabilities, 17, 55-73.

Wellman, H. M. (1990). The child's theory of mind.. Cambridge, MA: MIT Press.

Yirmiya, N., Solomoncia - Levi, D., Shulman, C. \& Pilowsky, T. (1996). Theory of mind Abilities in individuals with autism, Down syndrome, and mental retardation of unknown etiology: The role of age and intelligence, Journal of Child Psychology and Psychiatry 37 (8): 1003-14.

Younger, B. (1993). Understanding category members as "the same sort of thing": Explicit categorization in ten-month infants. Child Development, 64, 309-320

Zelazo, P. D., Burack , J . A., Benedetto, E. \& Frye, D. (1996). Theory of mind and rule use in individuals with Down's syndrome: A test of the uniqueness and specificity claims, Journal of Child Psychology and Psychiatry, 37 (4): 479-84.

Zelazo, P. D., \& Müller, U. (2002). Executive function in typical and atypical development. In U. Goswami (Ed.), Handbook of childhood cognitive development. Oxford: Blackwell.

Zwaigenbaum, L., Bryson, S., Rogers, T., Roberts, W., Brian, J., \& Szatmari, P. (2005). Behavioral manifestations of autism in the first year of life. International Journal of Developmental Neuroscience, 23, 143-152. 


\title{
Psychological Fitness in Young Adult Video Game Players
}

\author{
Mieczyslaw Pokorski, Lukasz Borecki and Urszula Jernajczyk
}

Additional information is available at the end of the chapter

http://dx.doi.org/10.5772/47921

\section{Introduction}

Video games have been available to the public for several decades and are increasingly used by persons of all ages, mostly as part of the entertainment world (Kent, 2001). The games are thought to have either positive or negative effects on the users; the unsettled effects are a matter of scientific scrutiny of late (for a review see Ferguson, 2007; Papastergiou, 2009). The games are often portrait as a potential source of social and health problems, which is of increasing concern to legislators and policymakers (Phillips, 2004; Gray \& Nikolakakos, 2007; Collier et al., 2008, Weaver et al., 2009). A number of studies show an impact on individuals of using video games. The use, or overuse, of certain types of games may increase aggressive behaviors. That concerns mostly 'violent games' which were found to increase children's aggression and to decrease school performance and attention (Hastings et al., 2009). In adults, interestingly, the more the game pertains to the real life situation, the more the players display aggressive thoughts and attitudes, and physiological arousal. Such effects are seen as quickly as 45 min into the play (Barlett \& Rodeheffer, 2009). The studies which pertain to the detrimental influence of games on behavior are however riddled with controversies stemming mostly from inadequate methodological issues. The great majority of these studies is carried out in children. The most common methodology consisting of the observation of free play does not fulfill the criteria of scientific scrutiny. Moreover, as in the study on the effects of violent video games alluded to above, usually short-term measures of aggressive consequences are taken into consideration. The negative effects of playing the video games are often associated with the games that include violent scenes and enable the player to virtually harm the other players' avatars (Griffiths, 1999).

The psychological maleficency of games, particularly when overused, is however debatable as there also are reports to the contrary, indicating that games may help manage untoward behaviors such as conflicts, frustration, aggression, and do not necessarily result in social withdrawal (Kestenbaum \& Weinstein, 1985). 
On the health front, there is considerable evidence that excessive use of video games may lead to elevated levels of anxiety, depression, and poorer general health status in both younger (Schmit et al., 2011) and older adults (Weaver et al., 2009; Mentzoni et al., 2011). Interestingly, sexually-oriented content of video games may give rise to sexual stereotypes. In a study by Behm-Morawitz \& Mastro (2009) undergraduate students were assigned to play a game containing a sexualized female character or no such character. The sexualized fable gave rise to unfavorable beliefs about women and the female player's self-esteem was unfavorable affected.

On the other side, evidence accumulates that video games may have an overall positive influence, particularly in young persons, in such domains as health and physical education, and social attitude, to the extent that games might be considered a useful incorporation in healthcare programs (Papastergiou, 2009). Playing action video games may improve a variety of visual and attentional skills, and the processing of multitask information or, in other words, of multiple sensory signals arriving from the periphery (Green \& Bavelier 2003; Boot et al., 2008).

Relatively little is known whether video games can be used to improve our brain, to enhance intellectual performance, or to alter one's psychological characteristics. Recent advances in neuroscience give us strong support it might be so. Video games offer a unique, still untapped opportunity to gain insight into the neural mechanisms underlying cognition, as they approach a real life-like environment in terms of problem solving complexity. Cognitive and emotional capacity comes from having more synapses in the hypothalamic areas of amygdala and hippocampus. Multitask training leads to the recruitment of new neuronal circuits which are used more efficiently and flexibly (Maclin et al., 2011). The brain may get a functional boost or even be physically altered and restructured, as the regions involved in specific sensory inputs expand, particularly if the task are used on a repetitive basis.

\section{Video games and mental fitness}

Video games, particularly the multitasks ones, involve all kinds of dynamic transformations of fictitious action the player encounters on his way, ranging from the shape and size of objects to the placement and location in time and environment. The games represent a highly variable stimulation of one's senses and put a demand on cognitive performance, which makes them obvious candidates for improving brain adaptive capacity. Nevertheless, reports on the enhancing effects on brain prowess of video games are, at best, scanty and confusing. A criticism often is raised that games used for the assessment of one's cognitive performance are created for the purpose of a study, subjects are recruited from the population of 'non-often players' and the time and intensity of 'training' is set by the researcher (Maclin et al., 2011), all of which being biases. In an attempt to sidestep this criticism, we performed a series of studies which seek to determine the effects of a computer-based action game on psychological fitness of habitual game players recruited from their community environment. We chose a video game called Counter Strike, because of 
its widespread popularity (Remo, 2008). This, created only for entertainment, game is set in a fictive violent battlefield and enables a player to impersonate a member of a military unit on a mission that requires players to shoot missiles, attack an enemy, or defend the player's position; the actions requiring the engagement of various cognitive and psychomotor skills. The rationale was to ensure strong mental stimulation and to make the optimal use of brain neuronal networks. We addressed the issue by examining the ability to control and switch attention between multiple gaming tasks, visual-spatial skills, memory, decision making, perceptual skills, and emotional and personality features of young adults who were habitual video game players and by comparing the results with those obtained in a matched control group of never-players.

There were 30 game players (F/M - 3/27; age range 20-25 years), who confirmed a regular use of the game Counter Strike, and 30 never-users entirely naïve to video gaming (F/M 4/26; age range 20-25 years) enrolled into the study. The regular use was considered as playing the games at least 3 days per week for 2 hours or more each time, and at least for the six months preceding the study time. All participants were university students. The game players were all using a standard PC computer with a keyboard and mouse as the main accessories for playing and all of them declared using the multiplayer mode to interact with other players. Participation in all tests and tasks was anonymous and voluntary.

Cognitive functions were investigated using sets of neuropsychological assessment tools that consisted of various thinking, memory, intelligence, and visual-spatial ability measures, such as the RehaCom (Hasomed $\mathrm{GmbH}$, Magdeburg, Germany), the Vienna Test System version 6 (Dr. G. Shuhfried GmbH, Mödling, Austria), and the Wechsler Adult Intelligence Scale (Polish adaptation-WAIS-R PL) (Brzezinski \& Hornowska, 1998). Specifically, episodic memory was tested with a WAIS-R Digit Span which assesses the number of digits remembered, and visual working memory with a RehCom BILD test, in which the person should recognize whether among many flashing names of objects on the screen is that that corresponds to one of the objects shown some time before. In the latter test, three arbitral break periods were used of 5-25, 26-55, and 56-85 sec; the longer the break and sustained good object recognition, the better is the visual memory.

Conceptual thinking, in turn, was tested with a WAIS-R Similarities test, logical reasoning with a RehaCom LODE test in which the subject has to add missing elements to the logically-structured column of symbols, perception of details with a WAIS-R Picture Completion test, perceptive processing with a VTS ATAVT Adaptive Tachistoscopic Traffic Perception test in which the respondent is quickly presented with a series of traffic pictures and then asked to report noticed details, and decisiveness and impulsiveness with a VTS AHA Attitudes to Work-Comparing Surfaces test in which the subject decides which of the two presented shapes is larger.

Emotional and personality aspects were assessed with the Coping Inventory for Stressful Situations (CISS) (Endler \& Parker, 1999) and the Eysenck Personality QuestionnaireRevised (EPQ-R) (Eysenck et al. 1985). 
The computerized paradigms and psychometric tools above outlined are all well standardized and sanctioned for the assessment of executive-control and emotional functioning.

\subsection{Cognitive enhancement of video game players}

The findings from our work concerning the cognitive fitness of video game players and the comparison with non-players are displayed in the consecutive figures. Fig. 1 demonstrates the results of episodic memory. The players scored significantly better on a WAIS-R Digit Span test than the non-players ( $16.7 \pm 0.8$ vs. $11.3 \pm 1.0$ digits remembered, respectively). The players also performed better on visual working memory. Here, a significant majority of 19 out of the 30 game users recognized the descriptions of pictures after the longest time break of the 55-85 sec range as opposed to none of the non-players, where the quickest lapses of memory prevailed (Fig. 2, Panel A). There were significant differences in favor of the game players noted in logical reasoning as well, where 20 out of the 30 players accomplished the highest number of positive hits compared with none of the non-players (Fig. 2, Panel B). In these two tests, the null hypothesis that there is no difference between the two distributions of subjects, video game players and non-players, was rejected.

Conceptual thinking also turned out significantly superior in the game players $(15.5 \pm 1.2$ vs.10.0 \pm 1.0 points in the non-players (Fig. 3). Concerning the decision making, the players displayed better results in decisiveness $(19.3 \pm 1.9$ vs. $12.5 \pm 2.2$ points in the non-players; $\mathrm{P}<0.001$, Mann-Whitney U test) (graphic data not shown) and also had a higher mean score in impulsiveness (19.6 \pm 0.6 vs. $17.9 \pm 0.7$ points, respectively) (Fig. 4). Finally, the players' superiority in cognitive tasks was completed by better outcomes in the perception of details (16.4 \pm 0.8 vs. $10.6 \pm 1.0$ points in the non-players) (Fig. 5) and in the perceptive processing assessed with a VTS ATAVT Adaptive Tachistoscopic Traffic Perception test (55.2 \pm 1.5 vs. $38.0 \pm 2.2$ points in the non-players; ${ }^{*} \mathrm{P}<0.001$, Mann Whitney $\mathrm{U}$ test) (graphic data not shown).

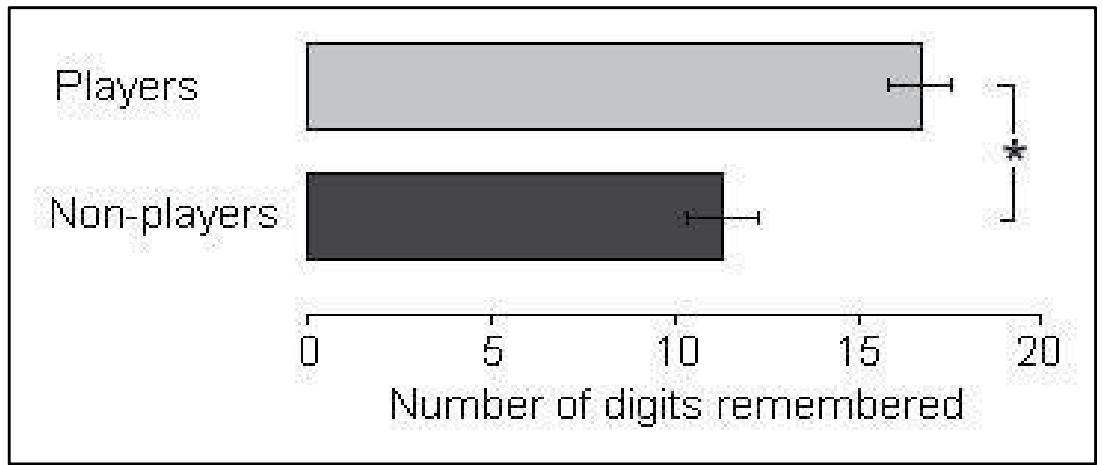

Figure 1. Number of digits remembered by game players and non-players in the WAIS-R Digit Span Test for episodic memory (data are means $\pm \mathrm{SD} ;{ }^{*} \mathrm{P}<0.001$, Mann-Whitney $\mathrm{U}$ test). 


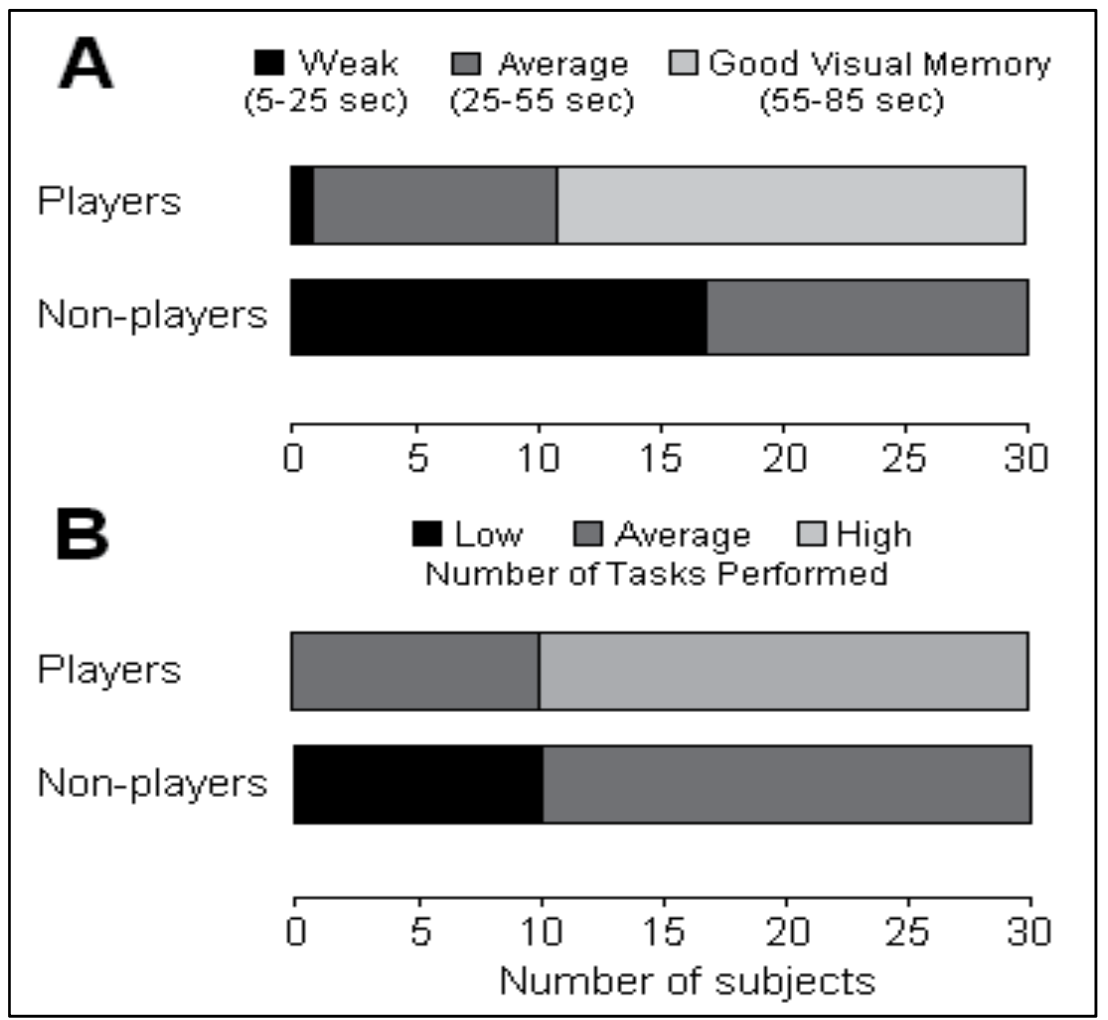

Figure 2. Panel A - Visual working memory of video games players $v s$. non-players assessed with a RehCom BILD Test $\left(\chi^{2}=30.5 ; \mathrm{P}<0.001\right)$; Panel B - Logical reasoning assessed with a RehaCom LODE Test (data distributed on 3-degree Likert scale, $\chi^{2}=33.3 ; \mathrm{P}<0.001$ ).

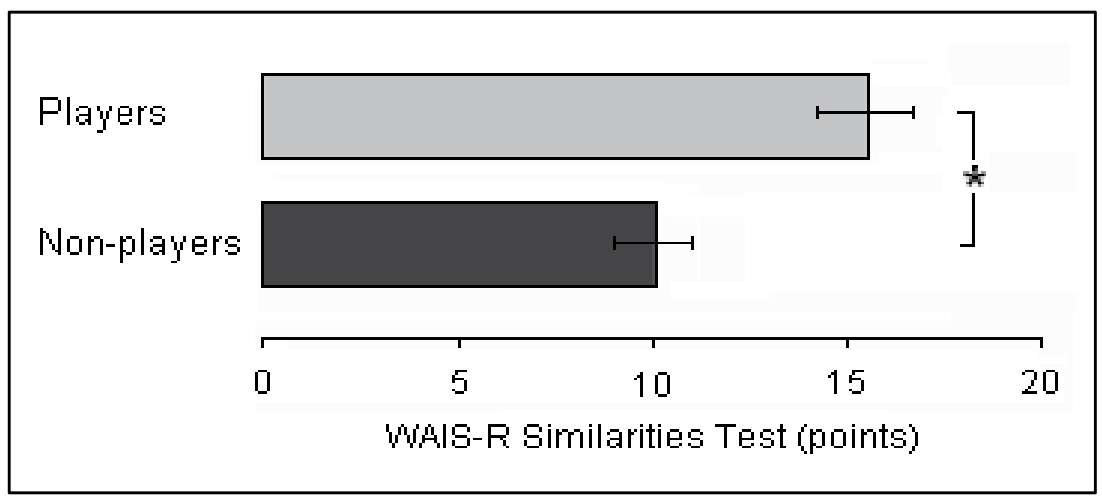

Figure 3. Differences between the video games players and non-players in the WAIS-R Similarities Test for conceptual thinking (data are means $\pm \mathrm{SD} ;{ }^{*} \mathrm{P}<0.001$, ANOVA). 


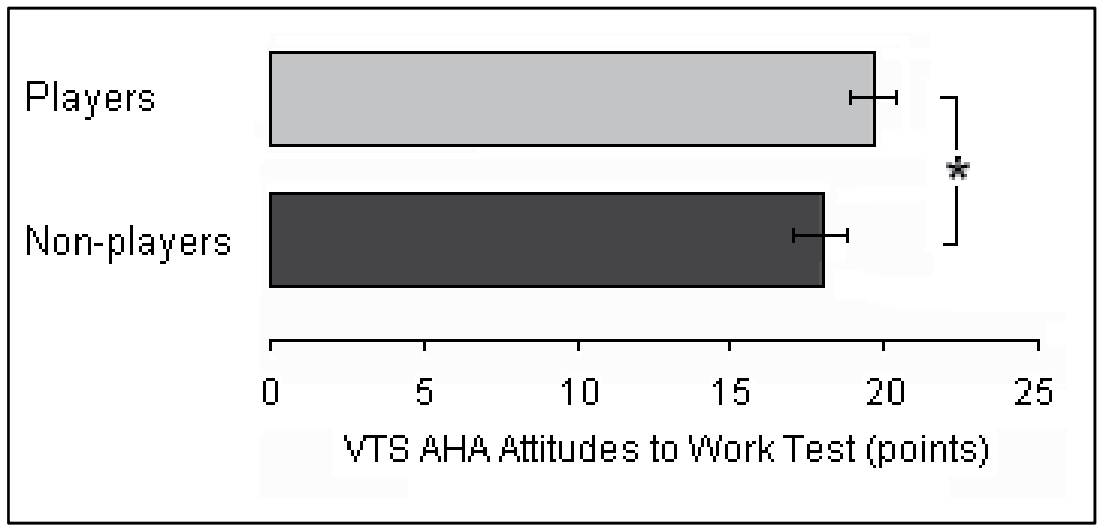

Figure 4. Differences between players and non-players in VTS AHA Attitudes Test for impulsiveness (data are means $\pm \mathrm{SD} ;{ }^{*} \mathrm{P}<0.001, \mathrm{ANOVA}$ ).

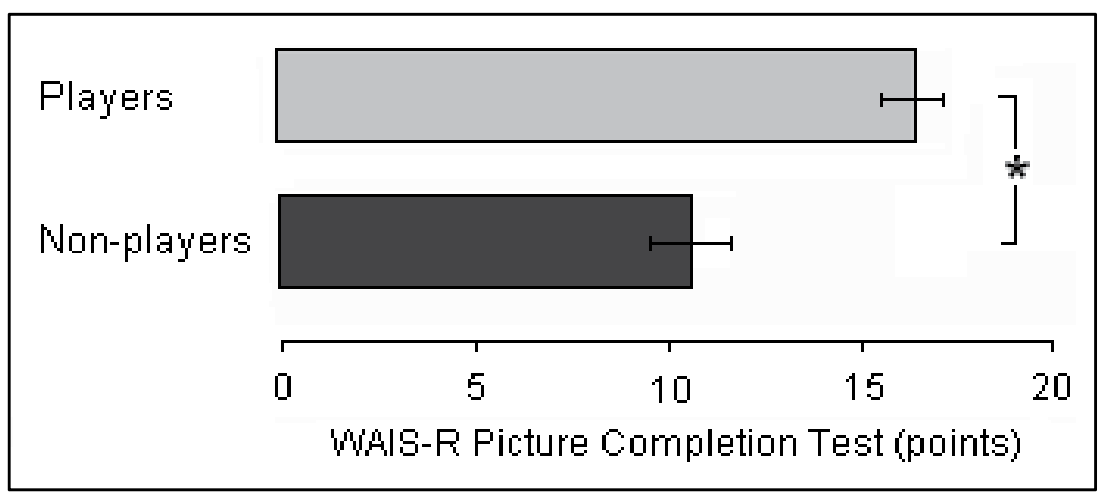

Figure 5. Difference between players and non-players in WAIS-R Picture Completion Test for perception of details (data are means \pm SD; ${ }^{*} \mathrm{P}<0.001$, Mann-Whitney $U$ test). 


\subsection{Emotional enhancement of video game players}

When we compared emotional stability between the video game players and nonplayers, as expressed by the level of neuroticism, it turned out that the players were appreciably less neurotic and more emotionally stable. The two populations of subjects not only significantly differed concerning the level of neuroticism, but the players also had characteristically different personality traits. This is shown in Fig. 6 which demonstrates the profiles of the introversion-extroversion continuum, expressed in stens. Extroversion appeared a clearly predominating personality trait in the majority of players (23 subjects), with but one subject scoring in the lowest sten division corresponding to introversion. This profile contrasted with that present in the nonplayers, where ambiversion predominated (15 subjects), followed by introversion in 10 subjects.

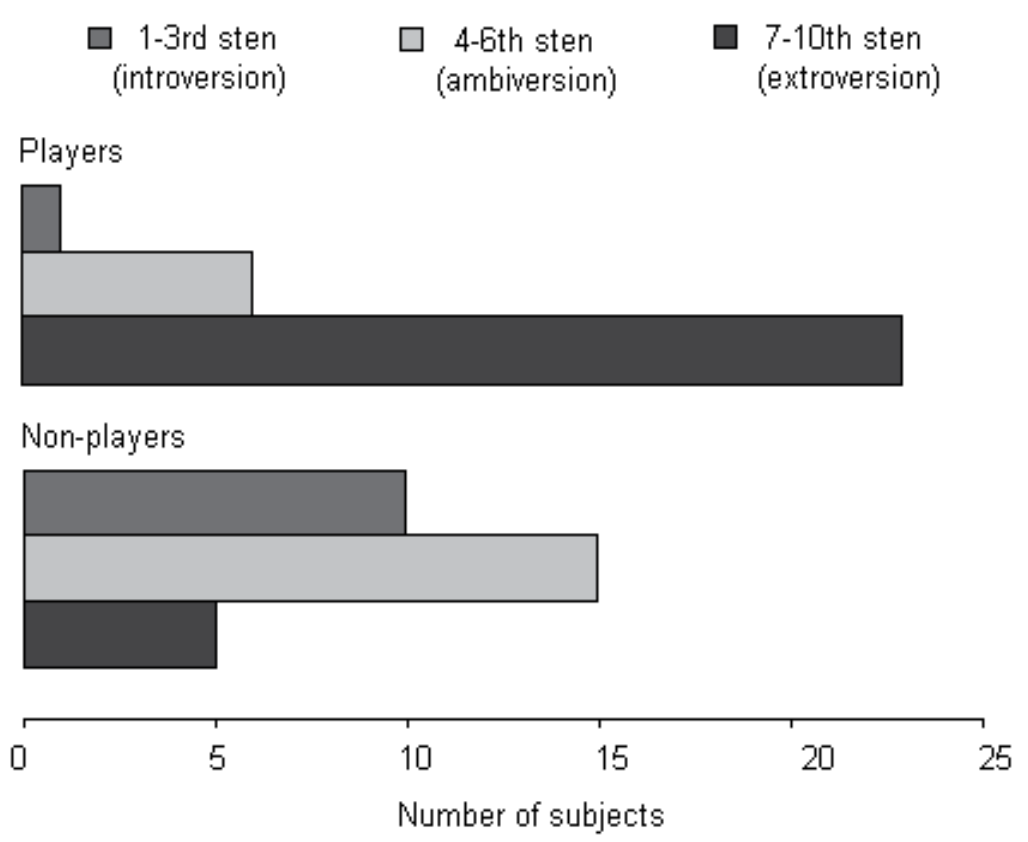

Figure 6. Personality traits in video game players and non-players surveyed with EPQ-R questionnaire $\left(\chi^{2}=22.8, \mathrm{P}<0.001\right.$; reproduced with permission from Borecki et al., 2011).

More adaptive emotional characteristics of video game players were also reflected in their tackling of stressful situations. The majority of them presented the advantageous taskoriented strategy of coping with stress. Other less adaptive styles of coping were present in a fewer number of players than in non-players; avoidance-oriented 0 vs. 8 subjects, distraction 2 vs. 13 subjects, social diversion 0 vs. 8 subjects, respectively. The only exception here was the emotion-oriented style of coping which appeared in eight players as opposed to one non-player. All these differences between the players and non-players were significant as depicted in detail in Fig. 7. 


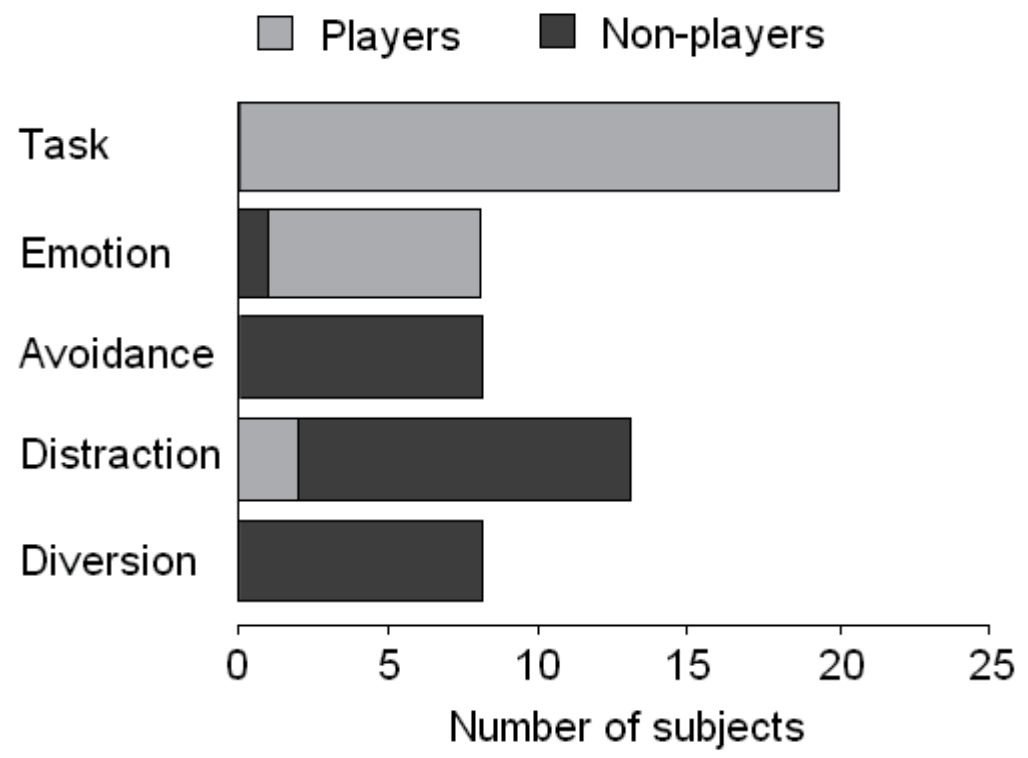

Figure 7. Styles of coping with stress in video game players and non-players assessed with CISS questionnaire $\left(\chi^{2}=49.5, \mathrm{P}<0.001\right.$; reproduced with permission from Borecki et al., 2011).

\section{Psychological agility of video game players}

\subsection{Cognition}

Video games have become a kind of appeasement genre. The games seem limitless in terms of technological progress which turns them into ever greater enjoyable experience for players. The popularity of games spurred research on their potential psychological effects. However, the influence of long-term repetitive video gaming on cognitive fitness is not full well clear. Our research above outlined demonstrates that spontaneous, uncontrolled video gaming activity, performed on a regular basis, increases cognitive fitness. Regular, avid video game players perform better on tests of episodic and visual working memory, decision making, perceptive processing, and conceptual and logical thinking than never-users of video games. Thus, game playing enhances mental agility in young adult players compared with that of non-players. These results are in accord with those of other studies which show the overall positive effects of heavy use of video games on attention, memory, and other executive-controlled brain functions (Boot et al., 2008, Maclin et al., 2011).

That video game players' perceptual and cognitive skills extend far beyond those demonstrated by never-players seems to have a sound neurophysiological foundation. Research shows that neuronal networks used regularly for a given multitask set will be recruited to a fuller extent or alternative networks will come into play. There will be more flexibility in problem solving (Stern, 2002; Green \& Bavelier, 2003). A habitual 'trained' 
game user might be able to use redundant neuronal pathways to accomplish the task or, in other words, approach the task from different angles.

\subsection{Personality and emotion}

Our work demonstrates the presence of a specific game-related psychological pattern developed as a result of repetitive gaming sessions. The on-line games require an active interaction and cooperation with other players. This is congruous with the more outgoing, more approachable, and socially interactive personality trait of extroversion present in the players. Players are better emotionally equipped. They employ emotionally superior taskoriented strategy of coping with stress and are, in general, more emotionally stable. Gaming acquaints with a highly competitive, i.e., stressful circumstances. Such circumstances may actually help the players adapt to other real-life stressful situations and make them feel more secure and of higher self-esteem, which is reflected in taking on the more adaptive task-oriented strategy of coping with stress. The players would then be less vulnerable to stress in the longer-run.

Choosing a more adaptive style of coping with stress is in correspondence with disconfirmation of less-adaptive styles by video game players, as seen in our results. Unexpectedly, the emotion-oriented style of coping was up in this group. Possibly, there were persons among the players who were inherently predisposed to the feelings of anger or sadness. Such feelings may have been mitigated during the gaming sessions, but came to light between the sessions.

The overall advantageous psychological pattern in video game players may likely have to do with more efficient and less susceptible to disruption use of neuronal networks. Emotional stability would then go in harmony with enhanced cognitive functions due possibly to coordinated interaction of neurons in wider spread areas as a result of repetitive 'training' sessions (Uhlhaas \& Singer, 2006).

\subsection{Piagetian aspects}

Repetitive, training-like binding of perceptive signals in the context of previously acquired experience and knowledge while using video games fits well into Jean Piaget's cognitive theory known as 'cognitive constructivism'. The theory was originally created to understand the successive stages of intellectual development from the neonatal to childhood age (Piaget, 1977). On the premise, however, that cognitive development does not end at the age of physical maturity and rather represents a sort of continuum throughout the life cycle (Commons \& Richards, 1984; Demetriou et al., 2010), we submit that the process of cognitive improvement in young adults due to video gaming may be seen extensional to this theory. One can find in the cognitive enhancement due to video gaming the basic tenets of Piaget's ideas. Games help classify or group subjects together on the basis of common features, which seems obvious in case of a battlefield or other action games. They help a person take new material into his mind from the fictitious fable and from the real environment 
pertaining to the interaction with other players. Games thus play on the senses to make one's mind pliable to accommodate concepts and to adapt to changing situations. This adaptation also has to do with playing back on the memories of prior experiences, which should be fostered by improved memory processing in the game users shown in the present study. Furthermore, gaming facilitates the thinking process by trying to work things out in the head on the basis of the representation in the mind of the actions contained in the game. Enhanced conceptual thinking and logical reasoning in the gamers go hand in hand with the overall improved thinking process. The multitask games develop a mind frame for taking into account multiple aspects of a problem to solve it; a feature named decentering in the Piagetian classification of mental operations. Finally, games enhance the ability to shift away from one action to another, all of which takes place under pressure of time and interaction with other players, which forces out decisiveness in action, an additional element liable to drive cognitive enhancement. Put it in another way, the video game players are called upon using earlier learned abilities and upon performing concrete operations which they would not have undertaken otherwise, which brings to light the players' untapped cognitive potential. Video gaming enhances what, in general terms, is called psychological maturity.

\subsection{Neural processing}

Contemporary neurophysiological research, unavailable at the time of Piaget, lends credence to the functional brain changes above outlined. Cognitive fitness has to do with coordinated synchronization of neural activity in different, often anatomically remote, brain areas. The better the temporal and spatial neuronal integration the better is the cognitive performance (for a review see Singer, 1999; Varela et al., 2001; Uhlhaas \& Singer, 2006). Although neurophysiological data are discordant, for instance, attentional processing occurring with complex task training is ascribed alternately to lower frequency alpha (Maclin et al., 2011) or higher frequency beta range (Singer, 1999) in EEG recordings, the necessity for a large-scale synchronization of neural activity to accomplish the task is beyond a question. The multitask actions, typical for the video game, like the one presented in this article, require a parallel processing of multisensory inputs. Repetitive use of video games is thus bound to increase the attention and task-dependent correlates of cognition, such as conscious and purposeful stimulus selection and processing or operative memory. These processes, in turn, enhance 'cognitive reserve', the term coined for the ability to optimize performance of currently functioning neuronal substrate when coping with excessive task demands in healthy individuals or to recruit alternate 'reserve' substrate not normally used in case of diseased individuals with brain damage (Stern, 2002). The applicability of the notion of 'cognitive reserve' to video games' effects has practical implications, such as the game training might help brain impaired persons cope with the handicap.

\subsection{Uncertainties}

Research on psychological role of video games is subject to frequent methodological flaws and the presented work is no exception. The participants were cross-sectional. The gamers 
did not play games while surveyed. They did the psychometric tests once at the time free of gaming. Nor was the crucial issue tackled of whether the video games enhanced cognitive fitness concerning the specific mental tasks used in game training or the enhancement held true for other unrelated tasks. However, there is evidence from other studies that video games, particularly those exerting a high action-related and heterogeneous demand on mental functions, have a globally improving effect on one's cognition and psychological functioning (Frostling-Henningsson, 2009; Papastergiou, 2009).

The cause-and-effect relation is difficult to prove in the design of the presented work. It is possible that expert players fared better on the tests squarely because it takes better cognitive skills to be a good gamer in the first place. Thus, gamers would have had an inherent advantage over never-gamers when tested. However, both groups of subjects were fairly well matched regarding age, gender, educational status, etc. Although the matching obviously does not preclude inter-group differences having a genetic or environmental background, any such differences would seem random rather than systematic in view of a substantial number of subjects tested. There is no reason to assume the never-gamers are $a$ priori inferior in cognitive or intellectual skills compared with gamers due to the sheer fact that they do not like playing the games. The major criterion of gamers selection was the long-term, for months, habitual use of video games. That criterion made it unworkable, for practical reasons, to carry out a longitudinal training study of the pre-post test type or tracing the cognitive gamers' history in their pre-habitual period. We purposefully chose a long-term habituation to gaming on the premise that it will enable us to bring out contrasts between gamers and never-gamers, which may not be the case in shorter time training protocols. Despite these limitations, we believe we have demonstrated that video gaming enhances cognitive and emotional fitness in young adult players.

\section{Concluding remarks}

This article describes the associations between playing the video games and psychological health. Commercial video games apparently offer an unintentional cognitive training, which makes them a psychomotor rehabilitation tool. Video games may supplement rehabilitative strategies in pathological conditions that affect adults, such as psychiatric and psychological disorders, including depression and neurodegenerative conditions in which cognitive performance and memory suffer or which may be accompanied by disordered thinking and decision-making (Gleichgerrcht et al., 2010). To this end, video games may also counter a natural cognitive decline of aging (Foos \& Sarno, 1998). Future research should explore the best ratio of regularity, time and effort put into playing the games to achieve the maximum effectiveness of cognitive self-training. Finding the right proportions will enable the rehabilitators to advocate natural or prescribed use of video games for cognitive enhancement.

Video games are often degraded to unwise activity and loss of time from the intellectual standpoint. We submit that negative attitudes toward the video games are not substantiated or are due to parental overreactions. Young persons should be motivated to start gaming 
activity and not to overuse it. The use of video games also may become part of educational adolescent activity. It seems hardly achievable to make young persons stop playing the games, and in the light of the presented research it may actually be undesirable to do so. To the contrary, when appropriately used, widely popular games can be utilized as a valuable tool for cognitive training. The positive effects of playing the games stand in opposition to an often held view by the lay public that games, particularly those of aggressive genre, are maleficent. Instead, playing the video games should be knowledgeably used to effectively support psychological health

The authors have no conflicts of interest to declare in relation to this article.

\section{Author details}

Mieczyslaw Pokorski*, Lukasz Borecki and Urszula Jernajczyk

Institute of Psychology, Opole University, Opole, Polan;

Medical Research Center, Polish Academy of Sciences, Warsaw, Poland

\section{References}

Barlett C. \& Rodeheffer C. (2009). Effects of realism on extended violent and nonviolent video game play on aggressive thoughts, feelings, and physiological arousal. Aggress Behav 35(3): 213-224.

Behm-Morawitz E. \& Mastro D. (2009). The effects of the sexualization of female video game characters on gender stereotyping and female self-concept. Sex Roles 61(11/12): 808-823.

Boot W.R., Kramer A.F., Simons D.J., Fabiani M. \& Gratton G. (2008). The effects of video game playing on attention, memory, and executive control. Acta Psychologica 129(3): 387-398.

Borecki L., Tolstych K. \& Pokorski M.. (2011). Emotions and coping with stress in video game users. Management and Education - Academic Journal of 'Prof. Dr. Assen Zlatarov' Burgas University 7: 112-117.

Brzezinski J. \& Hornowska E. (Eds.). (1998). Wechsler Intelligence Scale WAIS-R. Polish Scientific Publishers, Warsaw, PWN.

Collier J., Liddell Jr. P. \& Liddell G. (2008). Exposure of violent video games to children and public policy implications. Journal of Public Policy E Marketing 27(1): 107-112.

Commons M.L. \& Richards F.A. (1984). 'A general model of stage theory' - and - 'Applying the general stage model'. In: Commons M.L., Richards F.A. \& Armon C. (Eds.). Beyond formal operations: Vol.1: Late adolescent and adult cognitive development. New York: Praeger, pp. 120-157.

Demetriou A., Mouyi A. \& Spanoudis G. (2010). The development of mental processing. In: Overton W. F. (Ed.), Biology, cognition and methods across the life-span. Vol. 1: Handbook of Life-Span Development. Editor-in-chief: R. M. Lerner. Hoboken, NJ: Wiley, pp. 36-55.

" Corresponding Author 
Endler N.S. \& J.D.A. Parker. (1999). Coping inventory for stressful situations (CISS): Manual (Revised edition). Toronto: Multi-Health Systems.

Eysenck S.B.G., H.J. Eysenck \& Barrett P. (1985). A revised version of the psychoticism scale. Pers Individ Dif 6(1): 21-29.

Ferguson C.J. (2007). The good, the bad and the ugly: A meta-analytic review of positive and negative effects of violent video games. Psychiatr Q 78(4): 309-316.

Foos P. \& Sarno A. (1998). Adult age differences in semantic and episodic memory. J Genet Psychol 159(3): 297-312.

Frostling-Henningsson M. 2009. First-person shooter games as a way of connecting to people 'brothers in blood'. Cyberpsychol Behav 12(5): 557-562.

Gleichgerrcht E., Ibáñez A., Roca M., Torralva T. \& Manes F. (2010). Decision-making cognition in neurodegenerative diseases. Nat Rev Neurol 6(11): 611-623.

Gray G. \& Nikolakakos T. (2007). The self-regulation of virtual reality: Issues of voluntary compliance and enforcement in the video game industry. Can J Law Soc 22(1): 93-108.

Green C.S. \& Bavelier D. (2003). Action video game modifies visual selective attention. Nature 423(6939): 534-7.

Griffiths M. (1999). Violent video games and aggression: A review of the literature. Aggress Violent Behav 4(2): 203-12.

Hastings E., Karas T., Winsler A., Way E., Madigan A. \&Tyler S. (2009). Young children's video/computer game use: relations with school performance and behavior. Issues Ment Health Nurs 30(10): 638-649.

Kent S.L. (2001). The Ultimate History of Video Games. San Val Inc, US.

Kestenbaum G.I. \& Weinstein L. (1985). Personality, psychopathology, and developmental issues in male adolescent video game use. J Am Acad Child Psychiatry 24(3): 329-333.

Maclin E.L., Mathewson K.E., Low K.A., Boot W.R., Kramer A.F., Fabiani M. \& Gratton G. (2011). Learning to multitask: Effects of video game practice on electrophysiological indices of attention and resource allocation. Psychophysiology 48(9): 1173-83.

Mentzoni R.A., Brunborg G.S., Molde H., Myrseth H., Skouverøe K.J., Hetland J. \& Pallesen S. (2011). Problematic video game use: estimated prevalence and associations with mental and physical health. Cyberpsychol Behav Soc Netw 14(10): 591-6.

Papastergiou M. (2009). Exploring the potential of computer and video games for health and physical education: A literature review. Comput Educ 53(3): 603-622.

Phillips N. (2004). Interactive digital software ASS'N v. St. Louis County: the first amendment and minors' access to violent video games. Berkeley Technol Law J. Annual Review 19(1): 585-611.

Piaget J. The Essential Piaget. (1997). Gruber H. E. \& Jacques Vonèche J. (Eds.), New York: Basic Books.

Remo C. (2008). Analysis: Valve's lifetime retail sales for half-life, counter-strike franchises. Gamasutra. Available from: www.gamasutra.com/phpbin/news_index.php?story=2139

Singer W. (1999). Neuronal synchrony: A versatile code of the definition of relations? Neuron 24(1): 49-65. 
Schmit S., Chauchard E., Chabrol H. \& Sejourne N. (2011). Evaluation of the characteristics of addiction to online video games among adolescents and young adults. Encephale 37(3): 217-23 (Article in French).

Stern Y. (2002). What is cognitive reserve? Theory and research application of the reserve concept. J Int Neuropsychol Soc 8(3): 448-460.

Uhlhaas P.J. \& Singer W. (2006). Neural synchrony in brain disorders: relevance for cognitive dysfunctions and pathophysiology. Neuron 52(10: 155-168.

Varela F., Lachaux J.P., Rodriguez E. \& Martinerie J. (2001). The brainweb: phase synchronization and large-scale integration. Nat Rev Neurosci 2(4): 229-239.

Weaver J., Mays D., Weaver J.B. 3rd, Mays D., Sargent Weaver S., Kannenberg W., Hopkins G.L., Eroğlu D. \& Bernhardt J.M. (2009). Health-risk correlates of video-game playing among adults. Am J Prev Med 37(4): 299-305. 


\title{
The Impact of Moving Away from Home on Undergraduate Metacognitive Development
}

\author{
Kevin Downing \\ Additional information is available at the end of the chapter
}

http://dx.doi.org/10.5772/47269

\section{Introduction}

For many freshmen undergraduates around the world, the start of their undergraduate careers are marked by a number of significant challenges, not least amongst these is often the requirement to move away from the family home, usually for the first time, and engage in the processes required to manage your time without parental guidance and intervention. Most students seem to survive this 'rite of passage' and go on to make a success of their studies and the important new social relationships they form at this time. A few do not rise to the challenges, and consequently fail in their adaptation to the new circumstances which confront them. This chapter considers some remarkable quantitative evidence for what the author had previously observed during his career as an academic and residence master in a Hong Kong university. Namely, that moving away from home appears to have a significant positive impact upon the development of metacognition in undergraduates.

\section{Definitions of metacognition}

Perhaps the most practical definition of metacognition is that it is 'thinking about thinking' (Flavell, 1999; Metcalfe, 2000; Bogdan, 2000; Downing, 2009a; Ning \& Downing 2010) however this definition requires further elaboration, because metacognition also involves knowing how to reflect and analyse thought, how to draw conclusions from that analysis, and how to put what has been learned into practice. In order to solve problems, students are often challenged to understand how their mind functions. In other words, they need to perceive how they perform important cognitive tasks such as remembering, learning and problem solving.

Kluwe (1987) refined the concept of metacognition by noting two characteristics: the thinker knows something about their own and others' thought processes, and the thinker can pay attention to and change their own thinking. This latter type of metacognition Kluwe calls 
'executive processes'. Hacker (1998) points out the difference between 'cognitive tasks' (remembering things learned earlier that might help with the current task or problem) and 'metacognitive tasks' (monitoring and directing the process of problem solving), stressing the importance of learning more about thinking. Cornoldi (1998) emphasises the role of learners' beliefs about thinking and makes the point that if students feel confident that they can solve problems, they tend to do better work. In defining metacognition as thinking about thinking' or 'second-order cognition', Weinert (1987) acknowledges that purpose, conscious understanding, ability to talk or write about tasks, and generalisability to other tasks are also important factors in determining whether a given task is metacognitive and this viewpoint is supported by Brown (1987) who agrees that metacognition requires the thinker to use and describe the process of mental activity. Many other researchers also make the point that metacognition is best defined by acknowledging that it is both knowledge about, and control over thinking processes (Allen \& Armour-Thomas, 1991). Vadhan and Stander (1993) clearly distinguish between ordinary thinking and awareness and understanding of thinking, and this is a theme elaborated on by Hacker (1998) who divides metacognition into three types of thinking:

- Metacognitive knowledge: What one knows about knowledge.

- Metacognitive skill: What one is currently doing.

- Metacognitive experience: One' current cognitive or affective state.

Therefore, whilst cognition focuses on solving the problem, metacognition focuses on the process of problem solving (Marchant, 2001).

In addition to the knowledge people have about how they use their thoughts and strategies (Brown, 1987; Lynch et al., 2006), knowledge about how much they will be able to learn, and what kinds of strategies they use (Gleitman, 1985; Weinert \& Kluwe 1987), people also have a set of general heuristics. For example, how they plan, set goals, and process feedback (Frese et al. 1987; Ning \& Downing 2010d). The assumption is that these general heuristics can be either conscious or automatic (Brown, 1987; Flavell, 1987) and they may be highly generalised or specific.

\section{A brief history of metacognition}

The term metacognition first became part of the lexicon of higher education in the1970's when Flavell (1971) introduced the term 'metamemory'. However, the concept is much older than that (King, 2004) and draws on the work of more ancient philosophers like Plato, Aristotle, Confucius, Solomon, Buddha, and Lao Tzu.

Clearly, the potential importance of developing metacognitive skills was recognised long before the actual term was commonly used, with John Locke commenting in 1690, that most children gradually develop the ability to 'reflect' on their own thinking processes. For example, when young children are asked if they understand something, they often simply nod in agreement or fail to ask questions (Brown, 1973) but by adulthood most of us have a better understanding of the complex processes involved in knowing what we do, and do not, know (Piaget, 1972; Downing, 2009b). Brown (1987) and Hatton \& Smith, (1995) report that as early 
as 1917, Thorndike was testing metacognition by asking his students to problem-solve by answering questions on texts they had read. Consequently, when Flavell (1963) published a text on the developmental psychology of Jean Piaget the as yet unnamed, 'metacogniton' caught the attention of researchers and by 1975 had come into common use. More recently, a number of researchers have begun to explore the validity and reliability of the Learning and Study Strategies Inventory (LASSI) as a longitudinal measure of metacognition in university students (Ning \& Downing, 2010a) and even posit metacognition as indicative of another stage of intellectual development beyond Piaget's stage of formal operations.

\section{Metacognition and the learning and study strategies inventory (LASSI)}

Metacognition is assessed in a range of ways but one of the most popular methods currently in widespread use in schools, colleges and universities worldwide is through the use of questionnaires which require students' to report their perceptions about their thinking and problem-solving skills and strategies. It is generally accepted that most students who struggle at university could improve their performance considerably if they understood the learning process better. Weinstein (1988) points out that poor grades begin to rebound when students learn the tricks of pinpointing the key points in lectures, and asserts that learning is more effective when we engage in thinking about the process of learning, thinking, and problem-solving. Recent research studies have confirmed Weinstein's view (e.g. Ning \& Downing, 2010b), and have investigated other factors impacting upon metacognition such as gender differences (Downing et al., 2008) and the impact of problem-based learning approaches on metacognitive development (Downing et al., 2009). As a result of her work in the field of strategic learning at the University of Texas at Austin, Weinstein developed the Learning and Study Strategies Inventory (LASSI) which is now the most widely used learning inventory in the world (Weinstein, 1987). The LASSI measures student's perceptions of their study and learning strategies and methods. In other words, it is a measure of the students thinking about their thinking or metacognition. The tool consists of ten scales, and eighty items which provide an assessment of students' awareness about and use of learning and study strategies related to the skill, will and self-regulation components of strategic learning. Research has repeatedly demonstrated that these factors contribute significantly to successful study, and that they can be learned or enhanced through educational interventions such as learning and study skills courses (Weinstein, 1994a, 1994b; King, 1991; Letteri, 1992; Hanley, 1995).

The LASSI provides standardised scores for the ten different scales and provides students with a diagnosis of their strengths and weaknesses, compared to other students, in the areas covered. It measures three main areas of 'strategic learning':

\subsection{Skill component of strategic learning}

These scales examine students' perceptions (metacognition) of their learning strategies, skills and the thought processes related to identifying, acquiring and constructing meaning for important new information, ideas and procedures. The LASSI scales related to the skill component of strategic learning are: 
- Information Processing-the ability to process ideas by mentally elaborating on them and organizing them in meaningful ways.

- Selecting Main Ideas- the student's ability to identify the important information in a learning situation.

- Test Strategies-the student's ability to prepare effectively for an examination and to reason through a question when answering it.

\subsection{The will component of strategic learning}

These scales measure students' perceptions of their receptivity to learning new information, their attitudes and interest in college, their diligence, self-discipline, and willingness to exert the effort necessary to successfully complete academic requirements, and the degree to which they worry about their academic performance. The LASSI Scales related to the will component of strategic learning are:

- $\quad$ Attitude-the student's perceived motivation and interest to succeed in their study, and willingness to perform the tasks necessary for academic success.

- Motivation-the extent to which the student accepts responsibility for performing those tasks by using self-discipline and hard work.

- Anxiety-the degree of anxiety perceived by the student when approaching academic tasks.

\subsection{The self-regulation component of strategic learning}

These scales measure how students' perceptions of how they manage, self-regulate, and control the whole learning process through using their time effectively, focusing their attention, and maintaining their concentration over time, checking to see if they have met the learning demands for a class, an assignment or a test, and using study supports such as review sessions, tutors or special features of a textbook. The LASSI Scales related to the selfregulation component of strategic learning are:

- Concentration-the student's perceived ability to focus his or her attention, and avoid distractions, while working on school-related tasks like studying.

- Time Management-the student's perception of the extent to which they create and use schedules to manage their responsibilities effectively.

- Self-Testing-the student's awareness of the importance of self-testing and reviewing when learning material, and use of those practices.

- $\quad$ Study Aids-the student's perceived ability to use or develop study aids that assist with the learning process.

There is a wealth of research, making use of the LASSI as a measure of metacognition, which identifies the value of learning to learn interventions in schools, colleges and universities (Loomis, 2000; Downing, 2009; Ning and Downing, 2010c), however few studies have tried to identify factors outside the learning institution which might impact upon the development of metacognitive skills in students. For example, to what extent are metacognitive skills enhanced or inhibited by particular life events or circumstances? Most 
of us would accept that there are times in our lives when we are forced to review and take stock of our thinking, and moving away from home to study at university for the first time is probably one of these. Does this have an impact upon the development of our metacognitive skills? This study casts light on the potential importance of one particular life event (moving away from home), and identifies some interesting preliminary correlations using demographic data gathered from first year students at a university in Hong Kong.

\section{Method}

\subsection{Sample}

The LASSI is offered to all first-year undergraduate students at a university in Hong Kong in order to help them monitor and develop appropriate learning attitudes and strategies, and maximize their opportunities to enjoy a successful learning experience during university and beyond. The LASSI is offered on a voluntary, rather than compulsory, completion basis to all new undergraduate students within weeks 3 to 5 of their first semester at university. An interim test follows this pre-test around the middle of the student's undergraduate programme, and a post-test is also administered towards completion of the undergraduate programme. In other words, each undergraduate student will take LASSI three times during their undergraduate study at university. Therefore longitudinal data can be produced for diagnostic purposes and as evidence of growth in metacognitive ability over the time spent in undergraduate study. The entry and interim tests provide timely data and allow the university to correct any problems with this development early. The LASSI takes approximately 25 minutes to complete online and is offered to all freshmen shortly after registration (3 to 5 weeks).

\subsection{Materials}

The Learning and Study Strategies Inventory (2 ${ }^{\text {nd }}$ Edition) Weinstein \& Palmer, (2002).

Demographic 'entry' data collected, by the university in Hong Kong during the student admission process.

\subsection{Participants}

LASSI data was collected from a total of $1,821(\mathrm{~N}=1,821)$ new first-year undergraduate students at the university in Hong Kong, and correlated with variables taken from the same students' demographic data collected as a normal part of the admission process. The students were distributed into four groups for analysis. Therefore, the data related to LASSI score and background information for the following groups of students was obtained:
a. Full-time UGC (funded place) students $(\mathrm{n}=984)$
b. Part-time non-UGC (self-financed) students $(n=343)$
c. Foundation year students (all from the Chinese mainland/self-financed) $(n=134)$
d. Students not belonging to any of the above 3 groups $(n=360)$ (exception-see Table 1) 


\begin{tabular}{|ll|c|c|c|c|}
\hline & Frequency & Percent & Valid Percent & Cumulative Percent \\
\hline Valid & Exception & 360 & 19.8 & 19.8 & 19.8 \\
& Foundation & 134 & 7.4 & 7.4 & 27.1 \\
& UGC funded & 984 & 54.0 & 54.0 & 81.2 \\
Non-UGC funded & 343 & 18.8 & 18.8 & 100.0 \\
& Total & 1821 & 100.0 & 100.0 & \\
\hline
\end{tabular}

Table 1. Category of students

\subsection{Procedure}

In order to investigate some of the correlations between LASSI scores and other demographic and academic factors during the pilot period, a number of correlations were attempted with the four groups identified above, and the data presented in this study has been selected as of particular interest for further consideration. Although the original $\mathrm{N}=1821$, six cases were omitted from the analysis because of incomplete or confounding data, therefore $\mathrm{N}=1815$.

\section{Results}

Not surprisingly for a large-scale study of this type, a range of data for correlation was collected and analysed. However, the results presented relate primarily to group c above and have been selected because they are of particular interest, and they were somewhat unexpected. The relationship between scores on LASSI and the type of housing occupied by the students produced some particularly interesting findings (see Table 2). ANOVA analysis yielded highly significant results $(\mathrm{p}<.000)$.

This study demonstrates a significant relationship between LASSI score and type of housing, or more accurately, whether a student is living in the 'home' environment (Family Home or $\mathrm{FH}$ ). The students from the Chinese mainland coming to Hong Kong to study (moving away from 'home') with unidentified housing type obtained by far the highest overall LASSI scores $(n=127$, mean score=619.73) with those students living in the University's accommodation on campus producing the second highest LASSI scores $(n=45$, mean score $=580.58$ ). Perhaps less surprisingly, those living in private housing produced $(n=621$, mean score $=435.83)$ the third highest LASSI scores (see Table 2).

\begin{tabular}{|l|l|r|r|}
\hline & & N & Mean LASSI Score \\
\hline LASSI & & \\
\cline { 2 - 4 } & Staff quarters (FH) & 5 & 369.8000 \\
& HOS/PSPS (FH) & 269 & 419.3494 \\
& Private housing (FH) & 621 & 435.8293 \\
& Public housing (FH) & 748 & 418.4238 \\
& Student halls (NFH) & 45 & 580.5778 \\
& From Chinese Mainland (NFH) & 127 & 619.7323 \\
& Total & 1815 & 442.4887 \\
\hline
\end{tabular}

FH - Living in family home. HOS - Home Ownership Scheme. NFH - Living away from family home. PSPS - Private Sector Participation Scheme.

Table 2. Mean Total LASSI score according to Type of Housing (FH vs. NFH). 
When the total LASSI score is broken down into the three major components of the inventory, 'will', 'skill', and 'self-regulation' the following results are obtained (see Tables 3 to 5).

\begin{tabular}{|l|l|r|r|}
\hline & & N & Mean 'Will' Score \\
\hline & & & \\
\hline Will Component & Staff quarters (FH) & 5 & 83.2000 \\
& HOS/PSPS (FH) & 269 & 98.9182 \\
& Private housing (FH) & 621 & 104.7536 \\
& Public housing (FH) & 748 & 98.9184 \\
& Student halls (NFH) & 45 & 157.4667 \\
& From Chinese Mainland (NFH) & 127 & 159.0945 \\
& Total & 1815 & 106.5339 \\
\hline
\end{tabular}

Table 3. Mean 'Will Component' score according to Type of Housing (FH vs. NFH).

\begin{tabular}{|l|l|r|r|}
\hline & & N & \multicolumn{1}{|c|}{ Mean 'Skill' Score } \\
\hline & & & \\
\hline Skill & & 5 & 150.0000 \\
& Staff quarters (FH) & 269 & 136.7993 \\
& HOS/PSPS (FH) & 621 & 142.0177 \\
& Private housing (FH) & 448 & 133.6484 \\
& Public housing (FH) & 181.6889 \\
& Student halls (NFH) & 1815 & 199.3307 \\
& From Chinese Mainland (NFH) & 142.8110 \\
\hline
\end{tabular}

Table 4. Mean 'Skill Component' score according to Type of Housing (FH vs. NFH).

\begin{tabular}{|l|l|r|r|}
\hline & & N & Mean 'Self- regulation' Score \\
\hline & & & \\
\hline Self-regulation & Staff quarters (FH) & 5 & 136.6000 \\
& HOS/PSPS (FH) & 269 & 183.6320 \\
& Private housing (FH) & 621 & 189.0580 \\
& Public housing (FH) & 748 & 185.8570 \\
& Student halls (NFH) & 127 & 241.4222 \\
& From Chinese Mainland (NFH) & 1815 & 261.3071 \\
& Total & 193.1438 \\
\hline
\end{tabular}

Table 5. Mean 'Self-regulation Component' score according to Type of Housing (FH vs. NFH).

\begin{tabular}{|l|l|r|r|r|c|c|}
\hline & & Sum of Squares & \multicolumn{1}{c|}{ df } & Mean Square & \multicolumn{1}{c|}{ F } & Sig. \\
\hline will component & Between Groups & 531261.269 & 5 & 106252.254 & 40.561 & .000 \\
& Within Groups & 4738756.397 & 1809 & 2619.545 & & \\
& Total & 5270017.666 & 1814 & & & \\
skills components & Between Groups & 546883.932 & 5 & 109376.786 & 31.883 & .000
\end{tabular}




\begin{tabular}{|l|l|r|r|r|r|r|}
\hline & & Sum of Squares & df & Mean Square & \multicolumn{1}{c|}{ F } & Sig. \\
\hline & Within Groups & 6205872.248 & 1809 & 3430.554 & & \\
Telf-regulation & Total & 6752756.180 & 1814 & & & \\
component & Between Groups & 785366.094 & 5 & 157073.219 & 31.249 & .000 \\
& Within Groups & 9093021.373 & 1809 & 5026.546 & & \\
& Total & 9878387.468 & 1814 & & & \\
LASSI & Between Groups & 5478997.128 & 5 & 1095799.426 & 45.101 & .000 \\
& Within Groups & 43952864.391 & 1809 & 24296.774 & & \\
& Total & 49431861.518 & 1814 & & & \\
\hline
\end{tabular}

Table 6. ANOVA

\section{Discussion}

These results raise the question of the extent to which the metacognitive skills, assessed by the Learning and Study Strategies Inventory, are influenced or associated with moving away from the home environment in order to engage in undergraduate study. In other words, does a significant change in the social context, like moving away from home to study, impact positively upon metacognitive development and, if so, why is this likely to happen?

\section{Cognitive development, culture, and social context}

Piaget $(1929,1954,1977)$ describes the process of intellectual development in terms of a movement from 'egocentrism' to 'decentring'. This is a cognitive developmental process that culminates in attaining the formal operational stage characterised by advanced deductive logic and the ability to reason from abstract to logical conclusions. One criticism of Piaget's approach is that it asserts that much of cognitive development is a result of maturational processes within the child, and the environment has very little impact on how cognitive abilities change over time. However, since Vygotsky (1975) highlighted the role of social interaction in cognitive development, more contemporary researchers (Rogoff \& Chavajay, 1995; Lourenco \& Machado, 1996; Serpell \& Boykin, 1994; Downing \& Chim, 2004) have tended to focus on the role of culture and social interactions in cognitive development. This view posits that children and young adults develop through a process of internalisation, absorbing knowledge from their social context which has a major impact on how their cognition develops over time.

\section{Metacognitive development, culture, and social context}

Piaget himself recognised that an environment rich with challenges appropriate to the stage of a child's development was more important than trying to force the pace of change in order to help increase the pace of cognitive development. Therefore, it should not be surprising to find that metacognitive development also progresses as a result of challenges from the environment and, if these challenges are the result of a significant life event like 
leaving home (perhaps for the first time), it seems likely that this will involve the internalisation of new experiences and subsequent increases in metacognitive activity.

The data presented in this study suggests that these findings are equally relevant to metacognitive development. The overall LASSI scores presented in table 2 demonstrate that students who have moved from the Chinese mainland ( $n=127)$ to study in Hong Kong score significantly above the mean LASSI score $(\mathrm{N}=1815)$ for the sample. Additionally, students from Hong Kong who had moved into student halls of residence on campus, and so had moved away from home (although not quite so far in geographical terms) also scored well above the mean LASSI score, although somewhat lower than their mainland Chinese counterparts. The first of these findings suggests some element of cultural difference in metacognitive development (Serpell, 2000), and this suggestion might rely on the particular type of education experience encountered by the mainland Chinese group. However, the fact that the group of students living in halls, from the very different cultural context of Hong Kong also score much more highly than their Hong Kong counterparts living in the family home (the general norm for Hong Kong undergraduates) suggests that there is something about the changed social context (moving away from home) that impacts upon metacognitive development. Analysis of the component scores for 'will', 'skill', and 'selfregulation' casts some light on this process.

\section{Skill, self-regulation and social context}

The differences from the mean scores $(\mathrm{N}=1815)$ for the 'will' component are $52.56(\mathrm{n}=127)$ for the Chinese mainland students studying in Hong Kong and $50.93(n=45)$ for students living in halls of residence on campus, not much to write home about! However, differences between these two groups start to look more interesting when we consider the 'skill' and 'self-regulation' components. The differences from the mean scores $(\mathrm{N}=1815)$ for the 'skill' component are $56.52(\mathrm{n}=127)$ for the Chinese mainland students studying in Hong Kong and $38.88(n=45)$ for students living in halls of residence on campus. For the 'self-regulation' components these figures are $68.16(n=127)$ and $48.28(n=45)$ respectively suggesting that these two components are differentially influenced in the two groups and raising the question why? Once again the social context might provide us with a partial answer. The students from mainland China are geographically distant from their home base and their parent culture and so the requirement to self-regulate, and to think about this process (metacognition) is likely to be more pressing than those students living in their own culture but away from the family home. For both groups, the changed social context is likely to influence their perceived ability to concentrate and focus attention positively because they are not subject to the often considerable demands of living in the family home, and this will no doubt impact on the sense of control they perceive in relation to their time-management abilities. In terms of the perceived use of self-testing and study aid strategies, the changed social context gives students everyday opportunities to try out different problem-solving strategies ('skill' component) and weed out those that do not work as well, gradually evolving new strategies depending on changes in the situation in the same way as Siegler, (1996) describes for cognitive development. 
In line with Piaget's view that an environment rich with challenges appropriate to the stage of a child's development was more important than trying to force the pace of change in order to help increase the pace of cognitive development, it seems that everyday challenges emerging from the new social context in this study, provide fertile environments for the development of metacognition. The highest 'meta-level' of cognition is usually not implicated when we receive an outside task and when the task solution is known. This is one reason why we do not think about our life goals in our everyday activities. The metalevel only tends to be consulted when things go wrong or when the situation is new. Therefore, the meta-level tends to come into play when we move house or location, or we are encouraged to consider our life and or educational goals in a more general sense, something we are surely disposed to do when moving away from home environment and culture. In other words, the challenging new social context of living away from home, and for the mainland Chinese students, in a different culture increases the use of metacognition because the student cannot call upon routinised or 'automatic' cognition. There is almost a requirement in these circumstances to have knowledge about and control over thinking processes (Allen \& Armour-Thomas, 1991).

\section{Conclusion}

According to Driscoll (1994), there are three basic instructional principles on which Piagetian (cognitive) theorists generally agree:

- Principle 1: The learning environment should support the activity of the learner (i.e., an active, discovery-oriented environment).

- Principle 2: The learner's interactions with peers are an important source of cognitive development (i.e., peer teaching and social negotiation).

- Principle 3: Instructional strategies that make learners aware of conflicts and inconsistencies in their thinking promote cognitive development (i.e., conflict teaching and Socratic dialogue).

Why then should metacognitive strategies such as planning, monitoring and evaluating one's own learning evolve more effectively when undergraduates are away from their home environment and culture? Vygotsky's (1986) view was that in order to subject a function to intellectual and voluntary control, we must first possess that function. In other words, metacognition and self-reflection will develop first as a skill before it can be used as a series of consciously controlled strategies (Lynch et al., 2006). The emphasis on social interaction as a pre-condition for the training of reflective skills is today shared by many approaches to instruction (Von Wright 1991). For example, the use of reciprocal or 'peer' teaching forces the teacher to use a whole series of metacognitive processes such as identifying what the learner already knows, deciding what is to be learned and how; monitoring understanding and evaluating the outcome in terms of increased understanding. This, in turn, encourages the teacher to reflect upon their own thinking processes. In terms of social constructivist theory, metacognitive processes begin as social processes and gradually become "internalised" (Downing, 1991; Lewis \& Downing, 2000). The social context of living in an 
environment outside what might be termed your 'comfort zone' (Driscoll's, 1994, Principle 1) will undoubtedly provide an action and discovery oriented learning environment, whilst the scope for peer interaction and social negotiation is also considerably widened (Principle 2). Finally, Socratic Dialogue is a method widely used in Europe which allows for in-depth understanding of various issues concerning everyday life. Through rigorous inquiry and consensus students start to unravel some of their basic assumptions and develop metacognitive skills and knowledge. This approach has long valued everyday life as a formidable teacher of self-reflection (Principle 3).

Scruggs et al (1985) and Ning \& Downing (2010b) suggest that direct instruction in metacognitive strategies leads to increases in learning (e.g. Learning to learn courses), and that independent use of these strategies develops only gradually. Whilst there is a wealth of research in support of these viewpoints (Hanley, 1995; Bogdan, 2000; Driscoll, 2004;), it is also essential that educators do not neglect the crucial role of the student's experience outside of the classroom in the development of metacognitive skills. Independent use of metacognitive strategies is a by-product of coping with everyday new social contexts and cultures. It seems very likely from the data presented in this paper that the experience of moving away from home (and culture) creates a metacognitive environment which fosters the development of 'thinking about thinking' and provides students with more opportunities to become successful problem-solvers and lifelong learners. In our rapidly changing world, the challenge for teachers is to help undergraduate students develop skills which will not become obsolete. As such, metacognitive strategies are essential for the twenty-first century because they will enable students to successfully cope with new situations, and the challenges of lifelong learning. To return to Socrates, it is clear that moving away from home and culture into a new social context ensures that everyday life is examined, and this study suggests that this examination promotes the development of metacognitive skills which go some way to equipping student's for the demands of a worthwhile career in a rapidly changing world.

\section{Author details}

Kevin Downing

City University of Hong Kong, Yau Yat Tsuen, Kowloon, Hong Kong

\section{References}

Allen, B.A., \& Armour-Thomas, E. (1991), Construct validation of metacognition. Journal of Psychology, 127(2), 203-211.

Bogdan, R.J. (2000), Minding minds: Evolving a reflexive mind by interpreting others. Cambridge, MA: The MIT Press.

Brown, A. (1987), Metacognition, executive control, self-regulation, and other more mysterious mechanisms. In F. Weinert, \& R. Kluwe (Eds.), Metacognition, motivation, and understanding (pp. 65-116). Hillsdale, NJ: Erlbaum.

Brown, R. (1973), A first language: The early stages. Cambridge, MA: Harvard University Press. 
Cornoldi, C. (1998), The impact of metacognitive reflection on cognitive control. In G. Mazzoni \& T. Nelson (Eds.), Metacognition and cognitive neuropsychology (pp139159). Mahwah, NJ: Erlbaum.

Downing, K., (2001), Information Technology, Education and Health Care: constructivism in the 21st Century. Educational Studies, 27 (3), 229-235.

Downing, K., (2009a), Self-efficacy and metacognitive development. International Journal of Learning, Volume 16, Issue 4, 2009, Pages 185-200.

Downing, K., and Chim, T.M. (2004), Reflectors as online extraverts. Educational Studies, 30(3), 265-276.

Downing, K., Chan, S., Downing, W.K., Kwong, T., \& Lam, T. (2008), 'Measuring gender differences in cognitive functioning' Multicultural Education and Technology Journal. Vol. 2, No. 1, 4-18, 2008.

Downing, K., Kwong, T., Chan, S., Lam, I, \& Downing, W.K. (2009b) 'Problem-based learning and the development of metacognition' Higher Education 57 (5) 609-621.

Driscoll, M. P., (1994), Psychology of learning for instruction. Needham Heights, MA: Allyn \& Bacon.

Flavell, J.H. (1963), The developmental psychology of Jean Piaget. New York: Van Nostrand Reinhold.

Flavell, J.H. (1971), First discussant's comments: What is memory development the development of? Human Development, 14, 272-278.

Flavell, J.H. (1987), Assumptions on the concept metacognition and on the development of metacognitions. In F. Weinert \& R. Kluwe (Eds.), Metacognition, motivation and understanding (pp1-19), Hillsdale, NJ: Erlbaum.

Flavell, J.H. (1999), Cognitive development: Children's knowledge about the mind. Annual Review of Psychology, 50, 21-45.

Frese, M., Stewart, J. \& Hanover, B. (1987), Goal-orientation and planfulness: action styles as personality concepts. Journal of personality and Social Psychology 52: 1182-94.

Gleitman, H. (1985), Some trends in the study of cognition. In S. Koch \& D.E. Leary (Eds.) A Century of Psychology as Science: Retrospections and assessments. New York: McGraw-Hill.

Hacker, D.J. (1998), Definitions and empirical foundations. In D. Hacker, J. Dunlosky, \& A. Graesser (Eds.), Metacognition in educational theory and practice (pp1-23), Mahwah, NJ: Erlbaum.

Hanley, G.L. (1995), Teaching critical thinking: Focusing on metacognitive skills and problem solving. Teaching of Psychology, 22 (1), 68-72.

Hatton, N., \& Smith, D. (1995), Reflection in teacher education: Towards definition and implementation. Retrieved $6^{\text {th }}$ February 2006 from http://alex.edfac.usyd.edu.au/LocalResource/Study1/hattonart.html

King, A. (1991), Improving lecture comprehension: Effects of a metacognitive strategy. Applied Cognitive Psychology, 5, 331-346.

King, K. (2004), Just don't make me think: Metacognition in college classes. Selected papers from the $15^{\text {th }}$ International Conference on College Teaching and Learning, (Ed. Chambers, J.), 145-165. 
Kluwe, R.H., (1987), Executive decisions and regulation of problem solving behaviour. In F. Weinert \& R. Kluwe (Eds.) Metacognition, motivation, and understanding (pp1-19). Hillsdale, NJ: Erlbaum.

Letteri, C.A. (1992) Diagnosing and augmenting basic cognitive skills. In J.W. Keefe \& H.J. Walbert (Eds.), Teaching for thinking (pp 59-71). Reston, VA: National Association of Secondary Principals.

Lewis, T., \& Downing, K. (2000), Teaching and learning medicine and health-related disciplines. Educational Studies, 26(1), 249-254.

Lourenco, O., \& Machado, A.,(1996), In defense of Piaget's theory: A reply to 10 common criticisms. Psychological Review, 103, 143-164.

Lynch, R., Leo, S. and Downing, K. (2006) Context dependent learning: Its value and impact for workplace education. Education and Training, 48(1), 15-24.

Marchant, G.J. (2001), Metateaching: A metaphor for reflective teaching. Education, 109(4), 487-489.

Metcalfe, J. (2000), Metamemory: Theory and data. In E. Tulving \& F.I.Craik (Eds.). The Oxford handbook of memory. (pp. 197-211) New York: Oxford University Press.

Ning, H.K. and Downing, K. (2010a), Stability of the Learning and Study Strategies Inventory: A longitudinal analysis of Hong Kong and Mainland Chinese students. AsiaPacific Education Researcher, 19(3), 525-537.

Ning, H.K. and Downing, K. (2010b), The impact of supplemental instruction on learning competence and academic performance. Studies in Higher Education, 35(8), 921-939.

Ning, H.K. and Downing, K. (2010c), Connections between learning experience, study behaviour and academic performance: A longitudinal study. Educational Research, 52(4), 457-468.

Ning, H.K. and Downing, K. (2010d), The Reciprocal relationship between motivation and self-regulation: A longitudinal study on academic performance. Learning and Individual Differences, 20(6), 682-686.

Piaget, J. (1929), The child's conception of the world. New York: Harcourt, Brace.

Piaget, J. (1954), The construction of reality in the child. New York: Basic Books.

Piaget, J. (1972), Development and learning. In C. S. Lavatelli \& F. Stendler (Eds.), Readings in child behaviour and development ( $3^{\text {rd }}$ ed.). New York: Harcourt Brace Jovanovich.

Piaget, J. (1977), The development of thought: Equilibrium of cognitive structures. New York: Viking Press.

Rogoff, B., \& Chavajay, P., (1995), What's become of research on the cultural basis of cognitive development? American Psychologist, 50, 859-877.

Scruggs, Thomas E.; Mastropieri, M. A.; Monson, J.; \& Jorgenson, C. (1985, Fall). Maximizing what gifted students can learn: Recent findings of learning strategy research. Gifted Child Quarterly, 29(4), 181-185. EJ 333116.

Serpell, R., \& Boykin, A.W., (1994), Cultural dimensions of cognition: A multiplex, dynamic system of constraints and possibilities. In R.J. Sternberg (Ed.), Handbook of perception and cognition: Vol.2 Thinking and problem solving (pp369-408). Orlando, Fl: Academic Press.

Serpell, R., (2000), Intelligence and culture. In R.J. Sternberg (Ed.), Handbook of intelligence (pp549-577). Cambridge, U.K.: Cambridge University Press.

Siegler, R.S., (1996), Emerging minds: The process of change in children's thinking. New York: Oxford University Press. 
Vadhan, V. \& Stander, P. (1993), Metacognitive ability and test performance among college students. Journal of Psychology, 128(3), 307-309.

Von Wright, J. (1992). 'Reflections on reflection'. Learning and Instruction. Vol. 2. 59-68

Vygotsky, L.S. (1975). Mind in society. The development of higher psychological processes. Cambridge MA.: Harvard University Press.

Vygotsky, L.S. (1986). Thought and language. Cambridge MA.: MIT Press.

Weinert, F.E. \& Kluwe, R.H. (1987), Metacognition, motivation and understanding. Hillsdale, NJ: Erlbaum.

Weinert, F.E. (1987), Introduction and overview: Metacognition and motivation as determinants of effective learning and understanding. In F. Weinert \& R. Kluwe (Eds.), Metacognition, motivation and understanding (pp1-19), Hillsdale, NJ: Erlbaum.

Weinstein, C.E. \& Palmer, D. (1988) Learning and studies skills inventory. NCS Trans-Optic EP 30-27841, 321.

Weinstein, C.E. \& Palmer, D.R, (2002), LASSI User's Manual (2 ${ }^{\text {nd }}$ Edition). Clearwater, Fl. H \& H Publishing Company Ltd.

Weinstein, C.E. (1987) LASSI User's Manual, Clearwater, Florida, H \& H Publishing Inc.

Weinstein, C.E. (1994a), Strategic learning/strategic teaching: Flip sides of a coin. In P.R. Pintrich, D.R. Brown, C.E. Weinstein (Eds.), Student motivation, cognition and learning (pp 257-273). New Jersey: Erlbaum.

Weinstein, C.E. (1994b), Students at risk for academic failure: Learning to Learn classes. In K.W. Pritchard \& R.M. Sawyer (Eds.). Handbook of college teaching (pp 375-385). Westport, CT: Greenwood press. 



\section{Edited by Heidi Kloos, Bradley J. Morris and Joseph L. Amaral}

As a whole, the essays in this book address theoretical and empirical issues related to children's learning and cognition. The first essay, titled Learning in Cognitive Niches, treats the process of sense making on a theoretical level, discussing the complexity of factors that give rise to children's learning. It is followed by an essay, titled Using the Dynamics of a Person-Context System to Describe Children's Understanding of Air Pressure, that applies ideas from complexity science and dynamics-systems theory to children's learning about science. The next four essays summarize and synthesize already published findings, in an effort to go beyond individual viewpoints and present a more nuanced picture of children's sense making. In particular, two of these summaries, Preschoolers Learning Science: Myth or Reality? and The Emergence of Scientific Reasoning, focus on children's ability to make sense of their physical environment. The essay Cognition and the Child Witness: Understanding the Impact of Cognitive Development in Forensic Contexts seeks to shed light on children's sense making relevant to forensic issues. And the essay Beyond the Black-and-White of Autism: How Cognitive Performance Varies with Context ventures in the area of autism, a disorder that demonstrates atypical processes of combining pieces of information. The final two essays provide original data to add to the discussion of what factors affect cognitive functioning. In particular, the essay Cognitive Fitness in Young Adult Video Game Players seeks to re-assess the often-assumed relation between video gaming and various aspects of thinking, memory, intelligence, and visual-spatial abilities. And the essay Impact of Moving Away from Home on Undergraduate Metacognitive Development explicitly connects life circumstances to the ability to monitor and control one's thinking. Together, the collection of essays are a further step towards understanding the process of sense making as children and young adults interact with their environment. 